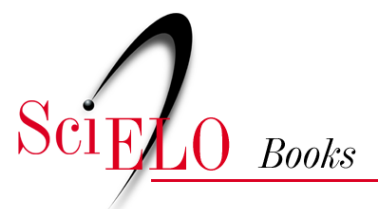

\title{
Segurança do paciente criando organizações de saúde seguras
}

\author{
Paulo Sousa \\ Walter Mendes \\ (orgs.)
}

SOUSA, P., and MENDES, W., comps. Segurança do paciente: criando organizações de saúde seguras [online]. 2nd ed. rev. updt. Rio de Janeiro, RJ : CDEAD, ENSP, Editora FIOCRUZ, 2019, 268 p. ISBN 978-85-7541-642-6. https://doi.org/10.7476/9788575416426.

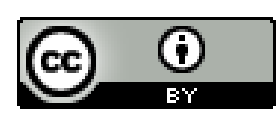

All the contents of this work, except where otherwise noted, is licensed under a Creative Commons Attribution $\underline{4.0 \text { International license. }}$

Todo o conteúdo deste trabalho, exceto quando houver ressalva, é publicado sob a licença Creative Commons Atribição 4.0. 
Segurança do Paciente:

criando organizações

de saúde seguras 


\section{Fundação Oswaldo Cruz - Fiocruz}

PRESIDENTE

Nísia Trindade Lima

VICE-PRESIDENTE DE EDUCAÇÃO, INFORMAÇÃO E COMUNICAÇÃO

Cristiani Vieira Machado

Editora Fiocruz

DIRETORA

Cristiani Vieira Machado

\section{EDITOR EXECUTIVO}

João Carlos Canossa Mendes

EDITORES CIENTÍFICOS

Carlos Machado de Freitas

Gilberto Hochman

CONSELHO EDITORIAL

Denise Valle

José Roberto Lapa e Silva

Kenneth Rochel de Camargo Jr.

Lígia Maria Vieira da Silva

Marcos Cueto

Maria Cecília de Souza Minayo

Marilia Santini de Oliveira

Moisés Goldbaum

Rafael Linden

Ricardo Ventura Santos
Escola Nacional de Saúde Pública Sergio Arouca

DIRETOR

Hermano Albuquerque de Castro

VICE-DIRETORA DE ENSINO

Lúcia Maria Dupret

COORDENADOR DE DESENVOLVIMENTO EDUCACIONAL E EDUCAÇÃO A DISTÂNCIA

Maurício de Seta 


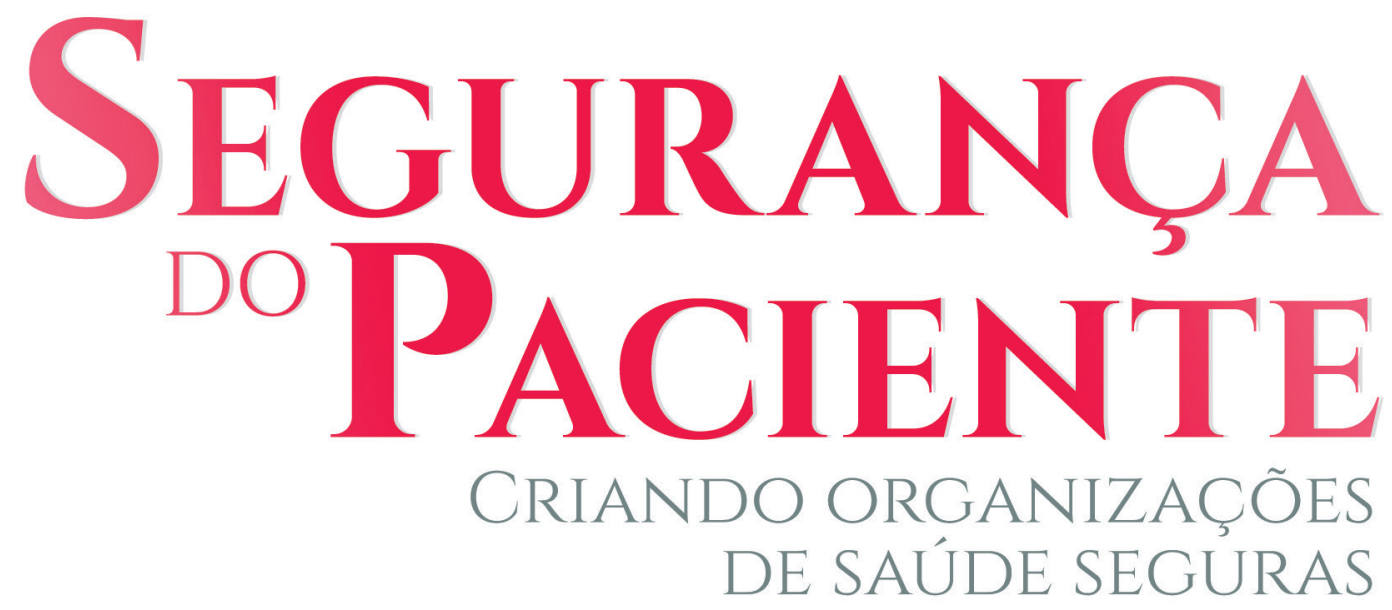

$2^{A}$ EDIÇÃO REVISTA E AMPLIADA

ui ieir:

.نुăo e nem

. vire e os dis $r$.

¿ segundo o meu pc.

srtal nem um conseilic

Ilaculada minha vida e min

us que disso cuidam. Em toda -

sedução sobretudo longe dos $: \cdots \cdot$

rrcício ou fora do exercício da prc.

ervarei inteiramente secreto. Se $f$.............

a profissão, honrado para sempre - is is homer

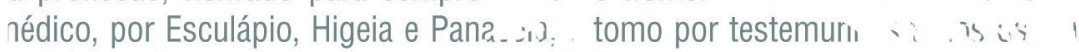

minha razão, a promessa que se segue: Estimar, tanto $i_{i}$ ?

’cessário for, com ele partilhar meus ber. Ter seus filhu: oor mt

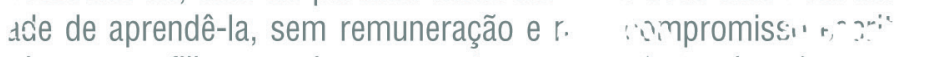

sino, meus filhos, os de meu mestre e c. $\therefore:$ es in in: $\quad \therefore$ os ro:

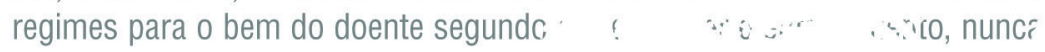

comprazer, nem remédio mortal nem $\omega_{1}$ y $\quad \therefore \therefore$ perda. Do

ia abortiva. Conservarei imaculada mirı́ $\quad$ i $\quad \therefore$ ivão praticarf ${ }^{i}$

'sa operação aos práticos que disso $c ;$ am. $E_{i}$, , d casa, aí entra

0 voluntário $\epsilon$ de toda a sedução sobretudo longt. is prazeres $d_{1}$ i an

'ruilo que no exercício ou fora do exercí . ar, eu conservarei inteiramente secreto. Se $3, \cdots$, rir este jurame ר

ninha profissão, honrado para sempre entre : ' 'mens; se :...

médico, por Esculápio, Higeia e Panaceia, e tc.i por test.ı!.

e minha razão, a promiessa 4. _ _ _u

PAULO SOUSA

se necessário ior, com ele partilhar meus ber,s;Ter s:' " "

WALTER MENDES

'essidade de aprendê-la, sem remuneração e ner'? comp:

ORGANIZADORES

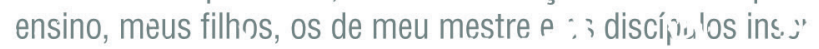

regimes para o bem do doen.r. . (i) $\because$ r. r., poder e ent

-

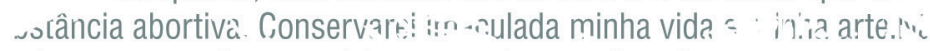

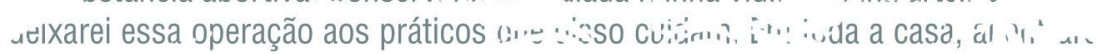

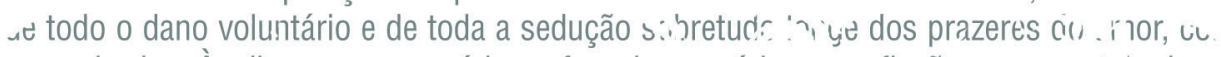

un escravizados. Àquilo que no exercício ou fora do exercícic 7 ' rofissãr? e no con

ão seja preciso divulgar, eu conservarei inteiramente secreto. SE etu r. $j^{\text {m- }}$

ste jurarrier. com fidelidau:

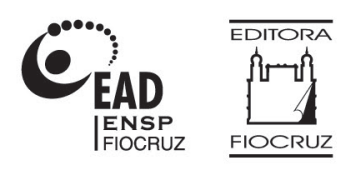
.lizmente da vida e da minha profissão, honrado para sempre entre

'ns; se at! $r$ : a me aizstar ou 
Copyright (C2014 dos autores

Todos os direitos de edição reservados à Fundação Oswaldo Cruz - Editora Fiocruz e ENSP/CDEAD

$1^{\text {a }}$ edição (2014)

$1^{\text {a }}$ reimpressão (2016)

$2^{\text {a }}$ edição revista e ampliada (2019)

SUPERVISÃO EDITORIAL

Maria Leonor de M. S. Leal

\section{ASSESSORIA PEDAGÓGICA}

Ana Paula Abreu-Fialho

Henriette dos Santos (2014)

Moacyr Torres Junior

Cleide Figueiredo Leitão (2019)

Suely Guimarães Rocha

Diogo César Nunes (2019)

REVISÃO METODOLÓGICA

Ana Paula Abreu-Fialho

Katlheen Gonçalves

REVISÃO TÉCNICA

Bárbara do Nascimento Caldas
REVISÃO E NORMALIZAÇÃO

Alda Maria Lessa Bastos

Ana Lucia Normando

Andréia Amaral

Christiane Abbade

Maria Auxiliadora Nogueira

Simone Teles

CAPA E PROJETO GRÁFICO

Jonathas Scott

ILUSTRAÇÕES

Luiz Marcelo Resende

EDITORAÇÃO ELETRÔNICA E TRATAMENTO DE IMAGEM

Quattri Design (2014)

Leevro, Design Editorial

\footnotetext{
Catalogação na fonte

Fundação Oswaldo Cruz

Instituto de Comunicação e Informação Científica e Tecnológica em Saúde

Biblioteca de Saúde Pública

S725s Sousa, Paulo (Org.)

Segurança do paciente: criando organizações de saúde seguras. / organizado por Paulo Sousa e Walter Mendes. - 2.ed (revista e ampliada) - Rio de Janeiro, RJ : CDEAD, ENSP, Fiocruz, 2019.

268 p. : il. color.

ISBN: 978-85-8432-062-2

1. Segurança do Paciente. 2. Qualidade da Assistência à Saúde. 3. Sistema Único de Saúde. 4. Gestão de Riscos. 5. Aprendizagem. 6. Educação a Distância. I. Mendes, Walter (Org.). II. Título.

CDD -362.104258
}

2019

\section{Editora Fiocruz}

Avenida Brasil, 4.036 - Sala 112

Manguinhos - Rio de Janeiro - RJ

CEP 21041-210

Tels.: (21) 3882-9039 ou 3882-9041

Telefax: (21) 3882-9006

www.fiocruz.br/editora
Coordenação de Desenvolvimento Educacional e Educação a Distância da Escola Nacional de Saúde Pública Sergio Arouca

Rua Leopoldo Bulhões, 1.480

Prédio Professor Joaquim Alberto Cardoso de Melo

Manguinhos - Rio de Janeiro - RJ

CEP 21041-210

Tel.: (21) 25982996

www.ead.fiocruz.br 


\section{Autores}

Ana Monteiro Grilo

Doutorada em psicologia com especialidade em psicologia da saúde. Professora adjunta da Escola Superior de Tecnologia da Saúde, Instituto Politécnico de Lisboa. Membro da equipa do Centro de Investigação em Ciência Psicológica da FPUL, com investigação e publicações em centração e envolvimento do doente nos cuidados de saúde e comunicação em saúde.

António de Sousa-Uva

Doutorado em medicina; professor catedrático de saúde ocupacional da Escola Nacional de Saúde Pública. Coordena o Departamento de Saúde Ocupacional e Ambiental. Coordena o curso de especialização em medicina do trabalho e o mestrado de segurança do doente. Autor e coautor de livros e capítulos de livros e de outras publicações na área da saúde e segurança do trabalho, da medicina do trabalho, da saúde pública, da segurança do doente e da alergologia e imunologia clínica.

Bárbara do Nascimento Caldas

Médica; doutora em saúde pública pela Escola Nacional de Saúde Pública Sergio Arouca da Fundação Oswaldo Cruz (ENSP-Fiocruz); mestre em administração de empresas pela Escola de Administração de Empresas de São Paulo da Fundação Getulio Vargas (EaespFGV). Autora de artigos e capítulos de livro sobre qualidade em saúde e segurança do paciente. Membro da Área da Qualidade e Segurança do Instituto Nacional de Cardiologia do Ministério da Saúde.

\section{Carla Simone Duarte de Gouvêa}

Médica; doutora e mestre em saúde pública pela Escola Nacional de Saúde Pública Sergio Arouca da Fundação Oswaldo Cruz (ENSP-Fiocruz). Assessora técnico-científica do Centro Colaborador para a Qualidade do Cuidado e Segurança do Paciente (Proqualis). Pesquisadora associada do Instituto de Medicina Social da Universidade do Estado do Rio de Janeiro (IMS-Uerj); e professora do Curso de Especialização de Gestão em Saúde do IMS-Uerj.

Cláudia Tartaglia Reis

Enfermeira; doutora em saúde pública pela Escola Nacional de Saúde Pública da Fundação Oswaldo Cruz (ENSP-Fiocruz); pós-doutorado em políticas, gestão e administração de saúde pela Escola Nacional de Saúde Pública da Universidade Nova de Lisboa. Autora de artigos e capítulos sobre cultura em segurança do paciente. Referência técnica em planejamento e gestão na Secretaria Municipal de Saúde de Cataguases, cargo vinculado ao Ministério da Saúde. Tutora do Curso Internacional de Qualidade em Saúde e Segurança do Paciente pela ENSP-Universidade Nova de Lisboa. Colaboradora do portal Proqualis.

Florentino Serranheira

Doutorado em saúde pública na especialidade de saúde ocupacional; licenciado em ergonomia. Professor na ENSP-UNL. Um dos colaboradores principais do estudo piloto e do estudo nacional dos eventos adversos em hospitais portugueses. Reviewer de diversas revistas científicas nacionais e internacionais na área da saúde ocupacional e da ergonomia; autor de vários artigos científicos sobre ergonomia, incluindo ergonomia e segurança do doente.

\section{Guilherme Brauner Barcellos}

Médico. Executivo do Programa de Gestão da Qualidade e Informação em Saúde (Qualis) do Hospital de Clínicas de Porto Alegre da Universidade Federal do Rio Grande do Sul (UFRGS). Coordenador nacional da Choosing Wisely Brasil. 
Heleno Costa Junior

Enfermeiro; mestre em avaliação pela Fundação Cesgranrio (UFRJ); especialista em administração hospitalar pelo Instituto de Medicina Social (Uerj); especialista em acreditação internacional (JCI-EUA). Autor do livro Qualidade e Segurança em Saúde: os caminhos da melhoria via acreditação internacional - relatos, experiências e práticas, Rio de Janeiro, DOC; 2015; e de capítulos de livros e artigos sobre avaliação da qualidade, acreditação e segurança em sistemas e serviços de saúde. Assessor de relações institucionais e coordenador de educação do Consórcio Brasileiro de Acreditação (CBA); representante da Joint Commission International (JCI) no Brasil.

Jorge Pontes

Licenciatura e doutorando em gestão no ISCTE-Lisboa. Gestor da qualidade e coordenador da acreditação hospitalar pela Joint Commission International no CHAA. Consultor e auditor de sistemas de gestão da qualidade em hospitais e clínicas em Portugal, Angola e Moçambique. Coordenou a pós-graduação de gestão da qualidade e auditoria na saúde - Cespu.

José Carvalho de Noronha

Médico; doutor em saúde coletiva pela Universidade do Estado do Rio de Janeiro (Uerj). Membro titular e colaborador do Colégio Brasileiro de Cirurgiões. Pesquisador do Instituto de Comunicação e Informação Científica e Tecnológica em Saúde da Fundação Oswaldo Cruz (Fiocruz); colaborador do Proqualis - Centro Colaborador para a Qualidade do Cuidado e Segurança do Paciente. Consultor do Consórcio Brasileiro de Acreditação; membro do Comitê de Acreditação da Joint Commission International (JCI). Perito da International Society for Quality in Health Care (ISQua).

José Fragata

Doutorado em medicina e cirurgia. Professor catedrático na Nova Medical School e diretor do Serviço de Cirurgia Cardiotorácica do Hospital de Santa Marta. Presidente da European Association for Congenital Heart Surgery. Cirurgião cardiotorácico. Investigador e autor de inúmeras publicações e livros sobre cirurgia cardíaca, transplantação torácica, gestão de risco e segurança dos doentes. Vice-Reitor da Universidade Nova de Lisboa.

Julian Perelman

Doutorado em economia; especialista em economia da saúde. Professor na ENSPUNL. Autor de vários artigos científicos nas áreas de avaliação económica em saúde, financiamento dos prestadores de cuidados e incentivos e desigualdades em saúde.

Margarida Cabugueira Custódio dos Santos

Doutora em psicologia com especialidade em psicologia da saúde. Professora coordenadora da Escola Superior de Tecnologias da Saúde de Lisboa (ESTeSL). Professora convidada da Faculdade de Psicologia da Universidade de Lisboa (FPUL). Elemento efetivo do Centro de Investigação em Psicologia da FPUL. Investigação/ pesquisa e publicações na área da comunicação em saúde, envolvimento do doente, adesão, doença crónica, e estresse nos profissionais de saúde. Fez parte do Conselho de Mestrado em Segurança do Doente da Escola Nacional de Saúde Pública da Universidade Nova de Lisboa.

Maria João Lage

Mestrado (MSc) em quality and patient safety no Imperial College, Londres, sob orientação do prof. Charles Vincent. Neonatologista no Hospital Dona Estefania em Lisboa e responsável pela gestão do risco desde 2007. Assistente convidada de pediatria na Faculdade de Ciências Médicas de Lisboa. Colaboradora no módulo de erros de medicação no mestrado de segurança do doente e no mestrado de saúde pública relato e análise de incidentes e medidas de melhoria. Tutora do CIQSSP nas edições promovidas pela ENSP-UNL. 
Paulo Sousa

Doutorado em saúde pública. Professor na ENSP-UNL. Perito da ISQua para as questões da qualidade e segurança do paciente. Tem colaborado com a OMS e com o IHI em várias iniciativas de melhoria da qualidade em saúde e da segurança do doente, em larga escala. Membro do corpo editorial e reviewer de algumas revistas científicas nacionais e internacionais. Autor de vários artigos científicos e capítulos de livros sobre avaliação da qualidade em saúde, gestão do risco e segurança do doente. Atualmente é o coordenador do mestrado em saúde pública e coordenador adjunto do curso de especialização em saúde pública, ambos da ENSP-UNL. Colaborador do portal Proqualis.

Rui Seabra Santos

Licenciado em recursos humanos; mestre em segurança do doente. Piloto comandante de linha aérea e formador em Crew Resources Management (CRM). Coordenou vários cursos de CRM em Portugal, Brasil e Angola. Autor de capítulos de livros sobre trabalho em equipa, liderança, comunicação e analogia entre a aviação civil e a saúde.

Vera Neves Marra

Médica; livre-docente em hematologia pela Universidade Gama Filho; especialista em segurança do paciente pela Fiocruz-RJ; especialista em metodologias de ensinoaprendizagem na área da saúde pela PUC-Rio. Membro do Comitê Estadual de Segurança do Paciente do Rio de Janeiro (Cesp-RJ) e do Subcomitê Estadual de Ensino e Pesquisa do Cesp-RJ; e assessora de ensino e pesquisa da Fundação Saúde do Rio de Janeiro.

\title{
Walter Mendes
}

Médico; doutor em saúde coletiva pela Ensp/Fiocruz. Autor de livros e artigos sobre avaliação da qualidade em serviços de saúde, segurança do paciente e atendimento domiciliar.

\section{Organizadores}

\author{
Paulo Souza
}

Walter Mendes 


\section{Apreciação analítica}

Adelia Quadros Farias Gomes

Adriana Carla de Miranda Magalhaes

Adriana Dias Silva

Alexandre Souza Morais

Alice Eulália Chaga Ribeiro

Ana Luiza Braz Pavão

Andrea Donato Drumond da Silva

Anne Caroline Oliveira dos Santos

Arminda Rezende de Pádua Del Corona

Arnaldo Sala

Betina Barbedo Andrade

Carlos Renato Alves da Silva

Catalina Kiss

Celia Maria de Andrade Bruno

Eliane Werneck Abrantes

Fernanda Cristina Manzini Sleutjes

Francis Solange Vieira Tourinho

Geovanna Cunha Cardoso

Helaine Carneiro Capucho

Helen Cristiny Teodoro Couto Ribeiro

Ivanise Arouche Gomes de Souza

Janaina Ferro Pereira

Janine Koepp

Josélia Giordani Hespanhol Duarte

Karla Crozeta Figueiredo

Keroulay Estebanez Roque

Lidia Maria Feitosa Guedes

Liliana Rodrigues do Amaral

Lúcia de Fátima Neves da Silva

Luciana Barcellos Teixeira
Luciana Regina Ferreira da Mata

Luciana Tricai Cavalini

Luciana Venhofen Martinelli Tavares

Margarete Perez Machado

Maria João Laje

Maria Lucia de Souza Monteiro

Mário Borges Rosa

Marisa Peter Silva

Michele Santos Malta

Moisés Kogien

Natália Custódio Almeida Akamine

Patricia Eliane de Melo

Renata Galvão Diniz

Rosane Cohen

Rosimeyre Correia Costa

Sebastiana Shirley de Oliveira Lima

Sergio Gelbvaks

Silvana Abrantes Vivacqua

Simara Lopes Cruz Damázio

Sonia Maria Cezar Goes

Sonia Maria Dias de Lima

Suiane Chagas de Freitas Baptista

Susana Ramos

Suzinara Beatriz Soares de Lima

Tatiana dos Santos Borsoi

Teresa Cristina Gioia Schimidt

Valeria Rodrigues de Lacerda

Vera Lucia Neves Marra

Viviane Euzébia Pereira Santos

Waldir Viana das Neves Junior 


\section{Sumário}

Prefácio da $2^{\mathrm{a}}$ edição

Apresentação da $2^{a}$ edição

Apresentação da $1^{a}$ edição

1. Organizações de saúde seguras e fiáveis/confiáveis

José Fragata, Paulo Sousa e Rui Seabra Santos

2. Consequências económicas de erros e eventos adversos em saúde Julian Perelman, Jorge Pontes e Paulo Sousa

3. Acreditação e segurança do paciente

José Carvalho de Noronha, Heleno Costa Junior e Paulo Sousa

4. Cultura de segurança em organizações de saúde

Cláudia Tartaglia Reis

5. Indicadores de segurança do paciente

Carla Simone Duarte de Gouvêa

6. Saúde do trabalhador, ergonomia e segurança do paciente

António de Sousa Uva e Florentino Serranheira

7. Comunicação entre os profissionais de saúde e a segurança do paciente

Guilherme Brauner Barcellos

8. Envolvimento e segurança do paciente: desafios e estratégias

Margarida Cabugueira Custódio dos Santos e Ana Monteiro Grilo

9. Investigação/pesquisa em segurança do paciente

Bárbara do Nascimento Caldas, Paulo Sousa e Walter Mendes

10. Disclosure: a "arte" de saber comunicar ao paciente um incidente relacionado com os cuidados de saúde

Maria João Lage e Paulo Sousa

11. O ensino de segurança do paciente Vera Neves Marra e Walter Mendes 


\section{Prefácio da $2^{\mathrm{a}}$ edição}

Se, talvez, já tenhamos convivido com certo senso comum de que o cuidado de saúde propiciava somente resultados positivos, evidências dão conta, no decorrer dos últimos vinte anos, de demonstrar seu potencial de produção de danos, os quais são traduzidos pela necessidade de prolongamento de internações/internamentos, complicações, sequelas e, até mesmo, mortes, variando em amplo espectro de gravidade, constituindo-se na ponta de um iceberg que também agrega, em sua base, incidentes cujo resultado, em parte por sorte, foram outros desfechos.

A segurança do paciente, uma das dimensões fundamentais da qualidade do cuidado de saúde, adquiriu protagonismo, passando a configurar quase como conceito "isolado", expresso, por exemplo, em nomes de fóruns e revistas científicas dedicadas ao tema. Hoje representa preocupação global, associada a velhos e novos desafios em países desenvolvidos, os quais já conseguiram avançar no dimensionamento do problema e implementação de medidas para seu enfrentamento, e imensuráveis desafios em países em desenvolvimento, onde questões estruturais e processuais básicas, por certo, a afetam.

O foco na segurança do paciente, assim como na melhoria da qualidade do cuidado de saúde, de forma mais geral, requer visão sistêmica, na intenção de compreender que setores de uma organização/área e organizações/áreas em uma rede precisam estar integradas e interagir adequada e oportunamente a fim de que sejam obtidos os melhores resultados. Momentos críticos de ameaça à segurança do paciente ocorrem justamente pela baixa integração das partes e falhas de comunicação em interações mal estabelecidas.

Proporcionar maior segurança ao paciente depende também da promoção de uma cultura favorável nas organizações/áreas de saúde, que facilite a responsabilização coletiva pelo paciente e, assim, permita que erros sejam discutidos de maneira aberta e efetiva, com o propósito de que sejam considerados fonte de aprendizado. Uma figura clássica, utilizada na representação de "falhas" com potencial de afetar a segurança do paciente, é a dos buracos do queijo suíço, justamente por se 
compreender que um dano ao paciente dificilmente decorre de uma única falha de processo, mas de falhas sucessivas, que, na ausência de barreiras, se acumulam. A abertura e disposição por parte de gestores e profissionais de organizações/áreas de saúde, com o intuito de reconhecer erros e mapear suas causas, são aspectos fundamentais para que se estabeleçam barreiras que impeçam sua recorrência.

Apresenta-se, ainda, a importância de se mobilizar lideranças que atuem em prol da segurança do paciente, seja na gestão/gerenciamento e regulação do sistema de saúde, seja nas organizações/áreas de saúde em níveis da gestão/gerenciamento central, núcleos de segurança e/ ou assessorias de qualidade, e, ainda, setores (microssistemas) em que se prestam cuidados. Tais lideranças têm papéis a desempenhar na indução da cultura favorável à segurança do paciente, assim como na ampla incorporação de práticas que estabeleçam barreiras contra danos ao paciente. As organizações/áreas de saúde devem estar habilitadas para registrar e dimensionar a ocorrência de incidentes, sem ou com danos, estabelecer estratégias à sua redução e monitorar seus efeitos produzidos.

Há muito trabalho a se fazer, além de indicações bem consolidadas de ações capazes de reduzir incidentes com danos (eventos adversos) mais frequentes no ambiente hospitalar. Questões pertinentes à segurança do paciente em outros ambientes de provisão do cuidado de saúde, em especial na atenção primária, compõem um campo a ser mais bem explorado. Independentemente do ambiente focado, mantém-se a necessidade de se testar e validar de modo científico novas intervenções sustentáveis, e emanam complexos desafios de casos de pacientes, mais velhos e doentes, e processos do cuidado de saúde.

Enfim, cada vez mais, aborda-se o importante papel que pacientes e familiares podem exercer na identificação de soluções que lhes propiciem maior segurança, bem como na implementação dessas e outras soluções. Ainda que seja uma trajetória ampla a ser construída, sem dúvida, valerá a pena!

O propósito de reduzir riscos que exponham pacientes a danos desnecessários é relevante e, certamente, torna-se um desafio cativante. Esta obra, em dois volumes, possibilita excelente aproximação com a área da Segurança do Paciente, abrangendo conceitos centrais e temas de interesse selecionados.

\section{Margareth Crisóstomo Portela}

Coordenadora do Proqualis/Fiocruz 


\section{Apresentação da $2^{a}$ edição}

As razões que nos levaram a proceder à atualização e alargamento do conteúdo do livro Segurança do Paciente: criando organizações de saúde seguras surgiram, também, da convergência de três fatores.

O primeiro tem a ver com a velocidade a que o conhecimento tem evoluído na ciência e tecnologia em geral e, em particular, na área da Qualidade em Saúde e Segurança do Paciente. Tal evolução é expressa no aumento exponencial de pesquisas/estudos que têm sido feitos e publicados em revista com significativo fator de impacto; no crescente número de iniciativas de avaliação, melhoria e garantia da qualidade e segurança dos cuidados que temos assistido, um pouco por todo o mundo, e pela quantidade cada vez maior de profissionais de saúde que têm demonstrado interesse e "paixão" pelo conhecimento, pesquisa/ investigação e ação em qualidade em saúde e segurança do paciente.

O segundo fator se relaciona com a circunstância de considerarmos importante refletir, nos dois tomos que compõem esta obra, a experiência que as três instituições parceiras - ICICT, ENSP Sérgio Arouca da Fiocruz e a ENSP da Universidade Nova de Lisboa - têm vindo a acumular ao longo dos últimos cinco anos e das cinco edições (duas no Brasil e três em Portugal) do Curso Internacional em Qualidade em Saúde e Segurança do Paciente (CIQSSP). Nestas cinco edições do curso foram envolvidos mais de 2.200 profissionais de saúde do Brasil, de Portugal, de Angola e de Cabo Verde, o que permitiu uma troca riquíssima de experiências e de conhecimento.

Neste livro foram atualizados, praticamente, todos os capítulos, ao nível dos conteúdos, dos exemplos apresentados e das referências bibliográficas. Foram ainda acrescentados dois novos capítulos Foram ainda acrescentados dois novos capítulos: "Disclosure: a "arte" de saber comunicar ao paciente um incidente relacionado com os cuidados de saúde" e "O ensino de segurança do paciente". 
O terceiro e último fator tem a ver com o nosso reconhecimento a todos os profissionais de saúde que, diariamente, em suas organizações se esforçam por prestar cuidados de saúde seguros e de elevada qualidade aos seus pacientes - por vezes, desenvolvendo suas funções em condições/contextos que não são os mais adequados ou desejáveis, mas, com elevada resiliência, dedicação e profissionalismo, conseguem ultrapassar as dificuldades com que se vão deparando.

Este é, também, o momento para homenagear e agradecer a todos que contribuíram para o sucesso deste livro: aos autores, aos revisores, à equipa de CDEAD da Fiocruz, à Bárbara Caldas (Brasil) e à Sónia Rodrigues (Portugal) pelo apoio na gestão do processo de revisão e atualização.

Paulo Sousa

Organizador 


\section{Apresentação da $1^{\text {a }}$ edição}

A ideia de organizar o livro Segurança do Paciente: criando organizações de saúde seguras surgiu da convergência de três fatores.

O primeiro relaciona-se com a importância do tema. Até o início deste século XXI, com a publicação do relatório Errar é Humano, do Institute of Medicine (IOM), as referências às questões da segurança do paciente ou aos eventos adversos eram relativamente escassas. À medida que se começou a avaliar a frequência (incidência e prevalência) com que os pacientes sofriam danos provenientes do cuidado de saúde, a magnitude do problema atraiu a atenção de profissionais e gestores da saúde, pesquisadores/investigadores, decisores políticos, grupos de direitos dos pacientes e da sociedade em geral. Hoje, os sistemas e organizações de saúde, um pouco por todo o mundo, buscam alternativas e soluções que objetivam melhorar a qualidade e a segurança do paciente.

O segundo fator diz respeito à escassez de publicações, principalmente em língua portuguesa, que integrem temas da qualidade em saúde e da segurança do paciente de uma forma sistémica e estruturada. Podemos encontrar conteúdos sobre esses temas, a maioria em língua inglesa, em várias revistas científicas, livros ou em documentos políticos e estratégicos, oficiais, de países ou organizações internacionais, tais como a Organização Mundial de Saúde (OMS), Joint Commission International, Agency for Healthcare Research and Quality (AHRQ), Institute for Healthcare Improvement (IHI) ou Health Foundation (HF), para citar apenas alguns.

O terceiro fator resulta da experiência acumulada pelas três instituições, parceiras em várias iniciativas - a Escola Nacional de Saúde Pública Sergio Arouca (ENSP), o Instituto de Comunicação e Informação Científica e Tecnológica (Icict) da Fundação Oswaldo Cruz (Fiocruz) e a Escola Nacional de Saúde Pública (ENSP) da Universidade Nova de Lisboa (UNL). Dentre as diversas iniciativas que ocorreram em conjunto, recebem destaque: i) o curso introdutório, na modalidade de ensino a distância (on-line), sobre Investigação em Segurança do Paciente. Esse curso foi realizado a convite, sob a chancela da OMS e a colaboração 
do e-Portuguese. Em cada uma das oito sessões, ministradas por professores do Brasil e de Portugal, assistiram cerca de 400 participantes, dos quatro cantos do mundo; ii) a participação em um portal de disseminação de conhecimento sobre segurança do paciente - Proqualis; iii) a tradução e adaptação para a língua portuguesa de um conjunto de aulas e cursos integrados no projeto "Open School", do Institute for Healthcare Improvement; iv) a larga experiência adquirida pelas duas Ensp em ensino e investigação no campo da qualidade em saúde e da segurança do paciente, o que já resultou em várias publicações em revistas, nacionais e internacionais, com arbitragem científica.

Mediante as práticas anteriormente descritas e apoiadas na evidência da demanda existente, as instituições se articularam para promover o Curso Internacional de Qualidade em Saúde e Segurança do Paciente, na modalidade de ensino a distância, direcionado a profissionais de saúde do Brasil, de Portugal e da Comunidade de Países de Língua Portuguesa (CPLP).

O livro foi elaborado com a finalidade não só de apoiar esse curso tornando-se o referencial, o ponto de partida e de chegada de conteúdos, de questões, dúvidas e reflexões -, como também ter vida própria, independente dele. Essa publicação reúne contributos de um vasto conjunto de autores brasileiros e portugueses, com extensa experiência em termos clínicos, investigação/pesquisa e operacional do terreno, além de conhecimentos muito sólidos. Dessa diversidade, riqueza e expertise dos autores resultou, estamos certos, uma obra que, baseada na mais recente evidência científica, constitui importante contributo para quem se dedica e se preocupa com a melhoria contínua da qualidade em saúde, da segurança dos cuidados e da excelência clínica.

Este livro está estruturado em duas partes.

A Parte I, "Qualidade em saúde e segurança do paciente: aspectos fundamentais", tem o propósito de introduzir os alunos no universo da segurança do paciente, como uma dimensão da qualidade em organizações de saúde. Pautados na concepção de que o erro é humano e pode ocorrer em qualquer ramo de atividade, inclusive na saúde, pretende-se apresentar a segurança do paciente em um contexto histórico, com arcabouço teórico, uma taxonomia robusta, estratégias e ações propostas em escala mundial. A culpa e punição do(s) profissional(ais) envolvidos com o erro serão discutidas sob os pontos de vista da teoria da qualidade em saúde e jurídico. O conteúdo da Parte I está distribuído em seis capítulos: 1. Qualidade do cuidado de saúde; 2. Perspectiva histórica e principais desenvolvimentos da segurança do paciente; 3. Taxonomia em segurança do paciente; 4 . O erro e as violações no cuidado de saúde; 5. Magnitude do problema e os fatores contribuintes do 
erro e dos eventos adversos; 6. Direito e segurança do paciente.

A Parte II, "Avaliação e gestão do risco em organizações de saúde", pretende discutir os vários tipos de riscos específicos em uma organização de saúde e as soluções já conhecidas, sustentadas em evidências científicas que contribuem para a prestação de cuidados mais seguros em sua prática de trabalho. O conteúdo da Parte II está distribuído em dez capítulos: 7. Infecções associadas aos cuidados de saúde; 8. Erros relacionados aos medicamentos; 9. Cirurgia segura; 10. A Segurança do paciente e o diagnóstico; 11 . Erros relacionados ao laboratório; 12. Gestão do risco de quedas, úlceras por pressão e de incidentes relacionados com transfusão de sangue e hemoderivados; 13. Segurança do paciente na atenção primária à saúde. 14. Superlotação dos serviços de emergência; 15. Gestão do risco não clínico; 16. Maternidade segura.

Alguns temas relacionados aos riscos específicos em organizações de saúde não foram deliberadamente abordados nos capítulos da Parte II, como o tromboembolismo venoso, as falhas relacionadas a conexões de linhas de infusão e cabos, o delirium em pacientes internados, o acidente vascular cerebral pós-operatório, as complicações cardiológicas pós-operatórias, o gerenciamento/gestão da dor, o uso único de dispositivos de injeção, a fadiga de alarmes, as interrupções do trabalho da equipe de enfermagem. No entanto, por considerarmos sua relevância para a segurança do paciente, optamos por incluí-los de forma sucinta em nove anexos ao final do livro.

Escrito conforme as normas do Acordo Ortográfico da Língua Portuguesa (1990), que passou a vigorar no início de 2009, a publicação, entretanto, contempla termos consagrados tanto no Brasil como em Portugal, como exemplos: prontuário ou processo clínico; plantão ou turno; leito ou cama; entre outros. Os leitores irão se deparar, ao longo do livro, com tais nomenclaturas separadas por uma barra como representação de que elas são utilizadas em cada país, por exemplo: prontuário/processo clínico.

Consideramos que este livro, no geral, apresenta-se com uma linguagem de fácil entendimento, além disso, nos capítulos, estão disponíveis diversas referências bibliográficas atuais, que permitem o aprofundamento de qualquer tema abordado no âmbito do curso.

O sonho dos organizadores desta obra é poder encontrá-la nas "estantes" de cada serviço ou organização de saúde espalhados pelo mundo lusófono - um livro com o propósito de difundir o tema na língua portuguesa, escrito por autores do Brasil e de Portugal, que se destina aos profissionais de saúde de três continentes. 


\section{Organizações de saúde seguras e fiáveis/confiáveis}

José Fragata, Paulo Sousa e Rui Seabra Santos

Este capítulo aborda as principais características das organizações de saúde fiáveis/confiáveis (na língua anglo-saxónica, High Reliable Organization), bem como a importância e o valor que elas atribuem às questões da segurança e do risco. É também referida a comparação que pode ser feita, em diversos aspetos entre a área da saúde e da aviação (outra área de organizações fiáveis/confiáveis).

\section{Em busca da fiabilidade/confiabilidade}

Vários autores, entre os quais nos incluímos, referem que as organizações de saúde têm características semelhantes, pela sua missão e natureza, às organizações fiáveis/confiáveis. Pela sua missão, na medida em que, nas organizações de saúde, realizam-se processos altamente complexos, e a interdependência entre serviços, departamentos, equipamentos, tecnologias e profissionais é por demais evidente. Pela sua natureza, porque o risco é uma realidade constante, o trabalho em equipa uma necessidade, e a influência da cultura de segurança e de uma liderança forte são questões-chave para a organização de saúde. Seguramente, na saúde, temos ainda longo caminho a percorrer rumo à "fiabilidade/confiabilidade".

Ao compararmos a área da saúde com outras consideradas fiáveis/ confiáveis, por exemplo, aviação e energia nuclear, facilmente se percebe o valor que se atribui às questões da segurança; o financiamento disponibilizado para a área da avaliação e gestão do risco (em média $5 \%$ do orçamento anual nas áreas referidas); a aposta em tecnologia e ferramentas para prevenir a ocorrência de incidentes ou mitigar seu 
impacte; e a resposta dada quando ocorre um incidente. Com base nessas observações, depreendemos que as organizações de saúde têm, ainda, muito que aprender e melhorar nesses domínios.

Com essas questões em mente, discutiremos, ao longo do capítulo, temas como:

繁 a complexidade nos sistemas de saúde;

橉 os determinantes do resultado em saúde;

慕 variação aleatória em saúde;

* sistemas complexos e os cuidados de saúde;

*a importância da segurança em outras organizações fiáveis/ confiáveis - fazendo algumas comparações com a área da aviação;

* a evolução da segurança na aviação civil; e

*a cultura de segurança em organizações fiáveis/confiáveis.

\section{A complexidade nos sistemas de saúde}

A prestação de cuidados de saúde é uma atividade de enorme complexidade. Complexidade ao nível do paciente tratado, mas também em relação a diferentes níveis que envolvem sua prática em consultórios, clínicas, hospitais e outras organizações de saúde. E, ainda, ao nível dos financiadores - pagadores, das organizações governamentais e não governamentais que constituem os intervenientes/atores (stakeholders) da saúde. Uma das características dos sistemas de saúde é a produção de resultados (outputs) incertos, muitas vezes expressos em erros e complicações, com elevados custos de eficiência e crescentes graus de insatisfação por parte da população tratada e dos prestadores.

Não deixa de ser curioso o facto de as medidas tomadas para reduzir os erros nos sistemas de saúde, como o uso de diretrizes clínicas (guidelines) terapêuticas e tantas outras iniciativas, aparentemente boas, não terem conseguido ainda fazer da prestação de cuidados de saúde uma atividade segura, eficiente, uniformemente geradora de valor e satisfação. Os sistemas de saúde têm sido tomados como sistemas "mecânicos", sendo, na verdade, sistemas "complexos" que devem ser tratados como tal. Os pontos seguintes tratam, de forma precisa, da "complexidade" na saúde e do modo como, olhando os cuidados de saúde dessa perspetiva, poderemos melhorar sua segurança. 


\section{Serão os cuidados de saúde uma atividade segura?}

Andar de avião em vias aéreas comerciais é hoje considerado muito seguro. Calcula-se que possa morrer um passageiro por cada 10 milhões de descolagens (107), um nível de segurança designado industrialmente por sigma 7. Atividades reguladas, como o tráfico rodoviário, são bem menos seguras, com níveis de risco de sigma 4, enquanto outras, por exemplo, o alpinismo, apresentam riscos da ordem de 1 por mil! Nos hospitais, à escala global, o risco de morte por erro, ocorrido durante o internamento/internação, é de 1 para 300 internamentos/internações, e o risco de eventos adversos, de qualquer tipo, atinge cerca de dez em cada cem.

Imaginemo-nos na porta de embarque para um voo intercontinental em que a hospedeira/comissária de bordo, após as boas-vindas e a informação sobre dados da viagem, avisasse, com honestidade, que o risco de morte no voo seria de 1 em 300. Pergunto-me: Quem embarcaria? No entanto, nos hospitais, todos os dias, são admitidos milhões de pacientes que irão, sem saber, incorrer nesse mesmo risco! A prestação de cuidados de saúde, em geral, encontra-se ao nível de sigma 3, exceção feita para a anestesiologia, que, sendo muito mais segura, atingiu níveis de sigma 5.

Essa insegurança confunde-se com a imprevisibilidade do resultado, ou seja, com excessiva variação aleatória que caracteriza a saúde, mas tem razões profundas de ser: fundamentalmente, a variação extrema do fenómeno biológico e os desvios da performance diagnóstica e terapêutica. Na aviação civil, talvez essa variação seja menor, mas, com toda a certeza, o nível de performance humana e do sistema cobre muita da que porventura existiria, tornando a atividade, de forma dominante, previsível e segura. 
Figura 1 - Níveis de segurança das atividades humanas

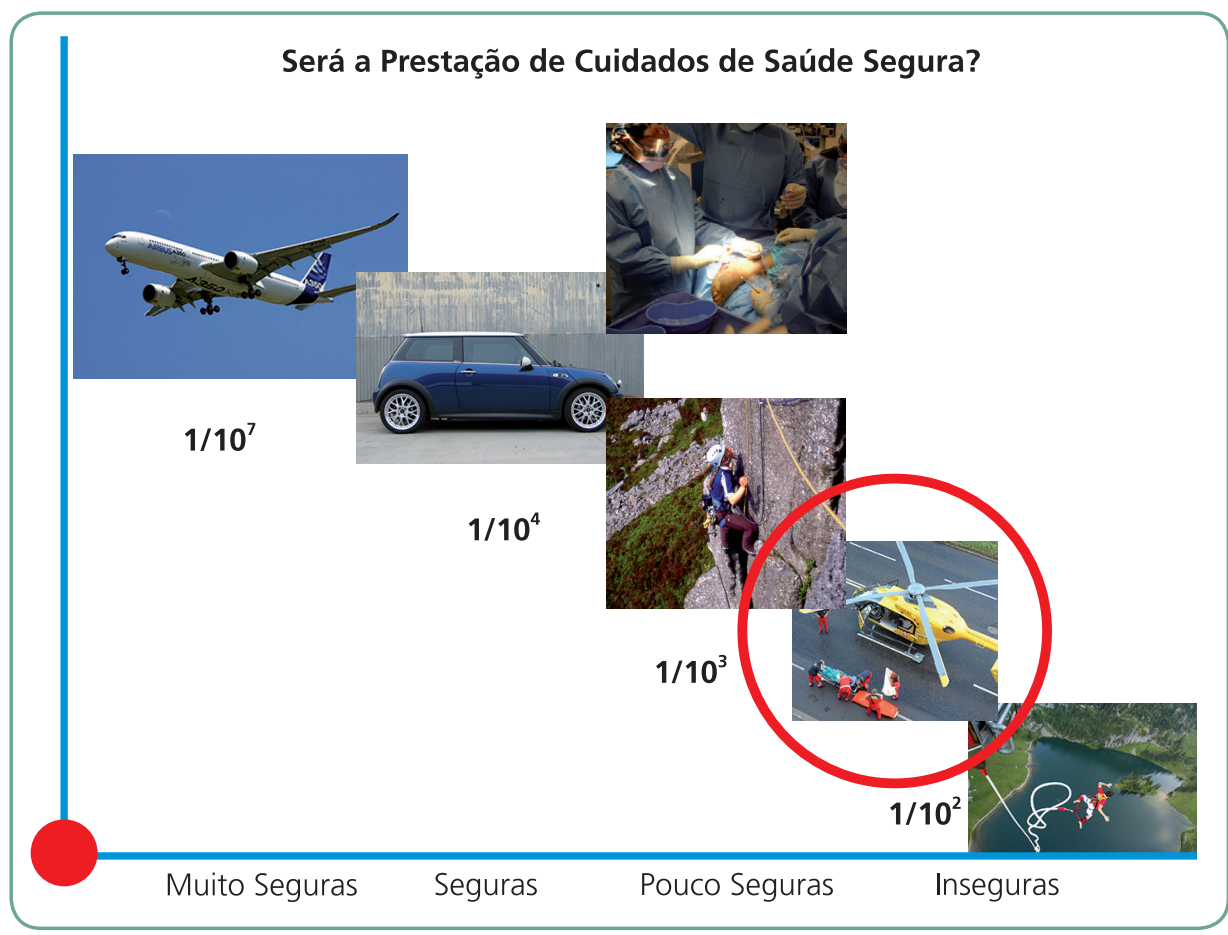

Fonte: Elaborado pelos autores com imagens da Wikimedia Commons e Flickr.

\section{Determinantes do resultado em saúde}

Os resultados em saúde, como em qualquer outra atividade humana, são determinados por:

镂 factores da dificuldade da atividade (gravidade da doença ou complexidade do procedimento, por exemplo);

䗉 factores relacionados com o ambiente envolvente (condições locais de momento, pressões, dotação de staff...);

橉 factores de performance (individual, de equipa e da organização...) e;

軑 factores aleatórios (variação não explicável).

A dificuldade de atividade representa um potencial para morte, complicações e agravamento de custos (todos esses outputs negativos), e pode ser contornada pelo nível da performance.

Entende-se, assim, que qualquer resultado em saúde deve ser indexado ao nível da complexidade tratada, o que é hoje feito por estratificação e ajustamento de risco, levando a apresentar resultados segundo o modelo de índices de resultado obtido versus resultado esperado. 
Percebe-se, então, que a correta gestão do risco clínico pode ajudar a obter melhorias de performance e melhores outputs. A complexidade de um caso é constante e transportada por cada paciente, o risco que lhe está associado varia em função da performance e pode ser modelado. Mesmo assim, não poderão ser evitados, em absoluto, erros e eventos adversos resultantes de ação humana direta (erros ou falhas ativas) e de defeitos organizacionais (erros ou falhas latentes) a múltiplos níveis. Obrigam-se os prestadores - indivíduos e organizações - à total correção de meios, mas não se poderão, nunca, vincular à obtenção de um dado resultado permanentemente bom.

\section{Variação aleatória em saúde}

Desde muito cedo, soube-se que os resultados em medicina estavam associados a uma variação incerta. Sir William Osler (citado por Fragata 2011), reputado médico canadiano/canadense do século XIX, afirmava que a medicina era a "arte do incerto e a ciência da probabilidade", e, apesar de todos os avanços tecnológicos, sociológicos e organizacionais verificados nos últimos duzentos anos, essa citação nunca pareceu tão atual. De onde provém a variação em medicina? Por exemplo, em campos com grande desenvolvimento tecnológico e dependência organizacional, como a cirurgia das cardiopatias congénitas, a variação de resultados de mortalidade para defeitos cardíacos mais graves e exigentes, como a cirurgia de Norwood para a síndrome do coração esquerdo hipoplásico (com níveis uniformes de complexidade), chega a variar 20 vezes conforme os centros e a geografia! Diremos que a variação excessiva será um resultado indesejável na saúde, havendo, assim, a variação expetável e a variação indesejável, definidas pela estatística como dois ou três desvios-padrão em torno da média, consoante o nível de exigência.

Figura 2 - Sir William Osler (1849-1919)

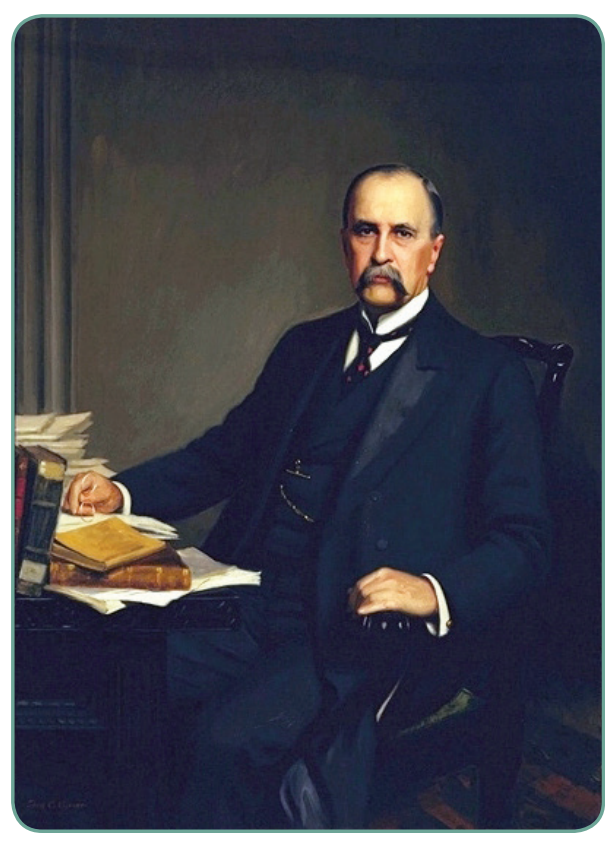

Fonte: Wikipedia (2007)

Sir William Osler foi um dos quatro professores fundadores do Johns Hopkins Hospital. Criou o primeiro programa de residência/internato para formação de médicos. 
A variação em medicina pode ser dita esperada e inexplicável (também apelidada de indesejada), sendo essa variação inexplicável hoje cada vez mais atribuída, com maior ou menor exatidão, à má performance médica e institucional e considerada um indicador de má qualidade na saúde. Com efeito, para atividades complexas e com grande dependência sistémica, os resultados melhores parecem inequivocamente associados ao maior volume de casos, o que sugere colocar a responsabilidade da variação indesejada do lado da má performance.

Na medicina, decidimos num quadro variável de concordância e certeza e, raramente, estamos 100\% concordantes e certos (na área da chamada Medicina Baseada na Evidência). Na maior parte das vezes, estamos no que Stacey (2003) apelidou de "margem do caos". Esse "caos decisional" resulta do facto da atividade de prestação dos cuidados de saúde ser exercida não no seio de sistemas mecânicos deterministas (Newtonianos), em que as mesmas causas, repetidas, condicionam os mesmos resultados, mas sim no seio de sistemas complexos, cuja variação dinâmica é a regra. Esses sistemas que explicam à escala cósmica as interações em campos tão diversos, como o espaço, o sistema imune, a meteorologia ou a variação financeira dos mercados, também explicam a variabilidade excessiva na saúde.

\section{Sistemas complexos e os cuidados de saúde}

Tomemos como exemplo um automóvel. Para o melhorarmos, poderemos decompô-lo em partes ou sistemas (motor, suspensão, sistema eléctrico...), melhorar cada parte e montar de novo. Esse processo de decomposição hierárquica funciona bem para sistemas mecânicos, mas não para sistemas de complexidade dinâmica, porque, por serem não lineares, não têm pontos de equilíbrio, parecendo antes aleatórios e caóticos; esses sistemas são constituídos por muitos agentes (médicos, enfermeiros, pacientes, pagadores, gestores...) que tendem a atuar dentro de redes profissionais e sociais, mas também independentemente, por interesses próprios e diferentes, não raras vezes conflituantes. Esses agentes são inteligentes, ganham cultura, experiência, que muda em função do tempo, adaptando-se num processo de auto-organização e, talvez o mais importante, não apresentam pontos únicos de controlo, ou seja, ninguém está, de facto, em controlo. Portanto, serão sempre mais facilmente influenciáveis no seu comportamento do que movíveis por qualquer controlo direto. 
Um sistema como esse - o sistema de saúde - não pode ser decomposto hierarquicamente, sob pena de se perder a informação relacional mais relevante. Entende-se assim que a complexidade do sistema de saúde o torna mais vulnerável a erros e resistente à mudança para melhor.

Atuando nesse tipo de sistema, quais as medidas que teriam mais efeito na redução da variação aleatória excessiva e na qualidade global dos serviços de saúde?

1. À medida que a complexidade da medicina aumenta, a simplificação para utentes/usuários (pacientes) e prestadores (médicos, técnicos e enfermeiros) deveria aumentar, nomeadamente por suporte tecnológico, fluxo de trabalho (workflows), itinerário clínico (clinical pathways), para dar alguns exemplos. Essa tendência tem sido protagonizada pelas empresas de telecomunicações, veja-se o caso da Apple®.

2. Outro aspeto prende-se com o design de toda a atividade, que deve primar pela integração desde os fluxos de tratamento, que não devem ser parcelares, mas contínuos, ao funcionamento dos cuidados em rede (primários, secundários) até a conceção do modelo de saúde global. Esse desenho deve privilegiar a integração e a flexibilidade, enquanto monitoriza e influencia padrões de atuação.

3. Finalmente, o modo como esses sistemas serão geridos deverá ser diferente, dado que essas organizações tendem a aprender, adaptar-se e se auto-organizar. Em vez das organizações tradicionais, geridas para minimizar custos, as organizações de saúde devem ser geridas para maximizar o valor.

Para melhor compreender, as diferenças entre uma organização "tradicional" e um "sistema dinâmico", veja a seguir o quadro comparativo:

Quadro 1 - Sistema tradicional versus dinâmico

\begin{tabular}{|l|l|}
\hline Sistema Tradicional & Sistema Dinâmico \\
\hline Gestão & Liderança \\
\hline Comando e controlo & Incentivos e inibições \\
\hline Atividades (atos médicos isolados) & Resultados finais (paciente tratado) \\
\hline Foco na eficiência & Foco na agilidade \\
\hline Relação contratual & Envolvimento pessoal \\
\hline Forte base de hierarquia & Hierarquia (ordem consensual) \\
\hline
\end{tabular}


O modelo que melhor responde às necessidades de modulação de um sistema complexo, como o da prestação de cuidados de saúde, será o que contempla a informação e a incentivação. A informação deve fluir livremente a todos os níveis, por exemplo, a notificação de incidentes ocorridos, que levará a aprendizagem e ao redesenho do sistema. Essa notificação deve ser feita sem culpabilização, voltada para o sistema, e não para o indivíduo, servindo sempre à aprendizagem, que leva ao conhecimento, feito ferramenta de segurança adaptativa.

Em sentido lato, a informação abrange fluxo de trabalho, listas de verificação e itinerários clínicos (workflows, checklists, clinical pathways), por exemplo, que tanto limitam os erros e melhoram a eficiência; inclui, ainda, a comunicação e a dinâmica da equipa - aspetos que a Joint Comission for Accreditation of Hospital Organizations (JCAHO) responsabilizou por $70 \%$ dos eventos adversos em saúde (Leonard et al. 2013). Essa dinâmica de equipa será, porventura, o meio mais eficaz de servir o modelo de microssistema clínico de prestação de cuidados que tanto parece limitar erros e desperdícios na prestação de cuidados.

A incentivação é uma dimensão lato que tanto pode significar a remuneração pelo que se produz efetivamente (valor criado ou tratamento final conseguido com sucesso), como o mero conhecimento inclusivo desse resultado. É curioso pensarmos que um dos meios mais poderosos de incentivar a notificação de eventos é dar feedback dos resultados da análise, das medidas e o seu impacte no terreno a quem notificou. Curiosamente, o feedback representa o elemento fundamental para a interligação que caracteriza esses sistemas adaptativos complexos.

Se é certo que o fenómeno da complexidade permite explicar, em parte, a variação nos resultados em saúde - variação expetada e variação indesejada -, sendo essa cada vez mais atribuída à deficiente performance, também é certo que a complexidade poderá ser modelada se o sistema for desenhado e gerido da forma adequada. Esses modelos, que pouco temos visto em uso no sistema (de saúde) tal como o conhecemos hoje, mas têm sido usados com enorme eficácia nas organizações ditas fiáveis/confiáveis (como as centrais nucleares ou a aviação, por exemplo), devem, agora, passar a ser aplicados às organizações de saúde em que, espera-se, venham a ter impacte igualmente favorável. 


\section{A importância da segurança em outras organizações fiáveis/confiáveis - o caso da aviação}

No contexto da aviação civil, segurança é “o estado em que os riscos associados com as atividades da aviação, relacionadas com, ou de apoio direto à operação de aeronaves, são reduzidos e controlados a um nível aceitável" (Icao 2013).

Embora a eliminação de incidentes graves e/ou acidentes com aeronaves continue a ser o objetivo final, é reconhecido que o sistema da aviação civil não está e nunca estará completamente livre de perigos e dos riscos associados. As atividades humanas ou os sistemas construídos com forte inter-relação homem-homem e/ou homem-tecnologia, como a aviação civil e a saúde, não garantem "risco zero" ou completa ausência de erros operacionais, eventos indesejáveis e das suas consequências (Helmreich 2000). Por conseguinte, nos sistemas complexos, como são as atividades da aviação civil, nuclear, aeroespacial, petroquímica e saúde, a segurança tem de ser dinâmica e acompanhar a evolução das atividades e dos riscos (Lipsitz 2012). É importante também referenciar que a aceitabilidade do desempenho da segurança é, muitas vezes, influenciada pelas culturas e normas locais, nacionais e/ ou internacionais.

Enquanto os riscos de segurança são mantidos sob um nível apropriado de controlo, um sistema tão aberto, complexo e dinâmico como a aviação civil (e a saúde) tem ainda de ser gerido para conseguir manter o equilíbrio adequado entre produção (lucro) e proteção (segurança).

\section{A evolução da segurança na aviação civil}

A história da evolução da segurança na aviação civil pode ser dividida em três épocas (Figura 3):

* A época da tecnologia (a partir do início do século passado até o final dos anos 1960) - No início do século XX, a aviação civil emergiu como uma atividade de transporte massivo de pessoas, em que as deficiências detetadas na segurança eram, inicialmente, relacionadas com factores técnicos e falhas tecnológicas. O foco dos esforços da segurança foi, portanto, colocado sobre a investigação de acidentes e incidentes (método reativo) e na melhoria dos factores técnicos. Na década de 1950, os avanços tecnológicos levaram ao declínio gradual na frequência de acidentes, e os processos de 
segurança foram redesenhados para abranger a necessidade do cumprimento da regulamentação e das normas (método preventivo) e permitir a fiscalização do seu cumprimento.

粼 A época dos factores humanos (a partir do início dos anos 1970 até meados da década de 1990) - No início de 1970, a frequência de acidentes na aviação civil foi significativamente reduzida em razão dos grandes avanços tecnológicos e da melhoria das normas de segurança. A aviação civil tornou-se o modo mais seguro de transporte, e o foco da segurança foi estendido para incluir o tema Factores Humanos (do inglês human factors), abrangendo a interface homem-máquina (Avermaete, Kruijsen 1998). Isso levou a uma procura de informações sobre segurança (método preventivo) para além do que foi gerado pelo processo de investigação de acidentes, anteriormente descrito (método reativo).

Apesar do investimento de recursos na mitigação do risco, o desempenho humano continuava a ser citado como um factor recorrente nos acidentes. A aplicação do conhecimento adquirido pela ciência dos factores humanos focou-se no indivíduo, por meio do desenvolvimento de formação e treino em CRM (Crew Resource Management), mas ainda sem considerar e alargar seu âmbito ao contexto operacional e organizacional (o sistema) em que o indivíduo desenvolve sua atividade (Helmreich 1999; Taylor et al. 2011). Mas, no início dos anos 1990, foi reconhecido, pela primeira vez, que os indivíduos trabalham num ambiente complexo, incluindo múltiplos factores, e cujo contexto tem o potencial de afetar seu comportamento e desempenho quer individual, quer em equipa.

䠌 A época organizacional (a partir de meados da década de 1990 até a atualidade) - Durante essa época, a segurança começou a ser vista através de uma perspetiva sistêmica que abrange os factores organizacionais para além dos factores humanos e tecnológicos. Como resultado, a noção de "acidente organizacional" começou a ser introduzida considerando o impacte da cultura e das políticas organizacionais na eficácia do controlo e mitigação do risco de segurança.

Para além disso, a recolha/coleta "tradicional" de informação ou dados e os esforços de análise, os quais tinham sido limitados à utilização de informação ou aos dados recolhidos/coletados por meio da investigação de acidentes e incidentes graves (método reativo), foram complementados com uma nova abordagem proativa (método preventivo) para a segurança. 
Essa nova abordagem baseou-se na recolha/coleta e análise contínua de informação ou dados obtidos na rotina diária da atividade (por meio de Registos Digitais de Dados do Voo e Gravação da Conversação no Cockpit - Flight Data Records e Cockpit Voice Record) utilizando metodologias proativas, bem como as reativas, nunca abandonadas, para monitorar os riscos de segurança conhecidos e detetados nas atividades produzidas.

Figura 3 - Factores contribuintes para o incidente/acidente

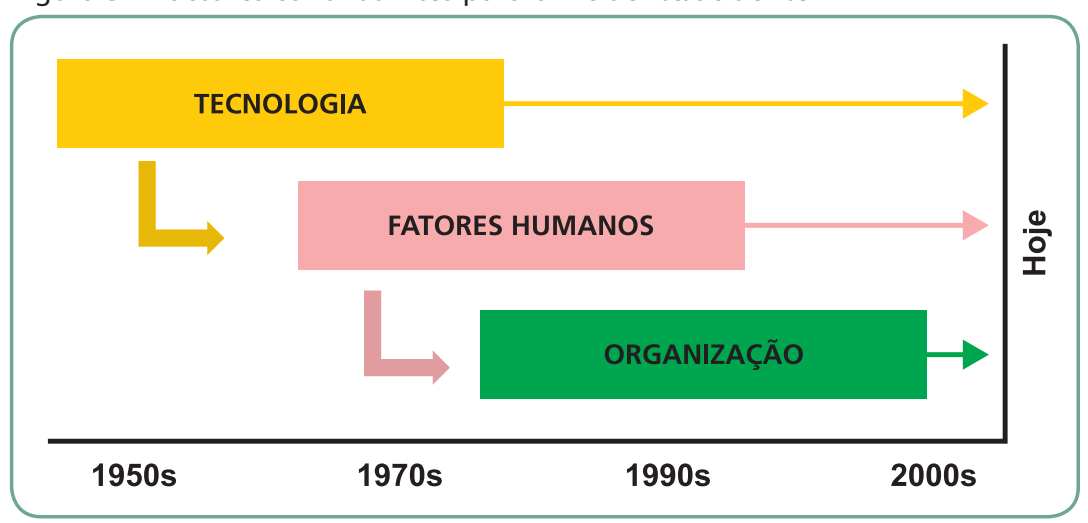

Fonte: Adaptado de Reason (2000).

Essa metodologia, assente numa perspetiva sistémica, é complementada por um sistema robusto, fiável/confiável e confidencial de obtenção de informação, por meio de sistemas de notificação de ocorrências (em que a mínima ocorrência, por exemplo, o erro, o incidente que não atingiu o paciente (near-miss), a fadiga, o estresse e outros eventos detetados ou com suspeita de influência são incentivados a serem reportados), para uma análise, partilha e aprendizagem organizacional (learning organization) de evitar ocorrências futuras, porque se sabe que, hoje, a ocorrência de um acidente ou incidente sério não resulta de um único factor contribuinte, mas de uma cascata de factores contribuintes "vivos no sistema" e que, alinhados num processo aleatório de difícil explicação e causalidade, contribuíram para o evento adverso.

Toda essa evolução e, principalmente, a nova forma de encarar a segurança justificou o surgimento da aproximação da necessidade de "gestão" para a segurança. Falamos, agora, da gestão da segurança.

Na aviação civil, a segurança (como obtê-la) faz parte da estratégia da organização, é transversal a toda a organização, e nenhum colaborador está isento da sua contribuição para manter o mais alto nível de segurança e o menor risco aceitável e possível na sua atividade diária (em cada minuto). 
No Capítulo 4 deste livro, a cultura de segurança será abordada mais aprofundadamente.
A segurança em organizações fiáveis/confiáveis requer uma atitude verdadeiramente inclusiva de todos, a par com uma resiliência muito própria. Mas todos esses valores descritos neste capítulo fazem parte de uma dimensão muito mais elevada - a cultura de segurança.

\section{Cultura de segurança em organizações fiáveis/confiáveis}

O conceito de "cultura de segurança" emergiu com maior visibilidade com o desastre de Chernobyl, em que se verificaram várias falhas de segurança, e ganhou relevo para os cuidados de saúde na linha do que sucedeu com a aviação civil, na qual tem sido seguido de forma exemplar.

Foto 1 - Sarcófago da Usina Nuclear de Chernobyl, na Ucrânia, desativada após o que é considerado o pior acidente nuclear da história

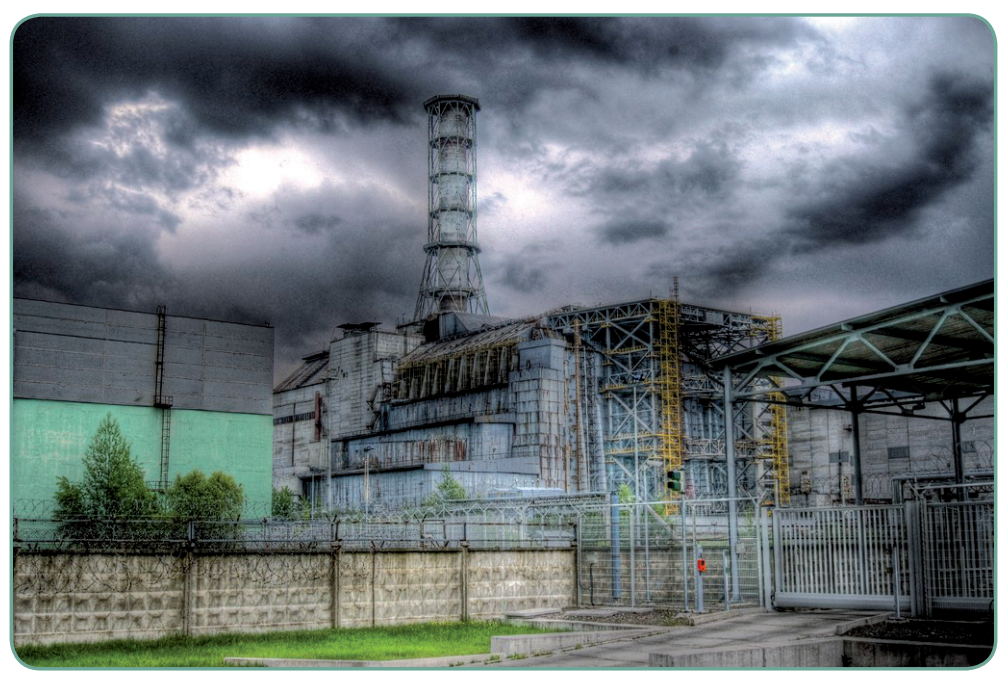

Fonte: Andryszczak (2010).

A cultura de segurança aplicada à saúde tem uma componente de perceção e outra, associada, de comportamentos de segurança; elas devem estar interiorizadas nos indivíduos, residir nas equipas e fazer parte integrante das organizações. Assim, entende-se que existam camadas ou ambientes de cultura sectoriais, mas cujos valores serão comuns e baseados numa atitude permanente de notificação sem culpa, de focagem no sistema, de aprendizagem e redesenho e de geração de conhecimento aplicável, de proatividade em relação aos eventos possíveis e sentido de vulnerabilidade e, ainda, de resiliência.

Essas dimensões devem ser exercidas em equipa, com forte componente de auto-organização e perfeita comunicação e, ainda, o envolvimento de 
todos os seus membros, a cada nível, de modo inclusivo, incorporando as normas e preocupações com a segurança nos "genes" da organização, que assim se tornará de facto segura. Essa cultura de segurança será uma cultura "justa", ou seja, responsabilizando sem culpabilizar, deixando a culpabilização exclusivamente para os casos em que exista a violação de normas ou de protocolos.

Para refletir

A partir da cultura de segurança existente em sua organização, que dificuldades se apresentam para a implementação dos valores descritos nos parágrafos anteriores?

\section{Ferramentas para alcançar a cultura de segurança - aviação e saúde o que têm em comum?}

A cultura da organização, a hierarquia rígida e a ausência de competências interpessoais (non-technical skills) são, sem dúvida, os factores que contribuem fortemente para os erros operacionais. Esses erros podem ainda ser potenciados num contexto em que, pela existência de um "clima", uma "atmosfera", uma "maneira" de atuação nas atividades, os profissionais "juniores" ou de determinado grupo profissional têm receio de falar ou expressar sua opinião, mesmo quando verificam a ocorrência de potenciais erros executados por si e/ou por outros profissionais na preparação, durante ou após uma atividade profissional (Flin 2009; McCulloch et al. 2011).

Para que essa tendência seja alterada, com o objetivo máximo de reduzir ou mitigar esses erros, procura-se, hoje, nas atividades da saúde, como no passado na aviação civil (ambas consideradas áreas/organizações complexas), estabelecer procedimentos que aumentem a segurança das atividades e processos a realizar.

Adaptados da área da aviação civil para a área da saúde, alguns conceitos são considerados fundamentais, como verificar. Nos procedimentos cirúrgicos, por exemplo, a palavra e, nalguns casos, a ação de verificar passaram a ser a regra. E verificar o quê? 
Esse assunto já foi visto nos Capítulos 3 e 9 do livro Segurança do paciente: conhecendo os riscos nas organizações de saúde.

\section{O que verificar? Verificar tudo antes do ato cirúrgico (talvez utópico...).}

Verificar a disponibilidade e bom funcionamento dos equipamentos (tecnologia) e dos instrumentos cirúrgicos.

Verificar se é o paciente certo.

Verificar se é o local correto (por exemplo, questões de lateralidade - perna esquerda ou perna direita?).

Verificar todos os procedimentos e etapas desde o momento da decisão cirúrgica até o início da cirurgia.

Verificar a constituição da equipa cirúrgica.

Verificar o estado de fadiga, vigilância e estresse dos intervenientes (equipa cirúrgica).

Verificar a disponibilidade de medicamentos, dispositivos, equipamentos (incluindo os que, apenas, são usados em situações de urgência, ou seja, que normalmente não são utilizados).

Verificar os procedimentos de contingência.

Verificar ... a verificação!!!
Parte dessa rotina de verificação deve ser feita com o "envolvimento" do paciente acordado e consciente (veja o caso da checklist cirúrgica em que o primeiro momento deve ser feito antes de o paciente estar anestesiado), exceto em casos de emergência.

Após a verificação, deve-se marcar. Marcar o local ou locais aonde e/ ou para onde vamos "voar" ou "operar". Essa marcação deve ser inequívoca (não ambígua), padronizada, comumente compreendida, bem visível. No caso de uma cirurgia, tal marcação deve ser feita com um marcador de tinta permanente, para que a marca não seja removida com facilidade. Essa marca deve ser feita pelo próprio cirurgião ou por um membro da equipa, mas na presença dele, envolvendo sempre os membros da equipa cirúrgica. Da mesma forma que o processo de verificação, o processo de marcação destina-se a introduzir redundância no sistema, mitigando o risco e aumentando os índices de segurança na cirurgia. 
"Time out" ou pausa breve antes da "ação". É nesse momento que a equipa fala sobre o caso em que irá "atuar", bem como as circunstâncias ou contexto em que tal ação irá se desenrolar (no caso de uma cirurgia, discute-se o caso - resumo da história clínica do paciente etc.), estratégia cirúrgica, equipamentos, recursos necessários - quer se a situação decorrer como o esperado, quer em termos de cenários que possam surgir (qualquer complicação ou "desvio" que possa ocorrer).

Reuniões breves antes da realização de uma atividade (time outs, ou mini briefings), como na aviação civil, são, hoje em dia, considerados momentos curtos, mas essenciais - oportunidades de concentração e de revisão da "tática" - antes de uma intervenção cirúrgica. Esses "time outs" facilitam a transferência e a partilha de informações críticas e criam uma "atmosfera" cooperativa, de motivação e de partilha entre os elementos da equipa cirúrgica (Flin 2010). Desenvolve-se, assim, uma cultura de segurança no local, um modo de atuar coordenado, a união de todos para um objetivo comum: a segurança do paciente e a efetividade do ato cirúrgico (Krause et al. 2009).

Com essas práticas de atuação, à semelhança da aviação civil, consegue-se perceber:

滕 Quem é quem dentro do bloco operatório (nome e função - o papel de cada elemento da equipa).

繗 Qual é o plano de intervenção a ser seguido (partilha de informação, liderança, quem atua (Pilot Flying) e quem supervisiona e monitoriza (Pilot Monitoring).

踏 Qual é a familiaridade com o procedimento a seguir e quais são as questões relevantes sobre as situações que possam ser encontradas durante o ato cirúrgico (proatividade em vez de reatividade).

Qual é o procedimento de contingência a seguir, caso surja essa necessidade.

Posteriormente, são utilizados protocolos de verificação pré-operatória, ou seja, listas de verificação (checklists), para que sejam seguidos todos os procedimentos tidos como corretos e verificados os recursos existentes para o início da cirurgia. Não há que confiar na memória de ninguém, pois ela é falível.

Na aviação civil, paralelamente, reconhece-se, há muito tempo, que a utilização de call-outs, cross-checks (e, de forma eventual, checkagain), briefings, minibriefings, procedimentos, checklists, simulação (praticar antes de "fazer" pela primeira vez e treinar e aperfeiçoar ao longo da
Essa é uma etapa fundamental, cujo objetivo é promover a comunicação entre os membros da equipa cirúrgica e o envolvimento, a participação e inclusão de todos no processo de tomada de decisão. 
vida, estando também preparado para situações novas - "emergência") e o conceito de sterile cockpit (ausência de comunicação não essencial nos momentos críticos da atividade a desenvolver) são ferramentas práticas, úteis e muito simples de executar que, embora se reconheça e aceite os limites do desempenho humano e os condicionalismos envolventes do contexto para o erro, servem para minimizar a possibilidade de erro e potenciar a segurança na aviação. O mesmo pode ser aplicado na saúde antes, durante ou após o ato cirúrgico.

Fotos 2 e 3 - Simulações são estratégias indicadas de treinamento e aperfeiçoamento em sistemas complexos como saúde e aviação civil
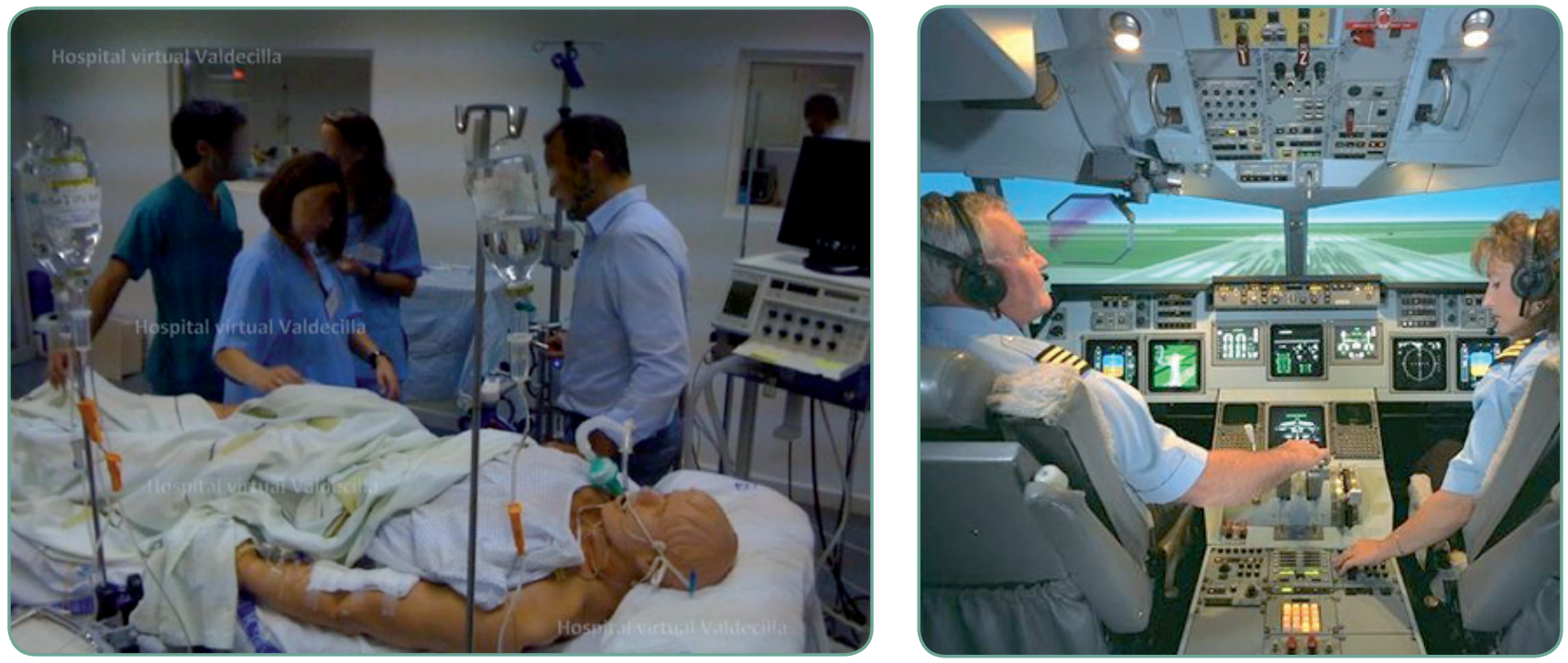

Fonte: JMMAESTRE (2012), Wikipedia (2008)

Na aviação, entende-se (e sabe-se) que até mesmo os tripulantes mais experientes cometem erros. Não é pelo facto de fazerem o mesmo tipo de voo, de operação (missão), aterragem e descolagem há muitos anos e terem bastante experiência acumulada que estão livres de cometer erros. Na aviação, assumiu-se que o factor humano é a causa principal dos acidentes e dos incidentes sérios. A área da saúde começa agora a dar os primeiros passos, mas são os mesmos de uma longa caminhada que a aviação civil já percorreu.

Para a indústria da aviação, quando os erros são identificados por quem os executa ou por quem os deve monitorizar, eles podem ser corrigidos, e a atividade de quem os comete pode ser readaptada: as margens de atuação alargam-se, o nível de atenção aumenta, e a vigilância situacional (situation awareness) é melhorada. 
Na aviação, para verificar se o resultado das ações dos pilotos é o esperado, utilizam-se, antes de uma "fase dinâmica" como a aterragem e a descolagem, as ferramentas de briefings, call-outs e cross-check. Por meio de call-outs, o piloto verifica se o resultado da sua ação é aquele esperado e, pela utilização do cross-check, se o resultado da ação do outro colega (piloto) é o pretendido naquela fase de voo. Os briefings servem para o estabelecimento de uma comunicação ativa e eficaz dentro do cockpit, criando-se um clima de confiança e participação de todos para um objetivo comum também de todos - a segurança.

\section{Para refletir}

Você atua no ou tem contacto com o bloco operatório de sua organização? Procure saber se seguem as boas práticas aqui listadas, se existe um "clima" participativo de todos.

Como é realizada a comunicação entre os integrantes desse bloco? Ela é efetiva e eficaz entre todos os intervenientes/atores (incluindo o paciente antes do ato)? A segurança do paciente é o objetivo comum da equipa cirúrgica (centralidade no paciente)?

Fazendo a "analogia" entre um cockpit e um bloco operatório, o que muda não é a intenção da ação, pois essa se mantém: Está, pelo menos, a vida de um ser humano nas nossas mãos, e teremos que gerir a situação para que, no decorrer da operação - seja ela cirúrgica ou o "simples" ato de voar -, não ocorram acidentes ou incidentes graves que coloquem em risco a vida desse ser humano.

Ambas as atividades têm um objetivo partilhado: gerir o risco por forma a evitar incidentes. Tendo em comum a ação e o objetivo partilhado, as práticas de atuação da tripulação dentro de um cockpit de um avião (e que ainda não descolou) podem ser a base das práticas a adotar por uma equipa cirúrgica num bloco operatório, na fase pré-operatória, ou seja, na fase "antes da descolagem" para uma intervenção cirúrgica segura.

Outro aspeto importante e transversal às organizações fiáveis/confiáveis relaciona-se com a resiliência dos "sistemas". Resiliência significa a capacidade de as organizações (nesse caso, organizações de saúde) resistirem, responderem e se adaptarem às "pressões dos diversos riscos" inerentes às atividades desenvolvidas no caso da saúde - riscos associados à prestação de cuidados de saúde (Carthey et al. 2001). 


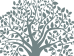

(2)

Para aprofundar mais esse tópico, sugerimos a entrevista com Erik Hollnagel, disponível no Portal Proqualis (http://proqualis.net/video/ entrevista-com-erik-hollnagel\#. VDrCMRa8qmQ), e a leitura do documento "Proactive approaches to safety management", The Health Foundation, 2012 (igualmente disponível no Portal Proqualis).
Considerada por alguns autores (Carthey et al. 2001; Hollnagel 2012) como a "face positiva" da segurança, a resiliência é intrínseca à organização e, simultaneamente, influenciada pela cultura de segurança; pela liderança; pelo compromisso dos profissionais para com as questões da segurança; pelo contexto social da organização; ou tão simplesmente, pelo valor atribuído às questões da segurança e os mecanismos de proteção e reação que a organização tem para resistir e responder aos riscos a que estão expostas. Nesse contexto, torna-se fundamental antecipar, monitorizar, responder e estar disponível para aprender. Tais características são cruciais para aumentar ou reforçar a resiliência das organizações, em particular das organizações fiáveis/confiáveis.

\section{Considerações finais}

Em síntese, os sistemas (organizações) fiáveis/confiáveis são aqueles que operam em ambientes complexos em que a probabilidade de ocorrência de erros ou incidentes é significativa, mas nos quais existem mecanismos que permitem a gestão dessas ocorrências e minimização do seu impacte. Convém não esquecer que, na área da saúde, como conjunto de organizações complexas, o risco zero é impossível de se obter. O desígnio dos profissionais, gestores e decisores políticos da área da saúde deve ser o claro compromisso com a segurança dos pacientes. Cabe a todos, incluindo os paciente e familiares, trabalhar em conjunto na busca de ações, ferramentas, metodologias, soluções e estratégias que visem prevenir ou mitigar esses riscos, como forma a reduzir e/ou eliminar a ocorrência de eventos adversos, e tornar as organizações de saúde seguras e verdadeiramente fiáveis/confiáveis.

\section{Referências} Andryszczak P. File:Chernobyl HDR.JPG. Wikimedia Commons, 2010 [citado 2014 jul 21]. Disponível
em: http://commons.wikimedia.org/wiki/File:Chernobyl_HDR.JPG

Ankerl T. Ficheiro:Oeamtc hubschrauber.jpg. Wikipedia, 2006 [citado 2014 jul 21]. Disponível em: http://pt.wikipedia.org/wiki/Ficheiro:Oeamtc_hubschrauber.jpg.

Avermaete JAG, Kruijsen EAC. NOTECHS: the evaluation of non-technical skills of multi-pilot aircrew in relation to the JAR-FCL requirements: final report. Amsterdam: [editor desconhecido]; 1998.

Carthey J, Leval MR, Reason JT. Institutional resilience in healthcare system. Qual Heath Care. 2001;10:29-32.

Flin R. Training in non-technical skills to improve patient safety. BMJ. 2009 Oct 31; 339:985-986.

Flin R. et al. Anaesthetis` non-technical skills. Br J Anaesth. 2010;105(1):38-44. 
Fragata J. Risco complexidade e performance. São Paulo: Almedina; 2006.

Fragata J. Segurança dos doentes: uma abordagem prática. [Local desconhecido]: Lidel; 2011.

Grabowski M, Roberts KH. Reliability seeking virtual organizations: challenges for high reliability organizations and resilience engineering. Saf Sci. 2016 Mar [citado 2019 jan 24]. Disponível em: https://www.sciencedirect.com/science/article/pii/S0925753516300017?via\%3Dihub

Hales DN, Chakravorty SS. Creating high reliability organizations using mindfulness. J Bus Res. 2016 Aug;69(8):2873-81.

Helmreich RL. The evaluation of crew resource management training in commercial aviation. Int J Aviat Psychol, 1999;9:19-32.

Helmreich RL. On error management: lessons from aviation. BMJ. 2000 Mar 18;320:781-785.

Hollnagel E. Proactive approaches to safety management. London: The Health Foundation; 2012.

International Civil Aviation Organization. Safety management. Annex 19 to the Convention on International Civil Aviation. Quebec: ICAO, 2013 Jul.

JMMAESTRE. File:Hospital virtual Valdecilla.jpg. Wikipedia, 2012 [citado 2014 jul 21]. Disponível em: http://en.wikipedia.org/wiki/File:Hospital_virtual_Valdecilla.jpg

Krause, Thomas R, Hidley JH. Taking the lead in patient safety: how healthcare leaders influence behavior and create culture. New Jersey: John Wiley \& Sons; 2009.

Kunzle $B$, et al. Ensuring patient safety through effective leadership behaviour: a literature review. Saf Sci. 2001;48(1):1-17.

Leonard $\mathrm{M}$ et al The essential guide for patient safety officers. 2nd ed. Washington, DC: The Joint Commission, Institute for Healthcare Improvement; 2013.

Lipsitz LA. Understanding health care as a complexity system. JAMA. 2012; 243:308-3.

MacNeil C. Extreme Bungee Jump. Flock, 2007 [citado 2014 jul 21]. Disponível em: https://www. flickr.com/photos/carla777/1039697905

McCulloch P et al. The effects of aviation-style non-technical skills training on technical performance and outcomes in the operating theatre. Qual Saf Health Care 2011;18:109-115.

Reason J. Human error: models and management. BMJ. 2000 Mar 18;320:768-70.

Rouse BW. Health care as a complex adaptative system: implications for design and management. The Bridge, Spring 2008.

Stacey RD. Strategic management and organizational dynamics: the challange of complexity. 4th ed. Harlow: Pearson Education; 2003.

Taylor CR et al. Effect of crew resource management on diabetes care and patient outcomes in an inner-city primary care clinic. Qual Saf Health Care. 2011;16:244-7.

Wikimedia Commons. File:Airbus A350-900 Maiden Flight (Low pass) 1.JPG. 2013 [citado 2014 jul 21]. Disponível em: http://commons.wikimedia.org/wiki/File:Airbus_A350-900_Maiden_Flight_ (Low_pass)_1.JPG.

Wikimedia Commons. File:Calcfx.jpg. 2010 [citado 2014 jul 21]. Disponível em: http://commons. wikimedia.org/wiki/File:Calcfx.jpg

Wikimedia Commons. File:Kate-at-fleshmarket.JPG. 2007 [citado 2014 jul 21]. Disponível em: http://commons.wikimedia.org/wiki/File:Kate-at-fleshmarket.JPG 
Wikimedia Commons. File:2004MINICooperS-001.JPG. 2005 [citado 2014 jul 21]. Disponível em: http://commons.wikimedia.org/wiki/File:2004MINICooperS-001.JPG.

Wikipedia. File:Sir William Osler.jpg. 2007 [citado 2014 jul 21]. Disponível em: http://en.wikipedia. org/wiki/File:Sir_William_Osler.jpg.

Wikipedia. File:AC97-0295-13 a.jpeg. 2008 [citado 2014 jul 21]. Disponível em: http:// en.wikipedia.org/wiki/File:AC97-0295-13_a.jpeg 


\section{Consequências económicas de erros e eventos adversos em saúde}

Julian Perelman, Jorge Pontes e Paulo Sousa

Este capítulo aborda algumas das principais questões que se relacionam com o impacte dos eventos adversos (EAs) em termos económicos. Tendo por base uma análise da literatura sobre o tema, tentou-se evidenciar o peso económico e social associado à ocorrência dos EAs, bem como a necessidade de que tal evidência deve ser do conhecimento dos profissionais, gestores e decisores políticos da área da saúde por forma a integrar esses conhecimentos nas tomadas de decisão e na definição de estratégias que visem melhorar a segurança do paciente. Assim, serão abordados, neste capítulo, os seguintes pontos:

橉 o contributo da economia na saúde e o porquê da importância em medir os custos dos EAs;

滕 quanto custam e quais os custos que devem ser apurados;

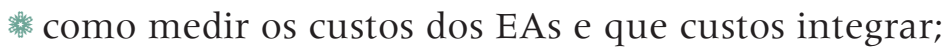

䟕 discussão sobre as metodologias utilizadas para apurar custos relacionados com os EAs.

\section{Por que medir os custos dos eventos adversos? O contributo da economia} na saúde

A ciência económica parte da constatação que os recursos são limitados e as necessidades inúmeras, obrigando a fazer escolhas, a tomar decisões e a "sacrificar" umas necessidades a favor de outras. A economia é a ciência das escolhas, e a saúde não escapa a esta realidade: mesmo na saúde, as 
arbitragens são necessárias. Quem investe na saúde, quem financia a saúde - Estado, seguradoras, cidadãos - confronta-se com recursos (orçamentos) limitados, que devem ser alocados entre diferentes terapias, programas de prevenção ou de promoção da saúde, entre profissionais, equipamentos, meios complementares de diagnóstico. Essa questão é ainda mais relevante se considerarmos o aumento notável das despesas em saúde ao longo das últimas décadas - por exemplo, quase 10\% em Portugal entre $2000 \mathrm{e}$ 2015, e 18\% no Brasil entre 2000 e 2013 (OECD 2017) -, e as inúmeras pressões para que esse aumento continue (emergência de novas tecnologias, expetativas altas da população, aumento dos preços e rendimentos, envelhecimento etc.).

As decisões são mais complexas na área da saúde do que noutras áreas por várias razões, tais como:

preponderância do sector público, que limita a possibilidade de "deixar o mercado decidir";

* multiplicidade de critérios de decisão (eficiência, equidade, qualidade, responsiveness, direitos humanos etc.);

镂 dificuldade em quantificar custos e benefícios em saúde.

A avaliação económica em saúde, que representa uma componente importante da economia da saúde, pretende responder a esse último desafio por meio de técnicas de medição de custos e benefícios em saúde e a sua integração para produzir informação objetiva, que possa apoiar a decisão nas políticas de saúde. A avaliação económica em saúde compara custos e benefícios de opções alternativas em saúde (terapêuticas, preventivas, organizativas) para determinar a "vantagem económica" de cada opção, o seu value for money, - para usar o termo inglês - ou seu "custo-efetividade" - para usar o termo técnico -, e será favorecida a opção que permita obter maiores ganhos em saúde pelo menor custo.

A medição de custos é, portanto, um instrumento essencial para o apoio à decisão na área da saúde. Assim, a medição dos custos dos eventos adversos é relevante por duas razões essenciais:

a) Por um lado, em conjunto com a medição da prevalência desses eventos, demonstra o peso económico da doença para a sociedade e, portanto, o seu caráter prioritário para as políticas de saúde. De facto, hoje em dia, não é suficiente demonstrar a forte prevalência ou incidência de uma doença para convencer os decisores políticos a intervir; também importa salientar o seu peso económico, em termos de custos para o Estado e para a sociedade, e de perdas, em termos de crescimento económico e desenvolvimento. O “custo 
dos eventos adversos" será comparado ao do VIH/Sida/HIV/Aids, da malária, do tabagismo ou da obesidade, para os quais já existe uma literatura relativamente abundante, em geral conhecida como cost-of-illness studies.

b) Por outro lado, a medição do custo dos EAs representa o pilar fundamental para poder avaliar intervenções alternativas que permitam reduzir os EAs, ou comparar essas intervenções com outras dentro da área da saúde.

\section{Quanto custam os eventos adversos? Resultados da literatura internacional}

Os custos dos EAs têm sido considerados em diversos estudos a nível internacional. Poucos estudos têm tentado estimar os custos adicionais dos EAs nos cuidados hospitalares e, ainda menos, os custos em serviços de saúde fora dos hospitais. Todos os estudos analisados demonstram que as lesões dos pacientes associadas aos cuidados de saúde aumentam substancialmente os custos, estimando-se entre 13 e $16 \%$ dos custos hospitalares (Jackson 2009), o que representa cerca de um dólar em cada sete dólares gastos no atendimento aos pacientes.

Nos EUA, o impacte dos EAs mensuráveis no aumento da despesa de saúde é considerável. Se incluirmos a má prática médica e os custos da medicina defensiva, estima-se que cheguem a atingir entre 2 a $10 \%$ dos custos totais da saúde, representando, em 2006, entre 50 a 250 biliões de dólares (Goodman et al. 2010). Grande parte desses custos é resultado de cuidados desnecessários, que também podem ser muito perigosos ao paciente. Há uma epidemia de erros médicos e infeções hospitalares que estão a aumentar os custos da prestação de cuidados de saúde, causam sequelas e até mesmo a morte para muitos pacientes (Smith et al. 2012).

Para enquadrar a problemática dos custos dos EAs, optamos por apresentar os estudos que consideramos mais relevantes, tendo em conta a sua dimensão e impacte internacional. A organização e a sequência dos estudos pretendem ser cronológicas, sendo apresentados, em primeiro lugar, os estudos transversais realizados principalmente nos EUA e Europa, que analisam e estimam os custos de todos os EAs, e, em seguida, os estudos que se dedicaram a analisar EAs específicos.

O Harvard Medical Practice Study (HMPS) (Brennan et al. 1991; Leape et al. 1991) foi considerado o primeiro estudo a estimar os custos dos EAs usando dados populacionais. Em 1984, no Estado de Nova York, os 
autores selecionaram uma amostra de 30.121 pacientes e, por meio da revisão dos seus processos clínicos/prontuário, utilizando como método 18 critérios de positividade, determinaram a taxa de incidência de EA de 3,7\% dos pacientes hospitalizados. Os custos de saúde estimados para esses EAs foram de 3,8 biliões de dólares (Brennan et al. 1991; Leape et al. 1991). O impacte nacional, com base nesse estudo, foi de mais de 50 biliões de dólares, representando cerca de $13 \%$ do total das despesas de saúde nos EUA. A metodologia do HMPS tem sido usada como referência em estudos posteriores dos EAs.

Um segundo estudo, realizado por Thomas et al. (1999) no Utah e no Colorado, veio reforçar e evidenciar o impacte financeiro dos EAs. A metodologia utilizada foi semelhante à do HMPS. Com uma amostra randomizada, foram revistos 14.732 processos clínicos/prontuários de 28 hospitais, e detetados 459 EAs, dos quais 265 eram evitáveis. Os custos totais dos EAs foram de 661,9 milhões de dólares. Nesse estudo, as complicações pós-operatórias são o tipo de EA mais dispendioso e o mais evitável, seguido pelos eventos relacionados com medicamentos, diagnósticos incorretos ou tardios e os procedimentos médicos (Tabela 1). A integração de custos da saúde domiciliária decorrente do EA representa cerca de $30 \%$ do total de custos e cerca de $50 \%$ dos custos de internamento/internação.

Os autores extrapolaram os resultados do estudo para um universo de 33 milhões de admissões hospitalares nos EUA (1993) e estimaram que os custos nacionais para os EAs seriam de 37,6 biliões de dólares. Em 1996, tal custo representava cerca de $4 \%$ das despesas de saúde nos EUA.

Tabela 1 - Custos de eventos adversos e evitáveis por tipo de evento - estudo Utah e Colorado

\begin{tabular}{l|l|l} 
Tipo de evento adverso & $\begin{array}{l}\text { Custos EAs totais em } \\
\text { milhões (USD*)/\% }\end{array}$ & $\begin{array}{l}\text { Custos EAs evitáveis em } \\
\text { milhões (USD)/\% }\end{array}$ \\
\hline Cirúrgico (operação) & $232.043 / 35,06 \%$ & $120.383 / 38,79 \%$ \\
\hline Relacionado com medicamentos & $213.750 / 32,29 \%$ & $50.740 / 16,35 \%$ \\
\hline Diagnóstico ou terapêutica & $114.650 / 17,32 \%$ & $72.372 / 23,32 \%$ \\
\hline Relacionado com procedimentos & $59.562 / 9,00 \%$ & $38.296 / 12,34 \%$ \\
\hline Outros & $41.884 / 6,33 \%$ & $28.591 / 9,21 \%$ \\
\hline Total & $661.889 / 100,00 \%$ & $310.382 / 100,00 \%$ \\
\hline
\end{tabular}

Fonte: Adaptado de Thomas et al. (1999).

*USD: Dólares americanos (United States Dollars) 
Mais recentemente, em 2008, a Society of Actuaries Health Section (SAHS), preocupada com os EAs, desenvolveu um estudo, também nos EUA, com o objetivo de medir a frequência anual dos erros médicos e o impacte dos custos totais mensuráveis na economia americana. Esses custos incluem o agravamento dos custos médicos, os custos relacionados com o aumento da mortalidade e os custos relacionados com a perda de produtividade após a ocorrência de um erro.

Nesse estudo da SAHS, para uma amostra de 564 mil EAs identificados e reclamados, os autores estimaram uma taxa de EA de 7\% na admissão, praticamente o dobro da verificada por Thomas et al. (1999), e no HMPS. A taxa de erros médicos por negligência é de 1,7\% das admissões (Shreve et al. 2010). De acordo com o relatório, o valor global anual de lesões médicas foi estimado em 6,3 milhões de pacientes. Foram identificados custos relacionados com erros médicos no valor de 19,5 biliões de dólares (Shreve et al. 2010) (17,1 biliões de custos diretos e 2,4 biliões de custos indiretos) durante o ano de 2008, nos EUA. Os autores usaram uma metodologia diferente em relação aos estudos anteriores (6), recorrendo à análise de uma extensa base de dados das seguradoras com as reclamações para pagamento de incidentes médicos aos prestadores de serviços de saúde.

Na Tabela 2, são apresentados os dez principais tipos de erros identificados no estudo da SAHS e que representam 69\% do total de EA com maior impacte económico. As úlceras de pressão e a infeção pós-operatória caracterizam-se por serem os tipos de EAs com custos mais elevados (7,5 biliões de dólares, cerca de 38,6\% dos custos totais) e, em conjunto com a infeção por punção periférica, têm taxa de lesões por erro médico superior a $90 \%$.
Custos diretos são aqueles aos quais é possível realizar a imputação direta a um determinado bem ou serviço produzido, por exemplo, o custo de uma medicação administrada.

Tabela 2 - Erros com o maior custo anual mensurável medido no estudo da SAHS

\begin{tabular}{|c|c|c|c|c|c|c|c|c|}
\hline Tipo de erro & $\begin{array}{l}\text { Lesões por } \\
\text { erros } \%\end{array}$ & $\begin{array}{l}\text { N. de } \\
\text { lesões }\end{array}$ & $\begin{array}{l}\text { N. de } \\
\text { erros }\end{array}$ & $\begin{array}{l}\text { Custo } \\
\text { médico } \\
\text { por erro } \\
\text { (USD\#) }\end{array}$ & $\begin{array}{l}\text { Custo } \\
\text { mortalidade } \\
\text { hospitalar } \\
\text { por erro } \\
\text { (USD) }\end{array}$ & $\begin{array}{l}\text { Desvio } \\
\text { padrão } \\
\text { por erro } \\
\text { (USD) }\end{array}$ & $\begin{array}{l}\text { Custo total } \\
\text { por erro } \\
\text { (USD) }\end{array}$ & $\begin{array}{l}\text { Total de } \\
\text { custos } \\
\text { (milhões } \\
\text { USD) }\end{array}$ \\
\hline $\begin{array}{l}\text { Úlcera por } \\
\text { pressão }\end{array}$ & $>90 \%$ & 394.699 & 374.964 & 8.730 & 1.133 & 425 & 10.288 & 3.858 \\
\hline $\begin{array}{l}\text { Infeção pós- } \\
\text {-operatória }\end{array}$ & $>90 \%$ & 265.995 & 252.695 & 13.312 & $\mathrm{~N} / \mathrm{A}$ & 1.236 & 14.548 & 3.676 \\
\hline
\end{tabular}


Tabela 2 - Erros com o maior custo anual mensurável medido no estudo da SAHS (cont.)

\begin{tabular}{|c|c|c|c|c|c|c|c|c|}
\hline Tipo de erro & $\begin{array}{l}\text { Lesões por } \\
\text { erros \% }\end{array}$ & $\begin{array}{l}\text { N. de } \\
\text { lesões }\end{array}$ & $\begin{array}{l}\text { N. de } \\
\text { erros }\end{array}$ & $\begin{array}{l}\text { Custo } \\
\text { médico } \\
\text { por erro } \\
\text { (USD\#) }\end{array}$ & $\begin{array}{l}\text { Custo } \\
\text { mortalidade } \\
\text { hospitalar } \\
\text { por erro } \\
\text { (USD) }\end{array}$ & $\begin{array}{l}\text { Desvio } \\
\text { padrão } \\
\text { por erro } \\
\text { (USD) }\end{array}$ & $\begin{array}{l}\text { Custo total } \\
\text { por erro } \\
\text { (USD) }\end{array}$ & $\begin{array}{l}\text { Total de } \\
\text { custos } \\
\text { (milhões } \\
\text { USD) }\end{array}$ \\
\hline $\begin{array}{l}\text { Complicação } \\
\text { mecânica de } \\
\text { dispositivo, } \\
\text { implante ou } \\
\text { enxerto }\end{array}$ & $10-35 \%$ & 268.353 & 60.380 & 17.709 & 426 & 636 & 18.771 & 1.133 \\
\hline $\begin{array}{l}\text { Síndrome pós- } \\
\text {-laminectomia }\end{array}$ & $10-35 \%$ & 505.881 & 11.823 & 8.739 & N/A & 1.124 & 9.863 & 1.123 \\
\hline $\begin{array}{l}\text { Infeção após } \\
\text { injeção. } \\
\text { Transfusão ou } \\
\text { vacinação }\end{array}$ & $>90 \%$ & 9.321 & 8.855 & 63.911 & 14.172 & N/A & 78.083 & 691 \\
\hline Pneumotórax & $35-65 \%$ & 51.119 & 25.559 & 22.256 & N/A & 1.876 & 24.132 & 617 \\
\hline $\begin{array}{l}\text { Infeção por } \\
\text { cateter venoso } \\
\text { central }\end{array}$ & $>90 \%$ & 7.434 & 7.062 & 83.365 & N/A & N/A & 83.365 & 589 \\
\hline
\end{tabular}

Fonte: Adaptado de Shreve et al. (2010)

* Biológicas, sintéticas, dispositivos, implantes e enxerto

\# USD: Dólares americanos (United States Dollars)

N/A: Não se aplica

Em 2010, a Medicare, dos EUA (Levinson 2010), publicou um estudo que visava estimar a incidência nacional de EAs nos seus beneficiários hospitalizados, avaliar a evitabilidade dos eventos e estimar seus custos. A taxa de incidência dos EAs foi estimada em 13,5\% dos beneficiários hospitalizados, e cerca de $1,5 \%$ dos pacientes experimentaram um evento que conduziu à morte. 
A metodologia do estudo da Medicare baseia-se numa amostra representativa de 780 utentes/usuários que receberam alta hospitalar no mês de outubro de 2008 e com recurso a auditores médicos que utilizaram as listas de EAs do National Quality Forum (NQF) e do Hospital-Acquired Conditions (HAC) para validar os eventos. Os médicos determinaram que $44 \%$ dos EA eram evitáveis.

Os custos adicionais da Medicare, associados aos EAs, foram estimados em 324 milhões de dólares, o que equivale a 3,5\% dos custos totais com o internamento/internação. No ano de 2009, as despesas totais com internamento/internação foram estimadas em 137 biliões de dólares, o que, a manter-se esse percentual de 3,5\%, significaria um custo acrescido de 4,4 biliões de dólares associado a EAs.

Na União Europeia (UE), estima-se que, nos seus Estados-membros (Council of the European Union 2009), entre 8\% a 12\% dos pacientes internados são vítimas de EA durante seu tratamento. Alguns estudos na UE sobre a incidência dos EAs abordam os custos associados.

Na Holanda, num estudo realizado em 2011-2012, com uma amostra de 2,975 pacientes de 20 hospitais, os autores utilizaram como metodologia a revisão retrospetiva dos processos clínicos, efetuada por enfermeiros e médicos, aplicando o protocolo do Canadian Adverse Event Study (CAES), originalmente usado pelo Harvard Medical Practice Study, que consiste na aplicação de um screnning de 18 critérios preditivos de EA. Os resultados do estudo mostram que os custos médicos atribuíveis aos EAs, nos hospitais, ascendem a 309 milhões de euros, após extrapolação ao território nacional, ou seja, 1,3\% das despesas hospitalares (Hoogervorst-Schilp et al. 2015). Segundo os autores, o excesso do tempo de internamento/internação foi em média de 4,7 dias, por paciente com EA, e um custo adicional de 2.337 euros.

Na Alemanha, também foi efetuada uma revisão retrospetiva dos internamentos hospitalares, no sentido de identificar eventos adversos relacionados com medicação, com base em três hospitais (49.000 pacientes). O excesso de custo foi de 970 euros, para 2,9 dias de internamentos adicionais. A extrapolação para o nível nacional resultou num excesso de custo de 1 milhão de euros (Rottenkolber et al. 2012).

Em Portugal, o estudo piloto dos EAs, realizado em 2010 (com base em processos clínicos/prontuários do ano de 2009) utilizou metodologia idêntica ao CAES e apurou que, em cerca de 58,2\% dos pacientes que sofreram um EA, houve prolongamento dos dias de internamento/ internação, e, em média, esse prolongamento foi de 10,7 dias com todas 


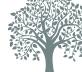

Em 2017, a OCDE realizou um estudo sobre os custos associados a eventos adversos. Sugere-se a sua leitura:

Slawomirski L, Auraaen A, Klazinga. The economics of patient safety: strengthening a value-based approach to reducing patient harm at national level. Paris: OECD; 2017 [citado 2019 jan 25]. Disponivel em: https://www. oecd.org/els/health-systems/ The-economics-of-patientsafety-March-2017.pdf as consequências em termos de custos e de dificuldades na gestão de camas/leitos que daí decorrem (Sousa et al. 2014). Outro estudo, mais recente, observou uma taxa de 1,46\% de eventos adversos em hospital relacionados com medicamentos, com base em todos os internamentos hospitalares para o período 2004-2013 (Scripcaru et al. 2017).

Um estudo realizado no Brasil (Travassos et al. 2010) apurou que os pacientes com EA apresentaram tempo médio de permanência no hospital de 28,3 dias superior ao observado nos pacientes sem EAs. Extrapolados para o total de internações nos dois hospitais, os eventos adversos implicaram gasto de RUSD 1.212.363,30, que representou $2,7 \%$ do reembolso total.

\section{Para refletir}

Você já havia pensado no impacte dos EAs sobre a questão da gestão de camas/leitos? Sua organização sofre com essa relação de causa e consequência?

Existe algum tipo de estimativa do impacte econômico dos EAs em seu país, região ou organização?

O Excess Costs of Adverse Events in Hospitals in France é o título do primeiro estudo (Nestrigue, Or 2011 ) realizado na França com objetivo de estimar o custo direto de nove tipos de EAs. A metodologia utilizada para detetar os EAs hospitalares baseou-se na avaliação de nove indicadores (PSI - Patient Safety Indicators) da Agency for Health Care Researchand Quality (AHRQ). Em 2007, o custo total dos EAs foi estimado em cerca de 700 milhões de euros. Nesse estudo, foram identificados quatro tipos de EAs responsáveis por $93 \%$ do total de custos, nomeadamente:

Gráfico 1 - Participação de EAs nos custos

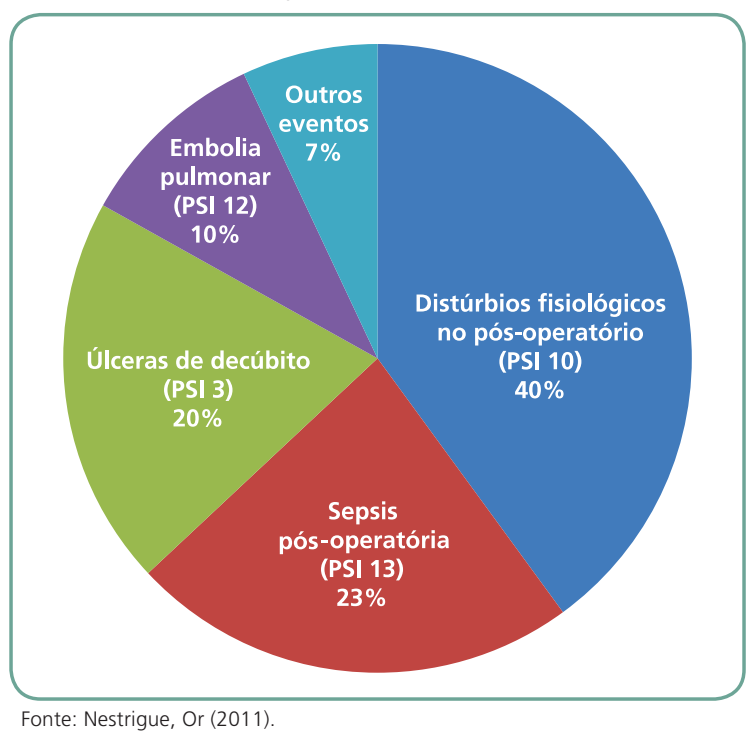


Nos países da UE, todos os anos, cerca de 4,1 milhões de pacientes sofrem de infeções associadas aos cuidados de saúde (IACS) hospitalar, dos quais cerca de 37 mil morrem (Council of the European Union 2009), correspondendo a uma taxa de mortalidade de 0,9\%. Os tipos de infeção mais frequentes são as do trato urinário (27\%), as do trato respiratório $(24 \%)$ e as infeções do sítio cirúrgico (17\%), sendo esse último tipo o que representa maior impacte económico. Em 2008, o custo das IACS na UE foi estimado em cerca 8 biliões de euros (Lamarsalle et al. 2013). Esses custos devem-se predominantemente ao aumento do tempo médio do internamento/internação superior a 9,8 dias.

Um estudo mais recente e alargado sobre o tema foi realizado no Canadá, baseado em dados de todos os internamentos hospitalares em hospitais de agudos (Chan, Cochrane 2016). Foi observada uma taxa de eventos adversos de 5,6\%, ou seja, uma em 18 hospitalizações, principalmente associados à medicação e às infeções relacionadas com cuidados. Observaram, também, uma taxa de mortalidade de $12,5 \%$ nas hospitalizações com ocorrência de evento adverso. O custo dos eventos adversos foi estimado em USD 685 milhões, o que representa cerca de $1 \%$ das despesas hospitalares no Canadá.

Nos EUA, de acordo com a CDC (Scott 2009), as IACS afetam cerca de 1,73 milhões de pacientes e representam um custo entre 16 e 19 biliões de dólares por ano, baseados em estimativas de 2002 de Klevens e atualizados a preços de 2007 (Scott 2009). O custo associado à infeção nosocomial estimado por Hassan et al. (2010) é de 10.375 dólares em razão, principalmente, do aumento do tempo médio de internamento/ internação e representa acréscimo de $24 \%$ relativamente aos custos de um internamento/internação sem infeção.

Dados recentes (2013) apresentados por Zimlichman et al. (2013) indicam o peso acentuado dos principais tipos de IACS nos EUA, cujo custo ronda os 9,8 biliões de dólares (Tabela 3). Os resultados desse estudo podem ser comparados com os da CDC (Scott 2009), tendo em conta que avaliam o mesmo tipo de infeção. 
Tabela 3 - Impacte financeiro das infeções associadas aos cuidados de saúde em pacientes internados em hospitais de adultos nos EUA (17)

\begin{tabular}{l|c|c|c}
$\begin{array}{l}\text { Tipo de infeção associada aos cuidados } \\
\text { de saúde }\end{array}$ & \multicolumn{3}{l}{ Custos (1) estimados a preços de 2012} \\
\cline { 2 - 4 } & $\begin{array}{l}\text { Total (milhões } \\
\text { USD*) }\end{array}$ & $\begin{array}{l}\text { Limite inferior } \\
\text { (milhões USD) }\end{array}$ & $\begin{array}{l}\text { Limite superior } \\
\text { (milhões USD) }\end{array}$ \\
\hline $\begin{array}{l}\text { Infeção do local cirúrgico (ferida } \\
\text { operatória) }\end{array}$ & 3297 & 2999 & 3596 \\
\hline $\begin{array}{l}\text { Infeções da corrente sanguínea associadas } \\
\text { ao cateter central }\end{array}$ & 1851 & 1249 & 2636 \\
\hline $\begin{array}{l}\text { Infeções do trato urinário associadas a } \\
\text { cateter }\end{array}$ & 28 & 19 & 37 \\
\hline $\begin{array}{l}\text { Pneumonia associada à ventilação } \\
\text { mecânica }\end{array}$ & 3094 & 2797 & 3408 \\
\hline $\begin{array}{l}\text { Infeções por Clostridium difficile } \\
\text { Total }\end{array}$ & 9778 & 8283 & 11491 \\
\hline
\end{tabular}

Fonte: Adaptado Zimlichman et al. (2013).

*USD: Dólares americanos (United States Dollars)

O número de casos de infeção por Clostridium difficile tem vindo a aumentar no mundo inteiro. Uma das principais razões para esse acréscimo do número de casos é o facto de os hospitais estarem, hoje em dia, melhor preparados para seu diagnóstico. Trata-se de infeção por uma bactéria que existe, em geral, no intestino humano e pode causar problemas se o paciente for vulnerável e estiver a fazer uso de antibióticos. Nesses casos, a bactéria multiplica-se exponencialmente, libertando toxinas, transmitindo-se com facilidade em ambiente hospitalar. A prevenção da sua transmissão é feita por meio do cumprimento das regras de higiene das mãos e do ambiente.

Figura 1 - Colônias de Clostridium difficile após 48 horas de crescimento em uma placa de ágar sangue

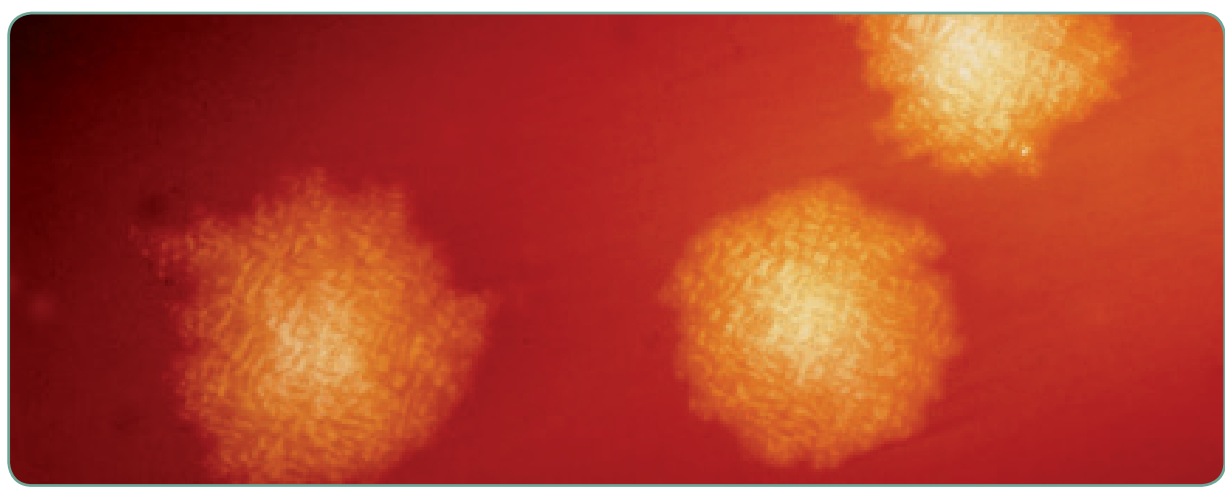

Fonte: Holdeman (1965)

O C. difficile é um bacilo Gram-positivo anaeróbio, sendo a causa mais frequente de diarreia associada a antibióticos. 
O NEHI e NQF (National Priorities Partnership, 2010) alertam para a oportunidade de se poupar 21 biliões de dólares na prevenção de erros de medicação. Esse organismo estima um custo com os erros de medicação evitáveis de 16,4 biliões de dólares para os pacientes internados e cerca de 4,2 biliões com os pacientes do ambulatório.

Os estudos anteriores mediram essencialmente os custos médicos, portanto do ponto de vista do chamado " $3^{\circ}$ pagador". Esse termo refere-se à entidade que financia os cuidados de saúde; não é nem o prestador de cuidados nem o utente/usuário, mas, geralmente, o Estado ou a seguradora privada. A análise dos custos sociais relacionados com os EAs, que permite estudar os custos na perspetiva da sociedade, é pouco abordada, mas merece reflexão e cuidado especial. O cálculo dos custos sociais deve ter em linha de conta com os anos de vida perdidos, as perdas de produtividade e o apoio de familiares ou de terceiros aos pacientes.

Baseado nos resultados da mortalidade dos estudos sobre EA $(2,4)$ publicados nos EUA, Goodman et al. (2011) estimularam que os custos sociais variam entre 393 biliões e 958 biliões de dólares americanos. O autor teve como referência os métodos de cálculo dos custos das lesões resultantes dos acidentes de trabalho, incluindo o valor económico da vida humana e aplicou-os ao EA.

Em síntese, no Quadro 1, apresentamos uma visão geral dos resultados dos principais estudos analisados.

Quadro 1 - Visão geral dos resultados dos principais estudos apresentados neste capítulo

\begin{tabular}{|l|l|l|l|l|l|l|l|}
\hline $\begin{array}{l}\text { Autor e ano } \\
\text { publicação }\end{array}$ & País & $\begin{array}{l}\text { Tipo } \\
\text { evento }\end{array}$ & Amostra & Método & $\begin{array}{l}\text { Resultados } \\
\text { EA/lesões }\end{array}$ & $\begin{array}{l}\text { Estimativa } \\
\text { custos }\end{array}$ & $\begin{array}{l}\text { Extrapolação' } \\
\text { dos custos }\end{array}$ \\
\hline $\begin{array}{l}\text { Leape L, } \\
\text { Brennan T et } \\
\text { al. } 1991\end{array}$ & EUA & EAs & $\begin{array}{l}30.121 \\
\text { pacientes } \\
\text { hospitalizados } \\
\text { em NY }\end{array}$ & $\begin{array}{l}\text { Revisão de processos } \\
\text { clínicos HMPS, } 18 \\
\text { critérios de preditivos } \\
\text { de EA }\end{array}$ & $\begin{array}{l}3,7 \% \\
\text { admissões }\end{array}$ & $\begin{array}{l}\text { USD 3,8 } \\
\text { biliões }\end{array}$ & $\begin{array}{l}\text { USD 50 biliões } \\
13 \% \text { total } \\
\text { despesas saúde }\end{array}$ \\
\hline $\begin{array}{l}\text { Thomas et al. } \\
1999\end{array}$ & EUA & EAs & $\begin{array}{l}14.732 \\
\text { pacientes } \\
\text { hospitalizados } \\
\text { em Uthan e } \\
\text { Colorado }\end{array}$ & $\begin{array}{l}\text { Revisão de processos } \\
\text { clínicos, adaptação do } \\
\text { HMPS }\end{array}$ & $\begin{array}{l}3,1 \% \\
\text { admissões }\end{array}$ & $\begin{array}{l}\text { USD 661,9 } \\
\text { milhões }\end{array}$ & $\begin{array}{l}\text { USD 37,6 biliões } \\
4 \% \text { total } \\
\text { despesas saúde }\end{array}$ \\
\hline $\begin{array}{l}\text { Shreve J. et al. } \\
2010\end{array}$ & EUA & EAs & $\begin{array}{l}564.000 \text { lesões } \\
\text { em pacientes } \\
\text { hospitalizados }\end{array}$ & $\begin{array}{l}\text { Reclamações às } \\
\text { seguradoras para } \\
\text { pagamento de } \\
\text { incidentes médicos. } \\
\text { Lesões identificadas } \\
\text { por ICD-9 }\end{array}$ & $\begin{array}{l}7 \% \text { admissões } \\
\text { USD } 19,5 \\
\text { biliões }\end{array}$ & - \\
\hline
\end{tabular}


Quadro 1 - Visão geral dos resultados dos principais estudos apresentados neste capítulo (cont.)

\begin{tabular}{|c|c|c|c|c|c|c|c|}
\hline $\begin{array}{l}\text { Autor e ano } \\
\text { publicação }\end{array}$ & País & $\begin{array}{l}\text { Tipo } \\
\text { evento }\end{array}$ & Amostra & Método & $\begin{array}{l}\text { Resultados } \\
\text { EA/lesões }\end{array}$ & $\begin{array}{l}\text { Estimativa } \\
\text { custos }\end{array}$ & $\begin{array}{l}\text { Extrapolação } \\
\text { dos custos }\end{array}$ \\
\hline $\begin{array}{l}\text { Levinson D. } \\
2010\end{array}$ & EUA & $\begin{array}{l}\text { EAs nos } \\
\text { beneficiários } \\
\text { da Medicare }\end{array}$ & $\begin{array}{l}\text { Amostra } \\
\text { representativa } \\
\text { de } 780 \\
\text { beneficiários } \\
\text { da Medicare }\end{array}$ & $\begin{array}{l}\text { Após alta dos } \\
\text { pacientes, revisores } \\
\text { médicos utilizaram as } \\
\text { listas de EA do NQF e } \\
\text { do HAC para validar } \\
\text { os eventos }\end{array}$ & $\begin{array}{l}13,5 \% \\
\text { admissões }\end{array}$ & $\begin{array}{l}\text { USD } 324 \\
\text { milhões }\end{array}$ & $\begin{array}{l}\text { USD } 4,4 \text { biliões } \\
3,5 \% \text { custos } \\
\text { totais da } \\
\text { Medicare }\end{array}$ \\
\hline $\begin{array}{l}\text { Nestrigue C. et } \\
\text { al. } 2011\end{array}$ & França & $\begin{array}{l}\text { Nove tipos } \\
\text { de EA - } \\
\text { indicadores } \\
\text { PSI - AHRQ }\end{array}$ & $\begin{array}{l}\text { População } \\
\text { hospitalizada } \\
\text { em } 2007\end{array}$ & $\begin{array}{l}\text { Query com as } \\
\text { variáveis (ICD-9) dos } \\
9 \text { EA, para extrair a } \\
\text { informação em base } \\
\text { de dados nacional, } \\
\text { com registo dos } \\
\text { pacientes com código } \\
\text { de ICD-9 e GDH }\end{array}$ & $\begin{array}{l}0,5 \% \\
\text { admissões } \\
\text { associadas aos } \\
9 \text { EA }\end{array}$ & - & $\begin{array}{l}€ 700 \text { milhões } \\
\text { para os } 9 \text { EAs }\end{array}$ \\
\hline $\begin{array}{l}\text { Rottenkolber, } \\
\text { D. et al. } 2012\end{array}$ & Alemanha & $\begin{array}{l}\text { EAs } \\
\text { relacionados } \\
\text { com } \\
\text { medicação }\end{array}$ & $\begin{array}{l}49.462 \\
\text { pacientes de } \\
\text { três hospitais }\end{array}$ & $\begin{array}{l}\text { EAs baseado } \\
\text { num algoritmo } \\
\text { desenvolvido pelos } \\
\text { autores }\end{array}$ & $1,1 \%$ & - & $\begin{array}{l}1.058 \text { milhões de } \\
\text { euros }\end{array}$ \\
\hline $\begin{array}{l}\text { Zimlichman, L, } \\
\text { et al. } 2013\end{array}$ & EUA & $\begin{array}{l}\text { Infeção } \\
\text { associada } \\
\text { aos } \\
\text { Cuidados } \\
\text { de Saúde } \\
\text { (IACS) }\end{array}$ & $\begin{array}{l}\text { Fontes de } \\
\text { dados para } \\
\text { estimativa } \\
\text { de custos } \\
\text { atribuíveis } \\
\text { realizando } \\
\text { uma revisão } \\
\text { sistemática da } \\
\text { literatura, (Pub } \\
\text { Med de } 1986 \\
\text { até abril de } \\
\text { 2013) }\end{array}$ & $\begin{array}{l}\text { Utilização da } \\
\text { simulação de } \\
\text { Monte Carlo, } \\
\text { foram geradas as } \\
\text { estimativas pontuais } \\
\text { e IC de } 95 \% \text { para } \\
\text { os custos atribuíveis } \\
\text { e para o tempo } \\
\text { de internamento/ } \\
\text { internação }\end{array}$ & - & - & USD 9,8 biliões \\
\hline $\begin{array}{l}\text { Hoogervorst- } \\
\text { Schilp, J et al. } \\
2015\end{array}$ & Holanda & EAs & $\begin{array}{l}2.975 \\
\text { pacientes } \\
\text { hospitalizados }\end{array}$ & $\begin{array}{l}\text { Revisão de processos } \\
\text { clínicos HMPS/ } \\
\text { CAES, } 18 \text { critérios de } \\
\text { preditivos de EA }\end{array}$ & $\begin{array}{l}10,9 \% \\
\text { admissões }\end{array}$ & - & $\begin{array}{l}\text { USD } 309 \text { milhões } \\
\text { 1,3\% total } \\
\text { despesas saúde }\end{array}$ \\
\hline $\begin{array}{l}\text { Chan, } \\
\text { Cochrane, } \\
2016\end{array}$ & Canadá & EAs & $\begin{array}{l}\text { Todas as } \\
\text { hospitalizações } \\
\text { do país }\end{array}$ & $\begin{array}{l}\text { Definição da OMS e } \\
\text { do Institute for Health } \\
\text { Information }\end{array}$ & $\begin{array}{l}5,6 \% \text { das } \\
\text { admissões }\end{array}$ & $\begin{array}{l}\text { USD } 685 \\
\text { milhões }\end{array}$ & \\
\hline
\end{tabular}

Fonte: Elaborado pelos autores.

1. Extrapolação é o cálculo aproximado do valor de uma função desconhecida, correspondente a um valor da variável situado fora do intervalo que contém os valores dessa variável, para os quais se conhece quanto vale a referida função. Por exemplo, calcular para um país os custos dos eventos adversos tendo por base os custos decorrentes em dois hospitais. 


\section{Como medir os custos? E que custos medir? Algumas dificuldades metodológicas}

A revisão da literatura demonstra que, a nível mundial, a segurança clínica e os EAs têm merecido a atenção dos governos, principalmente dos países desenvolvidos. Em 2004, a OMS definiu uma estratégia global por meio da World Alliance for Patient Safety sob o lema "First do no harm".

Apesar de, nos últimos 20 anos, terem sido realizados inúmeros estudos para avaliar o impacte clínico dos EAs, só recentemente se deu importância ao impacte económico desses eventos. E, como consequência, existem poucos estudos com estimativas do impacte dos custos adicionais dos EAs nos hospitais e, ainda menos, fora dos hospitais (nos cuidados de saúde primários, por exemplo).

Os resultados dos inúmeros estudos realizados e publicados comprovam que as lesões decorrentes dos EAs aumentam substancialmente os custos dos cuidados de saúde, como pode ser confirmado nos estudos apresentados neste capítulo. No entanto, pela análise dos estudos, também se constata que existe uma discrepância quanto aos métodos utilizados para a estimação dos custos associados aos EAs. A ausência de uma metodologia comum dificulta a comparação, e para a mesma população podem produzir resultados diferentes. A literatura revela, ainda, falta de consenso sobre que varáveis de custo devem ser medidas e não apresenta os custos de um programa para reduzir a incidência dos Eas (Jackson 2009). Ou seja, a literatura é escassa e apresenta em prioridade resultados sobre "custo da doença", enquanto negligencia a avaliação económica de estratégias alternativas para reduzir os EAs.

\section{Dificuldades em definir custos diretos}

A dificuldade passa pela definição dos parâmetros de medição e por algumas questões económicas importantes na segurança do paciente, nomeadamente: Quais as questões de segurança ou que tipo de incidentes a considerar?

滕 Que EAs aumentam o custo do atendimento ao paciente?

滕 Que custos devem ser imputados ao EA?

Qual o investimento para reduzir o EA?
Algumas pistas para responder a essas questões poderão ser seguidas nas reflexões finais. 


\section{Qualidade dos dados e suas fontes}

Existem algumas formas de contabilizar os EAs:

Registros de notificação de EA voluntários, que dependem

da cultura de segurança da organização.

Registros do sistema de codificação de pacientes por grupos diagnóstico homogéneo (GDH), tendo por base

- registro da lesão/doença (ICD) do EA, que dependem do

registro do incidente e da análise do codificador.

Registro de notas de alta, que depende do médico.

Estudo retrospectivo de revisão dos processos/prontuários

clínicos, através de uma lista detalhada com critérios

preditivos de EA, que embora sendo o 'gold standard'

depende da análise subjetiva do revisor para avaliar a

evitabilidade do evento.

Indicadores de Segurança do Paciente (PSI) da AHRQ

que depende da qualidade dos dados existentes na

base de dados.

Todas as formas de contabilizar os EAs apresentam fragilidades, no entanto, apesar dos custos de realização, o estudo de revisão de processos clínicos/prontuários com base numa lista detalhada de critérios preditivos de EA é o que reúne maior consenso (Brennan et al. 1991, Hoonhout et al. 2009, Thomas et al. 1999). No entanto, os indicadores da AHARQ têm ganhado alguns adeptos por permitir mais facilmente a comparação entre os estudos, apesar de estar mais dependente dos registos de codificação dos eventos e limitado ao conjunto de 18 indicadores.

\section{Medição da utilização de custos}

Embora não existam métodos padronizados para estimar os custos (decorrentes de EAs), observa-se que a estimativa dos custos é realizada utilizando várias abordagens como:

* Reclamações de pedidos de indenização ou de descontos (muito utilizados nos EUA), sendo essa abordagem uma técnica muita imperfeita, porque está dependente do registo do pedido de indenização.

膦 Técnica de microcusteio ou protocolo de custeio, com acesso a custospadrão por cada serviço ou pacotes de serviço aplicados ao paciente.

Método da faturação excedente (microcusteio) e dos custos médios GDH; embora mais fáceis de utilizar, são métodos cujos resultados tornam difícil a extrapolação. 


\section{Perspetiva adotada}

Finalmente, a medição de custos em avaliação económica pode ser efetuada segundo diferentes perspetivas, sendo as duas seguintes as mais comuns em Portugal e no Brasil:

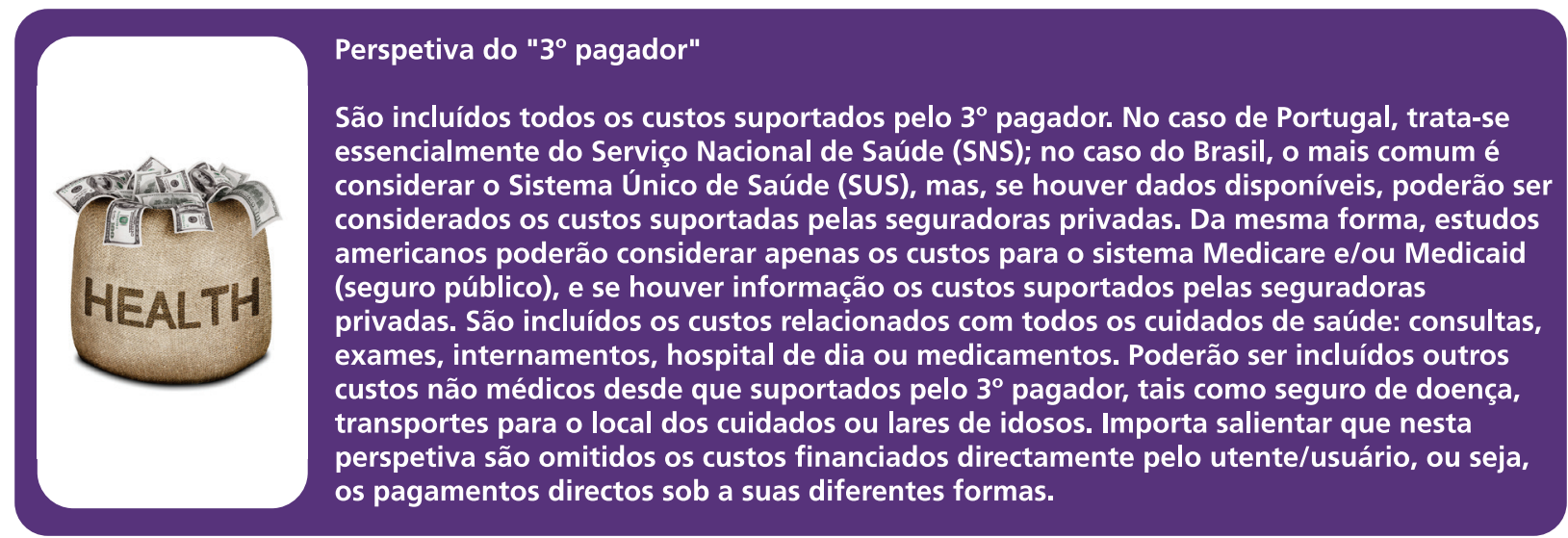

Fonte: 401(K) (2011).

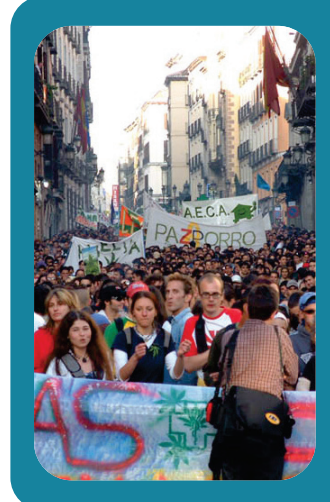

Perspetiva da sociedade

Aos custos suportados pelo $3^{\circ}$ pagador, acrescentam-se todos os custos suportados pelo utente/usuário, a saber todos os pagamentos directos, seja no sector público ou no sector privado. Serão incluídas também todas as outras despesas não médicas, relacionadas com a doença, e não suportadas pelo $3^{\circ}$ pagador, tais como subsídios de invalidez, e todas as despesas suportadas pelos acompanhantes do paciente, ou cuidadores informais. Finalmente, a perspetiva da sociedade inclui também, e sobretudo, os custos associados à perda de produtividade do utente/usuário, por faltas ao trabalho, invalidez ou morte prematura. Estes últimos custos são geralmente denominados "custos indirectos" e são particularmente relevantes quando a doença atinge populações jovens em idade de trabalhar. São geralmente estes custos indirectos que representam a maior diferença entre a perspetiva da sociedade e a perspetiva do $3^{\circ}$ pagador.

Fonte: Fotoblog Rare de VLC (2004).

Quando se trata de avaliar o "custo da doença", a perspetiva da sociedade deverá ser privilegiada, considerando os custos de um ponto de vista abrangente. Trata-se, de facto, de medir não apenas no curto prazo cuidados médicos, mas potenciais consequências para a economia e o desenvolvimento. No entanto, na prática, como verificado na secção anterior, os custos indiretos são raramente incluídos nos estudos sobre custos dos eventos adversos, por causa essencialmente das dificuldades e incertezas na sua medição.
Custos indiretos são aqueles em que é difícil, ou impossível, isolar a parte dos custos imputável a cada um dos produtos ou serviços produzidos. Para fazer a imputação dos custos indiretos a cada produto ou serviço, tornase naturalmente necessário estabelecer um critério para essa imputação. 


\section{Considerações finais}

A revisão da literatura demonstra que o efeito "bola de neve" dos eventos adversos tem importantes consequências económicas. Embora o valor (de custos) obtido num estudo publicado recentemente nos EUA (USD 9,8 bilhões) seja muito inferior aos valores encontrados, por exemplo, para o impacte económico da diabetes (USD 218 bilhões, (Dall et al. 2010)), das doenças cardiovasculares (USD 273 bilhões, (Heidenreich et al. 2011)), da asma (USD 56 bilhões, (Barnett et al. 2011)) ou da depressão (USD 83 bilhões, (Greenberg et al. 2003)), os custos dos EAs representam uma porcentagem significativa das despesas hospitalares. Num contexto de crise económica e de necessidade de contenção de custos, a importância económica dos EAs não pode ser negligenciada. O aumento dos prémios de seguro de saúde, provocado pela litigância médica, a medicina "defensiva" e a ausência de políticas e investimentos para reduzir a ocorrência de EAs são factores que determinam esse efeito. O desenvolvimento da indústria farmacêutica acelerou esses efeitos, estimando-se que por cada dólar gasto em medicamentos de ambulatório, um dólar é gasto para tratar os novos problemas de saúde causados pela medicação (Kumar, Steinebach 2008). Na perspetiva económica, essa informação permite, sobretudo, refletir a respeito de que outros cuidados, com benefícios para os pacientes, poderiam ser proporcionados se os EAs e seus custos fossem evitados.

A ocorrência de EA, com consequente lesão ou dano aos pacientes, é um problema mundial com impacte elevado nas despesas de saúde e a nível social. A solução para minimizar esse problema não é simples, nem única; a avaliação económica pode também contribuir para determinar quais alternativas para combater os EAs devem ser adotadas, por meio da comparação dos seus custos e benefícios. Várias estratégias foram identificadas na literatura para reduzir a incidência de eventos adversos, relacionadas com atitudes individuais, gestão ao nível das equipas ou mudanças organizacionais. A implementação dessas estratégias pode ser realizada por meio da formação dos profissionais, técnicas de avaliação do desempenho, colaborações multiprofissionais, incentivos financeiros, intervenções dos pacientes, entre outros. Todas essas estratégias e modos de implementação são sujeitas a avaliações em termos da sua efetividade. A avaliação económica acrescenta a dimensão dos custos e do "valor" agregado das medidas de prevenção. A aplicação da avaliação económica às estratégias de intervenção é praticamente inexistente, apesar da sua importância. É nossa convicção que essa será uma das linhas de investigação mais promissoras, para os próximos anos, no estudo dos eventos adversos, em particular, e da segurança do paciente, em geral. 


\section{Referências}

Barnett S, Beth L, Tursynbek A. Nurmagambetov. Costs of asthma in the United States: 2002-2007. J Allergy Clin Immunol. 2011; 127(1): 145-52.

Brennan T, Leape L, Laird N, Hebert L, Localio A, Lawthers A, et al. Incidence of adverse events and negligence in hospitalized. N. Engl. J. Med. 1991;324:370-6.

Brown P, Mcarthur C, New L, Lay-yee R, Davis P, Briant R. Cost of medical injury in New Zealand: a retrospective cohort study. J. Health Serv. Res. 2002 Jul;7:29-34.

Chan B, Cochrane D. Measuring patient harm in Canadian hospitals: with what can be done to improve patient safety? Ottawa, ON: Canadian Institute for Health Information, Canadian Patient Safety Institute; 2016.

Council of the European Union. Council Recommendation of 9 June 2009 on patient safety, including the prevention and control of healthcare associated infections. Off. J. Eur. Union. 2009:1-6.

Dall TM, Zhang Y, Chen YJ, Quick WW, Yang WG, Fogli J. The economic burden of diabetes. Health Aff. 2010, 29(2):297-303.

Fotoblog Rare de VLC. Ficheiro:Protests Madrid 2004 2.jpg. Wikipedia, 2004 [citado 2014 Jul 28]. Disponível em: http://pt.wikipedia.org/wiki/Ficheiro:Protests_Madrid_2004_2.jpg.

Goodman JC, Villarreal P, Jones B. The social cost of adverse medical events, and what we can do about it. Health Aff. (Millwood). 2011 Apr [citado 2014 Jul 28];30(4):590-5. Disponível em: http:// www.ncbi.nlm.nih.gov/pubmed/21471477

Greenberg PE, Kessler RC, Birnbaum HG, Leong SA, Lowe SA, Berglund PA, et al. The economic burden of depression in the United States: how did it change between 1990 and 2000? J Clin Psychiatry. 2003; 64(12):1465-75.

Hassan M, Tuckman HP, Patrick RH, Kountz DS, Kohn JL. Cost of hospital-acquired infection. Hosp. Top. 2010 [citado 2013 Aug 26];88(3):82-9. Disponível em: http://www.ncbi.nlm.nih.gov/ pubmed/20805070.

Healey BJ, College K, Mcgowan M. The enormous cost of medical errors. Acad. Health Care Manag. J. 2010;6(1):17-25.

Heidenreich PA, et al. Forecasting the future of cardiovascular disease in the United States a policy statement from the American heart association. Circ. 2011; 123.8: 933-44.

Holdeman (CDC). Ficheiro:Clostridium difficile 01.png. Wikipedia, 1965 [citado 2014 July 2007]. Disponível em: http://pt.wikipedia.org/wiki/Ficheiro:Clostridium_difficile_01.png.

Hoogervorst-Schilp J, Langelaan M, Spreeuwenberg P, Bruijne MC, Wagner C. Excess length of stay and economic consequences of adverse events in Dutch hospital patients. BMC Health Serv Res. 2015;15(1):531.

Hoonhout L, Bruijne M, Wagner C, Zegers M, Waaijman R, Spreeuwenberg P, et al. Direct medical costs of adverse events in Dutch hospitals. BMC Health Serv Res 2009 Jan [citado 2013 ago 26]; 9:27. Disponível em: http://www.pubmedcentral. nih.gov/articlerender.fcgi? artid=2645386\&tool=p mcentrez\&rendertype=abstract.

Jackson T. One dollar in seven: scoping the economics of patient safety: a literature review prepared for the Canadian Patient Safety Institute. Edmonton (AB): Canadian Patient Safety Institue; 2009 Sep.

Kumar S, Steinebach M. Eliminating US hospital medical errors. Int. J. Health Care Qual. Assur. 2008;22(5):444-71. 
Lamarsalle L, Hunt B, Schauf M, Szwarcensztein K, Valentine WJ. Evaluating the clinical and economic burden of healthcare-associated infections during hospitalization for surgery in France. Epidemiol. Infect. 2013 Dec [citado 2013 Dec 4];141(12):2473-82. Disponível em: http://www. pubmedcentral. nih.gov/articlerender.fcgi?artid=3821401\&tool=pmcentrez\&rendertype=abstract.

Leape L, Brennan T, Laird N, Lawthers A, Localio AR, Barnes BA, et al. The nature of adverse events in hospitalized patients: results of the Harvard Medical Practice Study II. N. Engl. J. Med. 1991;324(6):377-84.

Levinson D. Adverse events in hospital: national incidence medicare beneficiaries. Washington, DC: US Department of Health and Human Services, Office of the Inspector General, 2010. 75 p.

National Priorities Partnership. Preventing medication errors: a USD 21 billion opportunity. Compact action brief: a roadmap for increasing value in heath care. Washington, DC: National Quality Forum; 2010 Dec.

Nestrigue C, Or Z. Excess costs of adverse events in hospitals in France. Inst. Rech. Doc. en Économie la Santé. 2011 Dec;171:7.401(k). Health. Flick, 2013 [citado 2014 Jul 28]. Disponível em: https://www.flickr.com/photos/68751915@N05/6629088361/.

OECD. OCDE health statistics 2017. Paris: OECD; 2017 [citado 2017 out 19]. Disponível em: http:// www.oecd.org/els/health-systems/health-data.htm.

Rottenkolber D, Hasford J, Stausberg J. Costs of adverse drug events in German hospitals a microcosting study. Value Health, 2012;15(6);868-75.

Scott D. The direct medical costs of healthcare-associated infections in U.S. hospitals and the benefits of prevention. CDC. 2009 Mar:13. Disponível em: http://www.cdc.gov/HAl/burden. html_07Dezembro2013.

Scripcaru G, Mateus C, Nunes C. Adverse drug events: analysis of a decade. A Portuguese casestudy, from 2004 to 2013 using hospital database. PLoS ONE. 2017;12(6): e0178626. https://doi. org/10.1371/journal.pone.0178626.

Shreve J, Bos J, Gray T, Halford M, Rustagi K, Ziemkiewicz E. The economic measurement of medical errors. New York: Society of Actuaries' Health Section; 2010 Jun. p. 1-264.

Smith M, Saunders R, Stuckhardt L, Mcginnis JM. Best care at lower cost the path to continuously learning health care in America. Washington, DC: National Academies Press; 2012.

Sousa P, Uva A, Serraheira F, Nunes C, Leite E. Estimating the incidence of adverse events in Portuguese hospitals: a contribution to improving quality and patient safety. BMC Health Ser Res. 2014; 14:311.doi:10.1186/1472-6963-14-311.

Thomas E, Studdert D, Newhouse J, Zbar B, Howard K, Williams E, et al. Costs of medical injuries in Utah and Colorado. Inquiry. 1999 Jan;36(3):255-64. Disponível em: http://www.ncbi.nlm.nih.gov/ pubmed/10570659.

Travassos C, Porto S, Martins M, Mendes W. A magnitude financeira dos eventos adversos em hospitais no Brasil. Rev Port Saúde Pública. 2010;Vol. Temático(10):74-80.

Van Den Bos J, Rustagi K, Gray T, Halford M, Ziemkiewicz E, Shreve J. The USD 17.1 billion problem: the annual cost of measurable medical errors. Health Aff. 2011 Apr;30(4):596-603. Disponível em: http://www.ncbi.nlm.nih.gov/pubmed/21471478.

Zimlichman E, Henderson D, Tamir O, Franz C, Song P, Yamin C, et al. Health care-associated infections: a meta-analysis of costs and financial impact on the US Health Care System. JAMA Intern. Med. 2013 Sep 2 [citado 2013 Nov 27];02120:1-8. Disponível em: http://www.ncbi.nlm.nih. gov/pubmed/23999949. 


\section{Acreditação e segurança do paciente}

José Carvalho de Noronha, Heleno Costa Junior e Paulo Sousa

Pretende-se que este capítulo apresente aspectos relevantes do processo de acreditação, tendo em vista a importância do processo de acreditação para a melhoria da segurança do paciente. Este capítulo explora:

* As origens e desenvolvimento dos processos denominados acreditação de serviços de saúde.

As diferenças entre a acreditação, credenciamento e licenciamento de serviços de saúde.

膦 Os conceitos básicos de acreditação e os traços essenciais de sua metodologia.

* A relevância dos processos de acreditação para a segurança dos pacientes.

Um sumário com as características específicas dos principais métodos de acreditação em uso no Brasil e em Portugal.

滕 Os benefícios da acreditação.

\section{Origens}

O termo acreditação, na língua portuguesa, é de entrada recente no campo da saúde. Dicionários brasileiros não registravam sequer o termo até anos recentes.

O Dicionário Caldas Aulete (Geiger 2012) admite um significado que corresponde a seu emprego no campo da saúde: “Ação ou resultado de acreditar, de atestar oficialmente a boa qualidade de algo, a compe- 
tência técnica, a conformidade com um conjunto de requisitos previamente estabelecidos: certificado de acreditação".

Uma especificação dessa definição corresponde ao emprego do termo atualmente em uso corrente nos processos de avaliação da qualidade dos serviços de saúde e será detalhada mais adiante.

As origens da acreditação em saúde, tal como a entendemos hoje, pode ser traçada às decisões do Congresso Clínico de Cirurgiões de Nova Iorque em 1912. Ali foi decidida a criação do Colégio Americano de Cirurgiões, que ocorreu no ano seguinte, e aprovada uma resolução requerendo que "fosse desenvolvido algum sistema de padronização dos equipamentos hospitalares e do trabalho hospitalar" (Consórcio Brasileiro de Acreditação 1997). Foi instituído o Comitê de Padronização Hospitalar, e Ernest Codman, um cirurgião de Boston, chamado para presidi-lo.

Codman, logo no início de sua carreira de cirurgião, formulou a "Ideia do Resultado Final", propondo que os pacientes cirúrgicos fossem acompanhados de perto após o tratamento para verificar os resultados. De certa forma, essa iniciativa era semelhante àquela proposta por Florence Nightingale, fundadora da enfermagem moderna, durante a guerra da Crimeia. Ela pedira que médicos e hospitais reportassem os resultados cirúrgicos de maneira padronizada. Para cada paciente que tratava, Codman elaborava um "cartão de resultado final", o qual continha a história atual, o diagnóstico inicial, o tratamento dado, a ocorrência de complicações, o diagnóstico de alta e o resultado um ano depois. Ele desenvolveu um método de classificação de erros e eventos adversos e publicou seus resultados no relatório do hospital em que trabalhava relatando e documentando abertamente erros e mortes. Em 1918, publicou esses resultados em um livro intitulado Um estudo sobre a eficiência hospitalar, como demonstrado pelos relatos de casos dos primeiros cinco anos de um hospital privado (Brawer 2001).

Embora a proposta de Codman de que os hospitais adotassem a "ideia do resultado final" não tenha tido sucesso, a proposta de padronização dos hospitais avançou, e o Colégio Americano de Cirurgiões aprovou o chamado Minimum Standard em 1917, que continha requisitos dispostos em cinco itens (Figura 1). 


\section{Requisitos mínimos do Minimum Standard}

Presença de corpo clínico organizado.

Clínicos e cirurgiões devidamente licenciados, competentes e éticos.

Adoção de regras, regulamentos e políticas pelo corpo clínico, em conjunto com o corpo dirigente, para organizar o trabalho profissional da instituição.

Prontuários médicos/processos clínicos precisos, acessíveis e completos.

Disponibilidade de instalações diagnósticas e terapêuticas adequadamente supervisionadas.

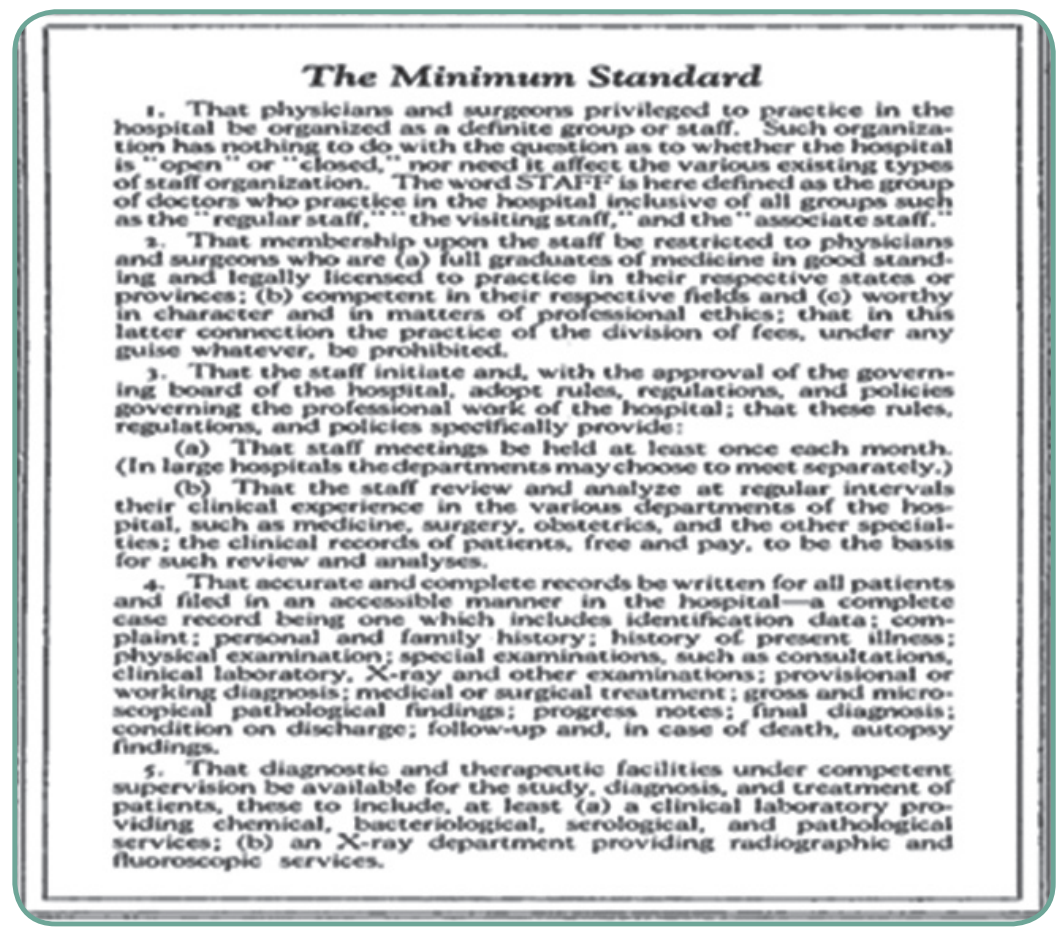

Fonte: American College of Surgeons (2006).

A primeira aplicação do padrão mínimo revelou que somente 89 hospitais, entre 692 avaliados, atenderam aos requerimentos. Diante desses resultados, temendo a repercussão na mídia/media, os relatórios dos hospitais foram queimados na lareira do hotel em que se realizava a reunião da Diretoria do Colégio. Mas a iniciativa acabou por prosperar e, em 1926, o Colégio publicou o primeiro Manual de Padronização de Hospitais. Posteriormente, em 1951, nos Estados Unidos, a partir da associação do 
Colégio Americano de Cirurgiões, da Associação Médica Americana, do Colégio Americano de Clínicos, da Associação Americana de Hospitais e da Associação Médica Canadense/Canadiana, foi criada a Joint Commission on Accreditation of Hospitals (JCAH) (Comissão Conjunta de Acreditação de Hospitais). Em 1952, o Colégio Americano de Cirurgiões, oficialmente, transferiu seu Programa de Padronização de Hospitais para a JCAH, que, com base em tal programa, em 1953, publicou seu primeiro manual para acreditação de hospitais. A Associação Médica Canadense/Canadiana se retirou dessa associação em 1959 e fundou um sistema nacional de acreditação no Canadá, atualmente chamado Accreditation Canada (Acreditação Canadá).

\section{Para praticar}

O item 3 do Minimum Standard prescreve literalmente:

"O corpo clínico do hospital...adota regras, regulamentos e políticas... [que] prevejam:

a) Que reuniões do corpo clínico sejam realizadas pelo menos uma vez por mês. (Nos hospitais grandes os departamentos podem preferir se reunirem separadamente);

b) Que o corpo clínico reveja e analise, em intervalos regulares, sua experiência clínica nos vários departamentos do hospital, como medicina, cirurgia, obstetrícia e outras especialidades; os prontuários/processos clínicos dos pacientes, gratuitos ou pagantes, devem ser a base dessa revisão e análise" (ACS 2006).

Verifique se a sua organização cumpriria com esses dois requisitos do Minimum Standard.

Discuta sua relevância para a segurança dos pacientes da sua organização.

A partir de 1966, outros tipos de organizações de saúde, além de hospitais, como cuidados prolongados, cuidados domiciliares, laboratórios clínicos, serviços ambulatoriais, saúde mental, passaram a ter manuais de acreditação. Em 1987, a JCHA alterou seu nome para Joint Commission on Accreditation of Healthcare Organizations (JCAHO) como hoje é conhecida (Comissão Conjunta de Acreditação de Organizações de Saúde) -, evidenciando assim o aumento e ampliação do escopo e alcance dos serviços cobertos por seus programas.

Em 1998, a JCAHO, por meio de uma subsidiária, a Joint Commission Resources (JCR), criou a Joint Commission International (JCI) (Comissão Conjunta Internacional). A JCI veio atender a uma demanda por 
modelos e programas de acreditação em diferentes países no mundo. A experiência adquirida pela JCAHO desde a sua criação em 1951 possibilitou a difusão da metodologia utilizada nos Estados Unidos, que foi apropriadamente adaptada para ser aplicada em países ao redor do mundo. A JCI passou a desenvolver processos de consultoria e de acreditação em todas as regiões do planeta, seja de forma direta nas instituições de saúde, ou por meio de parceria e associações com entidades governamentais, públicas e de caráter privado.

No Brasil, a JCI estabeleceu um acordo de Acreditação Internacional Conjunta com o Consórcio Brasileiro de Acreditação (CBA), também criado em 1998. Por meio do acordo, o CBA passou a conduzir avaliações conjuntas de acreditação, ou seja, com a participação de avaliadores internacionais, os quais são capacitados diretamente pela JCI, assim como dos avaliadores selecionados pelo CBA, por meio de programas de treinamento periódicos elaborados pela JCI e CBA. As avaliações abrangem acreditação e reacreditação de organizações de saúde, assim como, mais recentemente, a certificação de programas de cuidados clínicos, de acordo com procedimentos estabelecidos pela JCI.

A expansão dessa metodologia para fora dos Estados Unidos ampliou as fronteiras e os modelos e métodos de aplicação da acreditação. Diferentes países como Austrália, África do Sul, Nova Zelândia, França e Reino Unido adotaram modelos nacionais por meio de entidades, em geral, de caráter privado, que se constituíram para desenvolver e aplicar os próprios manuais e padrões de acreditação. A França, de forma diferenciada, adotou um modelo público, nacional, em que a acreditação se aplica aos profissionais de saúde, em especial médicos, e a certificação para as instituições de saúde, que devem, obrigatoriamente, se submeter ao programa. Na atualidade, outros países, em especial os do Leste Europeu e Ásia, têm avançado de forma expressiva na implantação de programas nacionais de acreditação, entre outros, China, Índia, Japão e Tailândia. A implantação dos programas nos diferentes países do mundo tem se inspirado em distintos modelos de acreditação, como os da JCI, da Acreditação Canadá e da CHKS (Reino Unido), dos quais as experiências mais antigas e consistentes têm sido inspiradoras para esses países.

A disseminação desses programas foi bastante incentivada pela International Society for Quality in Health Care (ISQua), sociedade científica fundada em 1984 com o objetivo de promover a qualidade dos cuidados de saúde por todo o mundo. A ISQua, em 1999, lançou um programa de lideranças para acreditação que, posteriormente, se transformou no programa internacional de acreditação de processos de avaliação externa. 


\section{Conceitos}

A acreditação, ao longo de sua evolução foi, por vezes, entendida ou utilizada de forma equivocada para substituir sistemas de licenciamento ou certificação, ou, ainda, de regulação de sistemas ou instituições de saúde. Rooney e Van Ostenberg (1999) apresentaram um estudo com as definições e aplicações dos processos de licenciamento, acreditação e certificação. Os autores buscavam também estabelecer as principais diferenças entre os processos. O foco de estudo dos autores foi baseado no uso dos processos com o objetivo de avaliar a qualidade dos serviços de saúde. Eles abordam que uma das primeiras etapas na seleção de um sistema de avaliação é o conjunto de necessidades que se pretende tratar, para que seja o mais efetivo possível.

A acreditação é um processo no qual uma entidade, separada e distinta da organização de saúde, geralmente não governamental, avalia a organização de saúde para determinar se ela atende a um conjunto de requisitos (padrões) projetados para melhorar a segurança e a qualidade dos cuidados (forma de avaliação externa).

A acreditação é geralmente voluntária. Os padrões de acreditação são estabelecidos em um nível ótimo e alcançável. A acreditação evidencia um compromisso da organização para melhorar a segurança e a qualidade do cuidado ao paciente, garantir um ambiente de cuidados seguro, e continuamente trabalhar a fim de reduzir os riscos para os pacientes e funcionários. A acreditação é considerada uma ferramenta para a avaliação da qualidade e para a gestão e, em especial, melhoria da segurança do paciente.

Com a expansão do uso do termo acreditação como uma metodologia avaliativa específica para a qualidade de organizações de cuidados de saúde, torna-se necessário explicitar os conceitos de termos correlacionados que também são empregados no setor.

O mais frequente é o licenciamento, que corresponde ao atendimento de requisitos formalmente exigidos pelo poder público por meio de leis, normas ou regulamentos infralegais. São exemplos os requisitos para a abertura e funcionamento de organizações de saúde, os códigos de posturas urbanas, os requerimentos de segurança contra incêndios, uso de material radiativo etc. Esses requisitos são estabelecidos como mínimos obrigatórios, sem os quais bens e serviços não podem ser empregados ou prestados. O licenciamento é, em geral, realizado por meio de inspeções ou visitas de fiscalização. O objetivo é, primariamente, verificar se requisi- 
tos ou requerimentos são ou não atendidos, conforme aplicável para cada perfil ou tipo de serviço que é inspecionado ou fiscalizado.

Outro termo é certificação, em que um organismo autorizado, seja uma organização governamental ou não governamental, avalia e reconhece um indivíduo ou uma organização como capaz de atender a requisitos ou critérios predeterminados. Embora os termos acreditação e certificação sejam, muitas vezes, usados como sinônimos, o primeiro, geralmente, aplica-se apenas a organizações, enquanto a certificação pode aplicar-se tanto a indivíduos como a organizações.

Quando aplicado a profissionais, a certificação normalmente implica ter o indivíduo recebido educação adicional e formação e competência demonstrada em uma área de especialidade, além dos requisitos mínimos estabelecidos para o licenciamento. Exemplo de um processo de certificação é o de um médico que recebe a certificação por um conselho de especialidade profissional na prática da obstetrícia. Quando aplicado a uma organização ou parte dela, como o laboratório, a certificação, normalmente, significa que a organização tem serviços, tecnologia ou capacidades adicionais além daqueles encontrados em organizações similares.

Outro termo empregado com frequência é o credenciamento, quando uma organização estabelece requisitos para a prestação de serviços específicos por pessoas ou outras organizações. Por exemplo, o credenciamento de médicos ou hospitais por planos de saúde, ou de organizações de saúde para efetuar transplantes de órgão pela autoridade sanitária, para que médicos realizem determinados procedimentos em um hospital.

Donahue e O'Leary (1997) abordam a questão da seleção de sistemas de acreditação, quando citam:

Não existe um único modo ótimo de avaliação na área da saúde, mas um número cada vez maior de países está vendo no modelo da acreditação a ferramenta de mudanças mais eficiente para eles. Entretanto, existem múltiplas variações quanto ao modelo apropriado de acreditação a ser construído para um determinado país. Dentre as variáveis-chave, incluem-se as estruturas e valores sociais e outras realidades culturais, políticas, econômicas e base em uma análise das suas próprias características, um país que desenvolve um sistema de acreditação pode se valer de componentes de outros sistemas e aperfeiçoá-los para que reflitam as suas prioridades.

Com a evolução e oportunidades de estudos relacionados com os programas e metodologias de acreditação, uma significativa mudança implementada foi a caracterização dos padrões como de excelência ou ótimo 
desempenho, em lugar de padrões mínimos. Com a adoção dessa nova característica, os padrões de acreditação passaram a ser uma referência ou expectativa a ser alcançada pelas instituições de saúde, estabelecendo assim um novo patamar de exigência para o atendimento ao conjunto de requisitos ou requerimentos determinados pelos padrões em relação à qualidade do cuidado prestado aos pacientes. Essa também é uma das diferenças que podem ser identificadas, quando comparadas a acreditação, o licenciamento e a certificação.

\section{Metodologia da acreditação}

Padrão, no campo da acreditação, é uma declaração que define as expectativas de desempenho, estruturas e processos que devem estar implementados para que uma organização forneça cuidados, tratamentos e serviços de elevada qualidade.
Como definido anteriormente, a acreditação requer a explicitação dos padrões pelos quais a organização será avaliada e um processo de avaliação.

Os padrões são apresentados em manuais e agrupados em capítulos seja de acordo com a estrutura das organizações de saúde, como laboratórios, internação/internamento, centro cirúrgico, ou com suas funções, como cuidado aos pacientes, governo e liderança, melhoria da qualidade. A Organização Nacional de Acreditação do Brasil (ONA) estrutura seus padrões mesclando estruturas e processos conforme pode ser visto no Quadro 1.

Quadro 1 - Estrutura do Manual Brasileiro de Acreditação: Organizações Prestadoras de Serviços de Saúde - versão 2014 da Organização Nacional de Acreditação do Brasil (ONA)

\begin{tabular}{|c|c|c|c|}
\hline $\begin{array}{l}\text { Seção } 1 \\
\text { Gestão e liderança }\end{array}$ & $\begin{array}{l}\text { Seção } 2 \\
\text { Atenção ao paciente }\end{array}$ & $\begin{array}{l}\text { Seção } 3 \\
\text { Diagnóstico e terapêutica }\end{array}$ & $\begin{array}{l}\text { Seção } 4 \\
\text { Apoio técnico }\end{array}$ \\
\hline $\begin{array}{l}\text { - Liderança } \\
\text { - Gestão de pessoas } \\
\text { - Gestão administrativa } \\
\text { - Gestão de suprimentos } \\
\text { - Gestão de segurança } \\
\text { patrimonial } \\
\text { - Gestão de estrutura físico- } \\
\text { funcional }\end{array}$ & $\begin{array}{l}\text { - Gestão de acesso } \\
\text { - Internação/internamento } \\
\text { - Atendimento ambulatorial } \\
\text { - Atendimento de emergência } \\
\text { - Atendimento cirúrgico } \\
\text { - Atendimento obstétrico } \\
\text { - Atendimento neonatal } \\
\text { - Tratamento intensivo } \\
\text { - Mobilização de doadores/dadores } \\
\text { - Triagem de doares e coleta/recolha } \\
\text { - Assistência hemoterápica } \\
\text { - Terapia dialítica } \\
\text { - Terapia antineoplásica } \\
\text { - Assistência farmacêutica } \\
\text { - Assistência nutricional }\end{array}$ & $\begin{array}{l}\text { - Processos pré-analíticos } \\
\text { - Processos analíticos } \\
\text { - Processos pós-analíticos } \\
\text { - Métodos diagnósticos e } \\
\text { terapêuticos } \\
\text { - Diagnóstico por imagem } \\
\text { - Medicina nuclear } \\
\text { - Radioterapia } \\
\text { - Radiologia intervencionista } \\
\text { - Métodos endoscópicos e } \\
\text { videoscópicos }\end{array}$ & $\begin{array}{l}\text { - Sistema de informação } \\
\text { do paciente } \\
\text { - Gestão de equipamentos } \\
\text { de tecnologia médico- } \\
\text { hospitalar } \\
\text { - Prevenção, controle } \\
\text { de infecções e eventos } \\
\text { sentinela } \\
\text { - Processamento e } \\
\text { liberação }\end{array}$ \\
\hline
\end{tabular}


Já no caso da JCI (Quadro 2), os padrões para hospitais estão organizados por funções e distribuídos em duas seções que reúnem os padrões:

a) com foco no paciente; e

b) de administração de instituições de saúde.

\section{Quadro 2 - Estrutura do Manual de Padrões de Acreditação da Joint Commission International para hospitais}

\begin{tabular}{|l|}
\hline Seção I - Padrões com foco no paciente \\
\hline Metas internacionais de segurança do paciente \\
\hline Acesso e continuidade do cuidado \\
\hline Direitos dos pacientes e seus familiares \\
\hline Avaliação dos pacientes \\
\hline Cuidados aos pacientes \\
\hline Anestesia e cirurgia \\
\hline Gerenciamento/gestão e uso de medicamentos \\
\hline Educação dos pacientes e familiares \\
\hline Seção II - Padrões de administração de instituições de saúde \\
\hline Melhoria da qualidade e segurança do paciente \\
\hline Prevenção e controle de infecções \\
\hline Governo, liderança e direção \\
\hline Gerenciamento/gestão e segurança das instalações \\
\hline Educação e qualificação dos profissionais \\
\hline Gerenciamento/gestão da comunicação e informação \\
\hline
\end{tabular}

Fonte: Joint Commission International (2010).

As funções se aplicam a toda a organização, chamada de instituição no manual, bem como a cada departamento, ou serviço existente no interior da organização. O enunciado de cada padrão é seguido de um esclarecimento de seu propósito, descrito com a finalidade de explicitar o sentido daquele requisito, e, também, da descrição do conjunto de elementos de mensuração que comporão a pontuação do grau de conformidade com aquele padrão.

A título de ilustração, no destaque a seguir, é apresentado um dos padrões do Manual da JCI (2010) de forte impacto na segurança dos 
pacientes, do Capítulo Gerenciamento/Gestão e Segurança das Instalações (FMS) e subcapítulo Sistemas Utilitários, com seus componentes.

\section{Padrão FMS.8}

A instituição planeja um programa para inspecionar, testar e manter equipamentos médicos e documentar os resultados.

\section{Propósito do FMS.8}

Para assegurar que os equipamentos estejam disponíveis e funcionando adequadamente, a instituição:

- faz o inventário dos equipamentos médicos;

- inspeciona regularmente os equipamentos médicos;

- testa os equipamentos médicos conforme apropriado ao seu uso e suas necessidades; e

- realiza manutenção preventiva.

Indivíduos qualificados prestam esses serviços. Os equipamentos são inspecionados e testados quando novos e depois regularmente, de acordo com a idade e o uso do equipamento ou de acordo com as instruções do fabricante. As inspeções, resultados dos testes e quaisquer manutenções são documentados. Isso ajuda a garantir a continuidade do processo de manutenção e o planejamento/planeamento dos recursos financeiros para fazer as substituições, reformas e outras mudanças.

\section{Elementos de mensuração do FMS. 8}

1. Os equipamentos médicos são gerenciados em toda a instituição de acordo com um plano.

2. Existe um inventário de todos os equipamentos médicos.

3. Os equipamentos médicos são inspecionados regularmente.

4. Os equipamentos médicos são testados quando novos e, depois, de acordo com a idade e uso do equipamento.

5. Existe um programa de manutenção preventiva.

6. Indivíduos qualificados prestam esses serviços. 
Foto 1 - Paciente na Unidade de Cuidados Intensivos ilustrando a quantidade de equipamentos em uso, por um único paciente, que requerem conformidade com o padrão FMS.8

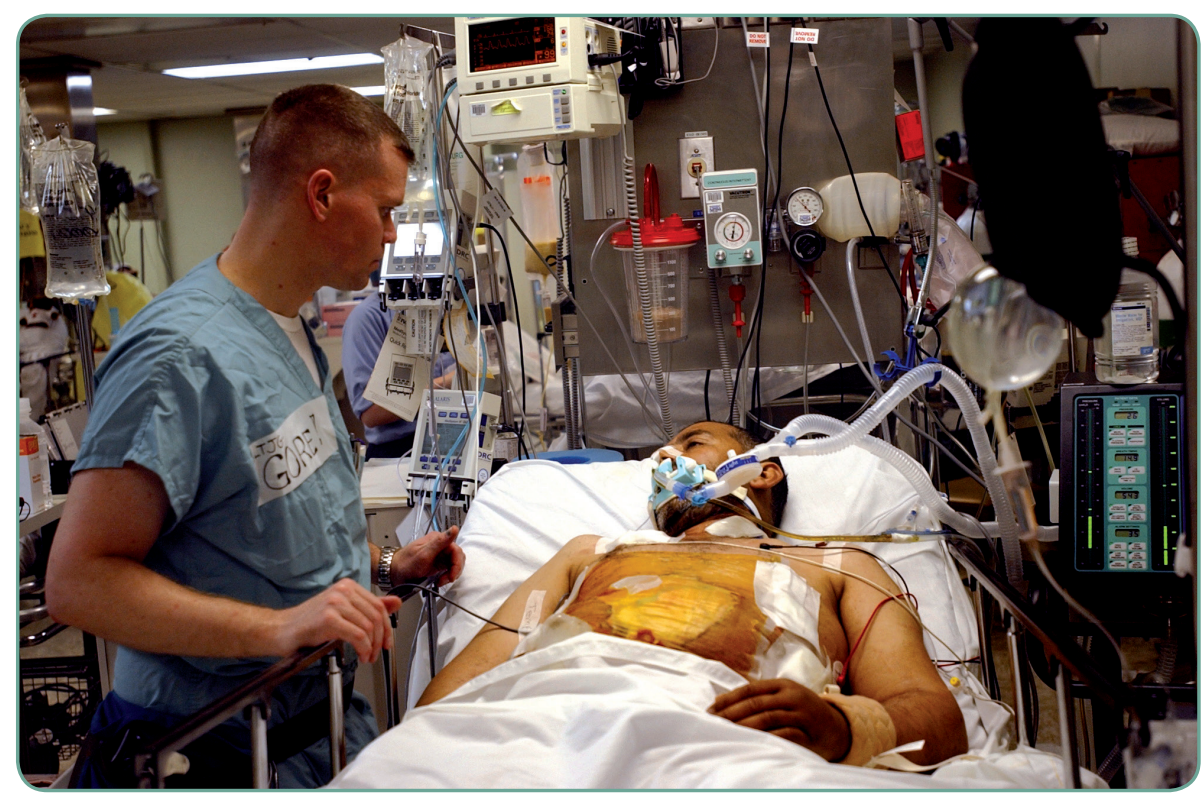

Fonte: Shane T. McCoy (2003).

\section{Para praticar}

Escolha cinco equipamentos de usos distintos em uma unidade de sua organização e verifique se eles estariam conformes ao padrão FMS.8.

Você pode encontrá-los no plano de manutenção preventiva (há algum?) da organização?

A não conformidade de algum deles coloca em risco grave o atendimento aos pacientes?

\section{Processo de avaliação}

O processo de avaliação da conformidade da organização com os padrões de acreditação é feito pela análise de documentos e visitas às unidades assistenciais para coleta/recolha das evidências. Uma equipe de avaliadores é, habitualmente, composta de um médico, um enfermeiro e um administrador especializado em saúde, devidamente treinados para o processo avaliativo. A duração da visita varia de acordo com o tamanho e complexidade da organização. Normalmente, para um hospital, a visita pode variar entre três e cinco dias. 
Como regra geral, a conformidade deve estar sempre presente em qualquer local da organização. Portanto, a não conformidade em qualquer sítio implica, no mínimo, em conformidade parcial. Isso faz com que a coleta/recolha de evidências não seja exaustiva, a pontuação dos diversos elementos de mensuração se dê por descontos e o resultado final pela pontuação recebida em relação ao máximo possível de ser obtido.

A JCI, desde alguns anos, emprega a metodologia de rastreamento. A atividade de rastreamento de um paciente individual visa rastrear as experiências de cuidado vividas por um paciente durante sua estadia no hospital. A metodologia de rastreador (tracer) é utilizada para analisar o sistema do hospital para prestar cuidado, tratamento e serviços usando pacientes reais. Com esse método, os avaliadores percorrem o trajeto do cuidado, tratamento ou serviço prestado ao paciente pelo hospital, que lhes permite avaliar:

As inter-relações entre disciplinas e departamentos, programas, serviços ou unidades e as funções importantes dos cuidados e serviços prestados.

O desempenho de processos relevantes, com foco especial na integração e coordenação de processos distintos, mas relacionados.

Identificar questões potencialmente preocupantes em processos relevantes.

$\mathrm{O}(\mathrm{s})$ avaliador(es) seleciona(m) pacientes de uma lista de pacientes "ativos" para rastrear suas experiências em todo o hospital. Os pacientes tipicamente selecionados são aqueles que receberam serviços múltiplos ou complexos e, portanto, tiveram mais contato com várias partes do hospital.

São também empregados rastreadores de sistema direcionados a um sistema ou processo específico do hospital, que se concentra nas vivências de pacientes específicos em atividades relevantes para eles. Difere dos rastreadores individuais, em que um paciente, durante todo o curso de seu tratamento, é avaliada em todos os aspectos do cuidado, em vez de avaliar o sistema de cuidado. Exemplos de sistemas nos quais são empregados são sistemas de gerenciamento/gestão de medicamentos, controle de infecções e o gerenciamento/gestão das informações. 


\section{Segurança e acreditação}

A dimensão segurança do paciente ocupa lugar de destaque na definição dos critérios e requerimentos que constam dos padrões de acreditação de caráter internacional. A seguir, apresentaremos a estrutura de capítulos e padrões adotados e aplicados pela metodologia da JCI. Duas seções de seu manual dão destaque ao tema da segurança do paciente. A primeira relaciona as seis Metas Internacionais de Segurança do Paciente. A adoção das metas como parte do manual JCI tem relação direta com o trabalho desenvolvido em parceria com a Organização Mundial de Saúde (OMS). A JCI apoia os estudos e trabalhos desenvolvidos como parte das ações do Centro Colaborador da OMS para Segurança do Paciente (WHO). O conteúdo das metas aborda processos considerados prioridades de atenção e monitoramento, para garantir que o cuidado prestado ao paciente seja desenvolvido de forma segura. As seis metas incluem requerimentos para:

蝶identificar os pacientes corretamente;

* melhorar a comunicação efetiva;

* melhorar a segurança dos medicamentos de alta vigilância;

* assegurar cirurgias com local de intervenção correto, procedimento correto e paciente correto;

* reduzir o risco de infecções associadas aos cuidados de saúde; e

繁reduzir o risco de lesões ao paciente decorrentes de quedas.

Fotos 2, 3, 4 e 5 - Semelhança das apresentações de soluções parenterais de pequeno volume, ilustrando a importância da conformidade com padrões de gerenciamento/ gestão e uso de medicamentos, da seleção, aquisição e armazenamento até o preparo e administração
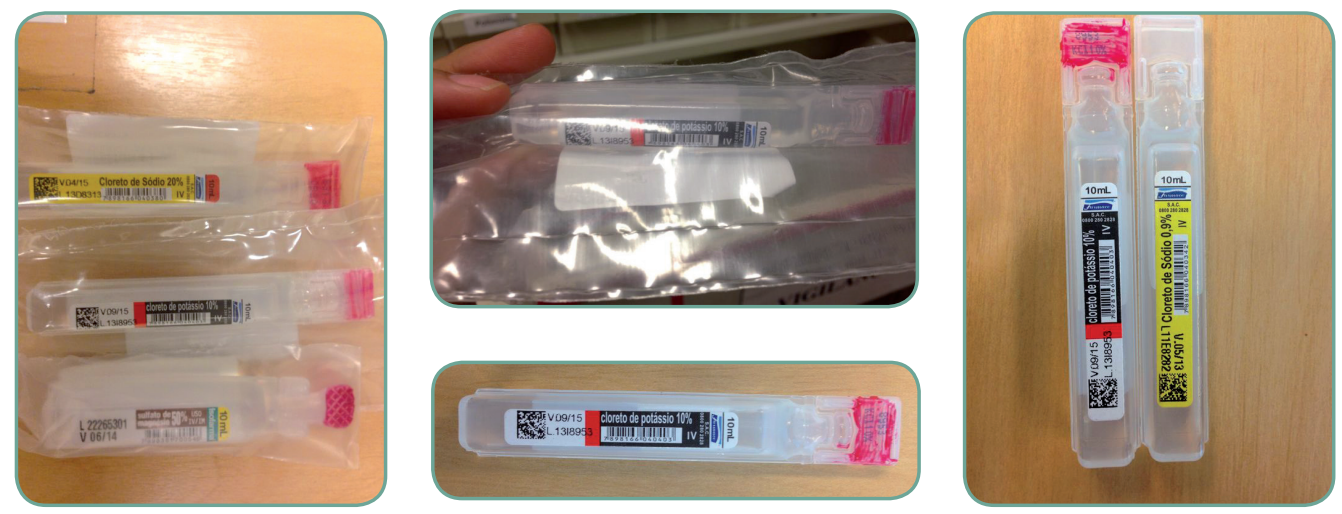

Fotos: Elaboradas pelos autores. 
A segunda seção, intitulada Melhoria da Qualidade e Segurança do Paciente, aborda requerimentos que definem a exigência e elaboração de um programa global de melhoria da qualidade e segurança institucional. O programa deve prever a definição e aplicação de conceitos específicos de segurança, incluídos a gestão de risco e princípios e procedimentos para análise e monitoramento de eventos sentinela e eventos adversos. Os requerimentos incluem a elaboração de um programa de gerenciamento/gestão de risco, que deve conter elementos que garantam a efetividade dos processos de identificação, priorização, monitoramento e ação dos riscos associados com os cuidados e tratamentos prestados e oferecidos aos pacientes.

Essa seção requer ainda que os líderes da organização identifiquem medidas-chave para serem utilizadas no plano institucional global de melhoria da qualidade e segurança dos pacientes e especifica que cada Meta Internacional de Segurança deve ter medidas-chave identificadas, apuradas e acompanhadas.

Para praticar

Verifique, em sua organização, para qual(is) meta(s) internacional(is) de segurança do paciente estão definidos, apurados e analisados indicadores.

O programa de acreditação usado pela Accreditation Canada, também aplicado em âmbito internacional, utiliza padrões que abordam sistemas gerais de instituições de saúde como governança, prevenção e controle de infecção, liderança e gerenciamento/gestão de medicamentos. Nos padrões relacionados com os sistemas de liderança, esses abrangem a criação e sustentabilidade de cultura de cuidado, o planejamento/planejamento e desenho de serviços, a alocação de recursos e a construção de infraestrutura e contempla, também, o monitoramento e a melhoria da qualidade e segurança (Accreditation Canada 2013).

Costa e Costa (2013) destacam que as principais vantagens da acreditação incluem a segurança dos pacientes e profissionais e a qualidade do cuidado, possibilitando assim uma concepção do conceito de equipes e de melhoria contínua. As mesmas autoras citam, ainda, o fato de que a acreditação pode ser utilizada como um instrumento que organiza as ações de gerenciamento/gestão a partir de objetivos concretos, expressos pelos padrões estabelecidos nos manuais. 


\section{Acreditação no Brasil}

A ISQua desenvolve um programa de acreditação de acreditadores utilizando um conjunto de padrões e critérios aplicáveis:

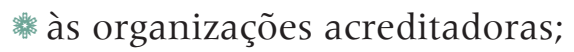

镂 aos padrões por elas empregados; e

踫ao treinamento de avaliadores (ISQua).

A diversidade e a quantidade de instituições já acreditadas listadas no site da ISQua denotam a crescente expansão da metodologia de acreditação em todo o mundo. No Brasil, na atualidade, podem ser identificadas diferentes metodologias, as quais são apresentadas no Quadro 3 a seguir.

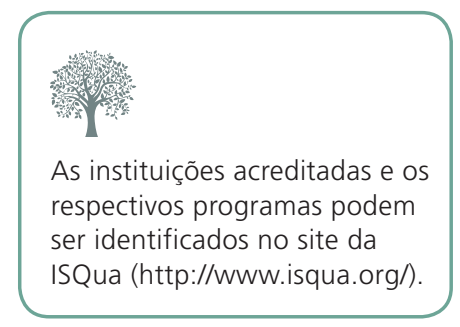

Quadro 3 - Metodologias de acreditação aplicadas no Brasil

\begin{tabular}{|l|l|l|l|l|}
\hline Instituição & Abrangência & Níveis de acreditação & $\begin{array}{l}\text { Prazo de validade } \\
\text { dos selos de } \\
\text { acreditação }\end{array}$ & Aplicação \\
\hline $\begin{array}{l}\text { Organização Nacional de } \\
\text { Acreditação (ONA) }\end{array}$ & Nacional & $\begin{array}{l}\text { 1. Segurança } \\
\text { 2. Gestão Integrada } \\
\text { 3. Excelência em Gestão }\end{array}$ & $\begin{array}{l}\text { Níveis 1 e 2 - dois } \\
\text { anos 3 - três anos }\end{array}$ & $\begin{array}{l}\text { Por meio de instituições credenciadas } \\
\text { como acreditadoras }\end{array}$ \\
\hline $\begin{array}{l}\text { Joint Commission } \\
\text { International (JCI) }\end{array}$ & Internacional & Acreditado (sem níveis) & Três anos & $\begin{array}{l}\text { Por meio de acordo com o Consórcio } \\
\text { Brasileiro de Acreditação (CBA) }\end{array}$ \\
\hline $\begin{array}{l}\text { Accreditation Canada } \\
\text { Internacional }\end{array}$ & Acreditado (sem níveis) & Três anos & $\begin{array}{l}\text { Por meio de sociedade com o } \\
\text { Instituto Qualisa de Gestão (IQG) }\end{array}$ \\
\hline $\begin{array}{l}\text { Accreditation for Healthcare } \\
\text { Organizations (NIAHO) }\end{array}$ & Internacional & Acreditado (sem níveis) & Três anos & $\begin{array}{l}\text { Por meio da empresa } \\
\text { DetNorskeVeritas (DNV) }\end{array}$ \\
\hline
\end{tabular}

Fonte: Elaborado pelo autor Costa Junior.

\section{Síntese da acreditação de organizações de saúde em Portugal}

Em Portugal, o "movimento" de acreditação teve início em 1999, aquando da assinatura do protocolo entre o Ministério da Saúde (por intermédio do Instituto da Qualidade em Saúde) e o King's Fund Health Quality Service (KFHQS, atualmente conhecido como CHKS). O referido protocolo, para desenvolvimento do processo de acreditação dos hospitais portugueses, teve duração de cinco anos. Em 2004, já com alguns hospitais públicos portugueses com o modelo jurídico de tipo S.A. 
(sociedade anónima), a então Unidade Gestora dos Hospitais S.A. (unidade de missão para os hospitais S.A.) assinou um protocolo com a Joint Commission International para a introdução do modelo de acreditação da JCI em alguns desses hospitais. A adesão a modelos de acreditação sempre ocorreu de forma voluntária. Mais recentemente, em 2009, o Ministério da Saúde, por intermédio do Departamento da Qualidade na Saúde, assinou protocolo com a Agência de Qualidade em Saúde de Andaluzia para a adoção do seu modelo de acreditação.

Em resumo, Portugal tem um sistema de saúde assente no Serviço Nacional de Saúde (público, universal e tendencialmente gratuito), em que coexistem três modelos de acreditação que têm em comum o facto:

踪 de serem de adesão voluntária;

滕 de assentarem em padrões de qualidade explícitos e em indicadores que permitem monitorizar a atividade;

滕 que visam pôr as instituições de saúde a "pensar" Qualidade; e

橉 que, nos últimos anos, incluíram padrões para a área da segurança do paciente (nomeadamente, relacionados com a medicação, infeção hospitalar; cirurgias, quedas etc.).

Atualmente, assistimos a um número significativo de hospitais privados (principalmente os que pertencem a grandes grupos de saúde) e de hospitais públicos com gestão privada a optar por aderir a modelos de acreditação, e a preferência tem recaído pelo modelo internacionalmente mais reconhecido, o da JCI.

O Conselho de Acreditação da ISQua, em 2013, fez uma resenha dos principais estudos sobre o valor e impacte da acreditação, dos quais destacamos alguns:

* Fornecer uma estrutura para ajudar a criar e implementar sistemas e processos que melhoram a eficácia e promover o avanço de resultados de saúde operacionais positivos.

橉 Reforçar a eficácia da equipa interdisciplinar.

噄Demonstrar credibilidade e compromisso com a qualidade e a responsabilização.

Reduzir o risco de eventos adversos.

* Permitir autoanálise continuada do desempenho em relação aos padrões.

* Garantir um nível aceitável de qualidade entre os prestadores de cuidados de saúde. 
Melhorar a reputação da organização entre os usuários/utentes finais e aumentar sua consciência e perceção da qualidade dos cuidados, bem como seu nível de satisfação geral.

* Diminuir as variações na prática entre os prestadores de cuidados de saúde e tomadores de decisões.

滕 Estimular esforços de melhoria da qualidade sustentável e, continuamente, elevar o limiar no que diz respeito a iniciativas, políticas e processos de melhoria da qualidade.

晋 Promover uma cultura de qualidade e de segurança.

Para refletir

Ao examinar a organização em que você trabalha, qual(is) dos benefícios listados anteriormente seria(m) considerado(s) mais relevante(s)? Justifique.

\section{Considerações finais}

Hoje em dia, as metodologias de acreditação se mostram mais presentes e cada vez mais utilizadas, o que pode ser comprovado pelo número crescente de organizações de saúde acreditadas em todo o mundo. Há, portanto, uma clara percepção de que as organizações que buscam os selos ou certificados enxergam benefícios e impactos na melhoria de seus serviços. Seja por fomento da própria melhoria da qualidade e segurança, seja pela perspectiva de marketing empresarial ou, ainda, de ganhos financeiros, a acreditação se coloca como importante ferramenta para construir o caminho da melhoria contínua.

\section{Referências}

Accreditation Canada. Leadership. British Columbia: AC; [2013 citado 2013 Dez 8]. Disponível em: http://www.accreditation.ca/accreditation-programs/qmentum/standards/leadership/.

American College of Surgeons. The 1919 "Minimum Standard" document. Chicago: ACS; 2006 [citado 2014 Feb 10]. Disponível em: http://www.facs.org/archives/minimumhighlight.html.

Brawer C. Champions of quality in health care: a history of the Joint Commission on Accreditation of Healthcare Organizations. Lyme (CT): Greenwich; 2001.

CONSÓRCIO BRASILEIRO DE ACREDITAÇÃO. Histórico: a história da acreditação. Rio de Janeiro: CBA; [1997 citado 2014 Mai 14]. Disponível em: http://www.cbacred.org.br/site/historico/. 
Costa V, Costa A. Acreditação hospitalar: uma ferramenta para incrementar a segurança do paciente? In: Fonseca A. Segurança do paciente. São Paulo: Marinari; 2013.

Donahue K, O'Leary D. Evolving health care organization accreditation systems. In: I. H. Federation. Hospitais and healthcare: past, present and future. London: International Hospital Federation; 1997. p. 128-32.

Geiger P, coordenador. Dicionário escolar da língua portuguesa. Rio de Janeiro: Lexikon; 2012.

International Society for Quality in Health Care. Accreditation. Dublin: ISQua; 2012 [citado 2013 Dez 8]. Disponível em: http://www.isqua.org/accreditation/accreditation.

International Society for Quality in Health Care. ISQUA's International Accreditation Programme Awards. Dublin: ISQua; 2012 [citado 2013 Dez 8]. Disponível em: http://www.isqua.org/ accreditation/iap-awards.

Joint Commission International. Padrões de acreditação da Joint Commission International para hospitais. Rio de Janeiro: Consórcio Brasileiro de Acreditação; 2010.

Mitchell Ji, Nicklin W, MacDonald B. The determinants of quality healthcare: implications for Canadian health leaders. Healthc Manage Forum. 2012;25(3):138-41.

Nicklin W, MacDonald B, Mitchell J. The power of accreditation data to inform system improvements in quality and safety. ISQua Conference, Edinburgh, 2013 Oct 16 [citado 2014 Ago 11]. Disponível em: http://www.isqua.org/docs/edinburgh-powerpoint-presentations-2013/1330c17--w-nicklin-fintry-wed-the-power-of-accreditation-data-to-inform-system-improvement. pdf?sfvrsn=2.

Organização Nacional de Acreditação (ONA). Manual Brasileiro de Acreditação Organizações Prestadoras de Serviços de Saúde. Versão 2014. São Paulo: ONA; 2014 [citado 2014 Maio 14]. Disponivel em: https://www.ona.org.br/Produto/74/

Rooney A, Van Ostenberg P. Licensure, accreditation, and certification: approaches to health services quality. Washington: USAID; 1999.

McCoy ST. File:US Navy 030423-N-6967M-060 Lt. j.g. John Gore checks on a patient who is recovering from a stomach wound.jpg. Wikimedia Commons, 2003 [citado 2014 Ago 1]. Disponível em: http://commons.wikimedia.org/wiki/File:US_Navy_030423-N-6967M-060_Lt._j.g._John_Gore_ checks_on_a_patient_who_is_recovering_from_a_stomach_wound.jpg?uselang=pt-br.

World Health Organization. WHO Collaborating Centre on Patient Safety Solutions. Geneve: WHO; 2007 [citado 2013 Dez 8]. Disponível em: http://www.who.int/patientsafety/solutions/patientsafety/ collaborating_centre/en/.

\section{Sítes de interesse:}

Accreditation Canada: www.accreditation.ca

Consórcio Brasileiro de Acreditação (CBA): www.cbacred.org.br

Haute Authorité de Santé (HAS): http://www.has-sante.fr

International Society for Quality in Health Care (ISQua): www.isqua.org

Joint Commission International: www.jointcommissioninternational.org

Organização Nacional de Acreditação (ONA): www.ona.org.br

The Joint Commision: www.jointcommission.org

www.chks.co.uk/Assurance-and-Accreditation

www.dgs.pt/departamento-da-qualidade-na-saude/qualidade-na-saude/acreditacao-/introducao.aspx http://pt.jointcommissioninternational.org/enpt/JCl-Accredited-Organizations/ 


\section{Cultura de segurança em organizações de saúde}

Cláudia Tartaglia Reis

Este capítulo tem por objetivos:

* Apresentar a cultura de segurança, seus conceitos e dimensões, bem como sua inserção como parte integrante da cultura organizacional geral.

Apresentar a abordagem sistêmica e a cultura de culpabilidade prevalente nas organizações de saúde.

Evidenciar a importância da notificação/relato de incidentes e da divulgação aberta de informações (disclosure) como partes integrantes de uma "cultura justa".

Descrever as formas de avaliação da cultura de segurança e sua aplicabilidade prática.

Apresentar os principais instrumentos utilizados para avaliar a cultura de segurança em organizações de saúde.

膦 Evidenciar a importância da cultura de segurança como fator indutor de um cuidado de saúde mais seguro e passível de intervenções. 


\section{O cuidado de saúde no contexto atual e a cultura de segurança}

Os cuidados de saúde, cada vez mais complexos e com demandas ascendentes, elevam o potencial para ocorrência de incidentes, erros ou falhas. Diante dos avanços tecnológicos, da diversidade de sistemas e de processos organizacionais que envolvem o contexto da prestação de cuidados de saúde no âmbito global, observa-se, a partir da última década, o interesse crescente por parte de pesquisadores/investigadores e profissionais de saúde em abordagens voltadas à melhoria da qualidade do cuidado e da segurança do paciente. Nesse cenário, a cultura de segurança ganha destaque, visto que reflete o comprometimento dos profissionais da organização com a promoção contínua de um ambiente terapêutico seguro e influencia comportamentos e resultados de segurança, tanto para os profissionais de saúde como para os pacientes.

A publicação do Institute of Medicine (IOM) dos Estados Unidos da América (EUA), intitulada To err is human (Kohn et al. 1999), enfatizou a necessidade do fortalecimento de uma cultura de segurança em termos organizacionais, como medida fundamental ao processo de melhoria da segurança do paciente no contexto hospitalar contemporâneo. Ela chamou a atenção das organizações de saúde para a importância de se considerar a aplicação de técnicas de segurança adotadas em organizações de alta confiabilidade/fiabilidade (OAC). Essas organizações apresentam elevados riscos envolvidos em seus processos de trabalho e registros de segurança muito positivos no gerenciamento/gestão desses riscos. São exemplos de OAC: indústria da aviação, da energia nuclear, petróleo e gás. Para essas organizações, o foco primário está no sistema e nos processos de trabalho, em vez de nos indivíduos.

A partir desse marco, partilhar uma cultura de segurança positiva nas organizações de saúde emerge como um dos requisitos essenciais na expectativa de reduzir a ocorrência de incidentes e, em especial, de eventos adversos, evitáveis tanto quanto possível, por meio do aprendizado proativo a partir dos erros ocorridos e redesenho dos processos (Handler et al. 2006).

Segundo a Organização Mundial da Saúde (OMS) (WHO 2009), uma ampla gama de estudos sustenta o conceito de que a cultura de segurança em organizações de alto risco, incluindo as organizações prestadoras de cuidados de saúde, traduz-se em um conjunto de crenças partilhadas que fornecem suporte a práticas seguras entre os profissionais que nelas trabalham. A segurança é prioridade no âmbito da cultura organizacional. 
A cultura de segurança é marcada pela comunicação aberta, trabalho em equipe, reconhecimento da dependência mútua, aprendizado contínuo com base nos registros das notificações/relatos de eventos e a primazia da segurança como prioridade em todos os níveis da organização (WHO 2009).

\section{A cultura organizacional}

Os estudos com enfoque na cultura organizacional tiveram seu ápice na década de 1980 do século XX. Incorporados à Teoria das Organizações, às análises administrativas e ao cotidiano das empresas, esses estudos passaram a ser frequentes, visto que os aspectos culturais são imprescindíveis em qualquer tipo de análise e prática organizacional (Freitas 1997).

O crescente interesse pela cultura organizacional deu-se a partir da percepção de que as teorias existentes não dispunham de instrumentos e métodos que permitissem compreender a natureza complexa das organizações, particularmente em contextos de mudança, em que se busca melhoria de desempenho ou aumento de competitividade. Nesse contexto, o estudo da complexidade das organizações envolve a compreensão da natureza das relações humanas como base para se conhecer as reações às mudanças dos diferentes grupos que compõem a organização, assim como a dinâmica de relações de poder existentes (Barreiros 2002).

Embora haja uma ampla gama de definições sobre cultura organizacional, Guldenmund (2000) identificou sete características desse tipo de cultura que são frequentemente referenciadas:

\section{As sete características}

É uma abstração e não um fenômeno concreto, e, portanto, é de difícil definição e operacionalização.

É relativamente estável ao longo do tempo.

Seu conceito é multidimensional.

É partilhada por grupos de pessoas.

Pode conter vários aspectos que coexistem dentro de uma organização, por exemplo, a cultura de segurança.

Leva a práticas ostensivas.

Atende a uma proposta funcional. 
Para Schein (1991), a cultura organizacional é um conjunto de pressupostos básicos que um grupo criou, descobriu ou desenvolveu ao aprender a lidar com problemas de adaptação externa e integração interna. Esses pressupostos, por terem funcionado razoavelmente bem, são considerados válidos e ensinados aos novos membros, como a forma correta de perceber, pensar e sentir em relação a esses problemas. A cultura organizacional influencia o caminho por meio do qual os profissionais aprendem e partilham o conhecimento.

A cultura orienta a maneira de fazer as coisas na organização; muitas vezes, valendo-se de pressuposições não escritas e nem sequer faladas. Apresenta-se em três diferentes níveis:

路 artefatos;

滕 valores compartilhados; e

蛅 pressupostos básicos.

Os artefatos constituem o primeiro nível da cultura, o mais superficial, visível e perceptível. Os artefatos são as coisas concretas que cada pessoa vê, ouve e sente quando se depara com uma organização. Eles abrangem os produtos, serviços/departamentos e padrões de comportamento dos membros da organização e se expressam no modo como as pessoas se vestem, comportam-se, sobre o que conversam e consideram importante e relevante.

Os valores compartilhados, em segundo nível, são relevantes, que se tornam importantes para as pessoas e definem as razões pelas quais elas fazem o que fazem.

As pressuposições básicas constituem o nível mais íntimo, profundo e oculto da cultura organizacional. São as crenças inconscientes, percepções, sentimentos e pressupostos predominantes e nos quais as pessoas creem (Schein 1991).

A cultura organizacional correlaciona-se positivamente com o comportamento do líder. Ele desempenha o papel do modelo a ser seguido, pois influencia o desenvolvimento de comportamentos, valores e crenças de seus subordinados, possibilitando o fortalecimento da cultura organizacional (Yafang 2011). A ideia subjacente é que o líder, mediante suas preocupações, configure a cultura de uma unidade ou organização. Ele demonstra suas preferências e comunica o que considera importante por meio de ações simbólicas. Essas preferências tornam-se as preocupações dos profissionais da organização, visto que poderão representar a concessão de recursos, recompensas ou punições (Westrum 2004). 


\section{A cultura e o clima de segurança}

O conceito de cultura de segurança tem sua origem fora do contexto dos cuidados de saúde, em estudos de OACs. O termo “cultura de segurança" difundiu-se a partir do acidente nuclear de Chernobyl em 1986, considerado o pior acidente na história da geração de energia nuclear. Uma "cultura de segurança fraca" foi atribuída como principal causa do acidente, de acordo com a International Atomic Energy Agency (IAEA). Posteriormente, dois acidentes graves ocorreram: a explosão na plataforma Piper Alpha, localizada no Mar do Norte da Europa, e o incêndio na estação de trem King Cross, em Londres. Os relatórios dos respectivos acidentes apontaram falhas humanas, administrativas e organizacionais, relacionadas às falhas na cultura de segurança, como as principais causas desses acidentes (Flin et al. 2000).

A cultura de segurança, como um aspecto da cultura da organização (Zohar et al. 2007), foi conceituada pela Health and Safety Comission (1993) como o produto de valores, atitudes, competências e padrões de comportamento individuais e de grupo, os quais determinam o compromisso, o estilo e proficiência da administração de uma organização saudável e segura. Organizações com uma cultura de segurança positiva são caracterizadas pela comunicação fundamentada na confiança mútua, pela percepção comum da importância da segurança e confiança na efetividade de medidas preventivas.

Para Cox e Cox (1991), uma organização com uma cultura de segurança efetiva é aberta e justa com seus profissionais quando incidentes ocorrem; os profissionais sentem-se motivados a notificar/relatar o erro; aprende-se com os erros em vez de culpar os indivíduos e procura-se olhar para o que deu errado dentro do sistema.

Nos estudos sobre cultura de segurança, observa-se, na literatura, o emprego de diferentes terminologias (Zhang et al. 2002; Flin et al. 2006; Halligan, Zecevic 2011). O termo clima de segurança é utilizado com pouca ou nenhuma diferenciação do termo cultura de segurança tanto em estudos com foco nas organizações industriais (Zohar 1980; Zhang et al. 2002) como naqueles voltados às organizações de cuidados de saúde (Flin et al. 2006; Halligan, Zecevic 2011). Não é raro o uso de ambos os termos de maneira intercambiável (Cox, Flin 1998). Embora seja utilizado em pesquisas como sinônimo de cultura de segurança, o termo clima de segurança é definido como as características superficiais da cultura de segurança a partir das atitudes e percepções dos indivíduos em um determinado ponto no tempo, ou como os componentes mensuráveis da cultura de segurança (Gaba et al. 2003; Colla et al. 2005). 


\section{Níveis de maturidade da cultura de segurança}

Em uma organização, a cultura de segurança pode se apresentar em graus diversos de maturidade e progredir através de cinco estágios ao longo do tempo (Hudson 2003). A Figura 1 apresenta os cinco estágios de maturidade da cultura de segurança.

Na cultura patológica, grau inferior de maturidade, a falta de segurança é compreendido como um problema causado pelos trabalhadores.

Na cultura reativa, a organização começa a considerar a segurança com maior seriedade, mas as ações são tomadas apenas após a ocorrência de incidentes.

Na cultura calculada, a segurança é gerenciada, mas as abordagens são ainda muito verticalizadas, com sistemas de gerenciamento/gestão de risco e foco na coleta/recolha de dados.

No estágio da cultura proativa, há um número maior de profissionais envolvidos no sentido de identificar e trabalhar os problemas de segurança, antecipando-se a ocorrência de incidentes; e por fim, no grau de maturidade mais elevado, na cultura geradora, há a participação de todos os níveis da organização, com aumento da confiança.

Figura 1 - Os cinco estágios de maturidade da cultura de segurança

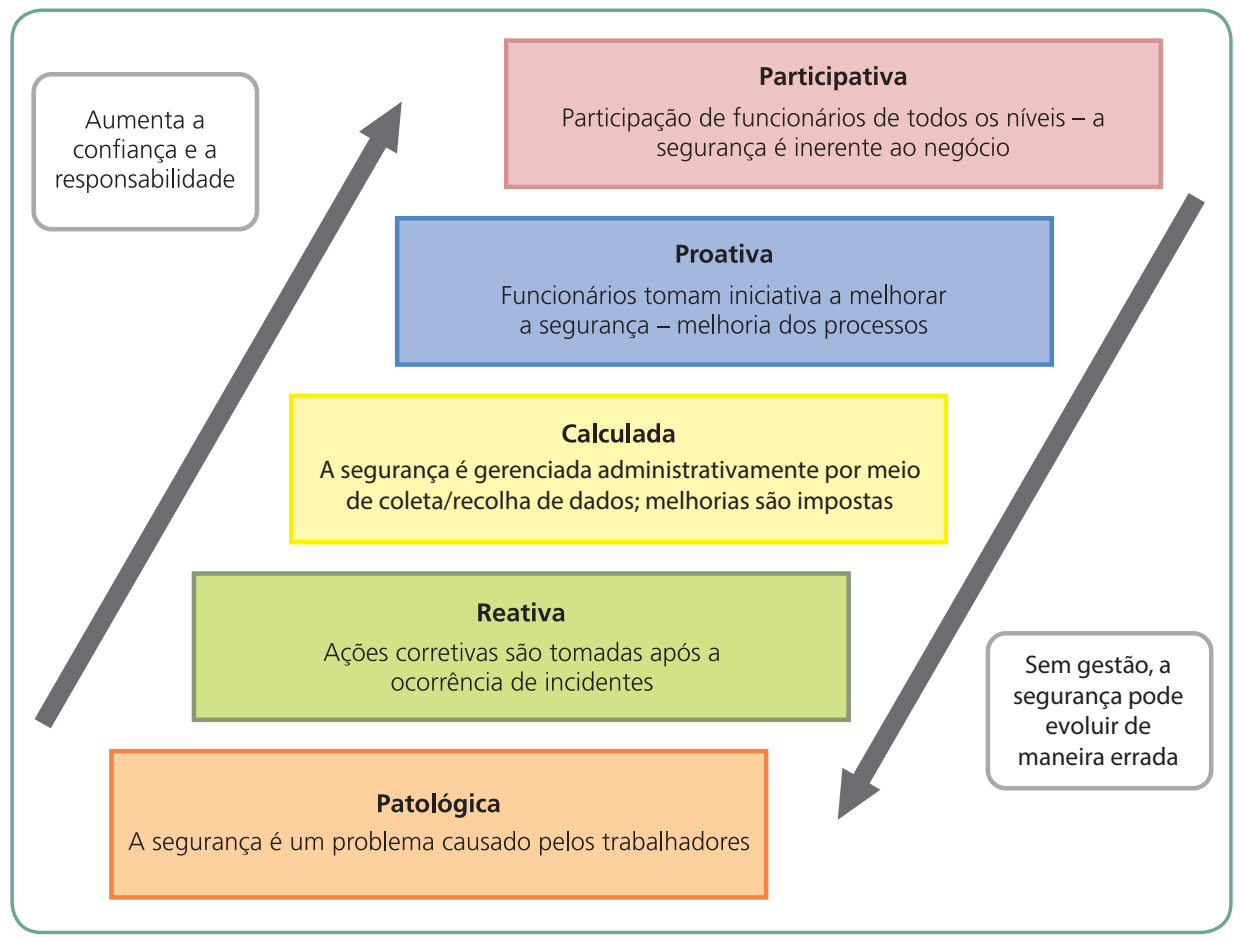

Fonte: Adaptado de Hudson (2003) 


\section{Para refletir}

Pense a respeito da cultura de segurança da organização em que você trabalha. Qual a sua percepção sobre as questões relacionadas à cultura de segurança?

Quando ocorre um incidente de segurança, os profissionais se sentem à vontade para notificá-lo/relatá-lo?

Há uma comunicação aberta e efetiva entre a equipe?

Os líderes são comprometidos com as questões relacionadas à segurança?

A segurança é prioridade para os gestores da organização?

Como você classificaria a cultura de segurança em sua organização quanto à sua maturidade?

\section{A cultura de segurança nas organizações de saúde}

Com o interesse crescente pela cultura de segurança, pesquisadores/ investigadores oriundos de diversas disciplinas (psicologia social e organizacional, gestão empresarial, negócios etc.) dedicaram-se a pesquisas/ investigações conduzindo a vários caminhos sobre a forma de conceituar cultura de segurança. Diante dessa diversidade e sem um conceito amplamente aceito, muitos pesquisadores/investigadores passaram a redefinir cultura de segurança enfocando a natureza dos problemas específicos da sua área de pesquisa/investigação (Guldenmund 2000).

Alguns pesquisadores/investigadores da área de Saúde que estudam as organizações de saúde também se preocuparam em adotar um conceito de cultura de segurança, como Nieva \& Sorra (2003). Esses autores adaptaram a definição estabelecida pela Health and Safety Commission, apresentada anteriormente, contribuindo para que ela fosse difundida na área de Saúde.

A OMS sustenta que a cultura é um fator que pode afetar todos os processos e defesas do sistema para melhor ou para pior. Segundo a OMS (WHO 2008), as organizações prestadoras de cuidados de saúde apresentam pelo menos dois obstáculos para fortalecer a cultura de segurança:

a crença de que, quando se treina o profissional, o problema está resolvido - ele está pronto para a tarefa;

a tendência em estigmatizar e punir a falibilidade - o erro se equipara à incompetência. 
Juntas, essas influências difundidas tornam difícil, para os prestadores de cuidados de saúde, admitir seus erros ou aprender coletivamente com base deles (WHO 2008). Agrega-se, ainda, o fato de a organização de saúde ser configurada como organização profissional, em que os recursos humanos centrais à produção do cuidado detêm um conhecimento específico e complexo que outorga grande autonomia de decisão e pouco controle do processo (Mintzberg 1982).

\section{Alta confiabilidade/fiabilidade para os cuidados de saúde}

A partir dos anos 2000, recomenda-se ao setor Saúde apropriar-se dos conceitos e técnicas da cultura de segurança adotados em OACs (Kohn et al. 1999). Essas organizações, tradicionalmente conhecidas por gerirem com muita eficiência seus processos de trabalho intrinsecamente complexos e perigosos, têm como prioridade minimizar os riscos de incidentes e mitigar eventos adversos.

As OACs intencionam estabelecer uma consciência coletiva relacionada à segurança, que se expressa por meio do compromisso com a segurança em todos os níveis da organização, desde seus prestadores da linha de frente até seus gerentes e executivos. Segundo Chassin \& Loeb (2011), a consciência coletiva significa que todos que trabalham nessas organizações, tanto individualmente como em equipe, têm plena conhecimento de que mesmo pequenas falhas nos protocolos e processos de segurança podem levar a resultados adversos catastróficos. Nessas organizações, como uma questão de rotina, os trabalhadores estão sempre procurando a menor indicação de que o ambiente ou um processo de segurança tenha sido alterado de algum modo, propiciando falha, caso algumas medidas não sejam tomadas para resolver o problema. Essa postura permite à organização identificar problemas de segurança ou de qualidade numa fase na qual eles são facilmente corrigidos.

Chassin \& Loeb (2011) contrapõem aspectos importantes entre a cultura de segurança presente nas OACs e a cultura dominante nas organizações de saúde (Quadro 1).

Quadro 1 - Aspectos importantes entre a cultura de segurança presente nas OACs e a cultura dominante nas organizações de saúde

\begin{tabular}{|l|l|}
\hline Organizações de alta confiabilidade/fiabilidade & Organizações de saúde \\
\hline Crença em que algo pode sair errado & Crença em que tudo vai dar certo \\
\hline Foco sobre a confiabilidade/fiabilidade do sistema & Foco sobre a eficiência do sistema \\
\hline
\end{tabular}


Quadro 1 - Aspectos importantes entre a cultura de segurança presente nas OACs e a cultura dominante nas organizações de saúde (cont).

\begin{tabular}{|l|l|}
\hline $\begin{array}{l}\text { Humildade para buscar entender e aprender o que } \\
\text { não se conhece }\end{array}$ & $\begin{array}{l}\text { Crença de que se sabe tudo o que se } \\
\text { precisa saber }\end{array}$ \\
\hline Comportamento que valoriza o trabalho em equipe & $\begin{array}{l}\text { Presença de elevados gradientes de } \\
\text { hierarquia entre os profissionais }\end{array}$ \\
\hline
\end{tabular}

Fonte: Adaptado de Chassin \& Loeb (2011).

Os gradientes de hierarquia entre profissionais, típicos das culturas das organizações de saúde, consistem na distância psicológica entre o trabalhador e seu supervisor (Wachter 2013). Níveis de gradiente de autoridade são esperados, mas, quando os profissionais sentem-se intimidados em compartilhar preocupações com seus superiores, receando serem punidos ou causarem irritação à sua chefia, esses gradientes tornam-se perigosos. Organizações seguras encontram maneiras de restringir hierarquias em todos os níveis encorajando os indivíduos a se manifestarem frente a situações inseguras ou quando suspeitam que algo pode não estar certo. Os gradientes de hierarquia estão presentes não apenas entre os profissionais que prestam cuidado clínico direto, mas também abrangem o auxiliar administrativo da enfermaria, o farmacêutico e demais profissionais, que podem perceber e apontar condições que apresentam riscos de danos ao paciente (Wachter 2013).

Para que as organizações de saúde passem a assemelhar-se culturalmente às organizações de alta confiabilidade/fiabilidade, Chassin $\delta$ Loeb (2011) sugerem a necessidade de três mudanças críticas e interdependentes no nível organizacional:

繗 O compromisso das lideranças como componente fundamental para difundir a ideia da necessidade de mudança de comportamento e de cultura. Esse compromisso requer incorporar os princípios da alta confiabilidade/fiabilidade nas declarações da visão e missão da organização, estabelecendo metas mensuráveis para monitorar sua realização.

蝶 A cultura de segurança deve envolver três imperativos que se sustentam mutuamente:

- a confiança;

- a notificação/relato; e

- a busca contínua por melhoria.

A confiança deve ser estabelecida entre todos os profissionais para que se sintam seguros quando identificarem algum problema que possa envolver erros cometidos por outros. Do mesmo modo, os profissionais devem confiar que a gestão irá buscar a solução dos problemas identificados nas notificações ou relatos de condições poten- 
cialmente inseguras ou procedimentos de segurança falhos, que dão oportunidade de identificar problemas em estágios iniciais antes que eles representem riscos elevados. As melhorias de segurança obtidas com base em notificações/relatos ou relatos, uma vez transmitidas de volta aos profissionais (feedback), reforçam a confiança que motivou o profissional a notificar/relatar, contribuindo para que a cultura de segurança da organização seja fortalecida.

* Ferramentas robustas de avaliação de processos devem ser adotadas, como a Lean seis sigma, a análise da causa raiz e outras. O poder dessas ferramentas reside em sua abordagem sistemática, que envolve o seguinte: a forma confiável/fiável de medir a magnitude do problema, identificar suas causas e mensurar a importância de cada causa; encontrar soluções para as causas mais importantes; comprovar a efetividade dessas soluções e implantar programas que assegurem a melhoria contínua ao longo do tempo.

Em síntese, para que a cultura de segurança de uma organização de saúde alcance a performance da cultura de segurança das OACs, as seguintes características principais devem ser seguidas:

O reconhecimento da natureza do alto risco das atividades da organização e a determinação em realizar as operações de forma consistentemente segura.

\section{A promoção de um ambiente livre de culpa em que os indivíduos são capazes de notificar incidentes ou quase-incidentes sem medo de serem punidos.}

O encorajamento da colaboração entre os diversos níveis e a disciplina em buscar soluções para os problemas de segurança do paciente.

O comprometimento organizacional relacionado à

disponibilização de recursos para fins de responder às questões de segurança (AHRQ 2013 a). 


\section{A cultura de segurança nas organizações de saúde: cultura de culpabilização $X$ abordagem sistêmica}

Observa-se a prevalência de uma cultura de culpabilização nas organizações de saúde em nível global, especialmente em hospitais (Agnew et al. 2013; Eiras et al. 2014; Fujita et al. 2014; Hamdan, Saleem 2013; Hefner et al. 2016).

A cultura de culpabilização ou punitiva caracteriza-se pela tendência de culpar o indivíduo pela ocorrência de um erro ou incidente de segurança, e representa importante fragilidade na cultura dessas organizações, visto que impede ou dificulta identificar os problemas de segurança. Temendo ser punido ou culpabilizado, o profissional não se sente encorajado a notificar/relatar os incidentes e eventos adversos. Logo, o ambiente de aprendizagem contínuo, preconizado por uma cultura de segurança fortalecida, torna-se inviável. Nesse contexto, como planejar/planear ações preventivas eficazes sem conhecer a realidade da organização?

O conceito de segurança do paciente privilegia a abordagem sistêmica, a qual aponta para as deficiências do sistema de prestação de cuidados de saúde, em sua concepção, organização e funcionamento, como principais fatores responsáveis pela ocorrência de incidentes de segurança, contrapondo-se a culpabilizar os indivíduos isoladamente. A premissa é que os seres humanos cometem falhas, e, portanto, erros são esperados. Os erros são consequências, e não causas. E, embora não se possa mudar a condição humana, é possível mudar as condições sobre as quais os seres humanos trabalham, criando defesas no sistema (Reason 2000).

A abordagem sistêmica relaciona a ocorrência de eventos adversos às deficiências existentes nos sistemas de prestação de cuidados de saúde, seja em suas estruturas ou seus processos de trabalho. A ideia é que, na grande maioria dos casos em que ocorre um erro ou incidente de segurança, conta-se com profissionais competentes e cuidadosos trabalhando em sistemas complexos e caóticos. A ocorrência de incidentes teria uma multicausalidade, ou seja, seria a consequência de um encadeamento de fatores sistêmicos, os quais incluem as estratégias da organização, sua cultura, práticas de trabalho, abordagem à gestão da qualidade, prevenção de riscos e a capacidade de aprendizagem com base no registro de incidentes de segurança (WHO 2009).

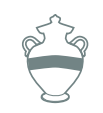

A abordagem sistêmica do erro foi tratada no Capítulo 4, "O erro e as violações no cuidado de saúde", do livro Segurança do Paciente: conhecendo os riscos nas organizações de saúde. Consulte esse capítulo para recordar os conceitos de falha ativa e falha latente, e o Modelo do Queijo Suíço de acidentes em um sistema. 
Figura 2 - Modelo de Yorkshire

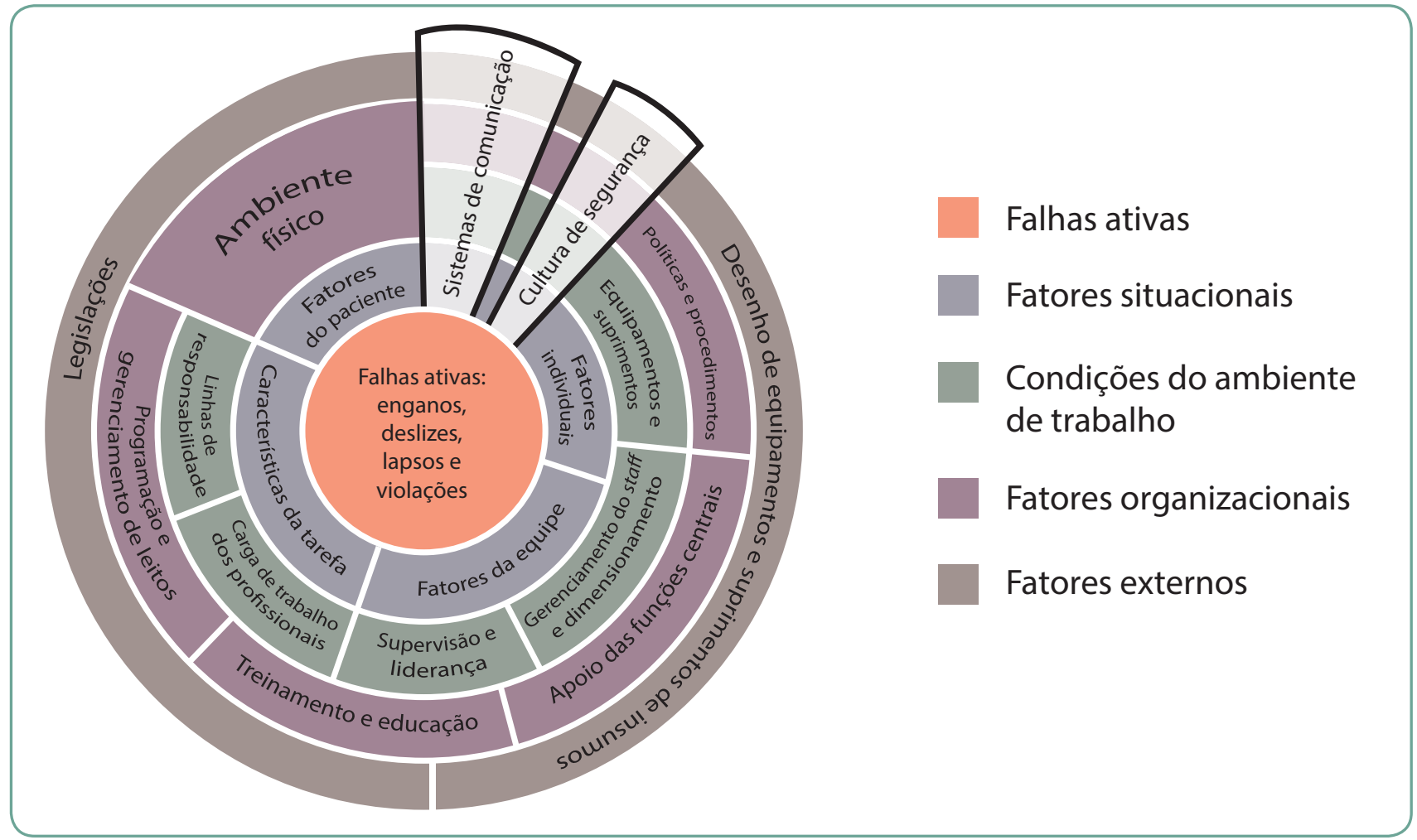

Fonte: Adaptado de Lawton et al. (2012).

A abordagem sistêmica impulsiona o foco para a melhoria do desempenho organizacional e promoção de uma cultura não punitiva, que encoraja o profissional a reconhecer e notificar/relatar os incidentes de segurança. A abordagem sistêmica propiciou muitas melhorias na segurança do cuidado, das quais são exemplos a prescrição eletrônica, o uso de códigos de barra, a padronização e simplificação de processos e melhorias no design de equipamentos, entre outras. A abordagem não punitiva parece não ser apropriada para a totalidade de incidentes de segurança que ocorrem nas organizações de saúde. Alguns erros exigem responsabilização. Se, por um lado, é fato que a cultura tradicional de culpabilidade individual prejudica o avanço de uma cultura de segurança, por outro, a cultura não punitiva, embora seja a postura adequada para a maior parte dos incidentes de segurança, não o é para determinados incidentes. A culpa é apropriada a indivíduos que cometem erros frequentes e descuidados, que falham em acompanhar sua especialidade, comparecem ao trabalho alcoolizados ou optam por ignorar normas sensatas de segurança, adotando comportamentos disruptivos (Wachter 2013). 
Comportamento disruptivo inclui aqueles que demonstram desrespeito pelos outros ou interações interpessoais que impedem a prestação de cuidado ao paciente. Os comportamentos disruptivos impossibilitam a criação de uma cultura de segurança, acentuam a hierarquia comprometendo o trabalho em equipe e bloqueiam o caminho para um contexto de não culpabilidade (Wachter 2013).

Segundo Dekker (2016), a abordagem sistêmica sustenta que tanto a falha como o sucesso são produtos multifatoriais. Logo, se algo é bem-sucedido na organização, não é provável que seja por mérito individual. Da mesma forma, quando ocorre uma falha, ela não se deve a uma deficiência individual; sob a ótica da abordagem sistêmica, em ambos os casos, o sucesso ou a falha, abrange equipe, organização e sistema. Por consequência, certa ansiedade, relativamente recente, sobre a abordagem sistêmica vem fomentando a popularidade do conceito de cultura justa para as organizações de saúde.

\section{Cultura justa para as organizações de saúde}

O conceito de cultura justa foi introduzido para conciliar as necessidades individuais de não culpabilização e a adequada responsabilização diante de incidentes de segurança.

A cultura justa identifica e aborda as questões dos sistemas que levam indivíduos a adotar comportamentos inseguros e estabelece tolerância zero para o comportamento imprudente (AHRQ 2010). Ela distingue entre o erro humano (por exemplo, cometer deslizes), o comportamento de risco (por exemplo, tomar atalhos) e o comportamento imprudente (por exemplo, ignorar os passos de segurança necessários), em contraste com uma abrangente abordagem de não culpabilidade defendida por alguns.

Em uma cultura justa, a reação frente a um incidente baseia-se no tipo de comportamento relacionado ao incidente, e não à sua gravidade. Wachter (2012) recomenda o uso de modelos para orientar a reflexão sobre questões envolvidas em um incidente de segurança, antes de decidir se uma punição se justifica.

A Figura 3 apresenta uma adaptação do modelo desenvolvido por Leornard \& Frankel (2010), que auxilia no julgamento se a responsabilização pessoal é justificada diante da ocorrência de um incidente. 
Figura 3 - Ações dos prestadores de cuidados e possibilidades de respostas para análise de riscos

O prestador de cuidados de saúde sabidamente tinha suas faculdades mentais prejudicadas?

(Em caso positivo, a punição pode ser justificada.)

O prestador de cuidados de saúde decidiu conscientemente realizar um ato inseguro? (Em caso positivo, a punição pode ser justificada.)

O prestador de cuidados de saúde cometeu um erro que indivíduos com o mesmo grau de experiência e treinamento cometeriam em circunstâncias semelhantes?

(Em caso negativo, a punição pode ser justificada.)

O prestador de cuidados de saúde tem uma história de atos inseguros? (Em caso positivo, a punição pode ser justificada.)

Fonte: Adaptado de Leonard \& Frankel (2010).

Para refletir

Como você observa a conduta tomada frente à ocorrência de incidentes em sua organização?

As circunstâncias relacionadas à ocorrência de um incidente são cuidadosamente analisadas?

E, em sua opinião, prevalece a cultura de culpabilização ou a cultura justa?

David Marx (2001) promoveu o conceito de cultura justa como forma de devolver o foco apropriado da não culpabilidade ao processo de cuidar. Uma cultura justa equilibra a necessidade de um ambiente aberto e honesto para notificação/relato de incidentes com a finalidade de garantir a qualidade de um ambiente de cultura de aprendizagem.

No modelo de Marx, a cultura justa faz a distinção entre o erro humano, comportamento de risco e comportamento imprudente. Apenas a última categoria, definida como agir em desrespeito consciente ao risco substancial e injustificável, seria passível de culpa. O Quadro 2 apresenta uma versão simplificada do modelo de Marx. 
Quadro 2 - Versão simplificada do modelo de cultura justa de Marx

\begin{tabular}{|l|l|l|}
\hline $\begin{array}{l}\text { Mecanismos de quebra no dever } \\
\text { para com o paciente }\end{array}$ & Descrição & Resposta apropriada do sistema \\
\hline Erro humano & $\begin{array}{l}\text { Uma ação inadvertida de um prestador de cuidado (um } \\
\text { deslize ou um engano). }\end{array}$ & Consolar o profissional \\
\hline Comportamento de risco & $\begin{array}{l}\text { Tomar atalhos: desvio consciente de comportamentos } \\
\text { seguros; o prestador de cuidado viola normas de segurança, } \\
\text { mas não vê isso como causa de dano (o equivalente a não } \\
\text { parar no sinal vermelho). }\end{array}$ & Aconselhar o profissional \\
\hline Comportamento imprudente & $\begin{array}{l}\text { O prestador de cuidado decide conscientemente adotar um } \\
\text { comportamento que sabe representar risco significativo; } \\
\text { ignora os passos de segurança necessários. }\end{array}$ & Disciplinar o profissional \\
\hline
\end{tabular}

Fonte: Adaptado de Leonard \& Frankel (2010).

Dekker \& Breakey (2016) corroboram que o objetivo de uma cultura justa vem, por um lado, em resposta às ansiedades sobre as abordagens sem culpa e, por outro, em uma preocupação em incentivar as pessoas a continuar a notificar/relatar questões relacionadas à segurança.

A cultura justa caracteriza-se por uma cultura de confiança, aprendizagem e responsabilidade. Ela é particularmente importante mediante a ocorrência de um incidente, quando alguma coisa não resulta bem e deve nortear como responder às pessoas envolvidas no incidente (pacientes, familiares e profissionais), bem como minimizar os impactos negativos e maximizar o aprendizado (Dekker 2016).

É importante ressaltar que os eventos adversos não afetam apenas os pacientes e seus familiares, mas podem ter efeitos devastadores sobre os provedores de cuidados, também denominados segundas vítimas, que são passíveis de sofrer consequências emocionais devido a eventos adversos que poderiam ser evitados e sofrer, subsequentemente, litígio por má prática (AAP 2016).

Há diferentes caminhos para abordar a cultura justa, tanto dentro da organização como fora dela. Uma abordagem baseia-se na justiça retributiva/punitiva, e a outra na justiça restaurativa. Diante de situações em que ocorre um evento adverso, a retribuição impõe uma punição merecida e proporcional; já a restauração pretende reparar a confiança e os relacionamentos danificados (Dekker 2016). 
As questões emergentes de processos retributivos e restaurativos frente à ocorrência de incidentes de segurança são apresentadas no Quadro 3. Dekker (2016) sugere que se olhe para as abordagens de justiça retributiva e restaurativa separadamente, a fim de observar como cada uma delas tenta gerar credibilidade, confiança e aprendizado, características fundamentais que devem compor uma cultura justa.

Quadro 3 - Questões retributivas e restaurativas frente à ocorrência de incidentes de segurança

\begin{tabular}{|l|l|}
\hline \multicolumn{2}{|c|}{ Questões } \\
\hline Retributivas & Restaurativas \\
\hline - Qual regra foi quebrada? & - Quem sofreu? \\
- Quem é o responsável? & - Quais as pessoas envolvidas? \\
$\begin{array}{l}\text { - Quão ruim foi a infração? Logo, o que } \\
\text { a pessoa merece? }\end{array}$ & $\begin{array}{l}\text { - De quem é a obrigação de atender às } \\
\text { necessidades? }\end{array}$ \\
\hline
\end{tabular}

Fonte: Adaptado de Dekker (2016).

Segundo Dekker (2016), a maioria das organizações que objetiva implementar uma cultura justa se respalda na justiça punitiva ou retributiva. Em crítica, o autor afirma ser a punição e o aprendizado condições mutuamente excludentes. Com base nisso, ele questiona sobre como restaurar a confiança e a responsabilidade nas organizações de saúde por meio de uma cultura justa.

Sob a ótica da justiça retributiva frente à ocorrência de um incidente, há a responsabilização dos profissionais que têm uma dívida moral a pagar com suas vítimas, organização, comunidade e sociedade; busca-se um culpado pelo ocorrido, e, como a resposta se concentra no indivíduo, as condições subjacentes que deram origem ao incidente podem ser perdidas e não identificadas (Dekker 2016). Um exemplo que se pode citar é o caso de uma enfermeira demitida do trabalho e processada após a morte de um paciente de 16 anos (Denham 2007). Um relatório posterior ao ocorrido, descreveu como as questões sistêmicas contribuíram para a ocorrência do erro de medicação que culminou com a morte do paciente (Wahlberg 2010).

Na justiça restaurativa, as pessoas pretendem, em conjunto, descobrir a forma de compensar os danos ocorridos a todos os envolvidos no incidente. O primeiro questionamento que se faz é quem sofreu o dano e o que as pessoas necessitam diante de tal situação. Segundo Dekker (2016), um incidente ocorrido, seja em um hospital, em uma companhia aérea, ou de petróleo, pode causar danos a várias pessoas. Reconhecer de que forma as pessoas foram prejudicadas e quais são suas 
necessidades é essencial quando se deseja uma cultura organizacional verdadeiramente justa, e esse esforço deve incluir todos os envolvidos:

* primeiras vítimas - pacientes, passageiros, colegas ou comunidade envolvidos e que sofreram consequências do incidente;

䟢 segundas vítimas - o(s) profissional(s) envolvido(s) que se sente pessoalmente responsável e sofre com a ocorrência do incidente e suas consequências; e

* comunidade organizacional que carece das informações sobre o incidente e da resposta organizacional dada a ele. A comunidade organizacional carece da oportunidade para ajudar as primeiras e segundas vítimas, de contribuir para restabelecer relacionamentos e confiança, e conseguir o senso comum na solução de problemas.

As duas possibilidades de abordagens em uma cultura justa - retributiva e restaurativa - também diferem quanto ao modo de lidar com a confiança. Retribuição cria confiança ao reforçar as regras e a autoridade de certas partes ou pessoas a fim de controlá-las e executá-las; como se, no local de trabalho, houvesse linhas que não devessem ser ultrapassadas. E, caso isso ocorra, haverá consequências. Por exemplo, quando pessoas burlam regras ou fazem trabalho desleixado, você confiaria que o sistema ou a comunidade iriam exigir responsabilidade? Sua confiança poderia ser restaurada se você vir uma resposta adequada e assertiva a esse comportamento. Você teria a certeza de que o sistema, ou sua comunidade, não aceitaria esse comportamento e responderia de maneira clara para todos (Dekker 2016).

A restauração, por outro lado, cria confiança ao reparar relações fiduciárias. As relações fiduciárias são aquelas de confiança entre pessoas que dependem umas das outras para fazer com que algo funcione. Considere o trabalho realizado em sua própria organização. As pessoas da sua organização dependem umas das outras. Todos os dias, talvez a cada minuto, elas têm que confiar umas nas outras para que certas coisas sejam feitas, de forma oportuna, apropriada e segura. Elas podem não fazer essas coisas por si mesmas, porque não estão no lugar certo, ou porque não têm competência ou autoridade para fazê-los. Logo, elas dependem dos outros. Isso cria uma relação fiduciária: uma relação de confiança. É essa relação que é ferida ou quebrada quando as coisas saem erradas. E é essa relação que precisa ser restaurada (Dekker 2016).

Ambos os tipos de confiança podem ser importantes para sua organização ou comunidade.

O Quadro 4 apresenta as diferentes maneiras pelas quais os processos retributivos e restaurativos tentam criar justiça. 
Quadro 4 - Maneiras pelas quais os processos retributivos e restaurativos tentam criar justiça

\begin{tabular}{|c|c|}
\hline Retributivos & Restaurativos \\
\hline $\begin{array}{l}\text { Considera que há um culpado pelo que } \\
\text { deu errado e exige punição como forma } \\
\text { de compensação. }\end{array}$ & $\begin{array}{l}\text { Considera que o que deu errado gera } \\
\text { necessidades e obrigações em conhecer } \\
\text { essas necessidades. }\end{array}$ \\
\hline $\begin{array}{l}\text { Acredita que a conta gerada por um } \\
\text { incidente é algo que o infrator paga ou } \\
\text { liquida. }\end{array}$ & $\begin{array}{l}\text { Acredita que a conta gerada por um } \\
\text { incidente é algo sobre o qual o infrator } \\
\text { conversa e ouve a respeito. }\end{array}$ \\
\hline $\begin{array}{l}\text { Pergunta quem é responsável pelo } \\
\text { incidente. }\end{array}$ & $\begin{array}{l}\text { Pergunta o que é responsável pelo } \\
\text { incidente. }\end{array}$ \\
\hline $\begin{array}{l}\text { Aprende e previne estabelecendo um } \\
\text { exemplo. }\end{array}$ & $\begin{array}{l}\text { Aprende e previne perguntando por que } \\
\text { faz sentido para as pessoas fazerem o que } \\
\text { fizeram. }\end{array}$ \\
\hline $\begin{array}{l}\text { Foca sobre o que as pessoas envolvidas } \\
\text { no incidente merecem. }\end{array}$ & $\begin{array}{l}\text { Foca sobre o que as pessoas envolvidas e } \\
\text { afetadas pelo incidente necessitam. }\end{array}$ \\
\hline $\begin{array}{l}\text { Cria justiça ao impor punição merecida e } \\
\text { proporcional. }\end{array}$ & $\begin{array}{l}\text { Cria justiça ao decidir quem atende às } \\
\text { necessidades decorrentes do incidente. }\end{array}$ \\
\hline Agrega ao dano, mais dano. & Agrega ao dano a recuperação. \\
\hline $\begin{array}{l}\text { Olha para trás para o dano feito e } \\
\text { atribui as consequências. }\end{array}$ & $\begin{array}{l}\text { Olha para frente na expectativa de reparar e } \\
\text { investir nos relacionamentos. }\end{array}$ \\
\hline $\begin{array}{l}\text { Constrói confiança ao reforçar as regras } \\
\text { e a autoridade para impor e policiar. }\end{array}$ & $\begin{array}{l}\text { Constrói confiança ao reparar as relações } \\
\text { entre as pessoas que dependem umas das } \\
\text { outras para realizar seu trabalho. }\end{array}$ \\
\hline
\end{tabular}

Fonte: Adaptado de Dekker (2016)

A linha entre retribuição e restauração não é inteiramente clara e é passível de que se faça um pouco das duas, ao mesmo tempo, em uma organização. Tanto a restauração como a retribuição podem ser consideradas ou tratadas como processos para ajudar a reintegrar uma pessoa dentro de uma comunidade ou organização. A recomendação é que não exageremos no contraste entre ambas, pois, independente do regime de restauração ou retribuição, alguma forma de penitência é fundamental tendo em vista os processos de perdão, os quais envolvem conversar sobre a história dos incidentes vivenciados, expressar desculpas e reconhecer parte da responsabilidade pelo desfecho. A maneira de fazê-los é que difere entre as práticas retributivas e restaurativas. 


\section{Para refletir}

Como já discutimos, a ocorrência de incidentes de segurança é inerente à vida profissional, seja pela própria falibilidade humana, seja pelo contexto complexo dos processos e estrutura das organizações de saúde. No entanto, existem diferentes situações que podem contribuir para a ocorrência de um dano ao paciente que justificam distintas formas de impor responsabilidades. Como a instituição em que você trabalha costuma lidar com essas questões?

\section{Os sistemas de notificação/relato de incidentes e a divulgação aberta da informação sobre erros no cuidado de saúde (disclosure)}

Uma cultura justa pressupõe o aprendizado contínuo, e, portanto, o apoio às pessoas a notificarem/relatarem questões relacionadas à segurança, sem medo de punições. As informações sobre os incidentes notificados/relatados são fundamentais para o aprendizado, pois ajuda a melhorar a segurança.

Frente à ocorrência de um erro, a adoção de condutas não punitivas e a divulgação aberta da informação sobre erros no cuidado de saúde (disclosure) desempenham papéis importantes na criação de uma organização segura e cultura justa.

Antes de comentar a respeito de cada uma dessas condutas, é importante fazer a distinção entre ambas:

A notificação/relato de incidentes provê informações aos supervisores, gestores de risco da organização ou a outras agências governamentais: notificar/relatar significa falar ou escrever alguma coisa que você observou, participou ou fez; é necessário porque contribui com o aprendizado organizacional; ajuda a organização (e os colegas) a compreender o que aconteceu de errado e como prevenir sua recorrência.

镂 Disclosure visa prover informação aos usuários/utentes, clientes, pacientes e familiares. A obrigação ética do profissional em divulgar seu papel em eventos adversos vem de um relacionamento exclusivo de confiança com aqueles que confiaram nele para a realização de um serviço, um produto, ou um cuidado de saúde (Dekker 2016). 
Para que seja útil, é desejável que o SNI seja de fácil uso, não punitivo e manejado por pessoa habilitada.
A criação de sistemas de notificação/relato de incidentes (SNI) tem sido encorajada, particularmente em hospitais, como forma de reunir dados que contribuam para a melhoria significativa da segurança e qualidade do cuidado. Logo, as estratégias de notificação/relato de incidentes precisam incluir a identificação das falhas, admitir os erros, corrigir situações inseguras e retroalimentar os profissionais sobre as melhorias realizadas.

A notificação/relato de incidentes refere-se à troca de informações entre provedores e reguladores; os sistemas de notificação/relato de incidentes podem ser internos à organização ou exigidos por agências governamentais.

Segundo Wachter (2013), é possível dividir as notificações/relatos de erro em três categorias principais: anônimas, confidenciais e abertas. Para as notificações/relatos anônimas, não é solicitada a identificação do notificador/relator. Embora apresentem a vantagem de encorajar a notificação/relato, os sistemas anônimos têm a desvantagem de não permitir que perguntas de acompanhamento de investigação sejam respondidas. Em um sistema de notificação/relato confidencial, a identidade do notificador/relator é conhecida, mas protegida de autoridades reguladoras ou representantes de sistemas legais (exceto em caso de má conduta do profissional ou ato criminoso). Esses sistemas tendem a capturar melhores notificações/relatos do que o anônimo, porque podem ser feitas perguntas de investigação. Nos sistemas de notificação/relato abertos, todas as pessoas e lugares são publicamente identificados. Eles são pouco utilizados na área de Saúde, uma vez que o potencial voltado à publicidade não desejada e acusações é muito forte.

Apesar de muitos hospitais terem investido na implantação de um SNI, sobretudo por meio de infraestrutura informatizada, os recursos e o foco necessários para mudar a cultura de notificação/relato e do manejo de incidentes têm sido menos evidentes (Wachter 2013). Por consequência, os SNI apresentam muitas limitações, e uma advertência a ser considerada é que os sistemas voluntários não podem ser utilizados para avaliar taxas de erros, de danos; e, portanto, as organizações de saúde e hospitais precisam lançar mão de outras técnicas que possibilitem identificar erros e situações de risco. Trabalhar a cultura de segurança dentro da organização é essencial para se alcançar um SNI efetivo. 
Os desafios de fazer com que os profissionais notifiquem/relatem os incidentes e de manter as taxas de notificação/relato elevadas relacionam-se principalmente a dois fatores: a maximização da acessibilidade ao sistema de notificação/relato e a minimização da ansiedade do profissional. É essencial haver uma política escrita na organização que explique a todos o significado do sistema de notificação/relato, as consequências de uma notificação/relato, bem como os direitos, privilégios, proteção e obrigações que as pessoas podem esperar delas. Fazer com que as pessoas notifiquem/relatem incidentes de segurança permeia a construção da confiança, sob o pressuposto de que informações fornecidas de boa-fé não serão usadas contra as pessoas que as informaram (Dekker 2016).

A divulgação das informações sobre incidentes de segurança aos pacientes e seus familiares é parte importante do cuidado centrado no paciente e requisito essencial para sustentar a confiança (Kim et al. 2017). Muitos países têm estabelecido essa abordagem como uma prática padrão ou amparada em lei (Kalra et al. 2005). O disclosure com os pacientes e seus familiares, após a ocorrência de um evento adverso (EA), pode prover benefícios aos pacientes (primeiras vítimas) e aos provedores do cuidado de saúde (segundas vítimas), reduzir ou mitigar danos subsequentes ao EA, propiciar melhor acompanhamento do caso e promover a cultura de segurança (AAP 2016).

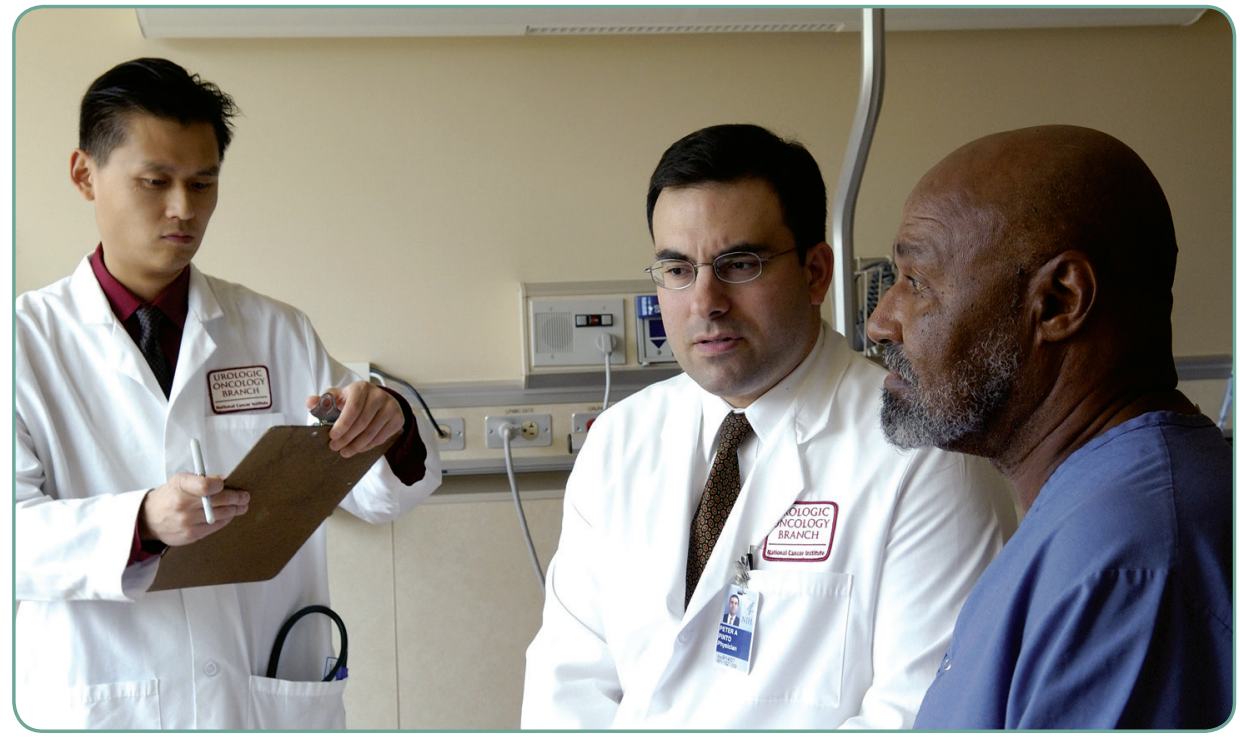

Fonte: https://commons.wikimedia.org/wiki/File:Doctor_consults_with_patient_(1).jpg 
O disclosure não é um relatório sobre o incidente ocorrido, mas sim uma prestação de contas a esse respeito. Envolve admitir que um erro ou incidente ocorreu e, tipicamente, mas não exclusivamente, refere-se a um provedor de cuidado que informa ao paciente ou seus familiares sobre erros ou resultados imprevistos.

O disclosure aborda as necessidades dos pacientes e membros da família e é frequentemente realizado por médicos e enfermeiros. No entanto, embora a vontade dos médicos em informar sobre os incidentes possa ser estimulada pela responsabilidade, honestidade, confiança, além da redução do risco de negligência, é possível que eles hesitem em divulgá-las por receio de repercussões profissionais, humilhação, culpa e falta de anonimato (Wolf, Hughes 2008).

Apesar dos benefícios convincentes e dos imperativos éticos para a divulgação aberta sobre um evento adverso, muitos médicos, todavia, continuam a ter dificuldade em executar a tarefa de informar os pacientes e suas famílias sobre EA (Gallagher et al. 2007). Várias barreiras são possíveis de criar obstáculos à divulgação, incluindo os riscos legais percebidos, o conselho cautelar de advogados, as preocupações com as habilidades de divulgação e o medo do constrangimento (McDonnell, Guenther 2008). Diferenças linguísticas e culturais também podem interferir com uma comunicação significativa sobre eventos adversos. Entre essas barreiras, os riscos percebidos e os aconselhamentos jurídicos que advertem contra a divulgação são os mais relevantes (Varjavand et al. 2012).

Para além do quanto a comunicação aberta entre profissionais, e entre esses e seus pacientes, constituem condições essenciais na construção de uma cultura de aprendizagem e de confiança, as organizações de saúde devem identificar as áreas frágeis de suas culturas organizacionais a fim de que seja possível planejar/planear intervenções de melhoria direcionadas a problemas específicos. Portanto, a avaliação da cultura de segurança é considerada o passo inicial para se estabelecer uma cultura de segurança efetiva em uma organização de saúde (Pronovost et al. 2004) e um ponto de partida para iniciar o planejamento/planeamento de ações que busquem mudanças, na intenção de reduzir a incidência de eventos adversos e garantir a prestação de cuidados de saúde seguros. 


\section{Avaliando a cultura de segurança em organizações de saúde}

Globalmente, observa-se, na comunidade científica e nas ações desenvolvidas por agências internacionais que se dedicam a melhorar o acesso e a efetividade dos cuidados de saúde, o interesse e o empenho na procura por soluções para reduzir o nível de risco para os pacientes, melhorar a qualidade do cuidado e desenvolver métodos e técnicas confiáveis/fiáveis que determinem o tipo e a natureza da cultura de segurança dos profissionais e de suas organizações ou serviços/departamentos nos hospitais. Com base na avaliação da cultura de segurança na organização, tem-se acesso às informações dos profissionais a respeito de suas percepções e comportamentos relacionados à segurança, permitindo identificar as áreas mais problemáticas com o intuito de ser possível planejar/planear e implementar intervenções (Sorra, Nieva 2004).

A avaliação da cultura de segurança é exigida por organismos internacionais de acreditação hospitalar e permite identificar e gerir prospectivamente as questões relevantes de segurança nas rotinas e condições de trabalho, a fim de monitorar mudanças e resultados relacionados à segurança. A avaliação da cultura de segurança pode ter múltiplas propostas:

* o diagnóstico da cultura de segurança e a conscientização/ consciencialização dos profissionais acerca do tema;

曗 a avaliação de intervenções para a segurança do paciente implementadas na organização e o acompanhamento de mudanças ao longo do tempo;

滕 a comparação com dados de referência internos e externos à organização; e

滕 a verificação do cumprimento de necessidades regulatórias (Sorra, Nieva 2004).

Para refletir

Sua organização já passou por uma avaliação da cultura de segurança? Em caso negativo, a que você credita essa ausência?

Se sua resposta foi positiva, você avalia que as propostas da avaliação listadas no texto podem ter sido alcançadas? 


\section{Métodos para avaliar a cultura de segurança em organizações de saúde}

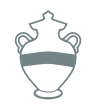

É imprescindível o envolvimento dos gestores e lideranças das organizações para o alcance de uma taxa de resposta adequada.

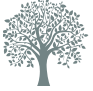

Consulte o questionário "Pesquisa sobre Cultura de Segurança do Paciente" em sua versão aplicável a hospitais (HSOPSC), disponível no portal Proqualis: http://https:// proqualis.net/sites/proqualis. net/files/000002442leoxaL.pdf
A multiplicidade de definições sobre cultura e clima de segurança reflete a diversidade de metodologias utilizadas para avaliar a cultura de segurança em uma organização (Nascimento 2011). Segundo essa autora, a abordagem epidemiológica quantitativa comumente utiliza questionários de autopreenchimento e está de forma estreita relacionada à avaliação de clima de segurança ou dos componentes mensuráveis da cultura de segurança. Por seu turno, a abordagem socioantropológica qualitativa prevê a avaliação da cultura de segurança por meio de técnicas de observação associadas a entrevistas.

Em organizações de saúde, a maior parte dos estudos que avalia cultura de segurança utiliza questionários como instrumento de coleta/ recolha de dados. Esses questionários baseiam-se em uma combinação de dimensões e são considerados estratégia eficiente por ser ela anônima e com custos mais reduzidos que as abordagens qualitativas para coletar/recolher dados sobre cultura de segurança (Flin et al. 2007). Os questionários diferem quanto ao número de itens e de dimensões que mensuram e em relação à variação em suas propriedades psicométricas - validade e confiabilidade/fiabilidade (Colla et al. 2005, Flin et al. 2006, Halligan, Zecevic 2011, Robb, Seddon 2010).

Um porcentual de resposta elevado é fundamental para o êxito dos estudos, os quais utilizam o questionário com o propósito de avaliar cultura de segurança. Desde que satisfeita essa condição, os questionários proveem a percepção das fraquezas e fortalezas da cultura da organização em sua totalidade, bem como dentro de departamentos/ setor ou serviços e categorias profissionais (Robb, Seddon 2010).

\section{Instrumentos disponíveis para avaliar cultura de segurança em organizações de saúde}

A seleção do questionário a ser utilizado dep ende de sua finalidade, das perguntas às quais se pretende responder, devendo ele, também, ser adequado em termos de suas propriedades psicométricas (Colla et al. 2005). Os dois questionários mais amplamente utilizados são a "Pes- 
quisa sobre Cultura de Segurança do Paciente" (Patient Safety Culture Survey), da Agency for Healthcare Research and Quality (AHRQ), e o "Questionário de Clima de Segurança" (Safety Attitudes Survey - SAQ) (AHRQ 2010, Colla et al. 2005, Sexton et al. 2006). A tradução de ambos os questionários encontra-se disponível para uso no Brasil; a Pesquisa/investigação sobre Cultura de Segurança do Paciente, em sua versão aplicável a hospitais (HSOPSC), foi adaptada e, posteriormente, validada (Reis 2013, Reis et al. 2012, Reis et al. 2016), assim como o SAQ (Carvalho 2011).

São elegíveis a responder o HSOPSC e o SAQ profissionais que trabalham em hospitais e têm contato direto ou interagem diretamente com os pacientes internados, bem como profissionais que não têm contato direto com o paciente, mas cujas funções desempenhadas no trabalho afetam diretamente o cuidado ao paciente internado (líderes, gerentes, supervisores e administradores). Esses questionários foram delineados com o objetivo de mensurar múltiplas dimensões da cultura de segurança do paciente; eles indagam a opinião de seus respondentes sobre pontos-chave relacionados à segurança - valores, crenças e normas da organização, notificação/relato de eventos adversos, comunicação, liderança e gestão.

A Figura 4 resume as dimensões da cultura de segurança mensuradas pelo HSOPSC e o número de itens que compõem cada dimensão.

O HSOPSC avalia sete dimensões do nível de departamento/setor do hospital e três dimensões do nível da organização hospitalar, dispostas do lado esquerdo da figura. As duas dimensões dispostas do lado direito são consideradas dimensões ou variáveis de resultado. Portanto, os dados obtidos com base em inquéritos que utilizam o HSOPSC como instrumento de coleta/recolha em hospitais permitem realizar análises estatísticas para verificar se os escores obtidos nas dimensões do âmbito hospitalar ou da unidade/serviço influenciam nos escores obtidos nas dimensões entendidas como variáveis de resultado. 
Figura 4 - Dimensões da cultura de segurança e variáveis de resultado mensuráveis pela Pesquisa sobre Cultura de Segurança do Paciente (HSOPSC)

Dimensões da Cultura de Segurança

(escalas de múltiplos itens)

\section{Dimensões do nível da unidade do hospital - 7 dimensões}

- Expectativas e ações de promoção de segurança dos supervisores e gerentes (4 itens)

- Aprendizado organizacional - melhoria contínua (3 itens)

- Trabalho em equipe no âmbito das unidades (4 itens)

- Abertura da comunicação (3 itens)

- Retorno das informações e comunicação sobre os erros (3 itens)

- Respostas não punitiva aos erros (3 itens)

- Adequação de pessoal (4 itens)

\section{Dimensões do nível da organização hospitalar -} 3 dimensões

- Apoio da gestão hospitalar para segurança do paciente (3 itens)

- Trabalho em equipe entre as unidades hospitalares (4 itens)

- Passagens de plantão/turno e transferências internas (4 itens)
Dimensões da Cultura de Segurança (escalas de múltiplos itens)

\section{Dimensões de resultado -} 2 dimensões

- Percepção geral da segurança do paciente (4 itens)

- Frequência de notificação de eventos (3 itens)

Fonte: Adaptado de Olsen (2008).

A cultura de segurança varia amplamente entre diferentes profissionais, e é fundamental questionar todos eles para se desenhar um retrato completo da cultura de uma organização (Wachter 2013).
A avaliação da cultura de segurança, baseada no uso de questionários, é feita por meio do cálculo do porcentual de respostas positivas aos itens das dimensões que compõem esses instrumentos; determina-se, então, um ponto de corte para classificar os pontos fortes e frágeis da cultura em cada dimensão, a fim de, posteriormente, serem trabalhados nas organizações (Reis 2013). Esses porcentuais podem ser calculados para a organização em sua totalidade, por unidades da organização e por categorias profissionais.

Estudos têm documentado variação considerável na percepção da cultura de segurança entre organizações, entre serviços/departamentos dentro da mesma instituição e entre categorias profissionais. Pronovost \& Sexton (2005) aplicaram o SAQ a médicos de 100 hospitais e encontraram ampla variação dos escores entre os hospitais (escores positivos variaram de 40 a $80 \%$ ); a variação foi ainda maior quando avaliaram os escores entre os serviços/departamentos dentro do mesmo hospital (escores positivos variaram de 0 a 100\%). Em pesquisas/investigações anteriores, os enfermeiros vêm, consistentemente, queixando-se da falta de um ambiente livre de culpa, e provedores de cuidado de todos os níveis têm notado problemas com o comprometimento organizacional para o estabelecimento de uma cultura de segurança (AHRQ 2013a). 


\section{O fortalecimento da cultura de segurança como um fator indutor do cuidado de saúde mais seguro}

O desenvolvimento da cultura de segurança apresenta-se como elemento central nos muitos esforços empreendidos na busca pela melhoria da segurança do paciente e da qualidade do cuidado de saúde prestado. A avaliação do status da cultura de segurança em organizações de saúde, particularmente em hospitais, tem sido objeto de diversos estudos pré e pós-intervenções, mostrando as necessidades percebidas em uma avaliação pré-intervenção e os ganhos alcançados a partir da implementação efetiva de intervenções de segurança.

Iniciativas recentes mostram evidências de associações entre medidas de fortalecimento da cultura de segurança e melhoria nos resultados obtidos. O estudo de Neily et al. (2010) revelou que programas de treinamento em equipe melhoraram os valores obtidos nos escores sobre cultura de segurança entre os profissionais e reduziram em 18\% a mortalidade decorrente de cirurgias em hospitais americanos. Os programas de treinamento implementados nesse estudo enfatizaram quatro competências principais: a liderança, o trabalho em equipe, o apoio mútuo e a comunicação. Segundo Wachter (2013), os programas de treinamento em equipe em organizações de saúde apresentam uma variedade de formas e tamanhos, mas, habitualmente, são prioridades:

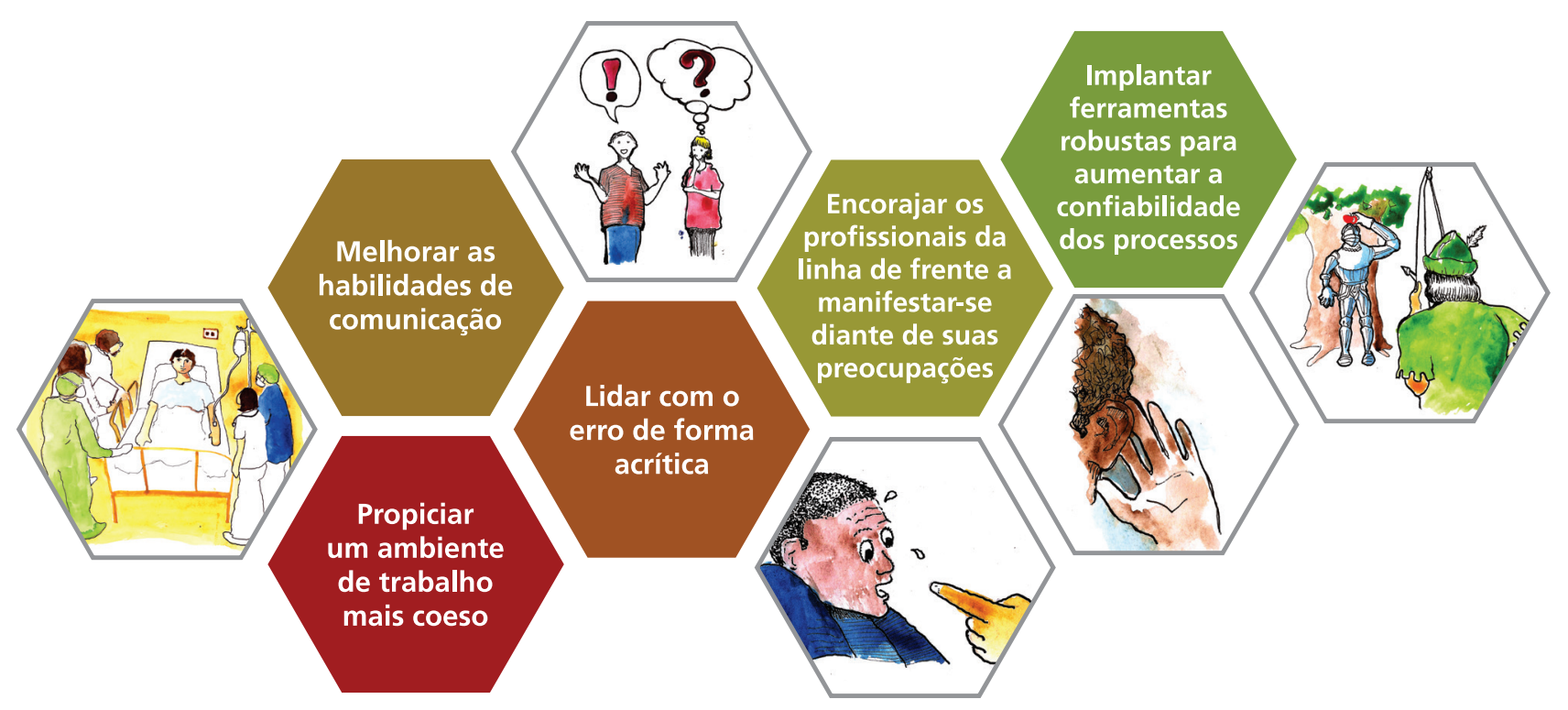




\section{Para refletir}

Quais os tópicos da lista de prioridades trabalhadas em programas de treinamento, que foram relacionadas no texto, você acredita que deveriam ser trabalhados em sua organização com objetivo de conferir maior segurança aos processos e melhores resultados?

Você sugeriria mais alguma questão a ser trabalhada que não esteja na lista?

O estudo de Schwendimann et al. (2013) mostrou o aumento nos escores da cultura de segurança em um inquérito realizado em 706 unidades hospitalares. O estudo revelou que os serviços/departamentos em que a maior parte dos profissionais participou de rondas com suas chefias (executive walkrounds) apresentaram melhores resultados relativos à cultura de segurança, com maior diminuição dos riscos relacionados à segurança e maior retorno sobre as ações implementadas a partir dos problemas levantados nas rondas realizadas. Destaca-se, nesse estudo, o envolvimento e a participação dos líderes como potenciais motivadores do fortalecimento da cultura.

Algumas ações, dentre elas a adoção de listas de verificação em processos suscetíveis a erros (checklists) e normas baseadas em sólidas evidências científicas, destacaram-se como exemplos do fortalecimento da cultura de segurança. Embora as listas de verificação não possam resolver todos os problemas de segurança, seu uso, associado a outras medidas de segurança, tais como padronização, simplificação, funções forçadas à dupla checagem, pode contribuir para a prestação do cuidado de saúde mais confiável/fiável e seguro. O estudo de Brilli et al. (2013) implementou um programa para melhoria da qualidade do cuidado de saúde baseado na prática de intervenções comuns nas organizações de alta confiabilidade/fiabilidade em um hospital pediátrico. Os autores observaram redução de $83 \%$ nos eventos adversos evitáveis, acompanhada da redução dos custos hospitalares e aumento nos escores de cultura de segurança.

\section{Considerações finais}

A cultura de segurança do paciente se reflete no comportamento dos membros de uma organização, serviço, departamento/setor ou equipe, em especial nos valores e crenças por eles partilhados, e retrata o quanto eles priorizam a segurança do paciente. Uma cultura de segurança do paciente fortalecida é caracterizada pela valorização do trabalho em 
equipe, pelo engajamento dos líderes da organização aos desafios de se proporcionar cuidados de saúde seguros, adoção de uma postura proativa desses líderes frente à ocorrência de erros, respaldada pela comunicação aberta entre os profissionais e o encorajamento da notificação/ relato de incidentes de segurança, que, por consequência, propicia o aprendizado organizacional efetivo.

Promover a cultura de segurança implica estabelecer um conjunto de intervenções enraizadas nos princípios da liderança, do trabalho em equipe, da comunicação aberta, do ambiente de contínuo aprendizado e na mudança de comportamento. As estratégias utilizadas para promover a segurança do paciente podem incluir intervenções únicas ou várias intervenções combinadas. Existe a possibilidade de elas incluírem mudanças em termos de sistema, por exemplo, na gestão, ou de estrutura, como na implantação de um sistema de relato de eventos efetivo. Diversas estratégias vêm sendo utilizadas para melhorar a cultura de segurança das quais são exemplos os treinamentos em equipe, que se referem a um conjunto de métodos estruturados visando otimizar os processos de trabalho em equipe, melhorando a comunicação, a colaboração e a liderança; e os rounds interdisciplinares em que há o engajamento das lideranças organizacionais diretamente com provedores do cuidado da linha de frente, discutindo as potenciais ameaças à segurança do paciente, partilhando responsabilidades e confiança (Weaver et al. 2013).

As organizações de saúde necessitam tornar-se resilientes, ou seja, conformar um sistema que continuamente previne, detecta, mitiga ou diminui o risco (circunstância ou agente com potencial de causar dano) ou a ocorrência de incidentes. A cultura de segurança em organizações de saúde desponta como indicador estrutural básico, facilitador de iniciativas que objetivam a redução dos riscos de incidentes e de eventos adversos nesse âmbito (AHRQ 2013b). Embora estudos recentes na literatura corroborem com essa afirmativa, diante da complexidade dos cuidados de saúde e da diversidade característica de suas organizações, estudos adicionais serão úteis para uma abordagem mais aprofundada sobre o tema. 


\section{Referências}

Agency for Healthcare Research and Quality. Culture of safety. Rockville (MD): AHRQ; 2013a [citado 2013 ago 22]. Disponível em: http://psnet.ahrq.gov/primer.aspx?primerlD=5.

Agency for Healthcare Research and Quality. Making health care safer II: an updated critical analysis of the evidence for patient safety practices. Rockville (MD): AHRQ; 2013b.

Agency for Healthcare Research and Quality. Patient safety culture surveys. Rockville (MD): AHRQ; 2010 Nov [citado 2013 ago 22]. Disponível em: http://www.ahrq.gov/qual/patientsafetyculture/

Agnew C, Flin R, Mearns K. Patient safety climate and worker safety behaviours in acute hospitals in Scotland. J Safety Res. 2013;45:95-101.

American Academy of Pediatrics (AAP); Committee on Medical Liability and Risk Management; Council on Quality Improvement and Patient Safety. Disclosure of adverse events in pediatrics. Pediatrics 2016;138(6):e20163215.

Barreiros D. Gestão da segurança e saúde no trabalho: estudo de um modelo sistêmico para as organizações do setor mineral [tese]. São Paulo: Escola Politécnica, Universidade de São Paulo; 2002.

Brilli RJ, McClead RE Jr, Crandall WV, et al. A comprehensive patient safety program can significantly reduce preventable harm, associated costs, and hospital mortality. J Pediatr. 2013. Inpress. Disponível em: http://www.sciencedirect.com/science/journal/aip/00223476 doi: 10.1016/j. jpeds.2013.

Carvalho REFL. Adaptação transcultural do Safety Attitudes Questionnaire para o Brasil; questionário de Atitudes de Segurança [tese]. Ribeirão Preto: Escola de Enfermagem de Ribeirão Preto da Universidade de São Paulo; 2011

Chassin MR, Loeb JM. The ongoing quality improvement journey: next stop, high reliability. Health Aff. 2011;30(4):559-68.

Colla JB, Bracken AC, Kinney LM, Weeks WB. Measuring patient safety climate: a review of surveys. Qual Saf Health Care. 2005; 14:364-66.

Cox SJ, Cox T. The structure of employee attitude to safety: a European example. Work Stress. $1991 ; 5: 93-106$.

Cox SJ, Flin R. Safety culture: philosopher's stone or man of straw? Work Stress. 1998;12(3):189201.

Denham CR. Trust: the 5 rights of the secod victim. J Patient Saf. 2007;3(2):107-19.

Dekker SWA. Just culture: restoring trust and accountability in your organization. 3rd ed. Burlington, VT: Ashgate; 2016.

Dekker SWA, Breakey H. "Just culture": improving safety by achieving substantive, procedural and retorative justice. Saf. Sci. 2016;85:187-93.

Eiras M, Escoval A, Grillo IM, et al. The hospital survey on patient safety culture in Portuguese hospitals: instrument validity and reliability. Int J Health Care Qual Assur. 2014;27(2):111-22.

Flin R. Measuring safety culture in healthcare: a case for accurate diagnosis. Saf Sci. 2007;45:65367.

Flin R, Burns C, Mearns K, Yule S, Robertson EM. Measuring safety climate in health care. Qual Saf Health Care. 2006;15:109-15. 
Flin R, Mearns K, O'Connor P, Bryden R. Measuring safety climate: identifying the common features Saf. Sci. 2000; 34(1-3):177-92.

Freitas ME. Cultura organizacional: o doce controle no clube dos raros. In: Motta FCP, Caldas MP, editors. Cultura organizacional e cultura brasileira. São Paulo: Atlas; 1997. p. 293-304.

Fujita S, Seto K, Kitazawa T, et al. Characteristics of unit-level patient safety culture in hospitals in Japan: a cross-sectional study. BMC Health Serv Res. 2014;14:508.

Gaba DM, Singer SJ, Sinaiko AD, et al. Differences in safety climate between hospital personnel and naval aviators. Hum Factors. 2003;45:173-85.

Gallagher TH, Studdert D, Levinson W. Disclosing harmful medical errors to patients. N Engl J Med. 2007;356(26):2713-19.

Guldenmund FW. The nature of safety culture: a review of theory and research. Saf. Sci. 2000;34:215-57.

Halligan M, Zecevic A. Safety Culture in healthcare: a review of concepts, dimensions, measures and progress. BMJ Qual Saf. 2011;20:338-43.

Hamdan M, Saleem AA. Assessment of patient safety culture in Palestinian public hospitals. Int J Qual Health Care. 2013;25(2):167-75.

Handler SM, Castle NG, Studentski SA, Perera S, Fridsma DB, Nace DA et al. Patient safety culture assessment in the nursing home. Qual Saf Health Care.2006;15:400-4.

Health and Safety Comission. Third report: organizing for safety: ACSNI Study Group on Human Factors. London: HMSO; 1993. p. 23.

Hefner JL, Hilligoss B, Knupp A, et al. Cultural transformation after implementation of a crew resource management: is it really possible? Am J Med Qual. 2016;1-7.

Hudson P. Applying the lessons of high risks industries to health care. Qual Saf Health Care 2003;12(Suppl. 1): i7-i12.

Kalra J, Massey KL, Mulla A. Disclosure of medical error: policies and practice. J R Soc Med. 2005;98(7):307-9.

Kim CW, Myung SJ, Eo EK, Chang Y. Improving disclosure of medical error trhough educational program as a first step toward patient safety. BMC Med Educ. 2017;17:52 doi 10.1186/s12909017-0880-9.

Kohn LT, Corrigan JM, Donaldson MS, editors; Committee on Quality in Health Care, Institute of Medicine. To err is human: building a safer health system. Washington DC: National Academy Press; 1999.

Lawton R, et al. Development of an evidence-based framework of factors contributing to patient safety incidents in hospital settings: a systematic review. BMJ Qual Saf. 2012 Mar 15 [citado 2019 fev 26]. Disponível em:http://qualitysafety.bmj.com/content/early/2012/03/14/bmjqs-2011-000443. abstract.

Leonard MW, Frankel A. The path to safe and reliable healthcare. Patient Educ Couns. 2010; $80: 288-92$

Marx D. Patient safety and the "just culture": a primer for health care executives. New York, NY: Columbia University; 2001.

McDonnell WM, Guenther E. Narrative review: do state laws make it easier to say "I'm sorry?" Ann Intern Med. 2008;149(11):811-6. 
Mintzberg H. Structure \& dynamique des organizations. Paris: Les Éditions d'Organisation; 1982.

Nascimento A. Sécurité des patient set culture de sécurité: une revue de lalittérature. Ciên Saúde Colet. 2011;16(8):3591-602.

Neily J, Mills PD, Young-Xu Y, et al. Association between implementation of a medical team training program and surgical mortality. JAMA. 2010; 304:1693-700.

Nieva VF, Sorra J. Safety Culture assessment: a tool for improving patient safety in health care organizations. Qual Saf Health Care. 2003;12:ii17-1123.

Olsen E. Reliability and validity of the hospital survey on patient safety culture at a Norwegian Hospital. In: Ovretveit J, Sousa PJ. Quality and safety improvement research: methods and research practice from the international quality improvement research network (QIRN). Lisboa: Escola Nacional de Saúde Pública, Universidade Nova de Lisboa; 2008. p. 173-186.

Pronovost PJ, Sexton B. Assessing safety culture: guidelines and recommendations. Qual Saf Health Care $2005 ; 14: 231-3$.

Pronovost PJ, Weast B, Bishop K, Paine L, Griffith R, Rosenstein BJ, et al. Senior executive adoptawork unit: a model for safety improvement. Jt Comm J Qual Saf. 2004; 30:59-68.

Reason J. Human error: models and management. BMJ 2000;(320):768-70.

Reis CT. A cultura de segurança do paciente: validação de um instrumento de mensuração para o contexto hospitalar brasileiro [tese]. Rio de Janeiro: Escola Nacional de Saúde Pública Sergio Arouca da Fundação Oswaldo Cruz; 2013.

Reis CT, Laguardia J, Martins M. Adaptação transcultural da versão brasileira do Hospital Survey on Patient Safety Culture: etapa inicial. Cad Saúde Públ. 2012;(28)11:2199-210.

Reis CT, Laguardia J, Vasconcelos AGG, Martins M. Reliability and validity of the Brazilian version of the Hospital Survey on Patient Safety Culture (HSOPSC): a pilot study. Cad. Saúde Públ. 2016; 32(11):e00115614.

Robb G, Seddon M. Measuring the safety culture in a hospital setting: a concept whose time has come? NZMJ. 2010; 123(1313):66-76.

Schein EH. Organizational culture and leadership. San Francisco: Jossey-Bass Publishers; 1991.

Schwendimann R, Milne J, Frush K, Ausserhofer D, Frankel A, Sexton JB. A closer look at associations between hospital leadership walkrounds and patient safety climate and risk reduction: a cross-sectional study. Am J Med Qual. 2013;20(10):1-8.

Sexton JB, Helmreich RL, Neilands TB et al. The safety attitudes questionnaire: psychometric properties, benchmarking data, and emerging research. BMC Health Serv Res. 2006;6:44.

Sorra JS, Nieva VF. Hospital survey on patient safety culture. Prepared by Westat, under Contract No. 290-96-0004. Rockville: AHRQ; Sept 2004. (AHRQ Publication No. 04-0041).

Varjavand N, Bochegowda LS, Gracely E, Novack DH. Changes in intern attitudes toward medical error and disclosure. Med Educ. 2012;46(7):668-77.

Wachter RM. Compreendendo a segurança do paciente. 2ª ed. Porto Alegre: AMGH; 2013.

Wachter RM. Personal accountability in healthcare: searching for the right balance. London: The Health Foundation; 2012 [citado 2013 Ago 2]. Disponível em: http://www. health.org.uk/public/ cms/75/76/313/3426/Personal\%20accountability\%20in\%20healthcare\%20searching\%20for\%20 the $\% 20$ right $\% 20$ balance $\% 20$ thought\%20paper.pdf?realName=Al5J91.pdf.

Wachter RM, Pronvost PJ. Balancing "no blame" with accountability in patient safety. N Engl J Med. 2009; 361:1401-06. 
Wahlberg D. Report: systemic problems at St. Mary's set stage for nurse's fatal drug error. Wis State J. 2010 Mar. 15;8.

Weaver SJ, Lubomski LH, Wilson RF, Pfoh ER, Martinez KA, Dy SM. Promoting a culture of safety as a patient safety strategy. Ann Inter Med. 2013; 158(5):369-75.

Westrum R. A typology of organizational cultures. Qual Saf Health Care. 2004;13(Suppl. 2):ii22-7.

Wolf ZR, Hughes RG. Error reporting and disclosure. In: Hughes RG. Patient safety and quality: an evidenced-base handbook for nurses. Rochville (MD): Agency for Healthcare Research and Quality; 2008.

World Health Organization (WHO). Patient safety: a global priority. Bull World Health Organ. 2004 [citado 2013 ago 2];82(12). Disponível em: http://www.who.int/bulletin/volumes/82/12/ editorial11204html/en/.

World Health Organization (WHO), World Alliance for Patient Safety: summary of the evidence on patient safety: implications for research. Geneva: WHO; 2008 [citado 2013 ago 2]. Sections III e IV, p. 49-90. Disponível em: http://whqlibdoc.who.int/publications/2008/9789241596541_eng.pdf.

World Health Organization (WHO), World Alliance for Patient Safety, Taxonomy: the conceptual framework for the international classification for patient safety. Final Technical Report. Geneva: WHO; 2009 Jan [citado 2013 jul 29]. Disponível em: http://www.who.int/patientsafety/taxonomy/ icps_full_report.pdf.

Yafang T. Relationship between organizational culture, leadership, behavior and job satisfaction. BMC Health Serv. Res. 2011;11:98.

Zhang W, Wiegmann DA, von Thaden TL, Sharma G, Mitchell AA. Safety culture: a concept inchaos? In: Proceedings of the 46th Annual Meeting of the Human Factors and Ergonomics Society; 2002. Santa Monica: Human Factors and Ergonomics Society; 2002.

Zohar D. Safety climate in industrial organizations: theoretical and applied implications. J Appl Psychol. 1980;65:96-102.

Zohar D, Livne Y, Tenne-Gazit O, Admi H, Donchin Y. Healthcare climate: a framework for measuring and improving patient safety. Crit Care Med. 2007;35:1312-7. 


\title{
5. Indicadores de segurança do paciente
}

\author{
Carla Simone Duarte de Gouvêa
}

A partir das duas últimas décadas, várias estratégias vêm sendo adotadas em diferentes países a fim de garantir cuidados de saúde mais seguros. Dentre elas, destaca-se a criação de programas para o monitoramento da qualidade e segurança com base em indicadores. Neste capítulo, serão apresentadas as principais características dos indicadores de qualidade em geral e dos indicadores específicos utilizados para monitorar a segurança do paciente.

\section{Características e atributos dos indicadores}

Um indicador é uma medida qualitativa ou quantitativa que permite conhecer em que nível determinado objetivo foi atingido. Os indicadores fornecem informação sobre determinados atributos e dimensões do estado de saúde e do desempenho do sistema de saúde (RIPSA 2002). Conforme o nome sugere, um indicador oferece pistas sobre uma situação e indica a direção a ser seguida, ou seja, ele sinaliza potenciais áreas com oportunidades de melhoria. Um indicador não é uma medida absoluta de bom ou mau desempenho, mas permite conhecer em que medida cumprimos ou não um objetivo. Eles identificam áreas ou setores em que há necessidade de maior número de investigações e análises para compreensão abrangente dos fatos e tomada de decisões mais acertadas. Seu uso permite a mensuração e o monitoramento da qualidade dos serviços, programas e sistemas de saúde, em geral. 
Taxa - variação de uma medida y em função da variação de uma medida $x$. A taxa é sempre referida a um período definido.

Razão - quociente entre duas medidas, em que o denominador não inclui o numerador.

Proporção - quociente entre duas medidas, em que o numerador está incluído no denominador.
O monitoramento de indicadores é "uma atividade planificada e sistemática para identificar problemas ou situações que devem ser estudadas de forma profunda ou ser objeto de intervenção para melhorar" (Anvisa 2013).

O monitoramento dos cuidados prestados aos pacientes, por meio de indicadores, permite:

滕 orientar a formulação e a hierarquização de políticas;

橉 monitorizar a melhoria de cuidados de saúde;

promover maior transparência das organizações de saúde;

滕 permitir que os usuários/utentes façam escolhas mais informadas.

Nesse contexto, pode-se dizer que um indicador expressa as ações de uma organização ou de um sistema de saúde em direção à melhoria da qualidade. Um indicador pode ser expresso como uma taxa, uma razão, uma proporção ou um evento (um número absoluto).

Para ser útil, um indicador deve conter alguns atributos, descritos no Quadro 1.

Quadro 1 - Atributos de um bom indicador

\begin{tabular}{|l|l|}
\hline Atributo & Definição \\
\hline Validade & Capacidade de medir o que se pretende. \\
\hline Sensibilidade & Capacidade de detectar o fenômeno analisado. \\
\hline Especificidade & Capacidade de detectar somente o fenômeno analisado. \\
\hline $\begin{array}{l}\text { Confiabilidade/ } \\
\text { Fiabilidade }\end{array}$ & $\begin{array}{l}\text { Capacidade de reproduzir os mesmos resultados quando aplicado em } \\
\text { condições similares. }\end{array}$ \\
\hline Viabilidade & Os dados estão disponíveis ou são fáceis de conseguir. \\
\hline Relevância & Responde às prioridades de saúde. \\
\hline Custo-efetividade & Os resultados justificam o investimento de tempo e recursos. \\
\hline
\end{tabular}

Fonte: RIPSA (2002). 


\section{Para praticar}

Faça a leitura do artigo "Uso de indicadores da qualidade para avaliação de prestadores de serviços públicos de odontologia: um estudo de caso" de Schelle Aldrei de Lima da Soller e Gilsée Ivan Regis Filho (2011), disponível em: http://www.scielo.br/pdf/rap/v45n3/03.pdf.

Identifique, no texto, as características de um bom indicador apresentadas pelos autores e compare-as aos atributos do Quadro 1.

Quando se pretende avaliar a qualidade dos cuidados de saúde, são vários os modelos que estão ao dispor. O modelo mais conhecido e amplamente utilizado, um pouco por todo o mundo, é o proposto por Donabedian (1988). Conhecido como a tríade de Donabedian, ele é composto de três componentes: estrutura, processo e resultado. A estrutura corresponde aos atributos dos setores em que os cuidados são prestados, o que inclui os recursos físicos, humanos, materiais e financeiros; o processo corresponde ao conjunto de atividades desenvolvidas durante a prestação de cuidados; e o resultado (outcome) corresponde ao efeito do cuidado no estado de saúde do paciente e das populações. Os outcomes podem ser de tipo clínico - por exemplo, morte, complicações; econômicos - por exemplo, dias de internação/internamento; custos diretos; ou resultados na perspectiva do paciente - por exemplo, grau de satisfação, qualidade de vida.

Ao se utilizar um indicador de processo, busca-se avaliar o que foi feito em um paciente ao longo da prestação dos cuidados de saúde. Para ser válido, deve existir evidência demonstrando que os processos avaliados conduzem a melhores resultados para os pacientes.

De modo semelhante, a validade de um indicador de estrutura está relacionada à comprovação de que os componentes estruturais aumentam a probabilidade de bons resultados, ou estão relacionados a processos que produzem essa melhoria nos resultados. Porém, é bom lembrar que boas condições estruturais, por si só, não garantem que os processos de cuidados sejam realizados de forma correta e efetiva.

Quanto aos indicadores de resultado, um aspecto importante a se considerar são os múltiplos fatores que interferem no estado de saúde dos pacientes. Variações nas características demográficas e condições clínicas dos pacientes, além do cuidado recebido, aumentam a possibilidade de resultados diferenciados. Para controlar essas características, são empregadas diferentes metodologias por meio de procedimentos de ajustamento de risco, por vezes bastante complexos, mas necessários para garantir análises e comparações mais fidedignas (Souza et al. 2007).
Sobre a tríade de Donabedian, sugerimos que você reveja o Capítulo 1, Qualidade do cuidado de saúde, do livro Segurança do paciente: conhecendo os riscos nas organizações de saúde.

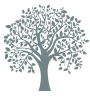

Para aprofundar o conhecimento a esse respeito, leia o artigo de Jain Mainz: Defining and classifying clinical indicators for quality improvement. Int J Qual Health Care. 2003 [citado 2014 jan 3];15:523-30. Disponível em: http://intqhc.oxfordjournals. org/content/15/6/523. full. pdf + html. 
Outra questão importante a ser considerada sobre indicadores de qualidade, especialmente aqueles usados em comparações e relatórios públicos, é a possibilidade de ocorrerem "efeitos ou consequências indesejáveis" decorrentes de sua utilização. No caso dos indicadores de processo, Chassin et al. (2010) dão como exemplo o indicador "administração da primeira dose de antibiótico para um paciente com pneumonia comunitária, nas primeiras quatro horas após a chegada ao hospital". Embora existam evidências de que esse processo melhore os resultados, seu uso indiscriminado ocasionou a administração inadequada de antibióticos a pacientes que não tinham pneumonia (Chassin et al. 2010).

Em projetos de melhoria da qualidade é importante estar atento, também, ao monitoramento de indicadores de equilíbrio (ou "balanço"), que podem ser definidos como marcadores de consequências não desejadas relacionadas às próprias ações de melhoria (McQuillan et al. 2016). Um exemplo de indicador de equilíbrio é a taxa de reintubação em pacientes de unidades de terapia intensiva (UTI), para monitoramento de eventuais eventos indesejados relacionados às ações de melhoria voltadas à redução do tempo em ventilação mecânica.

\section{Ficha técnica de indicadores}

Para cada indicador, é importante que se elabore uma ficha técnica contendo informações que dispõem sobre suas características e ajudam a sua construção e análise dos resultados. Há vários modelos de ficha técnica, disponíveis, com diferentes tipos de informações. Não há nenhum conjunto de regras explícitas e gerais que se aplique a todas as fichas técnicas; existem, porém, elementos mínimos que devem ser contemplados quando de sua elaboração. Cada organização de saúde deve acrescentar as informações que julgar necessárias para atender as suas especificidades, tais como: meta prevista para o indicador; periodicidade da coleta e análise de dados; responsável pela coleta dos dados e análise dos resultados do indicador; entre outras.

Observe o Quadro 2 em que estão listados os componentes mínimos de uma ficha técnica de indicador e suas definições.

Quadro 2 - Modelo de ficha técnica de indicador

Título: Nome do indicador; representa uma descrição sucinta, objetiva e rapidamente compreensível do objetivo do indicador.

Origem: Organização(ões) responsável(eis) pelo desenvolvimento do indicador.

Nível da informação: Estrutura, processo ou resultado. 
Quadro 2 - Modelo de ficha técnica de indicador (cont.)

Dimensão da qualidade: Classificação do indicador conforme a(s) dimensão(ões) da qualidade atribuída(s) pela(s) organização(ões) que desenvolveu(ram), por exemplo: segurança, efetividade, eficiência, entre outras.

Descrição do numerador (se for o caso): Inclui as especificações gerais de qualquer componente clínico, que forma a base para as inclusões e exclusões no numerador.
Descrição do denominador (se for o caso): Inclui as especificações gerais de qualquer componente clínico, que forma a base para as inclusões e exclusões no denominador.

Método de cálculo: Fórmula utilizada para calcular o indicador, definindo precisamente os elementos que a compõem.

Definição de termos: Descrição dos conceitos e termos utilizados na construção do indicador, necessários para sua melhor compreensão.

Racionalidade (rationale): Justificativa e evidência científica que suporta a implementação do indicador.

Ajustamento de risco: Método e/ou variáveis utilizadas para controlar as possíveis variações nos resultados do indicador, em decorrência de diferentes perfis de pacientes.

Estratificação: Categorias ou grupos de classificação dos dados do indicador com o intuito de aumentar sua capacidade de comparação. Por exemplo: tipo de organização de saúde; setor do cuidado; faixa etária e outros.

Interpretação: Explicação sucinta sobre o tipo de informação obtida e seu significado.

Limitações: Fatores que restringem a interpretação do indicador, referentes tanto ao próprio conceito como às fontes utilizadas.

Fonte dos dados: Fonte primária de onde os dados podem ser obtidos e/ou o(s) sistema(s) de informações que fornece $(m)$ os dados.

Fonte: Gouvêa (2011); RIPSA (2002).

\section{Indicadores de segurança do paciente}

A segurança é uma dimensão da qualidade em saúde. Um indicador de segurança do paciente pode ser definido como um indicador de desempenho que busca identificar, obter informação e monitorar a ocorrência de incidentes.

Para a área hospitalar, em 2002, a Agency for Healthcare Research and Quality (AHRQ) dos EUA desenvolveu indicadores de segurança do paciente (patient safety indicators - PSI), construídos com dados de bancos administrativos e identificados a partir de códigos da Classificação Internacional de Doenças, 9a Revisão, com Modificação Clínica (CID-9-MC) (McDonald et al. 2002). Inicialmente foram publicados 20 indicadores, cujos dados são obtidos de diagnósticos secundários das internações/internamentos. Sete desses indicadores podem ser usados para avaliar a segurança em uma área geográfica. Nesse caso, os dados são provenientes dos diagnósticos principais e secundários, possibilitando a identificação das primeiras internações/ internamentos e reinternações/reinternamentos em um mesmo hos- 
pital ou em hospitais diferentes. A AHRQ desenvolveu, também, uma medida composta que reúne dados de vários indicadores.

Os indicadores de segurança do paciente da AHRQ são definidos como:

indicadores da qualidade específicos que também refletem a qualidade do cuidado nos hospitais, mas focam em aspectos da segurança do paciente. Especificamente, os PSI rastreiam problemas que os pacientes vivenciam como resultado da exposição ao sistema de saúde, e que são susceptíveis à prevenção, através de mudanças ao nível do sistema ou do prestador (McDonald et al. 2002).

A seguir, no Quadro 3, estão listados os indicadores desenvolvidos e utilizados atualmente pela AHRQ (2017), e que foram adaptados para a Classificação Internacional de Doenças, $10^{a}$ Revisão (CID 10).

Quadro 3 - Indicadores de segurança do paciente desenvolvidos pela Agency for Healthcare Research and Quality, adaptados para CID 10

\begin{tabular}{|l|}
\hline Indicadores \\
\hline Taxa de mortalidade de pacientes cirúrgicos com graves condições tratáveis \\
\hline $\begin{array}{l}\text { Número de itens cirúrgicos retidos no corpo e/ou fragmentos de dispositivos não recuperados do } \\
\text { corpo* }\end{array}$ \\
\hline Taxa de infecção relacionada a cateter venoso depois de central \\
\hline Taxa de deiscência de ferida pós-operatória* \\
\hline Taxa de lesão renal aguda pós-operatória que exige diálise \\
\hline Taxa de embolia pulmonar ou trombose venosa profunda pós-operatórias Excluir asterisco \\
\hline Taxa de falência respiratória pós-operatória \\
\hline Taxa de queda com fratura de quadril/fratura de anca \\
\hline Taxa de hemorragia ou hematoma pós-operatórios* \\
\hline Taxa de óbitos em Grupos Diagnósticos Homogéneos (GDH) Relacionados (DRGs)** de baixa \\
mortalidade
\end{tabular}


Quadro 3 - Indicadores de segurança do paciente desenvolvidos pela Agency for Healthcare Researcha and Quality, adaptados para CID 10 (cont).

\begin{tabular}{l}
\hline Taxa de lesões no neonato (trauma no nascimento) \\
\hline Taxa de trauma obstétrico em partos vaginais com instrumentação \\
\hline Taxa de trauma obstétrico em partos vaginais sem instrumentação \\
\hline Indicador de segurança do paciente composto (composição de PSIs selecionados) \\
Fonte: AHRQ (2017). \\
* Indicadores também utilizados na avaliação de uma área geográfica. \\
** DRG - Diagnosis Related Groups: sistema de classificação de pacientes internados em hospitais que \\
atendem casos agudos, desenvolvido nos EUA.
\end{tabular}

A partir do trabalho da AHRQ, outros indicadores de segurança do paciente para hospitais foram desenvolvidos (Gouvêa, Travassos 2010). Dentre essasiniciativas, destaca-se o projeto europeu de desenvolvimento de indicadores de segurança do paciente da Organisation for Economic Cooperation and Development (OECD) e o Projeto Safety Improvement for Patients in Europe (SimPatIE) (McLoughlin et al. 2006; Kristensen et al. 2009).

O trabalho da AHRQ influencia muito a seleção de indicadores de outras agências internacionais em função, particularmente, de sua validade mais bem estudada em inúmeras pesquisas. A generalização desses indicadores tem a ver com a adaptação para a CID $10^{\mathrm{a}}$ Revisão utilizada em vários países, inclusive no Brasil e em Portugal (Quan et al. 2008). Também tem estimulado o desenvolvimento de pesquisas que avaliam sua aplicabilidade nas bases de dados de tipo administrativo de diferentes países e a possibilidade de comparações internacionais (Drösler et al. 2009, Drösler et al. 2012). Em Portugal, dados sobre 17 indicadores de segurança da AHRQ, no período de 2000 a 2005, foram utilizados para avaliar o Sistema Público de Saúde (Rocha et al. 2008). Os resultados mostraram taxas mais baixas em Portugal, o que poderia estar refletindo diferentes processos de codificação diagnóstica, entre outros fatores.

No Brasil, a possibilidade de uso dos indicadores de segurança do paciente da AHRQ é limitada pelo baixo preenchimento do diagnóstico secundário previsto na base de dados de tipo administrativo do Sistema de Informações Hospitalares do Sistema Único de Saúde (SIH-SUS) (Lobato et al. 2008).

Na atualidade, observa-se que o conjunto de indicadores mais utilizados pelas organizações de saúde tem abrangido resultados, práticas e processos específicos em áreas em que a ocorrência de problemas na 


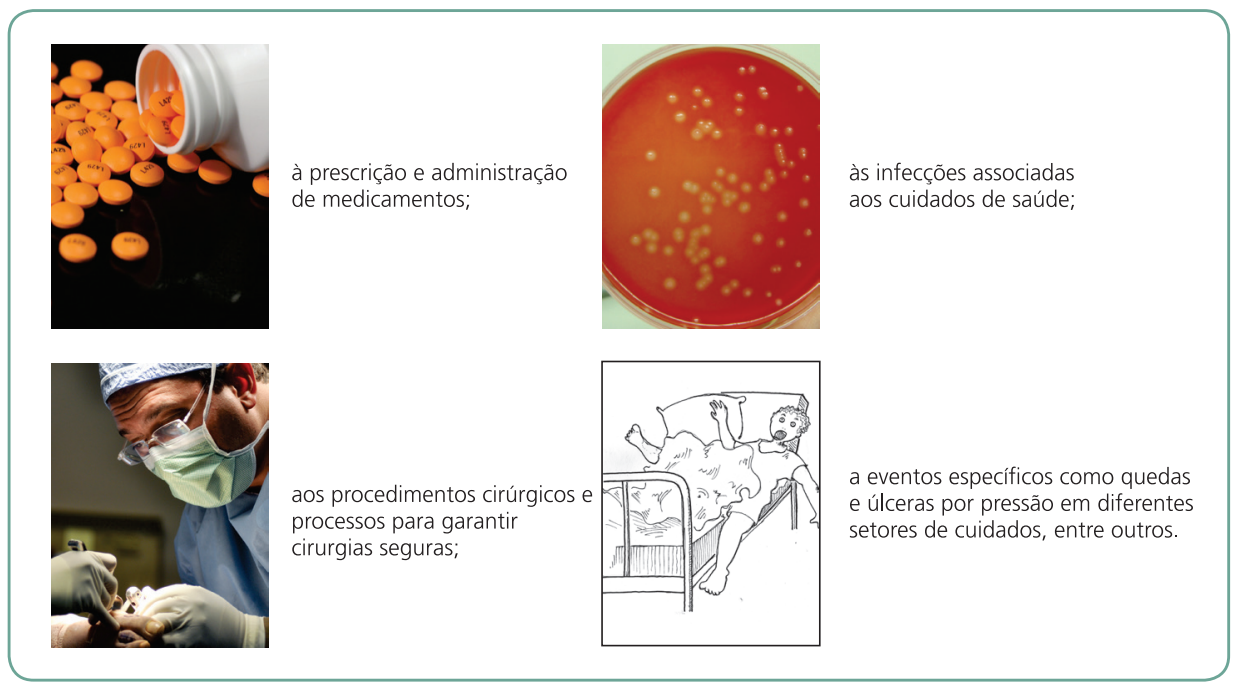

Fonte: Ragesoss (2008), Pandora (2011), Mutter (2010).

\section{Para refletir}

Sua organização utiliza algum tipo de indicador para avaliar a segurança do paciente? Quais?

No caso de resposta positiva, que tipo de ações são implementadas para alcançar melhorias?

Em caso de resposta negativa, a que você atribui a ausência desse tipo de avaliação?

Para aprofundar esses pontos, sugere-se a consulta dos websites das instituições referidas: www.dgs.pt; www. acss.pt; www.ers.pt segurança é mais frequente. Por exemplo, indicadores relacionados:

Em Portugal, a Direção-Geral da Saúde, a Administração Central do Sistema de Saúde e a Entidade Reguladora da Saúde (nomeadamente por meio do projeto SINAS Hospitais) têm desenvolvido e implementado programas de avaliação de indicadores de desempenho, de qualidade de cuidados e de segurança do paciente.

O Programa Nacional de Segurança do Paciente (PNSP), lançado pelo Ministério da Saúde brasileiro, em 2013, orienta a adoção de indicadores de monitoramento incluídos nos protocolos definidos:

protocolo para cirurgia segura;

蝶 protocolo para a prática de higiene das mãos em serviços de saúde;

protocolo para prevenção de úlcera por pressão;

protocolo de identificação do paciente;

啮 protocolo de prevenção de quedas; e

protocolo de segurança na prescrição, uso e administração de medicamentos (Ministério da Saúde 2013). 


\section{No Quadro 4, a seguir, estão descritos os indicadores previstos no PNSP.}

Quadro 4 - Indicadores de segurança do paciente propostos no Programa Nacional de Segurança do Paciente (Brasil)

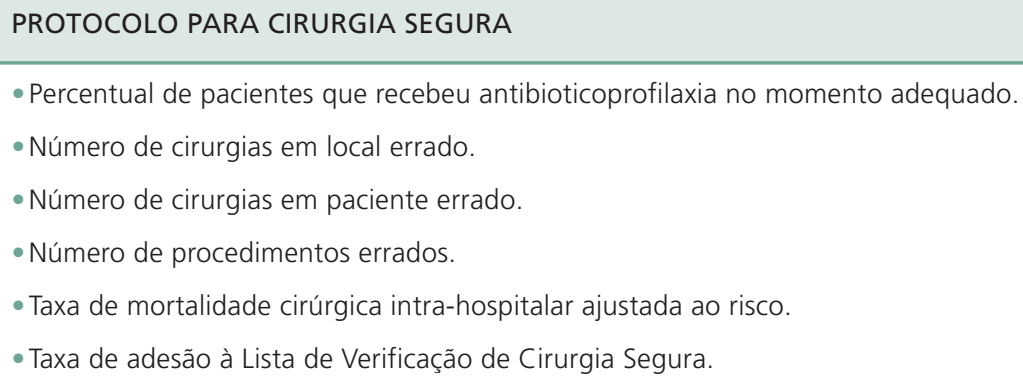

- Percentual de pacientes que recebeu antibioticoprofilaxia no momento adequado.

- Número de cirurgias em local errado.

- Número de cirurgias em paciente errado.

- Número de procedimentos errados.

- Taxa de mortalidade cirúrgica intra-hospitalar ajustada ao risco.

- Taxa de adesão à Lista de Verificação de Cirurgia Segura.

\section{PROTOCOLO PARA A PRÁTICA DE HIGIENE DAS MÃOS EM SERVIÇOS DE SAÚDE}

Indicador obrigatório

- Consumo de preparação alcoólica para as mãos: monitoramento do volume de preparação alcoólica para as mãos utilizado para cada 1.000 pacientes-dia.

- Consumo de sabonete: monitoramento do volume de sabonete líquido associado ou não a antisséptico utilizado para cada 1.000 pacientes-dia.

Indicador recomendável

- Percentual de adesão: número de ações de higiene das mãos realizadas pelos profissionais de saúde/número de oportunidades ocorridas para higiene das mãos, multiplicado por 100.

\section{PROTOCOLO PARA PREVENÇÃO DE ÚLCERA POR PRESSÃO - UPP}

- Percentual de pacientes submetidos à avaliação de risco para UPP na admissão.

- Percentual de pacientes de risco recebendo cuidado preventivo apropriado para UPP.

- Percentual de pacientes recebendo avaliação diária para risco de UPP5.

- Incidência de UPP.

\section{PROTOCOLO DE PREVENÇÃO DE QUEDAS}

- Proporção de pacientes com avaliação de risco de queda realizada na admissão.

- Número de quedas com dano.

- Número de quedas sem dano.

- Índice de quedas [(n. de eventos / n. de paciente-dia)*1.000].

\section{PROTOCOLO DE IDENTIFICAÇÃO DO PACIENTE}

- Número de eventos adversos devido a falhas na identificação do paciente.

- Proporção de pacientes com pulseiras padronizadas entre os pacientes atendidos nas instituições de saúde.

PROTOCOLO DE SEGURANÇA NA PRESCRIÇÃO, USO E ADMINISTRAÇÃO DE MEDICAMENTOS

- Taxa de erros na prescrição de medicamentos. 
Para praticar

Classifique os indicadores propostos pelo Programa Nacional de Segurança do Paciente de acordo com a tríade de Donabedian (1988).

O monitoramento, por meio de indicadores, constitui-se importante instrumento para auxiliar na identificação de áreas que precisam ser mais bem-estudadas, tendo em vista a melhoria da qualidade dos cuidados prestados aos pacientes. Vários países da Europa decidiram que a base de seus programas de avaliação e melhoria de qualidade e segurança assentaria, em parte, na definição, análise, monitorização e avaliação de indicadores. São deles exemplos Holanda, Alemanha, Suécia, Dinamarca, para referir apenas alguns.

No Brasil, um conjunto de indicadores de segurança do paciente para hospitais de pacientes agudos, foi divulgado no Portal Proqualis. Estes indicadores foram desenvolvidos após revisão sistemática da literatura (Gouvêa, Travassos 2010; Travassos et al. 2014), seleção e adaptação ao contexto nacional mediante o olhar de especialistas de diferentes áreas de conhecimento - profissionais da saúde, gestores e acadêmicos, por meio do Método Delphi em duas rodadas, e da Técnica de Grupo Nominal, ambos realizados com recursos de comunicação a distância pela Internet (Gouvêa 2011, Travassos et al. 2014).

Criado em 2009, o Proqualis é uma iniciativa brasileira direcionada à produção e disseminação de informações e tecnologias em qualidade e segurança do paciente. Vinculado ao Instituto de Comunicação e Informação Científica e Tecnológica em Saúde da Fundação Oswaldo Cruz (Icict/Fiocruz), conta com financiamento do Ministério da Saúde por intermédio da Secretaria de Atenção à Saúde.

São 96 indicadores hospitalares de segurança do paciente, classificados nos seguintes grupos:

a) 26 relacionados à prevenção e controle de infecções;

b) 26 relacionados ao uso de medicamentos;

c) 11 clínicos;

d) 8 relacionados às unidades de terapia intensiva de adultos;

e) 15 relacionados à anestesia e cirurgia;

f) 10 relacionados à ginecologia e obstetrícia. 
São indicadores válidos e de reconhecida relevância, selecionados por consenso de especialistas brasileiros. As especificações técnicas de cada um deles estão disponíveis em Fichas Técnicas, possibilitando sua construção e uso pelos diferentes serviços.

Em iniciativa também pioneira, o Projeto ISEP-Brasil (Gama et al. 2016), realizado entre 2012 e 2014, desenvolveu e validou um conjunto de indicadores de boas práticas para mensuração do nível de segurança em hospitais brasileiros que permite identificar pontos prioritários para ações de melhoria. O projeto aprovou 75 indicadores de boas práticas ( 39 de estrutura e 36 de processo) relacionados a 31 das 34 boas práticas de segurança do paciente recomendadas pelo National Quality Forum (NQF 2010). Os indicadores têm como fonte dos dados a observação direta, a revisão de prontuário e outros documentos, a entrevista com profissionais de saúde, o questionário e a auditoria.

Ao se utilizarem indicadores de segurança do paciente, alguns aspectos devem ser considerados. A escassa validade de alguns indicadores implica análises pouco fidedignas. Muitos indicadores de estrutura e processo carecem de evidência científica robusta que os vinculem aos resultados alcançados. As fontes de dados dos indicadores de segurança do paciente são, principalmente, os sistemas de notificação de incidentes, os prontuários dos pacientes/processos clínicos e as bases de dados administrativos. Essas fontes de dados podem, em função de baixo registro, falsear a frequência de incidentes. A ocorrência de incidentes, geralmente pouco notificados pelo receio de ações punitivas, pode rotular, de forma equivocada, as organizações com melhores sistemas de notificação de incidentes, como de "baixa qualidade", em virtude de suas inesperadas "taxas elevadas" (Pronovost et al. 2006). De modo semelhante, muitos incidentes também não são registrados nos prontuários/processos clínicos. Quanto às bases de dados administrativos, embora representem uma fonte com grande volume de dados, é limitada em sua capacidade de identificar e descrever incidentes relacionados à qualidade e segurança do paciente.

Por via de regra, é comum não haver dados disponíveis de boa qualidade para avaliar os cuidados prestados. A fim de atenuar essa situação, a Organização Mundial de Saúde (WHO 2010) propõe cinco métodos de avaliação de incidentes para ambientes hospitalares em que os dados disponíveis são de baixa qualidade, nomeadamente: 
Os cinco métodos: A revisão retrospectiva de prontuários/processos clínicos.

A revisão de prontuários/processos clínicos abertos (de pacientes que estão sendo assistidos).

Entrevistas com a equipe de profissionais de saúde sobre pacientes internados.

Observação direta e entrevistas.

Grupos nominais.

Indicadores e dimensões da qualidade também foram tratados no Capítulo 1, "Qualidade do cuidado de saúde", do livro Segurança do paciente: conhecendo os riscos nas organizações de saúde.

\section{Para refletir}

Em sua organização, existem indicadores de estrutura (por exemplo, número de enfermeiros por leito/cama), processo (por exemplo, taxa de prescrição de betabloqueador na alta hospitalar) e resultado (por exemplo, taxa de mortalidade hospitalar) para monitorar a qualidade dos cuidados prestados? Quais são os mais utilizados para ações de melhoria da qualidade?

Como você os classificaria com relação às dimensões da qualidade?

Como você avalia os dados disponíveis em sua organização? Seriam fontes confiáveis/fiáveis para avaliação?

Em caso negativo, que fatores você acredita serem determinantes para esse quadro? O que poderia ser feito para melhorá-lo?

\section{Considerações finais}

Independentemente do ambiente de cuidado, é importante que a seleção de indicadores de segurança do paciente priorize aqueles com comprovada evidência científica, relacionados a situações com impacto sobre a saúde e a segurança dos pacientes, e cujos resultados, obtidos por meio de seu monitoramento, possam ser influenciados por ações do sistema de saúde. Por certo, deve-se considerar a qualidade dos dados disponíveis e os custos envolvidos para sua obtenção ou de novos dados. Nenhum indicador, entretanto, é perfeito para todas as finalidades. Potencialidades e limitações dos distintos tipos de indicadores determinam a tendência de, sempre que possível, utilizar-se uma combinação de diferentes tipos de medidas com o objetivo de avaliar estruturas, processos e resultados. 


\section{Referências}

Agência Nacional de Vigilância Sanitária (BR), Gerência de Vigilância e Monitoramento em Serviços de Saúde (GVIMS), Gerência Geral de Tecnologia em Serviços de Saúde (GGTES). Assistência segura: uma reflexão teórica aplicada à prática. Brasília, DF: Anvisa; 2013. (Série Segurança do Paciente e Qualidade em Serviços de Saúde).

Agency for Healthcare Research and Quality. Patient safety indicators technical specifications. Version 4.5. Rockville (MD): ARHQ; 2013 [citado 2017 nov 20]. Disponível em: https://www. qualityindicators.ahrq.gov/Modules/psi_resources.aspx.

Agency for Healthcare Research and Quality. Patient Safety Indicators Technical Specifications Updates - Version v7.0 (ICD 10), September 2017 Disponível em: https://www.qualityindicators. ahrq.gov/Modules/PSI_TechSpec_ICD10_v70.aspx. Acesso em: 24/1/2017.

Chassin MR et al. Accountability measures to promote quality improvement. Engl J Med. 2010 Nov $11 ; 363: 1975-76$.

Donabedian A. The quality of care: how can it be assessed? JAMA. 1988 Sep;260(12):1743-48, Sept. 1988.

Drösler SE, Klazinga NS, Romano PS et al. Application of patient safety indicators internationally: a pilot study among seven countries. Int J Qual Health Care. 2009 Aug;21(4):272-8.

Drösler SE, Romano PS, Tancredi DJ, Klazinga NS. International comparability of patient safety indicators in 15 OECD member countries: a methodological approach of adjustment by secondary diagnoses. Health Serv Res. 2012;47(1 Pt 1):275-292. doi:10.1111/j.1475-6773.2011.01290.x.

Gama ZAS, Saturno-Hernández PJ, Ribeiro DNC, et al. Desenvolvimento e validação de indicadores de boas práticas de segurança do paciente: Projeto ISEP-Brasil. Cad. Saúde Pública. 2016 [cited 2017 nov 24];32(9): e00026215. Disponível em: http://www.scielo.br/scielo. php?script=sci_arttext\&pid=S0102-311X2016000905002\&lng=en. http://dx.doi.org/10.1590/0102311X00026215. Epub Sep 19, 2016.

Gouvêa CSD. Desenvolvimento de indicadores de segurança do paciente para hospitais de pacientes agudos [Tese]. Rio de Janeiro: Escola Nacional de Saúde Pública Sergio Arouca; 2011.

Gouvêa CSD, Travassos C. Indicadores de segurança do paciente para hospitais de pacientes agudos: revisão sistemática. Cad. Saúde Pública. 2010 Jun;26(6):1061-78.

Kristensen S, Mainz J, and Bartels P. Selection of indicators for continuous monitoring of patient safety: recommendations of the project 'safety improvement for patients in Europe'. Int J Qual Health Care. 2009;21(3): 169-75. doi:10.1093/intqhc/mzp015.

Lobato G; Reichenheim ME, Coeli CM. Sistema de informações hospitalares do sistema único de saúde (SIH-SUS): uma avaliação preliminar do seu desempenho no monitoramento da doença hemolítica perinatal Rh(D). Cad. Saúde Pública. 2008;24(3):606-14.

Mainz J. Defining and classifying clinical indicators for quality improvement. Int J Qual Health Care. 2003; 15:523-30.

McDonald KM, Romano PS, Geppert J, et al. Measures of patient safety based on hospital administrative data - the patient safety indicators. Rockville (MD): Agency for Healthcare Research and Quality; 2002. (Technical reviews, no. 5.).

McLoughlin V, Millar J, Mattke S, Franca M, Jonsson PM, Somekh D, et al. Selecting indicators for patient safety at the health system level in OECD countries. Int J Qual Health Care. 2006; 18(Suppl 1):14-20.

McQuillan RF, Silver SA, Harel Z et al. How to measure and interpret quality improvement data. Clin J Am Soc Nephrol. 2016 May 6;11(5):908-14. doi: 10.2215/CJN.11511015. Epub 2016 Mar 25. 
Ministério da Saúde (BR). Protocolos básicos de segurança do paciente. Brasília, DF: MS; 2013 [citado 2014 ago 2]. Disponível em: http://portal.saude.gov.br/portal/saude/Gestor/visualizar_texto. $\mathrm{cfm}$ ?idtxt=43104\&janela $=$.

National Quality Forum. Safe practices for better healthcare: 2010 update: A consensus report. Washington, DC: NQF; 2010.

Pandora N. Ficheiro: Streptococcus agalactiae.jpg. Wikipedia, 2011 [citado 2019 jan 23]. Disponível em: https://commons.wikimedia.org/wiki/File:Streptococcus_agalactiae.jpg

Pronovost PJ, Miller MR, Wachter RM. Tracking progress in patient safety: an elusive target. JAMA. 2006;296(6):696-9. doi:10.1001/jama.296.6.696.

Pronovost P, Needham D, Berenholtz S, Sinopoli D, Chu H, Cosgrove S et al. An intervention to decrease catheter-related bloodstream infections in the ICU. N Engl J Med. 2006 Dec 28;355(26):2725-32.

Quan H, Drösler S, Sundararajan V et al. Adaptation of AHRQ Patient Safety Indicators for Use in ICD-10 Administrative Data by an International Consortium. In: Henriksen K, Battles JB, Keyes MA, Grady ML, editors. Advances in patient safety: new directions and alternative approaches. Rockville (MD): AHRQ; 2008. vol. 1: Assessment.

Ragesoss. Ficheiro:Regular strength enteric coated aspirin tablets.jpg. Wikipedia, 2008 [citado 2019 jan 23]. Disponível em: https://commons.wikimedia.org/wiki/File:Regular_strength_enteric_coated_ aspirin_tablets.jpg

Rede Interagencial de Informações para a Saúde (RIPSA). Indicadores básicos para a saúde no Brasil: conceitos e aplicações. Brasília, DF: RIPSA; 2002.

Rocha A, Santos A, Cardoso C et al. Patient safety indicators in Portuguese hospitals: a way to improve healthcare. Porto: Faculdade de Medicina; 2008. Disponível em: http://medicina.med. up.pt/im/trabalhos07_08/www/t22/Site\%20Class\%2022/index.htm.

Soller SAL, Regis Filho GI. Uso de indicadores da qualidade para avaliação de prestadores de serviços públicos de odontologia: um estudo de caso. Rev. Adm. Pública. 2011;45(3):591-610.

Souza RC, Pinheiro RS, Coeli CM de et al. Aplicação de medidas de ajuste de risco para a mortalidade após fratura proximal de fêmur. Rev. Saúde Pública. 2007;41(4):625-31.

Travassos C et al. Desenvolvimento de indicadores para monitoramento da segurança do paciente em hospitais de pacientes agudos: relatório de pesquisa apresentado ao CNPq. Rio de Janeiro: Fiocruz; 2014.

World Health Organization. Assessing and tackling patient harm: a methodological guide for datapoor hospitals. Geneva: WHO; 2010. 


\section{Saúde do trabalhador, ergonomia e segurança do paciente}

António de Sousa-Uva e Florentino Serranheira

Considere situações de risco como a mobilização de pacientes, a administração de medicação e as infeções associadas aos cuidados de saúde (IACS).

Quais os elementos, em cada situação de trabalho, que estão ligados às relações entre a segurança do paciente e a segurança do prestador de cuidado? Como prevenir o erro e o evento adverso nessas situações?

Neste capítulo, pretende-se dar resposta às seguintes questões:

Será que as condições de trabalho e a atividade dos profissionais de saúde podem contribuir para maior ocorrência de erros associados à prestação de cuidados de saúde e eventos adversos?

Em caso afirmativo, qual a sua importância relativa nessas ocorrências?

\section{3. \\ (1)}

Procure saber mais sobre essas questões no texto: Serranheira F, Uva AS, Sousa P, Leite ES. Segurança do doente e saúde e segurança dos profissionais de saúde: duas faces da mesma moeda. Saúde \&Trab. 2009;7:5-29.

\section{Relações entre a segurança do paciente e a saúde do trabalhador}

Tudo leva a crer que as relações entre a segurança do paciente e a saúde e segurança do trabalhador da área de saúde influenciam, concretamente, os resultados em saúde (AHRQ 2003):

䟢 na organização do trabalho, por exemplo, o staff e os fluxos de trabalho podem influenciar a taxa de erros e a ocorrência de incidentes (entre outros, as infeções nosocomiais, as úlceras por pressão e as quedas);

* na existência de mecanismos de diminuição das interrupções e das distrações que reduzem a incidência de erros; e 
Para relembrar esse tema, releia - Capítulo 3,"Taxonomia em segurança do paciente", do livro Segurança do paciente: conhecendo os riscos nas organizações de saúde.

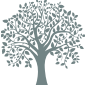

Para ajudá-lo a responder a essa questão, é importante que leia os artigos:

- Serranheira F, Uva AS, Sousa $P$, Leite ES. Segurança do doente e saúde e segurança dos profissionais de saúde: duas faces da mesma moeda. Saúde \& Trab. 2009;7:5-29.

- Serranheira F, Uva AS, Sousa P. Ergonomia hospitalar e segurança do doente: mais convergências que divergências. Rev Port Saúde Pública. 2010; Vol Temat(10):58-73.

Situação de trabalho é o sistema que engloba o trabalhador, o posto de trabalho e a organização em que esse posto se integra.

Sistema representa as componentes físicas, cognitivas e organizacionais com as quais a pessoa interage. Assim, sistema pode ser uma tecnologia ou um instrumento; um trabalhador, uma equipa ou uma organização; um processo, uma orientação política ou uma diretriz; pode ser até todo o envolvimento físico e/ou organizacional (Carayon 2007)
蝶 por existirem menos complicações evitáveis em procedimentos técnicos complexos, quando os profissionais de saúde os praticam frequentemente.

A taxonomia utilizada em segurança do paciente inclui, no conceito de incidente, as seguintes situações: circunstâncias notificáveis; near misses; incidentes sem danos; e eventos adversos (também denominados incidentes com dano). É importante referir, nesse contexto, que as denominações utilizadas em saúde do trabalhador e ergonomia não são idênticas. Apenas a título de exemplo, um incidente com dano denomina-se acidente de trabalho (ou doença profissional). Na terminologia utilizada em segurança do paciente, atualmente, não é utilizado o termo "acidente".

A interdependência entre a saúde do trabalhador, a ergonomia e a segurança do paciente está de tal modo presente que é difícil conceber intervenções para a prevenção de incidentes que não envolvam esses temas e não considerem a perspetiva sistémica nesse contexto. Serão a saúde do trabalhador e a segurança do paciente "duas faces da mesma moeda"?

A segurança do paciente é uma área de grande importância no contexto da prestação de cuidados de saúde em hospitais e outras organizações de saúde. Um dos seus principais objetivos é a eliminação de quaisquer incidentes envolvendo dano para o paciente.

A distinção efetuada por Rasmussen e por Reason (Rasmussen, Pedersen 1984; Reason 1990) entre condições latentes (latent conditions) e falhas ativas (active errors) é fundamental para se entender, realmente, tais situações (incidentes com ou sem dano). Sem a compreensão sistémica da situação de trabalho, torna-se difícil a análise da cadeia de acontecimentos que pode resultar num efeito adverso (Uva, Graça 2004; Uva 2010), limitando a opção pelas abordagens mais adequadas de gestão desses riscos, no intuito da sua prevenção.

As falhas ativas ou erros, designadamente as falhas, os lapsos e os enganos, são sentidos, quase no imediato, nos sistemas complexos (como são os hospitais) e resultam, no essencial, da interação entre o homem e seu "objeto de ação" (atividade de trabalho). No entanto, as condições latentes são um conjunto de elementos que se encontram dispersos no sistema (entre outros, as condições externas, a gestão, o envolvimento físico, o ambiente social e a interface homem-sistema) e estão frequentemente "invisíveis" nesse mesmo sistema (determinantes do trabalho). No decurso da prestação de cuidados de saúde, esses elementos podem tornar-se evidentes, por combinação com outros ou 
por simples casualidade, e "romper" as defesas existentes no referido sistema. É essa cadeia de acontecimentos que está quase sempre presente na origem dos erros, da qual podem resultar incidentes que afetam, num contexto concreto, a segurança dos pacientes.

\section{A complexidade dos serviços de saúde}

Os serviços de saúde e a prestação de cuidados de saúde envolvem sistemas de grande complexidade (Figura 1) com, também complexas, interdependências e interatividade a diversos níveis (Henriksen et al. 2008).

Figura 1 - Factores contributivos para a existência de acontecimentos adversos na prestação de cuidados de saúde

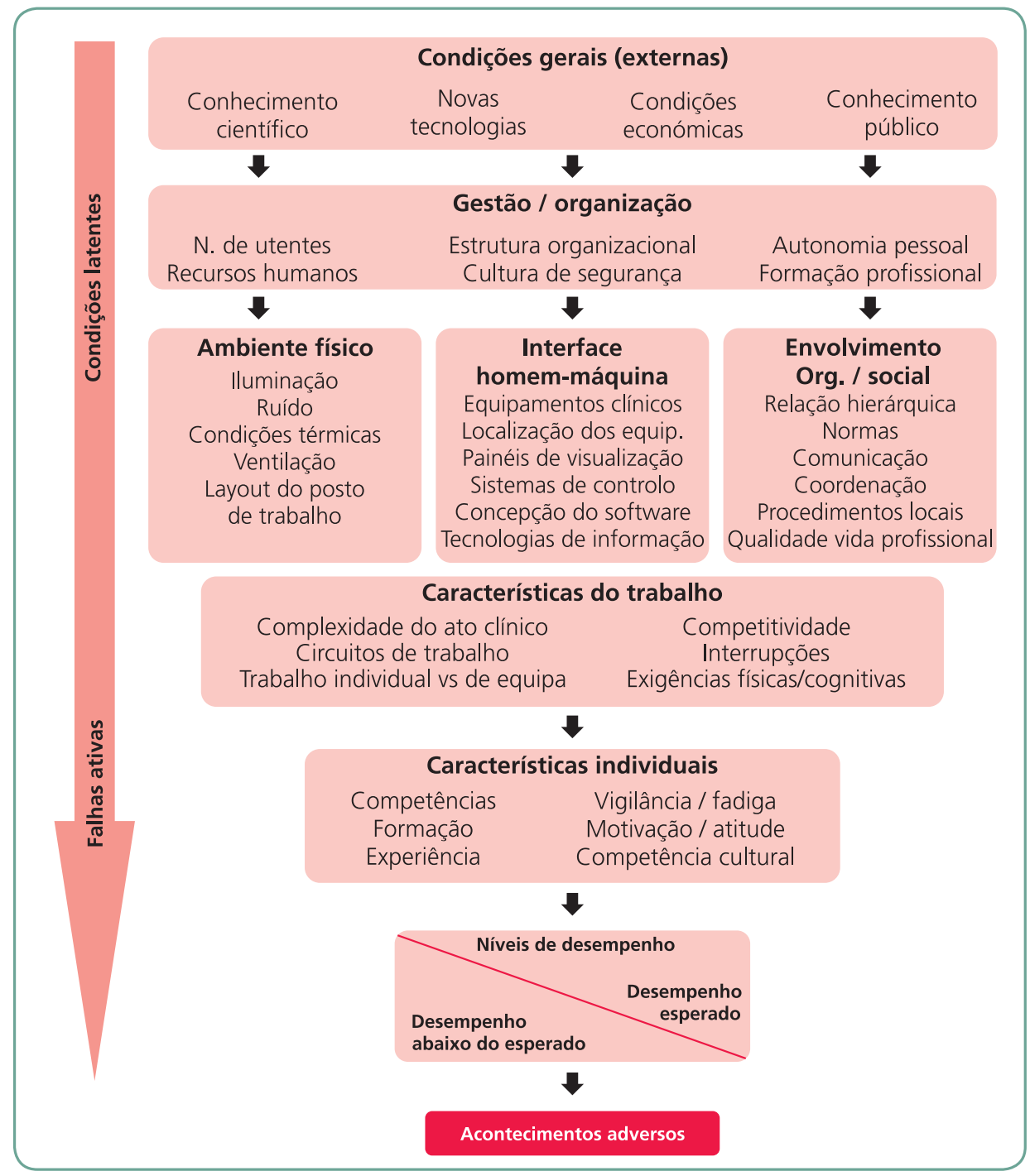

Fonte: Adaptado de Henriksen et al. (2008).
Esses conceitos já foram vistos no livro Segurança do paciente: conhecendo os riscos nas organizações de saúde, Capítulo 4, "O erro e as violações no cuidado de saúde". 
Para refletir

Analise, a partir de uma perspetiva sistémica, que factores (condições latentes) influenciam o desempenho dos profissionais de saúde da organização em que você trabalha e podem ocasionar erros na prestação de cuidados (falhas ativas), determinando desempenho abaixo do esperado e a potencial de eventos adversos (evitáveis).

A compreensão das situações que frequentemente determinam desempenhos inferiores ao planeado/planejado (ou erros) e podem originar incidentes pressupõe o conhecimento de várias componentes das situações de trabalho. Destacam-se entre esses determinantes:

As características individuais e/ou sociais dos intervenientes no processo de prestação de cuidados de saúde. Características como a idade, o género, a formação e a experiência profissional dos profissionais de saúde (Henriksen et al. 1993) ou outros aspetos como o seu envelhecimento e as decorrentes alterações que podem ter na execução da sua atividade de trabalho;

* As situações de trabalho em que existe frequentemente erro humano, em especial os lapsos e os enganos, com os inerentes incidentes e/ou acidentes no desempenho clínico (Reason 1993). Sua ocorrência está relacionada fundamentalmente com desvios de normas (trabalho prescrito) e a existência de situações clínicas novas, ou de elevada complexidade, que determinam uma sobrecarga de trabalho;

* As interfaces desadequadas entre o trabalhador da saúde e os dispositivos técnicos (ou outra tecnologia) frequentemente presentes, por exemplo, nos equipamentos utilizados na prestação de cuidados, na sua forma e/ou cor, constituição (design), ou nos softwares desenvolvidos e na sua "usabilidade". Essa desadequação pode envolver as sequências de utilização ou, por exemplo, o respetivo processo de visualização;

As situações estruturais resultantes, entre outras, da errada conceção/concepção dos espaços de trabalho, da má organização dos circuitos de trabalho, da incorreta disposição e implantação dos equipamentos ou dos fluxos de trabalho.

Os disfuncionamentos organizacionais e/ou de gestão assentes em diversos aspetos destacando-se, entre outros:

- a formação dos profissionais de saúde;

- as elevadas (ou desfasadas) exigências organizacionais; 
- as reduzidas equipas de trabalho;

- o excessivo número de pacientes observados ou tratados;

- a carência de recursos humanos disponíveis para as funções;

- a falta de empenho e motivação dos profissionais;

- os horários de trabalho (por exemplo, consecutivos e por turnos/ plantões) e;

- as dificuldades em estabelecer (ou fornecer) os melhores meios de comunicação.

\section{A perspetiva antropotécnica na segurança do paciente}

A prestação de cuidados de saúde tem tendência para um substantivo crescimento, desde logo relacionado com o envelhecimento da população, associado a importantes oscilações no número de prestadores de cuidados, o que pode determinar a necessidade de repensar a organização dessa prestação, sob pena de o sistema poder não dar resposta às solicitações da procura de cuidados.

Diversas estratégias de ação podem ser encaradas num contexto desse tipo, e, entre elas, a aposta nos princípios de (re)conceção/concepção dos sistemas sociotécnicos e/ou antropotécnicos pode constituir o elemento de diferença. No essencial, a "reinvenção" dos sistemas de saúde deve ter por base a necessidade de reconhecer a existência de desarmonias nas interfaces entre a pessoa e o sistema, por exemplo, no âmbito do design, dos layouts, dos equipamentos, dos instrumentos e dos meios e formas de comunicação. A complexidade intrínseca das atividades desempenhadas e a frequente elevada carga de trabalho (física e mental) dos profissionais de saúde poderão determinar algumas dificuldades em conciliar as características e as capacidades dos profissionais de saúde e o ambiente (hospitalar), incluindo o ambiente organizacional.

É por isso que os mecanismos e os processos de prestação de cuidados de saúde devem ser concebidos em função das características concretas dos sistemas complexos, como é o caso dos hospitais e outras organizações de saúde. Tal torna interdependente a conceção/concepção, disposição, organização dos componentes estruturais e as características concretas das pessoas que, nesse contexto, desempenham sua atividade. Assim, os serviços de saúde e os hospitais são sistemas sociotécnicos em que os resultados (ou "outcomes") decorrem da definição de processos que determinam as formas de interação entre as pessoas e a tecnologia (no seu sentido mais lato).
Antropotécnico é o sistema que seleciona e utiliza a tecnologia (equipamentos ou utensílios e outras ferramentas) numa estrutura organizacional que respeita as características específicas do trabalhador.

Sociotécnico é o sistema que engloba as relações entre a tecnologia e as pessoas, tendo sido, inicialmente, usado como sinónimo da interação entre o operário e a máquina. 
Atividade de trabalho: o que as pessoas fazem durante a realização do seu trabalho.
A conceção/concepção dos sistemas complexos (determinante da "estrutura") e sua organização (determinante dos "processos") são impossíveis de imaginar se forem avaliadas de forma independente do trabalho real, isto é, da forma de interação entre os profissionais de saúde (médicos, enfermeiros, técnicos, auxiliares...), os restantes componentes organizacionais e técnicos (ou tecnológicos) e o paciente.

A atividade real de trabalho dos profissionais de saúde é, portanto, uma resposta às exigências organizacionais, num envolvimento físico de trabalho determinado, com os meios técnicos colocados à disposição, considerando as características do paciente e, igualmente, as capacidades e limitações do próprio profissional de saúde.

Na prática, o primeiro elemento de suporte à prevenção de problemas, no contexto da segurança do paciente e da saúde do trabalhador, é um eficiente e efetivo planeamento/planejamento estrutural, designadamente em relação ao design hospitalar, da definição de circuitos e da implantação e disposição de equipamentos (Uva, Serranheira 2008), integrado num sistema participativo de todos os envolvidos, que se beneficia com o apoio da ergonomia.

A atividade de trabalho na prestação de cuidados de saúde é uma resposta individual, num determinado momento, a um conjunto de condicionantes internas (características, capacidades e limitações dos profissionais de saúde) e externas (envolvimento físico, organizacional, tecnológico, social...), cujos efeitos podem incluir o erro e o consequente efeito adverso ao paciente.

A ergonomia (também denominada factores humanos e/ou engenharia humana), de facto, pode contribuir para a segurança do paciente, entre outros, por meio de intervenções no âmbito:
Intervenções da conceção do design dos postos e locais de trabalho;

dos processos e organização hierárquica, temporal e relacional do trabalho;

da seleção dos equipamentos e sua implantação; assim como 
A visão inicial da ergonomia foi a da antropometria, da biomecânica e da fisiologia como suporte das relações homem-máquina, sendo o homem mais "uma componente" que a máquina deveria respeitar. Tratava-se, no essencial, da perspetiva da Human Factors - ou Factores Humanos - que se mantém presente na atual corrente de ergonomia com origem nas engenharias e desenvolvida, principalmente, nos Estados Unidos da América. Ao mesmo tempo, com o início das correntes da psicologia ergonómica (abordagem francófona), designadamente com Ombredanne e Faverge e sua inigualável obra Analyse du travail (Ombredane, Faverge 1955), nasceu outra corrente da ergonomia, designada apenas Ergonomics. Essa corrente propôs uma nova metodologia sistémica e integrada de análise do trabalho, como um instrumento essencial para a compreensão desse trabalho na sua globalidade (Figura 2). Na perspetiva desses autores, tal abordagem permitia a integração e a compreensão dos diversos elementos e factores implicados e em interação numa situação de trabalho, visando à emergência de novas ideias, soluções ou possibilidades, no sentido da transformação do trabalho e da sua adaptação à pessoa.

Figura 2 - Modelo de análise da situação de trabalho

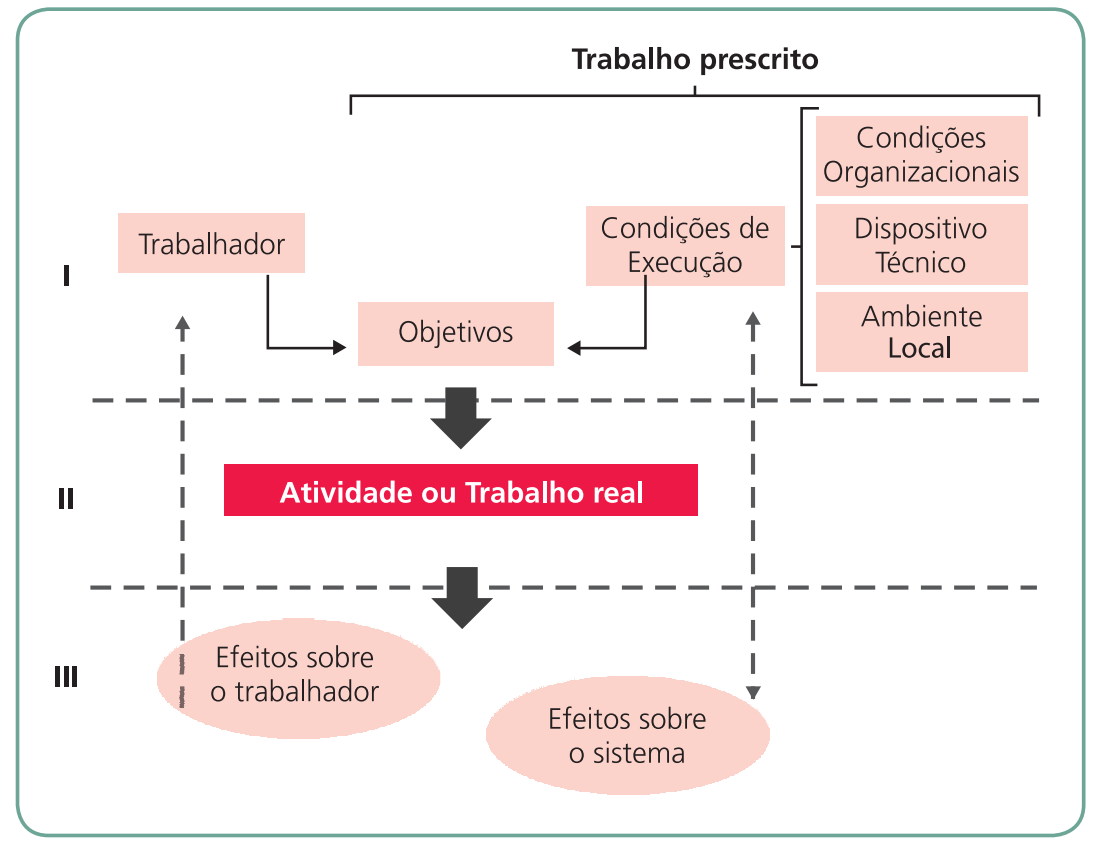

Fonte: Adaptado de Leplat, Cuny (2005).

Atualmente, observa-se uma tentativa de interligação dessas correntes - Human Factors and Ergonomics (HFE) -, ainda que se mantenham perspetivas díspares, com diferentes objetivos e metodologias, quer de análise, quer de intervenção. 
A ergonomia de base normativista (Human Factors) é integrada, de forma mais fácil, por outras disciplinas como a arquitetura, o design ou a segurança do trabalho, visto fornecer dados para uma conceção/concepção destinada ao público, enquanto a ergonomia da atividade (Ergonomics) se centra sobre casos concretos e, por consequência, é menos "portátil" para outras áreas de conhecimento. A ergonomia objetiva, no essencial, a adaptação do trabalho (suas condições e exigências) à pessoa (IEA 2000).

O ambiente e as condições de trabalho hospitalares, quando comparados com outros sectores produtivos, designadamente a indústria, apresentam considerável conjunto de circunstâncias, oportunidades e desafios para a ergonomia. De facto, é do conhecimento geral que o trabalho em meio hospitalar, assim como em outras unidades de saúde, apresenta diversas peculiaridades. Trata-se, como já se referiu, de um meio com elevada complexidade (física, tecnológica, instrumental), com constante pressão temporal e substancial tensão relacionada à prestação dos melhores cuidados possíveis. Inclui-se, nesse contexto, entre outros, a diversidade (e variabilidade) humana; a prevalência do sexo feminino; o progressivo envelhecimento dos profissionais; as elevadas exigências físicas; o trabalho emocional; o trabalho noturno e por turnos ou plantões. Para além desses factores, importa destacar, igualmente, os aspetos organizacionais do trabalho hospitalar, em particular os aspetos hierárquicos e relacionais entre profissionais de saúde.

Apesar de o tema "melhoria das condições de trabalho em meio hospitalar" ser reconhecidamente importante, a ergonomia, na área dos hospitais (ergonomia hospitalar e em outras organizações de saúde), dá ainda os primeiros passos. Nesse contexto, são pouco divulgados os potenciais contributos/colaborações que podem trazer para os profissionais de saúde, para os pacientes, para a organização dos serviços e a administração dos hospitais.

O envolvimento físico hospitalar tem um efeito substantivo na segurança de pacientes e na saúde e, ainda, na segurança de profissionais de saúde (Figura 3). Apesar disso, paradoxalmente os hospitais continuam a não ser concebidos com o objetivo explícito de promover a segurança do paciente e dos profissionais de saúde, principalmente por meio de investimentos na melhoria da sua implantação, design e funcionalidade. Os hospitais são, de facto, concebidos, de maneira essencial, em função da "estrutura" e do "processo" e menos nos resultados (e ainda menos em aspetos pouco valorizados, como a saúde e segurança do trabalho). 
Figura 3 - Modelo integrado das condições de trabalho da prestação de cuidados de saúde e o clima organizacional e segurança

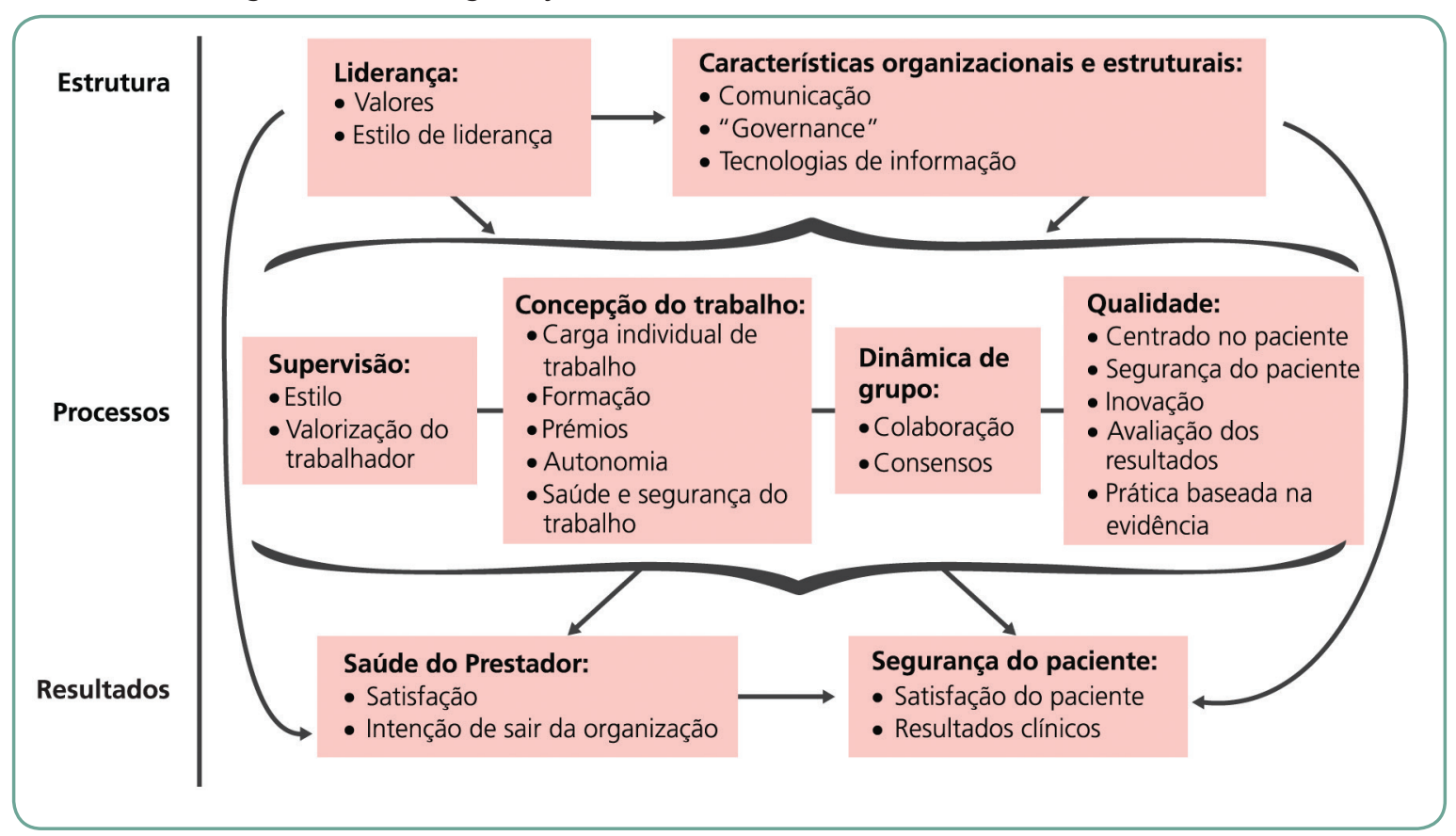

Fonte: Adaptado de Stone et al. 2005.

Entre outros, os seguintes aspetos de design ergonómico em hospitais e serviços hospitalares deveriam ser implementados (Serranheira et al. 2010):

滕 Garantir a flexibilidade e a adaptabilidade do sistema - quer

a pacientes, quer a profissionais - no sentido da prevenção

das condições latentes e das falhas ativas (Reiling et al. 2004) com base em processos de conceção/concepção sistémicos, que apostem na antecipação, identificação, prevenção do erro e cultura organizacional de segurança.

滕 Automatizar e normalizar procedimentos e processos, de acordo com o conhecimento científico na área específica.

噒 Criar facilidade de acesso e visualização do paciente, quer se trate de um serviço de urgência, quer de outro serviço hospitalar (Reiling, Chernos 2007). O layout dos serviços deve considerar fundamental que os profissionais de saúde tenham contacto visual permanente com os pacientes sob seus cuidados.

䗲 Integrar as características e capacidades - quer dos profissionais de saúde (por exemplo, idade, sexo, morfotipo), quer dos pacientes. O contributo/colaboração para a redução da fadiga (física e mental), o trabalho noturno e por turnos ou plantões e, por vezes, os longos períodos de trabalho consecutivo, com substantivas exigências, são 
bons exemplos da necessidade de tê-los em conta na conceção/ concepção do trabalho hospitalar (Gaba, Howard 2002; Jha et al. 2001).

Todos os aspetos determinantes da saúde do paciente ou dos profissionais de saúde devem ser observados de forma sistémica e integrada. Por exemplo, a queda do paciente de uma maca, da qual resultou uma fratura do colo do fémur, determina a identificação das suas causas, que pode ser incompleta se apenas se considerar a inadequação dos equipamentos (dispositivo técnico) ou sua má utilização (erro humano). De facto, uma perspetiva sistémica poderá identificar aspetos organizacionais, como os recursos humanos presentes no serviço, com a atribuição de responsabilidades na vigilância dos pacientes em maca e, até mesmo, a carga de trabalho existente nesse período (manhã, tarde ou noite), que poderão ser determinantes na sua árvore causal.

Só por meio da análise da situação real, integrando sua complexidade e suas interdependências e, no caso em apreço, agregando as características dos prestadores de cuidados e dos pacientes, será possível detetar e prevenir os factores causais do incidente.

Nesse contexto, a adequação do posto de trabalho não deve ser vista apenas como um simples elemento de conforto, mas sim uma condição indispensável, um meio imprescindível ao trabalho, com potenciais repercussões na segurança do paciente, devendo contemplar para tal, entre outros:

o dimensionamento do local e dos equipamentos;

a disposição do equipamento no espaço;

a sequência de ações/gestos/movimentos;

a acessibilidade das vias e circuitos e

a minimização das exigências físicas, cognitivas e psicológicas. 
É, portanto, indispensável que exista uma adequação do posto de trabalho às características dos trabalhadores. Por exemplo, no que concerne aos planos de trabalho, designadamente do alcance (a colocação de equipamentos ou de sistemas de apoio ao paciente deve privilegiar os limites antropométricos dos profissionais de saúde) e das posturas de trabalho (as posturas de trabalho devem ser concebidas no sentido do conforto e da adequação à natureza da atividade, permitindo que as exigências sejam harmoniosas com as capacidades dos profissionais de saúde).

Um exemplo de adequação imprescindível é o posto de trabalho de enfermagem numa enfermaria. Deve ser ajustável aos utilizadores masculinos, femininos, de diferentes percentis e permitir trabalhar preferencialmente sentado, mantendo o contacto visual da enfermaria. Deve, igualmente, promover a movimentação e a alternância de gestos e posturas, incluindo sistemas de ajustabilidade às posições ortostática e sentada.

A conceção/concepção de espaços, locais e circuitos de trabalho em hospitais deve partir das exigências concretas da atividade de trabalho e das características dos trabalhadores para ser harmoniosa e garantir aspetos como a segurança do paciente e do prestador.

A conceção/concepção deve partir do interior para o exterior, isto é, do local de trabalho, do espaço funcional e do circuito determinando a volumetria exterior do edifício.

A conceção/concepção, o design e a implantação de mobiliário e equipamento nos locais de trabalho são alguns dos principais aspetos que influenciam a interação harmoniosa entre o trabalhador, esses equipamentos (de saúde e de apoio) e o sistema de prestação de cuidados de saúde (Wickens et al. 2004). Destacam-se, nesse contexto, para a otimização dos espaços e postos de trabalho, entre outros, a necessidade de identificar o espaço livre, a acessibilidade de profissionais e pacientes, a sequência da atividade real e a margem de manobra dos profissionais de saúde, cujos aspetos previstos, frequentemente (quase sempre), são distintos da realidade. Devem existir zonas livres de acesso aos leitos, zonas de circulação, entre outros aspetos dimensionais do espaço de trabalho, não apenas para garantir a acessibilidade, como também para, por exemplo, diminuir a probabilidade de infeção relacionada com a prestação de cuidados de saúde.
Um percentil é uma medida da posição relativa de uma unidade observacional em relação a todas as outras (\%). 

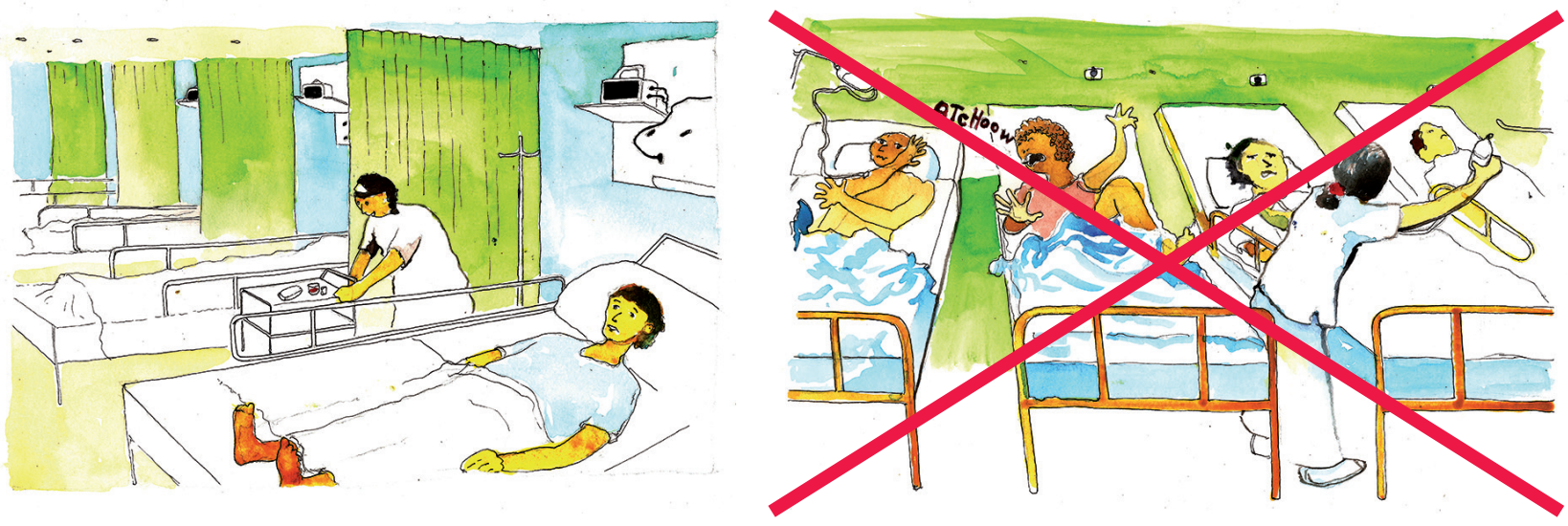

Entre as situações mais frequentes (condições latentes) na origem de erros surgem, por exemplo, os equipamentos, cuja interação não é sequencial ou lógica, os écrans de visualização (ou displays) fora da zona de conforto visual dos utilizadores, a impossibilidade de observação da zona de trabalho médica ou de enfermagem dos quartos e dos pacientes e a ausência de sistemas de informação próximos dos pacientes.

\section{Para refletir}

Na sua organização, você percebe que houve preocupação, por exemplo, com a conceção/concepção (ergonómica) dos espaços e definição dos circuitos de trabalho? Que alterações você sugeriria se fosse possível?

Já se deparou com alguma situação em que houve risco para a segurança de algum profissional ou paciente, decorrente da conceção/ concepção inadequada de equipamentos ou outros aspetos ambientais?

Outro aspeto importante relaciona-se com diversos factores da situação de trabalho. Destaca-se a carga de trabalho, que pode contribuir para a existência de fadiga nos profissionais de saúde, diminuir a fiabilidade/ confiabilidade esperada e, por vezes, provocar alterações relacionadas à resiliência humana. A fadiga, em particular a fadiga resultante de longos períodos consecutivos de trabalho, em que se identificam disrupções do ritmo circadiano, há muito que foi identificada como um problema no contexto da prática clínica. Diversos estudos identificam a fadiga como uma das importantes causas das falhas, lapsos, enganos e, em geral, do erro (Reiling, Chernos 2007). Apesar disso, não é completamente conhecida a associação entre a fadiga e a ocorrência de acontecimentos (ou eventos) adversos no âmbito da segurança do paciente. 
Outros elementos a considerar nesse contexto são o trabalho noturno (e por turnos ou plantões) e, em certas circunstâncias, os longos períodos de trabalho contínuo associados a elevadas cargas de trabalho, frequentemente considerados no âmbito organizacional como uma inevitabilidade.

A prestação de cuidados de saúde é feita por profissionais de saúde maioritariamente competentes, que nunca são super-homens ou supermulheres, não sendo aceitável a perspetiva baseada na culpabilização. O foco de atenção deverá ser a conceção/concepção e a implementação de sistemas que, mesmo nos limites das capacidades humanas, reduzam tendencialmente a zero (ou impeçam) a probabilidade de existência de erros nos serviços de saúde, recorrendo aos meios disponíveis (técnicos, organizacionais ou de outra natureza) para tal objetivo. E essa atenção centra-se, cada vez mais, na prevenção dos incidentes também pela aposta em programas de saúde e segurança dos profissionais de saúde (Yassi, Hancock 2005).

\section{Relações trabalho-saúde-segurança do paciente em meio hospitalar}

A prevenção das doenças profissionais adquiriu grande visibilidade em meio hospitalar nos últimos anos, na sequência da identificação do agente da síndrome da imunodeficiência adquirida e da necessidade de prevenir eventuais casos de doença relacionados com a prestação de cuidados. Mais recentemente, os programas de prevenção da alergia ao látex (Uva 1997; Alves et al. 2008a; Alves et al. 2008) têm concentrado a atenção da medicina do trabalho em hospitais e outras organizações de saúde, assim como a exposição a anestésicos halogenados ou a microrganismos multirresistentes.

Também a prevenção de lesões musculoesqueléticas ligadas ao trabalho (LMELT) em hospitais e outras unidades de saúde tem vindo a ser implementada por meio de programas de saúde e segurança, por exemplo, na movimentação de pacientes, em que se incluem medidas centradas no envolvimento (por exemplo, zonas de trabalho com dimensões adequadas), nos equipamentos (por exemplo, implementação de sistemas de elevação mecânica de pacientes) e nos profissionais de saúde (por exemplo, formação sobre aspetos posturais e biomecânicos na manipulação de pacientes).

A profissão com maior taxa de incidência de LMELT é a enfermagem. De acordo com dados estatísticos de 2007 do Bureau of Labor Statistics 
dos Estados Unidos (US Bureau of Labor Statistics, 2009), essa taxa é de 252 casos por 10 mil enfermeiros (taxa sete vezes superior à observada no conjunto de todos os trabalhadores). Diversos estudos referem valores ainda mais elevados (Lagerstrom et al. 1995; Engels et al. 1996; Estryn-Béhar 1996; Ando et al. 2000).

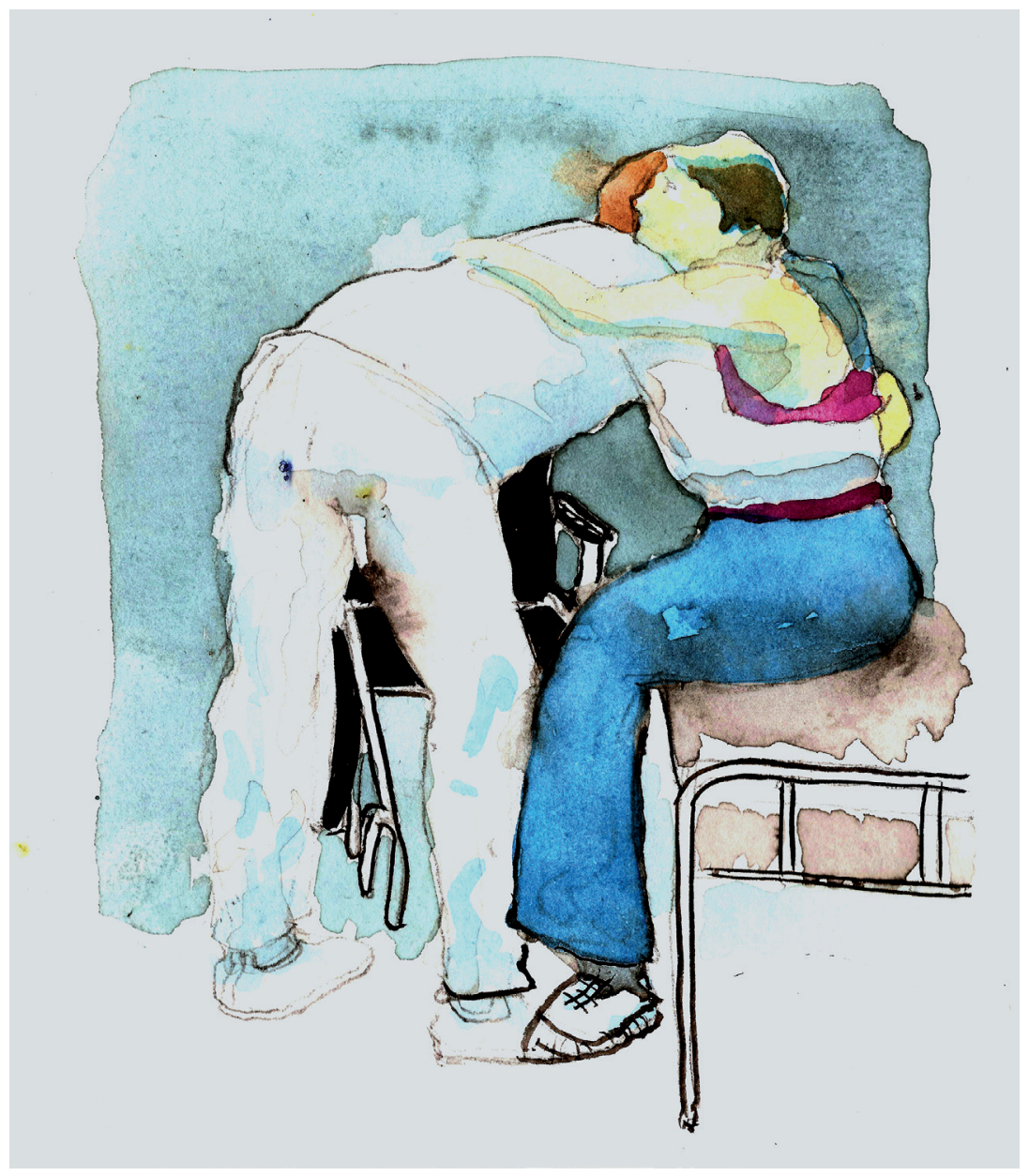

Assim, os profissionais e também os pacientes podem estar em risco na movimentação, verificando-se, designadamente, risco de queda e aspetos relacionados com consequências negativas oriundas da ansiedade e até da dor ou desconforto em razão dessas mobilizações.

Outro aspeto importante refere-se aos factores de risco de natureza psicossocial. O National Institute for Occupational Safety and Health dos Estados Unidos da América (NIOSH) define estresse "relacionado com o trabalho" como a resposta, física e emocional, que ocorre quando as exigências do trabalho excedem as capacidades, os recursos e as necessidades do trabalhador (NIOSH 2006). Tal não anula a influência da 
personalidade do indivíduo e de outros factores individuais que afetam a avaliação, por parte de cada indivíduo, de um acontecimento como gerador de estresse (Spector 1999).

Também o burnout é um fenómeno complexo e específico, constituindo-se das componentes de exaustão emocional, de despersonalização e de falta de realização profissional, em que a componente de exaustão emocional é semelhante ao distresse crónico relacionado com o trabalho (Schaufeli, Enzmann 1998).

\section{Para refletir}

Você já apresentou ou conhece algum colega com alguma das condições clínicas discutidas no texto? Como lidou com essa(s) questão(ões)? Em algum momento, você acreditou que poderia(m) afetar os pacientes que dependiam do seu trabalho?

A atividade dos profissionais de saúde caracteriza-se por apresentar múltiplas exigências não só em termos físicos, mas sobretudo em termos psicológico, o que justificou, por parte do Health and Safety Executive (HSE 2003), a inclusão do exercício da medicina e da enfermagem entre as sete profissões mais estressantes. Um estudo que envolveu 22 mil trabalhadores de 130 profissões distintas concluiu que, entre as 27 profissões caracterizadas como as que estavam mais associadas ao estresse, 7 pertenciam ao sector da saúde (Smith 1978, citado por McIntyre 1994).

As circunstâncias indutoras de estresse são múltiplas e relacionam-se com aspetos organizacionais e também socioemocionais. Apesar de a responsabilidade por pessoas constituir um factor indutor de estresse inerente à atividade do profissional de saúde e, em determinadas circunstâncias, poder contribuir de forma significativa para a presença de estresse, a coexistência de outros factores, nomeadamente de natureza organizacional, poderá ser determinante para esse processo de estresse.

De facto, a quantidade de trabalho que cada indivíduo sente como sobrecarga e a "pressão do tempo" têm sido referidas entre as principais circunstâncias indutoras de estresse para os profissionais de saúde em diversos estudos (Gray-Toft Anderson 1981; McIntyre, McIntyre, Silvério 1999; McVicar 2003; Chang et al. 2006). Também os conflitos entre profissionais, os custos emocionais, a ambiguidade de papéis e muitos outros factores de natureza organizacional (como o estilo de liderança) têm sido identificados (Schaufeli 1999; McVicar 2003). 
Suporte social diz respeito a inter-relações adaptativas entre o trabalhador e o meio em que se insere (a comunidade, a família ou os colegas de trabalho).
Alguns grupos profissionais, tais como os médicos em período de formação, podem trabalhar muitas horas semanais e por períodos sem descanso adequado, condicionando exigências físicas e mentais substantivas. Apesar de estarem presentes níveis de suporte social elevados, Fielden e Peckar encontraram uma correlação direta entre o número de horas trabalhadas e os níveis de estresse (Fielden, Peckar 1999).

Um estudo de Shanafelt e colaboradores (Shanafelt et al. 2010) dirigido a 24.922 cirurgiões do Colégio Americano de Cirurgia, a que responderam 7.905, com média de 18 anos de prática e de 60 horas semanais de trabalho, indica que $40 \%$ dos respondentes estão em burnout, e 30\% têm sintomas de depressão. Quase 9\% indicam ter cometido um erro médico nos três meses precedentes, ainda que mais de $70 \%$ o atribuam mais a factores de natureza individual do que sistémicos. Demonstra-se a relação entre o grau de burnout e o erro médico.

McIntyre e colaboradores estudaram as respostas de estresse, as circunstâncias indutoras de estresse e os recursos de coping (lidar adequadamente com uma situação) disponíveis em 62 enfermeiros de serviços de internamento/internação de cardiologia, de reabilitação e de medicina de um hospital central e relacionaram essas variáveis com sua experiência profissional. As primeiras quatro circunstâncias indutoras de estresse eram de natureza organizacional (sobrecarga de trabalho, deficientes condições físicas e técnicas, carência de recursos e grande número de pacientes), tendo sido classificada, apenas em quinto lugar, a incapacidade para responder às exigências emocionais dos pacientes (McIntyre, McIntyre, Silvério 1999).

Outros estudos (Elfering, Semmer, Grebner 2006) identificam a documentação incorreta e os pacientes violentos como estressores mais frequentes, valorizando, com o "baixo controlo no trabalho", esses estressores profissionais como factores de risco relacionados com a segurança dos pacientes.

Também o envolvimento organizacional das organizações de saúde, a formação dos profissionais de saúde e a "cultura médica" face ao erro podem dar origem a substantivo impacte emocional nos prestadores de cuidados de saúde e nos médicos, em particular (Schwappach, Boluarte 2009). O envolvimento dos prestadores em situações nas quais se verificaram erros, tem, com frequência, consequências negativas no que diz respeito ao sofrimento emocional, assim como ao desempenho, em especial nos médicos (Figura 4). 
Figura 4 - Ciclo recíproco do erro, estresse emocional e futuros erros

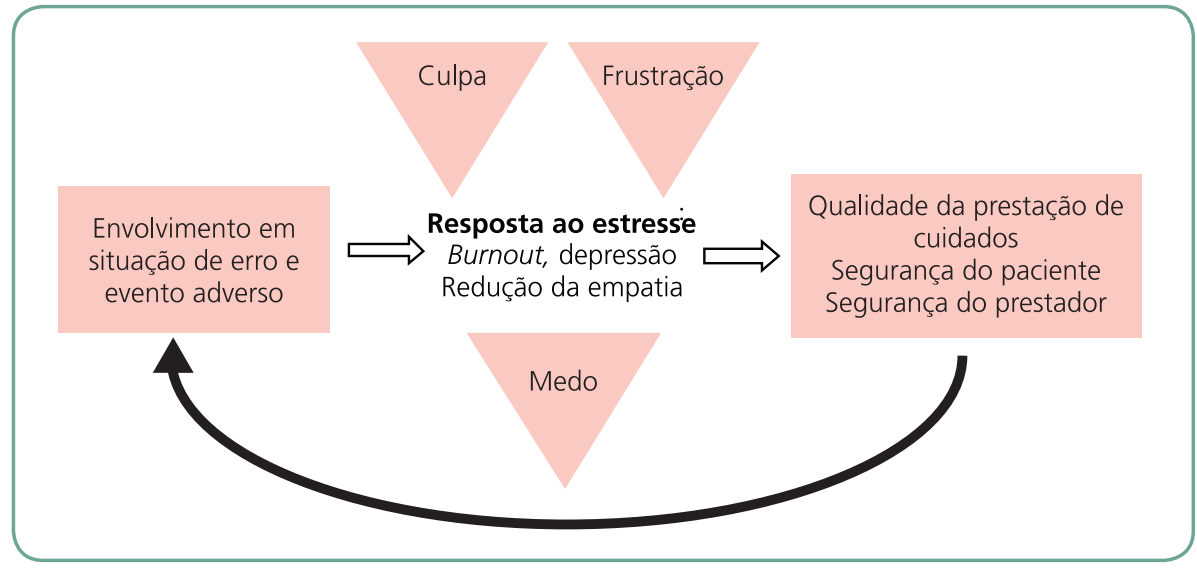

Fonte: Adaptado de Schwappach; Boluarte (2009).

\section{Para praticar}

Os efeitos decorrentes da atividade de trabalho são evidentes, quer nos profissionais de saúde, quer na segurança do paciente.

Recorde, agora, as questões que propomos para sua reflexão logo no início do capítulo. Em seguida, refaça sua reflexão e busque uma revisão bibliográfica que dê suporte à relação entre segurança do paciente e a saúde e segurança dos trabalhadores da saúde na perspetiva sistémica.

Diversos estudos referem que a resposta dos profissionais de saúde a um erro com consequências para seus pacientes se traduz em graves problemas emocionais, podendo tais emoções conduzir a "cicatrizes emocionais" permanentes. Em face a eventuais efeitos como estresse e burnout sobre o bem-estar, o desempenho e a saúde dos prestadores, as instituições de saúde devem assumir a responsabilidade de garantir a existência de sistemas formais (e informais) de apoio a esses profissionais de saúde.

Verifica-se, portanto, que as características estruturais, e também organizacionais, dos diferentes locais de trabalho poderão facilitar, por exemplo, a ambiguidade de papéis e os conflitos interpessoais, contribuindo também para as diferenças verificadas nos níveis de estresse de profissionais de saúde, nas várias unidades. A organização de cada local de trabalho condiciona a perceção/percepção dos vários factores indutores de estresse de natureza profissional referidos pelos profissionais de saúde. 
Dessa forma, factores como a sobrecarga de trabalho, as deficientes condições físicas e técnicas ou a inadequação entre recursos humanos e o número (e gravidade das situações de doença) de pacientes podem determinar situações com potenciais implicações para a segurança do paciente.

Dawson e Reid (1997) referem a tal propósito que a comparação entre a redução dos índices de performance ocasionada pela fadiga seria equivalente à redução provocada por uma alcoolemia de 0,8 a $1 \mathrm{gr} / \mathrm{L}$ de álcool (Dawson, Reid 1997).

Também a dimensão das equipas prestadoras de cuidados pode determinar, quando reduzidas, disfunções relacionadas, entre outros, com a administração de medicação, insuficiente vigilância de pacientes ou, por exemplo, incumprimento parcial de procedimentos relacionados com a prestação de cuidados. Constatou-se, por exemplo, que os pacientes internados em hospitais com pior taxa enfermeiro por paciente (oito pacientes por enfermeiro) têm mais 31\% de risco de morrer do que em hospitais com taxa enfermeiro por paciente de quatro pacientes (Clarke, Sloane, Aiken 2002). Existe mesmo aumento de risco de burnout de $23 \%$ e de insatisfação profissional de $15 \%$ por cada paciente a mais do que quatro pacientes por enfermeiro.

Os recursos humanos são indispensáveis para tratar os pacientes, e, portanto, as condições em que prestam cuidados apresentam-se como decisivas para a qualidade desses mesmos cuidados, que dependem, por certo, da saúde e segurança dos prestadores (Uva et al. 2008). A importância da compreensão das causas dos erros (Leape et al. 1995; Department of Health 2003; Audit Commission 2001) passa sempre pela compreensão de elementos de saúde e segurança do trabalho dos prestadores (Kho et al. 2005). A esse propósito, são frequentemente encontradas, na língua inglesa, as afirmações: "feeling good = doing good" ou "staff care = patient care".

Também o trabalho por turnos ou plantão e o trabalho noturno podem determinar alterações do sono e da vigília que se podem repercutir, quantitativa e qualitativamente, no trabalho prestado. Uma meta-análise de vários estudos aponta para o aumento de risco de eventos adversos de mais de $18 \%$ para os turnos vespertinos e noturnos em relação aos matutinos (Folkard et al. 2010).

De facto, existem diversos estudos relacionados com várias técnicas médicas que apontam para maior número de erros relacionados com a fadiga e o trabalho por turnos/plantões (incluindo o trabalho noturno) 
(Smith-Coggins et al. 1997; Aya et al. 1999; Grantcharov et al. 2001; Henriques et al. 2003). Outro estudo (Tanaka et al. 2010) analisou a relação entre o erro clínico e o trabalho de enfermagem em dois turnos diários e três turnos diários tendo demonstrado que existem mais eventos adversos no regime de três turnos.

Outro aspeto importante relaciona-se com o "clima" organizacional. Clarke e colaboradores, no seu estudo, relacionam esse (mau) clima e o menor número de profissionais com duas vezes mais "near misses" e acidentes com exposição a sangue (incidentes na taxonomia utilizada em segurança do paciente) e derivados relativamente a unidades em que tal não se observa (Clarke, Sloane, Aiken 2002).

A segurança do paciente está, portanto, intimamente relacionada com a segurança (e saúde) do prestador (Sousa et al. 2009), e qualquer intervenção preventiva tendente a reduzir a probabilidade de ocorrência de acontecimentos evitáveis deve valorizar os aspetos relacionados com a prestação de cuidados na perspetiva da saúde e segurança de quem os presta.

Nesse contexto, a formação dos profissionais de saúde (médicos, enfermeiros, técnicos e outros), assim como dos gestores da saúde (entre outros, administradores hospitalares e gestores do risco clínico) deveria integrar a perspetiva sistémica da gestão do risco e da segurança do paciente em ambiente hospitalar. Tais alterações permitiriam, por certo, passar da cultura da culpa para a cultura da aprendizagem com os erros, e exigiriam, para além de uma alteração radical de mentalidades dos intervenientes nos sistemas de prestação de cuidados de saúde, maior atenção, meios e recursos para implementar a saúde e segurança dos profissionais de saúde e, também, na perspetiva da segurança dos pacientes.

\section{Considerações finais}

A prestação de cuidados de saúde é hoje considerada, sem margem para dúvidas, uma atividade com factores de risco e riscos importantes, quer para os pacientes, quer para os profissionais de saúde. Bastaria a tal propósito referir alguns eventos sentinela (cirurgia do lado errado, erros de transfusão ou erros medicamentosos graves) ou, no caso da saúde e segurança do trabalho, na violência no local de trabalho, nos riscos (micro)biológicos ou na carga (física) de trabalho relacionada com a movimentação manual dos pacientes.

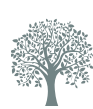

Para saber mais sobre esse tema, é importante complementar com a seguinte leitura: Sousa P, Uva AS, Serranheira F, Pinto F, Ovretveit J, Klazinga N, et al. The patient safety journey in Portugal: challenges and opportunities from a public health perspective. Rev Port Saúde Pública. 2009;№. Esp.:91-106. 


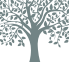

Para saber mais sobre esse tema, procure complementar seus estudos com os textos listados a seguir:

- Uva AS, Serranheira F. Saúde, doença e trabalho: ganhar ou perder a vida a trabalhar. Lisboa: Diário de Bordo. No prelo 2013.

- The Joint Commission. Improving patient and worker safety: opportunities for synergy, collaboration and innovation. Oakbrook Terrace (IL): The Joint Commission, 2012 Nov. Disponível em: http://www.jointcommission. org/

- Uva AS, Serranheira F, Sousa P, Leite E, Prista J. Occupationa health and ergonomics toward patient safety. In: Ovretveit J, Sousa P, editors.Quality and safety improvement research: methods and research practice from the international quality improvement resarch network (QIRN). Lisboa: Escola Nacional de Saúde Pública Lisboa; 2008. p. 263-87.
A segurança do paciente e a ergonomia e a saúde e segurança do trabalho (ou saúde do trabalhador) dos profissionais de saúde são, de facto, "duas faces da mesma moeda" (Serranheira et al. 2010). Sua interdependência obriga a que, nos sistemas complexos (como é o caso dos hospitais), haja suficiente investimento, tanto num como noutro, para se obterem os melhores resultados em qualidade em saúde.

Seria, de resto, difícil de conceber um bom clima (ou cultura) de segurança sem um importante compromisso e liderança organizacionais. Tal determina não só o compromisso organizacional da(s) perceção(ões)/ percepção(ões) da(s) necessidade(s) de prevenção, mas também a implementação de normas organizacionais que deem corpo a essas perceções/percepções e crenças.

Dessa forma, segurança do paciente e saúde e segurança dos trabalhadores têm percursos convergentes, senão mesmo sinérgicos, para a qualidade e melhoria contínuas em saúde.

Trying harder will not result. Changing systems will (IOM 2001). (Em uma tradução livre: O aumento do empenho não resulta. Alterar o sistema resulta.)

A intervenção sobre as condicionantes do trabalho, sobre as condições latentes permite ganhos em segurança, quer para o paciente, quer para o prestador de cuidados ou profissional de saúde.

A prevenção dos erros e dos eventos adversos passa, necessariamente, pela intervenção sistémica nos hospitais e instituições de saúde. Reflita em torno dessa afirmação. Agora, retorne ao texto que iniciou o capítulo e procure responder às questões que foram formuladas.

\section{Referências}

Agency for Healthcare Research and Quality (AHRQ). The effect of health care working conditions on patient safety. Rockville (MD): AHRQ; 2003 May.(AHRQ publication, n. 03-E031).

Alves RR, et al. Alergia ao latex em profissionais de saúde hospitalares. Rev Port Imunoalergol. 2008a;16(4):349-76.

Alves RR, Uva AS, Ferreira MB. Alergia profissional ao latex em meio hospitalar. Ver Port Saúde Pública. 2008b;26(1):77-88.

Ando $S$, et al. Associations of self estimated workloads with musculoskeletal symptoms among hospital nurse. Occup Environ Med. 2000;57(3):211-6.

Audit Commission (UK). A spoonful of sugar. London: Audit Commission; 2001. 
Aya $A$, et al. Increase risk of unintentional dural puncture in night-time obstretic epidural anesthesia. Can. J. Anaesth. 1999;46:655-9.

Bureau of Labor Statistics (US). Musculoskeletal disorders and days away from work in 2007. Washington, DC: Bureau of Labor Statistics, 2009 [citado 2009 Jul 27]. Disponível em: http://www. bls.gov/opub/ted/2008/dec/wk1/art02.htm.

Carayon P., editor. Handbook of human factors and ergonomics in health care and patient safety. New York: CRC Press; 2007.

Chang $E$, et al. The relationships among workplace stressors, coping methods, demographic characteristics and health in Australian nurses. J Prof Nurs. 2006;22(1):30-8.

Clarke S, Sloane D, Aiken L. Effects of hospital staffing and organizational climate on needle stick injuries to nurses. Am J Public Health. 2002;92:1115-9.

Dawson D, Reid K. Fatigue, alcohol and performance impairment. Nature. 1997;388:235-7.

Department of Health (UK), Design Council. Design for patient safety: a system-wide design-led approach to tackling patient safety in the NHS. London: Design Council, Department of Health; 2003.

Elfering E, Semmer NK, Grebner S. Work stress and patient safety: observer-rated work stressor as predictors of characteristics of safety-related events reported by young nurses. Ergonomics. 2006;49(5-6):457-69.

Engels J, et al. Work related risk factors for musculoskeletal complaints in the nursing profession: results of a questionnaire survey. Occup Environ Med. 1996;53(9) :636-41.

Estryn-Béhar M. Ergonomie hospitalière: théorie et pratique. Paris: Editions Estem; 1996.

Fielden S, Peckar C. Work stress and hospital doctors: a comparative study. Stress Med. $1999 ; 15(3): 137-41$.

Folkard S, et al. Shifwork safety, sleepiness and sleep. Ind. Med. 2010;13:20-3.

Fonseca R, Serranheira F. Sintomatologia músculo-esquelética auto-referida por enfermeiros em meio hospitalar. Rev Port Saúde Pública. 2006;vol temático:37-44.

Gaba D, Howard S. Fatigue among clinicians and the safety of patients. N Engl J Med. 2002;347(16):1249-55.

Grantcharov T, et al. Laparoscopic performance after one night on call in a surgical department: a prospective study. BMJ. 2001;323:1222-3.

Gray-Toft P, Anderson J. Stress among hospital nurses staff: its causes and effects. Soc Sci Med. 1981;15A:639-47.

Health and Safety Executive (UK). Occupational stress statistics bulletin 2002/03. London: HSE; 2003 [citado 2006 Nov 22]. Disponível em: http://www.hse.gov.uk/statistics/overall/ohsb0203.pdf.

Henriksen K, et al. Understanding adverse events: a human factors framework. In: Hudges R, editor. Patient safety and quality: an evidence-based handbook for nurses. Rockville (MD): Agency for Healthcare Research and Quality: U.S. Department of Health and Human Services; 2008.

Henriksen K, Kaye R, Morisseau D. Industrial ergonomic factors in the radiation oncology therapy environment. In: Nielsen R, Jorgensen K, editor. Advances in industrial ergonomics and safety, 5. Washington, DC: Taylor and Francis; 1993. p. 267-74.

Henriques JP, et al. Outcome of primary angioplasty for acute myocardial infarction during routine duty hours versus during off-hours. J Am Col Cardiol. 2003;41:2138-42. 
Institute of Medicine, Committee on Quality of Health Care in America. Crossing the quality chasm: a new health system for the 21st century. Washington, DC: National Academies Press; 2001.

International Ergonomics Association (IEA). Definition of ergonomics. Washington, DC: IEA; 2000 [citado 2013 Set 17]. Disponível em: http://www.iea.cc/01_what/What\%20is\%20Ergonomics.html.

Jha AK, Duncan B, Bates D. Fatigue, sleepiness, and medical errors. In: Making health care safer: a critical analysis of patient safety practices. Rocville (MD): Agency for Healthcare Research and Quality; 2001. p. 519.

Kho M.E. Carbone JM, Lucas J, Cook DJ. Safety climate survey: reliability of results from a multicenter ICU survey. Qual Saf Health Care. 2005;14:273-8.

Lagerstrom M, et al. Occupational and individual factors related to musculoskeletal symptoms in five body regions among Swedish nursing personnel. Int Arch Occup Environ Health. 1995;68(1):27-35.

Leape L, et al. Systems analysis of adverse drug events: ADE Prevention Study Group. JAMA. 1995;274(1):35-43.

Leplat J, Cuny X. As condições de trabalho: ergonomia: conceitos e métodos. Lisboa: Dinalivro; 2005. p. 143-57.

McIntyre T. Stress e os profissionais de saúde: os que tratam também sofrem. Anal Psicol. 1994;12(2-3):193-200.

Mclntyre T, Mclntyre S, Silverio J. Respostas de stress e recursos de coping nos enfermeiros. Anal Psicol. 1999;17(3);513-27.

McVicar A. Workplace stress in nursing: a literature review. J Adv Nursing. 2003;44:633-42.

National Institute for Occupational Safety and Health. Stress...at work. Atlanta (GA): NIOSH; 2006 [citado 2006 Nov 22]. Disponível em: http://www.cdc.gov/niosh/docs/99-101/.

NHS. Disponível em: http://www.nrls.npsa.nhs.uk/resources/patient-safety-topics/human-factorspatient-safety-culture/

Ombredane A, Faverge J. L'analyse du travail: facteur d'économie humaine et de productivité. Paris: Presses universitaires de France; 1955.

OSHA. Disponível em : https://www.osha.gov/SLTC/ergonomics/index.html, 2009.

Rasmussen J, Pedersen O. Human factors in probabilistic risk analysis and risk management: operational safety of nuclear power plants. Vienna: International Atomic Energy Agency; 1984.

Reason J. L'erreur humaine. Paris: Presses Universitaires de France; 1990.

Reason J. Managing the management risk: new approaches to organizational safety: Reliability and Safety in Hazardous Work Systems. Hove, UK: Lawrence Erlbaum Associates; 1993. p. 7-22.

Reiling J, Chernos S. Human factors in hospital safety design: handbook of human factors and ergonomics in healthcare and patient safety. Mahwah (NJ): Lawrence Erlbaum Associates; 2007. p. 275-287.

Reiling J, Knutzen BL, Wallen TK, McCullough S, Miller R, Chernos S.. Enhancing the traditional hospital design process: a focus on patient safety. Jt Comm J Qual Patient Saf. 2004;30(3):1-10.

Schaufeli W. Burnout. In: Firth-Cozens J, Payne R. Stress in health professionals: psychological and organizational causes and interventions. Chichester: John Wiley \& Son; 1999. p. 17-32.

Schaufeli W; Enzmann D. The burnout companion to study and practice: a critical analysis. London: CRC Press; 1998. 
Schwappach D, Boluarte T. The emotional impact of medical error involvement on physicians: a call for leadership and organizational accountability. Swiss Med WkI. 2009; 139(1): 9.

Serranheira F, Uva A, Sousa P. Ergonomia hospitalar e segurança do doente: mais convergências que divergências. Rev Port Saúde Pública. 2010;vol temático:58-73.

Shanafelt et al. Burnout and career satisfaction among American surgeons. Ann. Surg. 2010;251(6): 995-1000.

Smith-Coggins R, et al. Rotating shiftwork schedules: can we enhance physician adaptation to night schifts? Acad. Emerg. Med. 1997;4: 951-61.

Sousa P, Uva AS, Serranheira F, Pinto F, Ovretveit J, Klazinga N, et al. The patient safety journey in Portugal: challenges and opportunities from a public health perspective. Rev Port Saúde Pública. 2009; No. Esp.:91-106.

Spector P. Individual differences in the job stress process of health care professionals. In: FirthCozens J, Payne R. Stress in health professionals: psychological and organizational causes and interventions. Chichester: John Wiley \& Son; 1999. p. 33-42.

Stone PW, Harrison MI, Feldman P, et al. Organizational climate of staff working conditions and safety: an integrative model. In: Henriksen K, Battles JB, Marks ES, et al., editors. Advances in patient safety: from research to implementation (Volume 2: concepts and methodology). Rockville (MD): Agency for Healthcare Research and Quality; 2005 Feb. Disponível em: http://www.ncbi.nlm. nih.gov/books/NBK20497/.

Tanaka K, et al. Differences in medical error risk among nurses working two- and three-shift systems at teaching hospitals: a six month prospective study. Ind Health. 2010;48:357-64.

Uva AS. Comentário ao trabalho de Sousa Caixeiro, M.I. Luvas de látex: factor de risco nos profissionais de saúde. Rev Port Saúde Pública. 1997;15(4):63-4.

Uva AS. Diagnóstico e gestão do risco em saúde ocupacional. Lisboa: ACT; 2010. (Segurança e saúde no trabalho. Estudos, 17).

Uva AS, et al. Occupational health and ergonomics toward patient safety. In Ovretveit J, Sousa P, ed. lit. Quality and safety improvements research: methods and research practice from the international quality improvement research network (QIRN). Lisboa: Escola Nacional de Saúde Pública: MMC Karolinska Institutet; 2008.

Uva AS, Graça L. Saúde e segurança do trabalho: glossário. Lisboa: Sociedade Portuguesa de Medicina do Trabalho; 2004. (Cadernos avulso, 4).

Uva AS, Serranheira F. A segurança do doente também depende da saúde e segurança de quem presta cuidados. Hosp Futuro. 2008;7:25-6.

Wickens $C$, et al. An introduction to human factor engineering. 2nd ed. Upper Saddle River (NJ): Prentice-Hall; 2004.

Yassi A, Hancock T. Patient safety: worker safety: building a culture of safety to improve healthcare worker and patient well-being. Health Q. 2005;8 Spec No:32-8. 


\title{
7. Comunicação entre os profissionais de saúde e a segurança do paciente
}

\author{
Guilherme Brauner Barcellos
}

Iremos tratar, neste capítulo, de aspectos da comunicação entre médicos envolvidos no cuidado do paciente, entre médicos e outros profissionais, e entre os profissionais da saúde de modo geral. Também serão abordados os impactos que essas complexas interações podem determinar na segurança do paciente e as técnicas disponíveis para melhorar a comunicação. Evito, propositalmente, resumir o tema em comunicação entre os membros da equipe de cuidado, pois equipe é um grupo de pessoas que, formando um conjunto solidário, dedica-se à realização de um trabalho.

\section{A importância da comunicação e os impactos da fragmentação do cuidado}

Muitas vezes, no cuidado em saúde, somos incapazes de formar um conjunto solidário. E, sem trabalho em equipe, a segurança do paciente dificilmente consegue ser garantida. A inexistência de equipe torna as dificuldades maiores, e as ferramentas para aprimorar a comunicação passam a ser menos efetivas. O trabalho em equipe era menos importante no passado, mas, diante do aumento crescente da complexidade no cuidado em saúde, surgem evidências da sua importância.

Outro importante ponto dessa discussão é reconhecer que, em um ambiente no qual o cuidado é exageradamente fragmentado, além do necessário e do justificável, a efetividade também fica comprometida. Em uma situação utópica, os pacientes estariam sempre em uma única organização de saúde e seriam cuidados pela mesma pessoa - médicos assistentes não iriam para casa, o médico residente responsável pelo caso não seria trocado ao final do mês, não haveria necessidade de trocas de

Bons resultados no atendimento de pacientes com trauma ou infarto/ enfarte agudo do miocárdio, por exemplo, dependem mais da qualidade do trabalho em equipe que do brilhantismo do médico assistente (Wachter 2012). 
informações entre os profissionais. Mas a realidade do cuidado em saúde não é essa. A modernidade, cada vez mais, propicia quebras de continuidade do cuidado. A maioria das quebras de continuidade são inevitáveis (e para as quais buscaremos maneiras de torná-las o mais seguras possível), outras são evitáveis e simplesmente não devem ocorrer.

A fragmentação do cuidado (ainda mais comprometedora quando associada à falta de coordenação) é considerada por muitos especialistas em segurança do paciente um dos grandes desafios ou problemas da atualidade. Em um estudo clássico, investigadores descobriram que receber atendimento por médico estranho à equipe foi um preditor de complicações mais importante que a gravidade da doença do paciente (Petersen 1994). Em artigo há pouco publicado, foi descrita uma situação em que nove diferentes equipes se envolveram no cuidado de um mesmo paciente criticamente enfermo (Stavert, Lott 2013). O resultado foi um caos no cuidado em consequência de uma passividade coletiva. O título escolhido para esse artigo foi "O efeito espectador na saúde", em alusão ao fenômeno psicológico também conhecido como Síndrome de Genovese. Essa síndrome leva o nome de Catherine Susan Genovese, esfaqueada até a morte estando próxima de sua casa em Kew Gardens, no Queens, Nova York, sem que nenhum vizinho a ajudasse. As circunstâncias de sua morte e a falta de reação dos vizinhos tiveram grande repercussão na imprensa e instigaram investigações desse fenômeno do comportamento humano, chamado "difusão de responsabilidade".

Na saúde, o resultado de uma fragmentação necessária e da injustificável gera grande vulnerabilidade aos erros de comunicação nas transferências de pacientes ou nas trocas de informações.

A atenuação dos problemas poderia economizar USD 240 bilhões por ano nos EUA (IOM 2012). Dados da The Joint Commission têm demonstrado que problemas de comunicação são os mais comumente encontrados nas análises de causa-raiz dos eventos sentinela. 
Gráfico 1 - Eventos Sentinela mais comuns

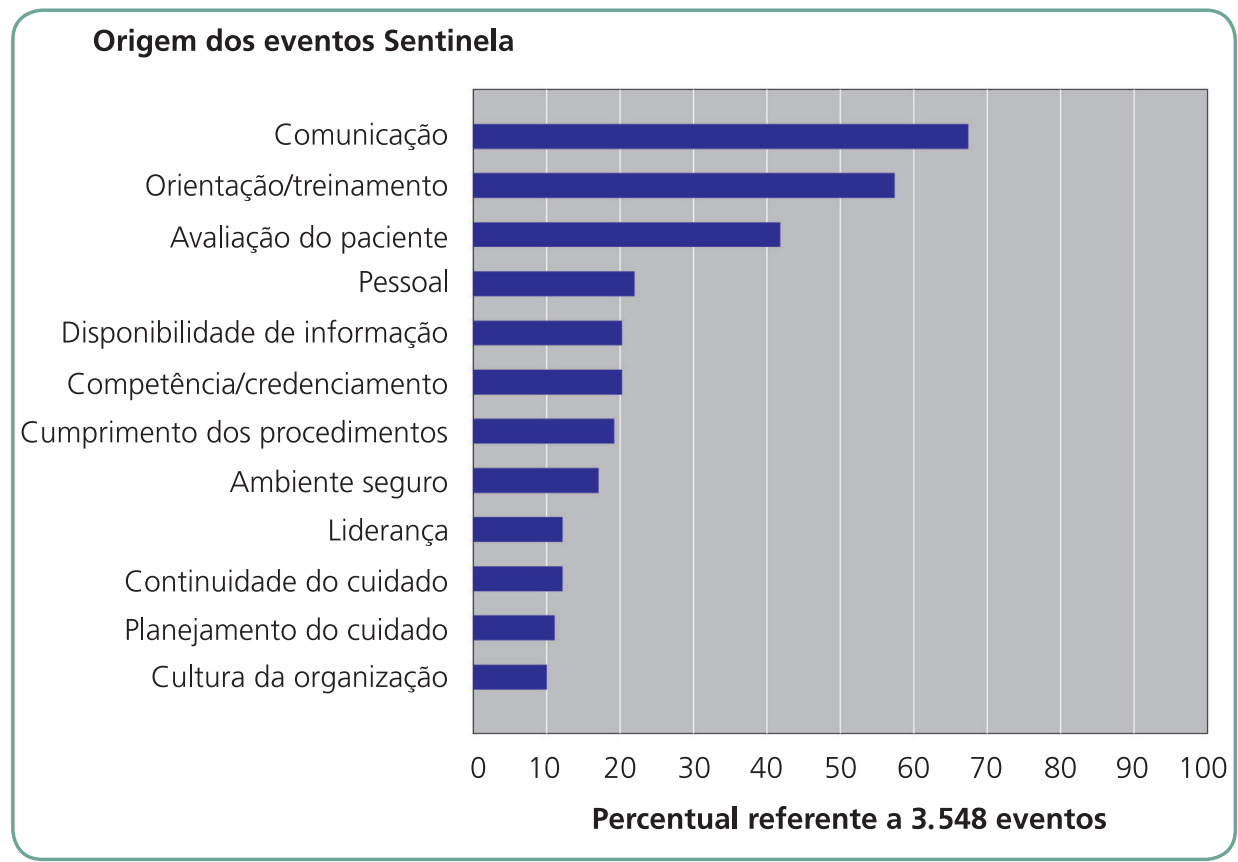

Fonte: Adaptado de ARHQ (2013).

Outro estudo acompanhou a troca de informações entre profissionais de ambulatório e descobriu que dados da consulta anterior estavam disponíveis em apenas $22 \%$ das vezes (van Walraven et al. 2008). Toda transição de cuidados carrega um potencial de dano, e todas merecem ser analisadas para promover reduções de riscos.

A Aliança Mundial para a Segurança do Paciente foi criada em 2004 pela Organização Mundial da Saúde com o objetivo de chamar a atenção ao problema da segurança do paciente. Em 2005, a Aliança identificou áreas de atuação prioritárias, por exemplo, melhorar a efetividade da comunicação entre os profissionais do cuidado, influenciada pelas metas de segurança do paciente da Joint Commission on Accreditation of Healthcare Organizations. 


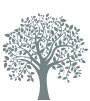

No endereço http://youtu.be/ Cr5WvJvEU5A, você pode ver como é possível um hospital melhorar a comunicação.
Figura 1 - Cartaz do Ministério da Saúde do Brasil sobre as metas de segurança do paciente, com destaque para a meta 2: "Melhorar a Comunicação"

\section{SEGURANCA DOPACIENTE}

Identificar corretamente o paciente.

Melhorar a comunicaçào

entre profissionais de Saúde.

Melhorar a segurança na prescriçalo,

no uso e na administraçấo de medicamentos.

Assegurar cirurgia em local de intervençăo, procedimento e paciente corretos.

Higienizar as mäos para evitar infeç̧ōes.

Reduzir o risco de quedas

uúlceras por pressda.

Melhorar sua vida, nosso compromisso.

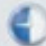

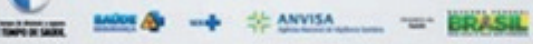

Fonte: http://portalsaude.saude.gov.br

Para ilustrar a importância de uma boa comunicação, apresentarei dois casos vivenciados ao longo de minha trajetória profissional e dos quais guardo forte lembrança. Em ambos, ocorreram erros complexos.

Em 2001, eu era residente de medicina interna e estava estagiando no setor de Emergência de um hospital. O médico responsável pelo serviço chegou até mim dizendo:

- Quer fazer uma cardioversão?

- O que é o caso? - perguntei.

- Se não quiser, eu mesmo faço, disse ele.

E, então, eu fiz! 
Para realizar esse procedimento, a paciente foi sedada. A cardioversão elétrica foi bem-sucedida, fazendo com que o ritmo passasse de fibrilação/fibrilhação atrial (a arritmia) para sinusal (normal). Somente depois fui revisar o caso. Tratava-se de paciente idosa, que havia chegado ao hospital com história de palpitações há duas horas. Não apresentava critérios de instabilidade, que costumam justificar uma cardioversão de emergência. O contexto foi interpretado como de fibrilação/fibrilhação atrial aguda (até porque a paciente trazia um eletrocardiograma prévio em ritmo sinusal), em que cardioversão elétrica costuma ser opção. Mas, em medicina e na vida, nem tudo que parece ser é.

Dona Laura (nome fictício) sofria de hipertensão, insuficiência cardíaca e de fibrilação/fibrilhação atrial paroxística. Ela já tinha passado por vários atendimentos em outros hospitais por episódios da arritmia. Se tivesse sido mais bem avaliada na admissão, a simples presença, no exame físico, de desvio grosseiro do ictus para além do $5^{\circ}$ espaço intercostal ou de um sopro cardíaco mitral já poderia ter "sinalizado". Não a examinei e não sei se alguém o fez, até a decisão de realizar a cardioversão. Se tivéssemos aguardado os familiares da paciente, e havia tempo e estratégias para isso, o diagnóstico correto teria sido realizado. Como Dona Laura demorou a acordar da sedação, foi estimulada. Percebeu-se, imediatamente, sinal de lateralização no exame neurológico. A paciente desenvolveu um acidente vascular cerebral - um evento adverso - como complicação do tratamento, que não costuma ser a primeira opção em casos de fibrilação/fibrilhação atrial crônica ou paroxística.

Quando eu estava no terceiro ano de residência/internato em medicina interna, um médico do serviço de emergência solicitou que eu fizesse um procedimento para obter o acesso venoso central em um paciente. Questionei exatamente a mesma coisa: - O que é o caso? Dessa vez, recebi uma resposta em tom áspero, mandando-me fazer. Fiz, e o paciente teve uma complicação - hemopneumotórax. A indicação do procedimento era questionável, e, além disso, o paciente tinha uma coagulopatia. A informação sobre a coagulação sanguínea alterada já estava disponível no momento do procedimento, mas só foi observada depois.

Em ambos os casos, o gradiente de autoridade entre o médico residente e o médico supervisor gerou problemas para os pacientes envolvidos. Erros como esses, nos quais um jovem médico (ou, muitas vezes, uma enfermeira) suspeita que alguma coisa está errada ou apenas quer mais informações, mas não se sente confortável em reforçar suas preocupações, infelizmente são frequentes. Isso não ocorre somente na área de saúde. Na maior colisão de tráfico aéreo de todos os tempos, o acidente de Tenerife, pouco antes de dois aviões colidirem causando a morte de 
583 pessoas, o copiloto fez ao comandante uma pergunta muito parecida com a minha: "O que é o caso?". E foi ignorado.

\section{Para refletir}

Você já vivenciou ou soube de alguém que tenha vivenciado alguma situação semelhante às relatadas no texto? Especificamente em relação à perda ou má compreensão de informação?

Qual foi o resultado? Como você imagina que esse tipo de situação possa ser contornada?

Nos casos relatados, além dos erros de trabalho em equipe e de comunicação, ocorreram erros na troca de informações (resultado de exame disponível e não considerado, histórico do paciente em outra organização não prontamente disponível). Não está no escopo deste capítulo a discussão sobre como melhorar o fluxo de informação entre hospitais distantes, mas fica o registro da importância de bancos de dados padronizados, que possam disponibilizar informação útil e oportuna. A partir de agora, vamos discutir os problemas e soluções dentro da organização de saúde e, em especial na alta hospitalar.

\section{Estratégias e técnicas para minimizar erros nas trocas de informações e de comunicação dentro de um hospital}

Este é um assunto abrangente. Darei preferência a apresentar as estratégias capazes de serem replicadas com alguma facilidade nas organizações de saúde. A maioria dessas estratégias não envolve barreiras intransponíveis e altos custos financeiros, mas todas dependem de liderança comprometida, equipe de trabalho coesa e forte, além de conhecimento de princípios básicos de melhoria da qualidade em saúde. Envolvem mudanças em sistema complexo e devem ser vistas através do olhar dos fatores humanos (antes, durante e após eventual implantação), para se certificar de que atenderão localmente suas finalidades e não criarão consequências inesperadas.

Não discorrerei, embora não seja menos importante, sobre a necessidade de formar profissionais da saúde que compreendam a importância do trabalho em equipe. Como também não mencionarei a 
importância da educação continuada em saúde, que precisa incorporar conteúdo de segurança do paciente, qualidade e administração em saúde, contribuindo para que profissionais tenham uma postura diferente frente ao erro humano e visão crítica a gradientes de autoridade que ultrapassam o necessário e o bom senso.

\section{Unidades geográficas}

São locais, nos hospitais, entregues a um propósito específico (por exemplo, uma enfermaria de clínica geral) e para profissionais pré-definidos (se não todos, ao menos aqueles mais envolvidos com o dia a dia do cuidado, por período), com limites geográficos, que podem ser físicos, como as paredes e portas que definem uma enfermaria inteira ( $7^{\circ}$ norte, por exemplo), ou virtuais, como quando um grupamento de leitos/camas dentro de uma área física maior é reservado para a mesma equipe de saúde. O esperado é que seja um facilitador para a formação de um conjunto solidário.

Estudos recentes têm demonstrado que estruturas assim estabelecidas estão associadas com melhor comunicação entre os profissionais da equipe (Gordon et al. 2011; Singh et al. 2012). Médicos sequer precisam ser hospitalistas (veja definição a seguir), podem seguir atuando no modelo tradicional, passando visita, mas a enfermeira saberá quem são, a hora que costumam passar, como localizá-los. Médicos e enfermeiros tendem a conhecer até mesmo gostos e preferências uns dos outros, poderão, com mais facilidade, pactuar rotinas e padrões. Pense no contrário agora, imaginando um enfermeiro enfrentando dificuldade com paciente cujo responsável é um médico que sequer conhece, e o quanto isso pode comprometer eficiência e satisfação de vários envolvidos. Em um dos estudos destacados anteriormente, com unidade geográfica e equipes fixas, perceberam-se $51 \%$ menos chamados por mensagens (acionamento dos médicos por meio de seus pagers ou celulares), embora tenham viabilizado mais encontros do médico responsável com seus pacientes (Singh et al. 2012). 
Figura 2 - Esquema de unidades geográficas

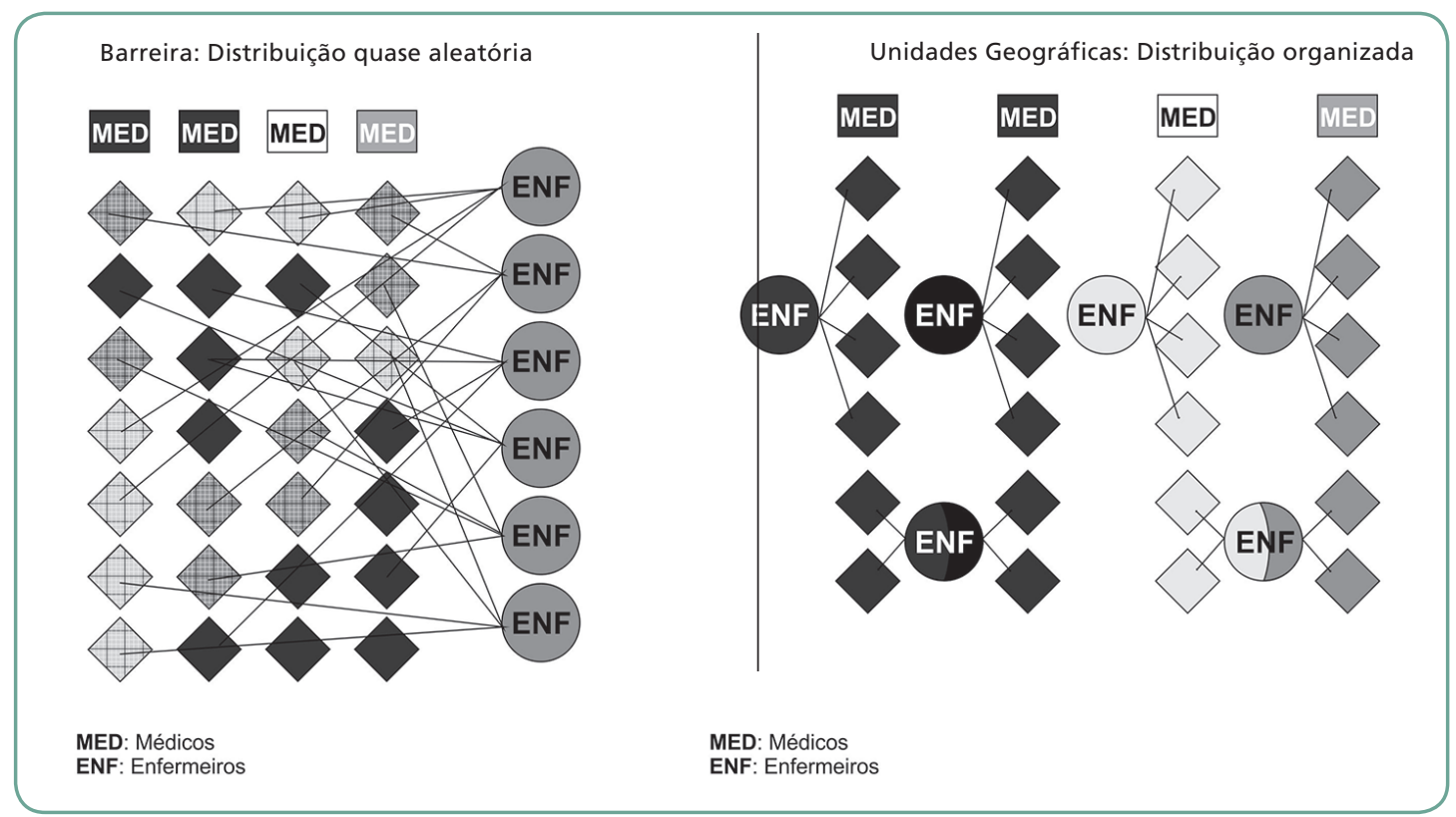

Fonte: Elaboração do autor.

Nota: À esquerda, um modelo tradicional em que os pacientes são distribuídos entre médicos, sem uma lógica. Nesse modelo, um médico pode ficar com um paciente em cada andar (leia-se cada andar com uma enfermeira, uma secretária, e assim por diante). No modelo da direita, temos a representação de uma unidade geográfica em que se concentram o máximo possível de pacientes em uma área com limites geográficos definidos e para uma equipe mais coesa.

As complexidades logísticas e políticas de organizar esse tipo de abordagem nos serviços de saúde não devem ser subestimadas, principalmente em hospitais com alta taxa de ocupação. Cabe registrar, ainda, que não há necessidade de implantá-la de maneira "tudo ou nada", podendo-se optar por favorecer, sempre que possível, organizações por áreas e equipes fixas.

\section{Rounds interdisciplinares estruturados}

Rounds interdisciplinares devem, idealmente, reunir todos os integrantes da equipe de cuidado, pelo menos em um momento do dia, para discutir seus pacientes, as ocorrências desde o último encontro, as metas e o plano terapêutico, caso a caso, em um formato colaborativo e pactuando decisões. Esses encontros não deveriam ter por objetivo apresentar o quadro clínico dos pacientes diariamente para um novo grupo de profissionais. Assim, os rounds tornam-se encontros longos e improdutivos. Devem ter foco nas metas e plano terapêutico, averiguando que mudanças de rumo são necessárias. 
Evidências demonstram que essa estratégia é capaz de:

\section{Resultados} dos rounds
Melhorar processos específicos (como adequação de caterização vesical, aderência a práticas baseadas em evidências) (Fakih et al. 2008, Ellrodt et al. 2007);

Favorecer melhores desfechos doença-específicos (como redução de pneumonia associada à ventilação mecânica) (Stone et al. 2011);

Melhorar a comunicação e colaboração entre os membros da equipe;

Diminuir o tempo médio de internação (Dutton et al. 2003, O’Mahony et al. 2007);

Reduzir os eventos adversos evitáveis (ÓLeary et al. 2011); e

Os rounds ocorrem mais frequentemente em unidades fechadas, como a Unidade de Tratamento Intensivo (UTI). A complexidade para o desenvolvimento dessas estratégias em unidades abertas é maior por diversas razões. Em um recente estudo (O'Leary et al. 2012), encontrou-se uma significativa variação de performance de trabalho de equipe em rounds dessa natureza, escancarando que não basta existirem. Uma sugestão é que, em paralelo, as chefias ajudem a garantir o bom andamento dessas iniciativas, observando, por exemplo, se um membro do time não domina completamente a discussão, ou se um gradiente de autoridade inadequado impede a participação confortável de outros membros da equipe.

Experiências práticas e opinião de experts sugerem que combinar unidades geográficas com rounds interdisciplinares estruturados pode tanto facilitar esses encontros como potencializá-los.

Os rounds devem seguir roteiros, como horário para iniciar e terminar, definição prévia de quem deve participar e qual o papel de cada um, em que e como deve contribuir. Os participantes precisam ser objetivos e ter o paciente como foco. A utilização de cartão de objetivos diário ou lista de verificação envolvendo questões estratégicas são muito úteis. Rounds interdisciplinares estruturados melhoram a comunicação entre membros da equipe, reduzem o tempo de permanência do paciente no hospital e melhoram o desempenho de vários indicadores de qualidade (Pronovost et al. 2003, Dubose et al. 2008, Dubose et al. 2010, Weiss et al. 2011). 
Quando visitei a Mayo Clinic, nos Estados Unidos da América, pude ver isso funcionar muito bem no Saint Marys Hospital. Com o auxílio de uma lista de verificação, era discutida, diariamente, a manutenção ou não, por exemplo, da sonda vesical de demora e do acesso venoso central. As listas de verificação são instrumentos que podem ser utilizados em diversas situações de cuidado em saúde para o bom gerenciamento/ gestão de informações do paciente sobre atividades a serem executadas, tópicos a serem enfatizados.

\section{Uso da técnica SBAR}

Com o intuito de melhorar a qualidade das trocas de informações entre os profissionais de saúde, algumas técnicas têm sido desenvolvidas para que mensagens importantes sejam ouvidas e atitudes sejam tomadas. Uma dessas técnicas é SBAR - Situation (situação), Background (história prévia), Assessment (avaliação) e Recommendation (recomendação). Originalmente, foi desenvolvida pela marinha nos EUA para ser usada em submarinos nucleares. Mais recentemente, tem sido usada com sucesso na saúde, sendo de fácil aplicação com bom treinamento.

Na maioria dos programas de treinamento, o foco é a enfermagem a fim de estruturar a comunicação com os médicos, de forma a capturar atenção e gerar ações apropriadas. A necessidade para o treinamento surgiu a partir do reconhecimento de que muitos enfermeiros têm sido educados para relatar histórias, enquanto os médicos têm sido treinados para pensar e, também, processar informações objetivas.

A seguir, apresentamos um exemplo de caso adaptado do livro Understanding Patient Safety (Wachter 2012).

No modo tradicional, a enfermeira Joana Silva (nome hipotético) se comunicaria com o médico da seguinte forma:

- Olá, doutor. O sr. João está tendo uma dor. Ele estava caminhando pelo corredor, depois de se alimentar bem no jantar. Ele estava um pouco sudorético quando teve a dor, mas Ihe dei todos os seus medicamentos, incluindo a insulina e o antibiótico. Ele foi submetido à cirurgia hoje, mais cedo.

Após o treinamento SBAR, a mesma enfermeira diria:

- Sou Joana Silva, enfermeira da enfermaria do $7^{\circ}$ andar e estou acompanhando o seu paciente, o sr. João dos Santos. Ele teve uma dor torácica de grau 8, em uma escala de 10, há cerca de cinco minutos, associada à dificuldade respiratória, sudorese e palpitações (Situação). 
É um homem de 68 anos, sem história prévia de doença cardíaca, que sofreu, ontem, uma resseção abdominoperineal sem complicações (História prévia).

Minha preocupação é que ele possa estar tendo uma isquemia cardíaca ou uma tromboembolia pulmonar (Avaliação).

Seria muito importante se você pudesse estar aqui dentro dos próximos cinco minutos (Recomendação).

\section{Uso da técnica de read back}

Muitas mensagens trocadas entre profissionais induzem ao erro, principalmente por telefone. Em um estudo que avaliou 822 chamados telefônicos sobre a comunicação de resultados críticos de laboratório, foram capturados 29 erros $(3,5 \%)$, alguns deles bastante relevantes (Barenfanger et al. 2004).

Essa situação existe não só na comunicação de resultados de laboratório, mas na ordem verbal do médico para o enfermeiro ou para médico residente, ou para o médico plantonista.

Essa técnica prevê que uma prescrição ou o resultado de exame fornecido verbalmente, ou por telefone, seja anotado por quem recebeu e, depois, relido para quem fez a solicitação. Também usada na aviação e em outras indústrias para prevenir erros de mensagens, passou a fazer parte das metas internacionais de segurança do paciente do manual da Joint Commission International.

\section{Processo normatizado de passagem de plantões/turnos}

A passagem de plantões/turnos é considerada o momento do cuidado de alto risco. Por isso, é fundamental existir um processo normatizado de passagem de plantões/turnos. Esse processo deve ocorrer em local determinado e adequado e horário pré-definido. Os profissionais envolvidos na passagem de plantão/turno devem estar disponíveis pelo tempo necessário para transmissão das informações necessárias. Além da troca verbal de informações, é importante o registro dos itens mais relevantes relativos ao cuidado.

Há um crescente reconhecimento das vantagens dos sistemas de registro computadorizados sobre as tradicionais fichas escritas para o registro de itens mais relevantes na passagem de plantão/turno. Um grupo 
da Universidade de São Francisco, na Califórnia, desenvolveu um módulo computadorizado de passagem de plantão denominado Synopsis (Wachter 2012). Esse módulo não é nada mais que um script para que as informações essenciais não deixem de constar. Uma das vantagens é que muitas informações da memória do prontuário eletrônico/ processo clínico do paciente são importadas, para que, no momento da conversa, os profissionais não percam tempo transferindo informações como resultados de exames laboratoriais verbalmente.

\section{Para refletir}

Você conhecia alguma das técnicas descritas anteriormente? Alguma delas é utilizada em sua organização?

Como você se comunica com os outros membros da equipe com a qual trabalha?

O que acredita ser possível melhorar na atual forma de troca de informações?

Publicação interessante a ser destacada como forma de demonstrar a importância de projetos para melhorar as passagens de casos nas organizações diz respeito à avaliação do I-PASS Handoff Bundle, por meio de estudo prospectivo multicêntrico recentemente publicado (Starmer et al. 2014).

Os autores foram capazes de demonstrar redução de $23 \%$ em erros envolvendo essas questões. Muito além de apenas uma ferramenta já existente e que representa um mnemônico auxiliar às passagens de casos orais e escritos, a iniciativa contou com a incorporação de conteúdos teóricos relacionados ao assunto no currículo formal daqueles em treinamento nas organizações envolvidas, capacitações, inclusive dos instrutores, mecanismos de feedbacks, além de pesada campanha institucional para melhor aproveitamento e sustentabilidade do programa. Dada ênfase no período da intervenção direcionada à educação de residentes e estagiários, muitos programas de residência médica nos EUA e no Canadá estão incluindo ou aprimorando currículos a fim de que a comunicação ganhe maior importância e, quem sabe, sejam capazes de reproduzir os resultados.

\section{A presença dos médicos hospitalistas}

Para entendermos o modelo em que atuam os hospitalistas, chamado Medicina Hospitalar (MH) - Hospital Medicine (HM) -, vamos revisar um pouco a evolução histórica nos EUA, em que o modelo tem se des- 
tacado, e, em seguida, discutir as suas características e como ele pode auxiliar no trabalho em equipe e na boa comunicação.

\section{O contexto histórico}

Até poucos anos atrás, a regra era: o mesmo médico que atendia a pessoa no ambulatório ou em casa se encarregava de cuidar dela também durante uma eventual internação/internamento - "passando visita". Ocorre que inúmeros fatores alteraram gradativamente essa realidade nas enfermarias (já havia acontecido algo parecido nas unidades de terapia intensiva e emergência). Os hospitais e os pacientes foram se tornando, progressivamente, mais complexos. Os médicos americanos que atuavam na atenção primária e não atendiam um alto volume de pacientes internados foram perdendo o interesse, principalmente em função da mudança no modelo de remuneração. Os custos do cuidado hospitalar atingiram patamares alarmantes.

Maior eficiência, por meio da redução de custos, tornou-se obrigatória, e o tempo de internação/internamento precisava ser reduzido. Em 1999, o relatório do Institute of Medicine (Kohn et al. 1999) trouxe à tona a questão dos erros no cuidado à saúde, e, a partir dele, o movimento de segurança do paciente e da qualidade assistencial ganhou força. Os gestores começaram a se dar conta de que precisavam mais dos médicos, ou de pelo menos parte deles, envolvidos no dia a dia das organizações, e não somente como visitantes. O modelo tradicional em que o médico "passa a visita" - foi se mesclando, aos poucos, com o de $\mathrm{MH}$, no qual os médicos passam a atuar mais dedicados às enfermarias. Três tipos de médicos categorizados de acordo com sua relação com os hospitais foram surgindo:

a aqueles com atuação eminentemente ambulatorial;

瞵 os chamados “visitantes importantes", os subespecialistas indispensáveis à terapêutica moderna;

os intensivistas, emergencistas e, mais recentemente, os médicos generalistas, que foram "criando raízes" nas enfermarias.

Ao perceber esse movimento, em 1996, o pioneiro Robert Wachter cunhou o termo hospitalista (hospitalist) em artigo publicado no New England Journal of Medicine (Wachter, Goldman 1996). No ano em que foi cunhado o termo, já havia cerca de 800 profissionais atuando como hospitalistas, em processo de aprendizado para lidar, principalmente, com as necessidades do sistema. Em 2006, eram 20 mil e, atualmente, são mais que 30 mil hospitalistas, consolidando essa como a área de atuação médica que mais rapidamente cresceu na história da medicina moderna americana (Wachter, Goldman 1996). 
Até 2004, metade dos programas de $\mathrm{MH}$ norte-americanos ainda não existia. Em 2009, a American Hospital Association mostrou que mais da metade dos 4.897 hospitais já empregavam hospitalistas, e a grande maioria dos hospitais com mais de 200 leitos/camas possuía programas de MH. No mesmo ano, outro estudo publicado no New England Jounal of Medicine descreveu que a chance de um paciente ser cuidado por hospitalista, de 1997 a 2006, aumentou aproximadamente 30\%. Valendo-se de dados do Medicare, investigadores descobriram, ainda, que os hospitalistas já respondiam pelo cuidado de mais de um terço dos pacientes internados (Kuo et al. 2009).

\section{O modelo medicina hospitalar}

MH é um modelo com características bem peculiares. Não se trata de plantão/turno clínico ou de uma equipe de apoio clínico e/ou gerencial. Classicamente, um grupo de médicos generalistas assume o cuidado do paciente e a coordenação dos processos assistenciais enquanto ele estiver hospitalizado, considerando os processos administrativos. $\mathrm{O}$ sinergismo da lógica assistencial e lógica administrativa orienta a ação, com foco no paciente e na eficiência dos serviços. Esse modelo pode reduzir, em média, o tempo de internação/internamento dos pacientes em $12 \%$ e os custos em $13 \%$.

Os hospitalistas são médicos generalistas que conduzem o cuidado clínico de pacientes e coordenam as equipes multidisciplinares, que recebem pacientes encaminhados pelos médicos da atenção primária e, eventualmente, de subespecialistas e os reencaminham para o colega, ao final da internação/internamento. A quebra de continuidade entre o hospital e o ambulatório é, com certeza, uma consequência do modelo; potencialmente, pode trazer problemas e, por isso, precisa ser bem trabalhada.

Hoje em dia, praticamente todos os melhores hospitais dos EUA - clínicas Mayo e Cleveland, hospitais de ensino da Harvard (Brigham and Women's e Beth Israel Deaconess) e os hospitais das Universidades da Califórnia e Chicago, entre outros - adotaram a MH. A maior parte das seguradoras e planos de saúde dos EUA - Humana, Kaiser, Aetna, Pacifi Care, Cigna - apoia o modelo. O encaminhamento de pacientes costuma ser voluntário.

As organizações de hospitalistas, Society of Hospital Medicine nos EUA, e o movimento por mim alavancado no Brasil (Barcellos et al. 2007) têm se posicionado contra o direcionamento compulsório de pacientes para hospitalistas. Médicos que queiram podem seguir internando no modelo tradicional. 


\section{Para refletir}

Ainda há muita confusão acerca do que são hospitalistas.

Você conhecia o tema? Achou que existia em sua organização, mas percebeu uma definição diferente?

Que vantagens um médico melhor posicionado para o trabalho em equipe pode trazer na intenção de melhorar a troca de informações entre profissionais?

Se o termo hospitalista ganhou notoriedade nos EUA, muito pela designação surgida no artigo de Robert Wachter, citado previamente, além da grande quebra de paradigma proporcionada pelo modelo de lá, é verdade que já existiam médicos atuando no modelo de $\mathrm{MH}$ em outros países. Na Europa, muitos sistemas já nasceram com o médico fazendo parte da coalisão interna dos hospitais, junto aos demais profissionais da saúde e gestores, formando equipe sem membro predominantemente a distância. Ocorre que em muitos casos não foi o generalista de Wachter que revolucionou o cuidado nos EUA, mas um modelo com ênfase em subespecialistas.

Frente a uma mudança comum a vários destes países no perfil epidemiológico dos pacientes, cada vez mais multimórbidos e complexos, percebe-se a tendência global ao generalismo, a partir da qual hospitais representados por departamentos em silos migram para proposta mais integrativa. Há, ainda, alguns exemplos na Europa de hospitalistas "puro sangue", e anteriores aos norte-americanos. Ocorre em Portugal, por exemplo, onde preferem utilizar o termo "internistas hospitalares", referindo-se a generalistas com formação em medicina interna e dedicação exclusiva a hospital, que exercem a função de coordenadores do cuidado. Assumem não somente atribuições clínicas, mas também atuam fortemente em comissões hospitalares, ensino e pesquisa. O que vem a ser isto senão um bom exemplo de hospitalista? Talvez, com algumas características que já estão sendo buscadas até mesmo pelos norte-americanos, com maior continuidade do provedor ao longo da hospitalização.

No Brasil, hospitalistas têm crescido em número e qualidade. Há programas bem alicerçados, como no Hospital da Cruz Vermelha Brasileira (HCV), no Paraná, onde reduziram muito expressivamente o tempo de permanência, aumentaram em eficiência e custo-efetividade do cuidado, e melhoraram a comunicação entre médicos e outros profissionais. Os hospitalistas do HCV situam-se em hospital geral de 172 leitos, onde até $70 \%$ dos pacientes hospitalizados são atendidos por esta equipe de 12 médicos (até agosto de 2017). Começaram no final de 2013 com um único profissional. 


\section{Gestão da alta hospitalar}

As altas ou transferências hospitalares são comumente tratadas como algo banal, mas não deveriam ser. Compõem uma etapa crítica do processo de cuidado.
Após as altas hospitalares, cerca de metade dos pacientes experimenta, ao menos, um erro associado ao cuidado em saúde, mais comumente relacionado a medicamentos. Um a cada cinco sofrem eventos adversos, e uma proporção significativa (metade em alguns estudos) é considerada evitável, atribuída a uma programação da alta inexistente ou malfeita (Wachter 2012).

Uma das consequências das altas mal programadas é a readmissão. Cerca de $20 \%$ dos pacientes que participam do programa Medicare nos EUA são readmitidos dentro de um mês após a alta, e um terço retorna em 90 dias (Jencks et al. 2009). No mesmo estudo, estimou-se em 17 bilhões de dólares o custo dessas readmissões evitáveis. Um estudo brasileiro analisou internações/internamentos hospitalares durante um ano no país e as readmissões em até um ano após. Foram selecionados 10.332.337 indivíduos para o estudo, totalizando 12.878 .422 internações/internamentos - dados oriundos dos sistemas de internações/ internamentos (SIH) do Sistema Único de Saúde (SUS) e de internações/internamentos não realizadas no SUS (CIH). A proporção de readmissões foi de 19,8\% (Moreira 2010).

Sunil Kripalani publicou estudo evidenciando que poucos sumários de alta chegam ao médico da atenção primária até o momento em que o paciente retorna para sua primeira consulta pós-alta hospitalar (Kripalani et al. 2007). Em um estudo no qual foram avaliados 1.501 sumários de alta de cinco hospitais de Boston, não havia registro:

De exame físico na admissão em $11,4 \%$.

Da condição clínica do paciente na alta em $14,2 \%$.

Da lista de medicações pré-admissão em 20,3\%.

De razões para alterações nas medicações em 35,3\%.

Do lembrete de exame complementar com resultado pendente em $47,2 \%$.

Do planejamento do follow up em 11,1\% (Gandara et al. 2009). 
Outro estudo publicado em 2006, após revisão de medicações por farmacêuticos do Brigham \& Women's Hospital, constatou que havia discrepâncias entre a lista de medicações pré-admissão e a alta em 49\%, sendo metade considerada potencialmente danosa. Havia discrepâncias também entre a lista da alta e das medicações em uso domiciliar em $29 \%$. Os autores avaliaram que o efeito de uma intervenção simples (aconselhamento do paciente por farmacêutico no momento da alta e após 3-5 dias por contato telefônico) seria capaz de reduzir os eventos adversos (Schnipper et al. 2006). De 2.644 altas de dois centros médicos acadêmicos, em 1.095 (41\%) havia resultados de exames complementares pendentes, e dois terços dos médicos do ambulatório desconheciam as pendências. Dessas pendências (investigadores e médicos entrevistados concordaram), 37\% demandavam ações e em 13\% eram consideradas urgentes (Roy et al. 2005).

Podemos fazer melhor? Sobre isso, Robert Wachter aponta: "Gestão da alta hospitalar não é ciência espacial, exige vontade institucional, uma equipe de trabalho forte e apreciação de princípios básicos de melhoria da qualidade."

Um pacote de medidas passíveis de replicação - Re-Engineered Discharge Project (RED), composto de aconselhamento antes da alta pelo enfermeiro (com educação do paciente, conciliação medicamentosa e agendamento de follow-up), um relatório de alta, um telefonema realizado por farmacêutico logo após a alta e uma consulta médica de seguimento em tempo adequado - foi capaz de minimizar parte dos problemas já discutidos (Jack et al. 2009).

Recentemente, a aplicação de uma iniciativa denominada de Better Outcomes for Older adults through Safe Transitions (BOOST) da Society of Hospital Medicine foi avaliada em 11 hospitais e apresentou redução média de readmissões em 30 dias de 13,6\%. O BOOST é um conjunto de medidas aplicáveis em qualquer país ou hospital (Hansen et al. 2013).

\section{Considerações finais}

Não é possível falar sobre segurança em saúde sem se referir à qualidade da interação e da comunicação entre os responsáveis pelo cuidado (Santos et al. 2010). Estratégias existem para facilitar a comunicação entre os diversos profissionais e funcionam melhor quanto melhor for o posicionamento deles para facilitar essa interação. Quem sabe você queira tentar alguma das sugestões aqui mencionadas em sua organização? Quem sabe tentar amanhã? 


\section{Referências}

Agency for Healthcare Research and Quality. TeamSTEPPS: Iong-term care version: module 1. Rockville, MD: AHRQ, 2013 [citado 2014 Ago 11]. Slide 16: Top contribution factors to medical erros (optional contente). Disponível em: http://www.ahrq.gov/legacy/teamsteppstools/ longtermcare/module1/igltcintro.htm\#s16.

Auerbach AD, Wachter RM, Katz P, et al. Implementation of a voluntary hospitalist service at a community teaching hospital: Improved clinical efficiency and patient outcomes. Ann Intern Med. 2002;137:859-65

Barcellos GB, Wajner A, Waldemar FS. Brazil blossoms: hospital medicine gains ground in South America. Hospitalist. 2007 Mar [citado 2014 Ago 11]. Disponível em: http://www.the-hospitalist. org/details/article/240537/ Brazil_Blossoms.html.

Barenfanger J, Sautter RL, Lang DL et al. Improving patienty safety by repeating (read-back) telefone reports of critical information. Am J Clin Pathol. 2004;121:801-3.

Davis KM, Koch KE, Harvey JK, et al. Effects of hospitalists on cost, outcomes, and patient satisfaction in a rural health system. Am J Med. 2000 Jun 1;108(8):621-6.

Dubose JJ, Inaba K, Shiflett A, et al. Measurable outcomes of quality improvement in the trauma intensive care unit: the impact of a daily quality rounding checklist. J Trauma. 2008 Jan;64(1):22-7.

Dubose J, Teixeira PG, Inaba K, et al. Measurable outcomes of quality improvement using a daily quality rounds checklist: one-year analysis in a trauma intensive care unit with sustained ventilatorassociated pneumonia reduction. J Trauma. 2010 Oct;69(4):855-60.

Dutton RP, Cooper C, Jones A, et al. Daily multidisciplinary rounds shorten length of stay for trauma patients. J Trauma. 2003 Nov;55(5):913-9.

Ellrodt G, Glasener R, Cadorette B, et al. Multidisciplinary rounds (MDR): an implementation system for sustained improvement in the American Heart Association's get with the guidelines program. Crit Pathw Cardiol. 2007 Sep;6(3):106-16.

Fakih MG, Dueweke C, Meisner S, et al. Effect of nurse-led multidisciplinary rounds on reducing the unnecessary use of urinary catheterization in hospitalized patients. Infect Control Hosp Epidemiol. 2008 Sep;29(9):815-9.

Gandara E, Moniz T, Ungar J, et al. Communication and information deficits in patients discharged to rehabilitation facilities: an evaluation of five acute care hospitals. J Hosp Med. 2009 Oct; 4(8):E28-33.

Gordon MB, Melvin P, Graham D, et al. Unit-based care teams and the frequency and quality of physician-nurse communications. Arch Pediatr Adolesc Med. 2011;165:424-8.

Hansen LO, Greenwald JL, Budnitz T, et al, Project BOOST: Effectiveness of a multihospital effort to reduce rehospitalization. J Hosp Med. 2013 Aug;8(8):421-7.

Huddleston JM, Long KH, Naessens JM, et al. Medical and surgical comanagement after elective hip arthoplasty. A randomized, controlled trial. Ann Intern Med. 2004;141;28-38.

Institute of Medicine [IOM]. The healthcare imperative: lowering costs and improving outcomes: workshop series summary. Washington, DC: The National Academies Press; 2010 [citado 2014 Ago 11]. Disponível em: http://books.nap.edu/catalog.php?record_id=12750.

Jack BW, Chetty VK, Anthony D, et al. A reengineered hospital discharge program to decrease rehospitalization: a randomized trial. Ann Intern Med. 2009 Feb 3;150(3):178-87.

Jencks SF, Williams MV, Coleman EA. Rehospitalizations among patients in the Medicare fee-forservice program. N Engl J Med. 2009 Apr 2;360(14):1418-28. 
Kohn L, Corrigan J, Donaldson M. To err is human: building a safer health system. Washington (DC): National Academy Press; 1999.

Kripalani S, LeFevre F, Phillips CO, et al. Deficits in communication and information transfer between hospital-based and primary care physicians: implications for patient safety and continuity of care. JAMA. 2007 Feb 28;297(8):831-41.

Kuo YF, Sharma G, Freeman JL, et al. Growth in the care of older patients by hospitalists in the United States. N Engl J Med. 2009 Mar 12;360(11):1102-12.

Lindenauer PK, Rothberg MB, Pekow PS, et al. Outcomes of care by hospitalists, general internists, and family physicians. N Engl J Med. 2007 Dec 20;357(25):2589-600.

Lundberg S, Balingit P, Wali S, et al. Cost-effectiveness of a hospitalist service in a public teaching hospital. Acad Med. 2010 Aug;85(8):1312-5.

McHugh MD. Daily multidisciplinary team rounds associated with reduced 30-day mortality in medical intensive care unit patients. Evid Based Nurs. 2010 Jul;13(3):91-2.

Meltzer D, Manning WG, Morrison J, et al. Effects of physician experience on costs and outcomes on an academic general medicine service; results of a trial of hospitalists. Ann Intern Med. 2002;137:866-74.

Moreira ML. Readmissões no sistema de serviços hospitalares no Brasil [tese]. São Paulo: Faculdade de Medicina da Universidade de São Paulo; 2010.

O'Leary KJ, Boudreau YN, Creden AJ, et al. Assessment of teamwork during structured interdisciplinary rounds on medical units. J Hosp Med. 2012 Nov/Dec;7(9):679-83.

O'Leary KJ, Buck R, Fligiel HM, et al. Structured interdisciplinary rounds in a medical teaching unit: improving patient safety. Arch Intern Med. 2011;171:678-84.

O'Mahony S, Mazur E, Charney P, et al. Use of multidisciplinary rounds to simultaneously improve quality outcomes, enhance resident education, and shorten length of stay. J Gen Intern Med. 2007 Aug;22(8):1073-9.

Petersen LA, Brennan TA, O'Neil AC, et al. Does housestaff discontinuity of care increase the risk for preventable adverse events? Ann Intern Med. 1994;121:866-72.

Pronovost P, Berenholtz S, Dorman T, et al. Improving communication in the ICU using daily goals. J Crit Care. 2003;18:71-5.

Roy $C L$, Poon EG, Karson AS, et al. Patient safety concerns arising from test results that return after hospital discharge. Ann Intern Med. 2005 Jul 19;143(2):121-8.

Roytman MM, Thomas SM, Jiang CS. Comparison of practice patterns of hospitalists and community physicians in the care of patients with congestive heart failure. J Hosp Med. 2008;3(1):35-41.

Santos MC, Grilo A, Andrade G, Guimarães T, Gomes A. Comunicação em saúde e a segurança do doente: problemas e desafios. Margarida Custódio dos Santos. Rev Port Saúde Pública. 2010; Vol Temat (10):47-57.

Schnipper JL, Kirwin JL, Cotugno MC, et al. Role of pharmacist counseling in preventing adverse drug events after hospitalization. Arch Intern Med. 2006 Mar 13;166(5):565-71.

Singh $S$, Tarima $S$, Rana $V$, et al. Impact of localizing general medical teams to a single nursing unit. J Hosp Med. 2012 Sep;7(7):551-6.

Starmer AJ, et al. Changes in medical errors after implementation of a Handoff Program. N Engl J Med 2014 Nov 6; 371:1803-12. Disponível em: http://www.nejm.org/toc/nejm/371/19/ Nov 6, 2014. doi: 10.1056/NEJMsa1405556. 
Stavert RR, Lott JP.The bystander effect in medical care. N Engl J Med. 2013;368:8-9.

Stone ME Jr, Snetman D, O' Neill A, et al. Daily multidisciplinary rounds to implement the ventilator bundle decreases ventilator-associated pneumonia in trauma patients: but does it affect outcome? Surg Infect (Larchmt). 2011 Oct;12(5):373-8.

Van Walraven C, Taljaard M, Bell CM, et al. Information exchange among physicians caring for the same patient in the community. CMAJ 2008;179:1013-18.

Wachter RM. Understanding patient safety. New York: McGraw-Hill Companies; 2012

Wachter RM, Goldman L. The emerging role of "hospitalists" in the American health care system. N Engl J Med. 1996; 335:514-7.

Weiss $\mathrm{CH}$, Moazed F, McEvoy CA, et al. Prompting physicians to address a daily checklist and process of care and clinical outcomes: a single-site study. Am J Respir Crit Care Med. 2011 Sep $15 ; 184(6): 680-6$. 


\section{Envolvimento e segurança do paciente: desafios e estratégias}

Margarida Cabugueira Custódio dos Santos e Ana Monteiro Grilo

Neste capítulo, será abordada a temática do envolvimento do paciente no âmbito da segurança. Ao contrário do que ocorre com outras áreas relacionadas a esse tipo de envolvimento, como a adesão ou a satisfação, o papel do paciente nas questões de segurança tem sido ainda pouco estudado e, apesar de resultados positivos de muitas das ações já implementadas, esse é um assunto que necessita continuar a ser refletido e incluído na agenda da investigação/pesquisa científica e da formação dos profissionais de saúde.

Pretendendo abordar as questões principais do envolvimento do paciente em matérias de segurança, o capítulo integra, após a introdução ao tema, um ponto sobre a perspetiva do paciente, referindo-se aí às áreas e tarefas de envolvimento, os determinantes e os limites do envolvimento; um segundo ponto a respeito da perspetiva do profissional de saúde, quando se aborda o modelo subjacente ao envolvimento do paciente, os desafios e seus benefícios; um terceiro relativo aos desafios que o envolvimento representa para as organizações/serviços de saúde; e um quarto ponto que se centra nas estratégias de promoção do envolvimento.

\section{Participação e envolvimento do paciente nas questões de saúde e doença}

"Quem estuda medicina sem livros embarca num mar sem cartas de navegação. Quem estuda medicina sem os pacientes não deve, sequer, embarcar" (Osler 1937). 


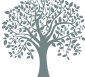

Sobre este tema, sugerimos, como leitura complementar, caso você tenha facilidade com a língua inglesa, o livro Best Care at Lower Cost; The Path to Continuously Learning Health Care in America S-23, uma publicação do Institute of Medicine, cujo pdf gratuito você pode obter mediante seu cadastro, no link https://www. nap.edu/catalog/13444/bestcare-at-lower-cost-the-path-tocontinuously-learning.
Na década de 1970, do século XX, a Organização Mundial da Saúde (OMS) referia a participação do paciente como um “objetivo desejável das políticas de saúde" e apelava para a necessidade de implementação de meios de promoção dessa participação (WHO 1978).

Hoje, é consensual que a promoção da participação e do envolvimento do paciente e da família, nos mais variados níveis dos cuidados de saúde, representa benefícios para os pacientes, os profissionais de saúde e as organizações. De facto, um conjunto alargado de investigações/pesquisas tem demonstrado que o envolvimento do paciente e da sua família está positivamente associado à melhoria dos cuidados de saúde, expressa pelo aumento da satisfação do paciente e da família (Dykes et al. 2017), por níveis mais elevados de motivação do paciente, adesão ao tratamento (WHO 2008), menor tempo de recuperação (Adams et al. 2001, Simmons et al. 2014) e melhoria da saúde geral do paciente (TNS Qual+, European Commission 2012).

O envolvimento do paciente tem vindo ainda a ser reconhecido como factor de redução dos custos de saúde e de maior eficiência nos cuidados, quer na fase de diagnóstico, quer no tratamento (Hibbard, Green 2013; WHO2016). Constituindo um determinante importante da relação de colaboração entre o profissional de saúde e os pacientes e/ou seus familiares, o envolvimento do paciente está ainda relacionado com maior transparência na comunicação, menor número de litígios por má prática médica (Studdert et al. 2006) e diminuição de eventos adversos (Thormton et al. 2017).

Numa recente revisão de literatura, realizada por Simmons et al. (2015), sobre a relação entre o envolvimento do paciente crónico e a melhoria da sua condição clínica, concluíram que o não envolvimento deveria ser quantificado como um risco para a gestão/gerenciamento efetiva da doença.

Nos últimos quarenta anos, assistiu-se a uma mudança importante na forma como profissionais de saúde e leigos compreendem o papel do paciente no seu processo de doença/saúde. Essa mudança é determinada, por um lado, pelo aumento da exigência dos pacientes e das famílias em relação ao conhecimento das questões do diagnóstico e do tratamento e, por outro lado, pelo abandono de uma atitude rigidamente paternalista do médico, que limitava a participação do paciente, negligenciando-a e desincentivando-a.

Atitudes mais congruentes, tais como modelos holista e de centração no paciente, têm vindo, progressivamente, a valorizar a participação do 
paciente, a quem é atribuído papel ativo na promoção da saúde e na prevenção e tratamento da doença.

A constatação dos benefícios do envolvimento do paciente e da família tem resultado em ações de informação e de educação dos pacientes, familiares e profissionais de saúde (AHRQ 2004, Joint Commission 2004), em recomendações institucionais e normas no âmbito de políticas de saúde (Finkelstein et al 2012, NHS Plan 2000) ou em programas e projetos de inclusão do paciente em questões que lhe dizem respeito (Anvisa 2012, Lindblad et al. 2017, WHO 2016).

O alargado consenso quanto à importância do envolvimento do paciente não exclui reservas que merecem ser consideradas e serão refletidas neste capítulo.

\section{Envolvimento do paciente nas questões de segurança relacionadas com a saúde e a doença}

Ao contrário do que ocorre em áreas como a adesão ao tratamento ou a decisão de procedimentos médicos, o envolvimento do paciente nas questões de segurança e de prevenção de eventos adversos tem sido menos estudado.

Na discussão sobre o envolvimento do paciente em matéria de segurança, distinguem-se três grandes áreas:

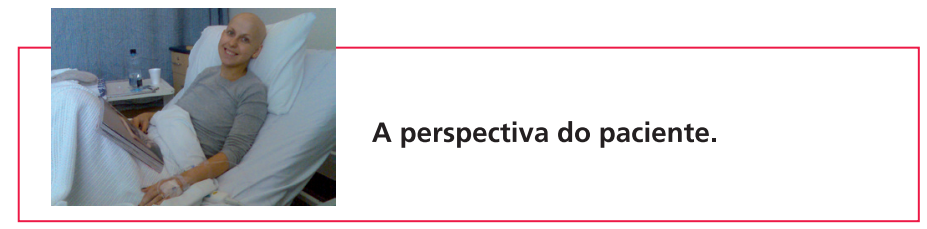

Fonte paciente: http://commons.wikimedia.org/wiki/File:Cancer_patient.jpg - Autor: jennifrog/2008.

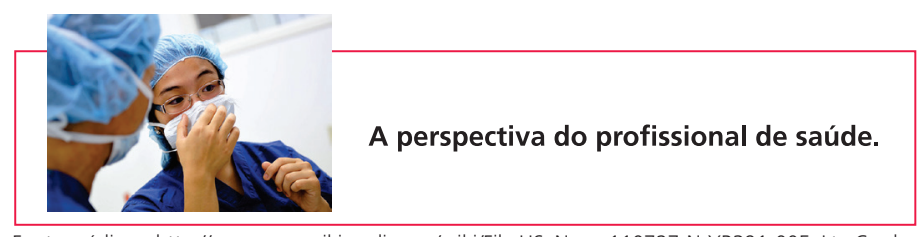

Fonte médicos: http://commons.wikimedia.org/wiki/File:US_Navy_110727-N-YR391-005_Lt._Cmdr. Jennifer_Freeman,_an_Obstetrics-Gynecology_physician_at_Naval_Hospital_Jacksonville.jpg.

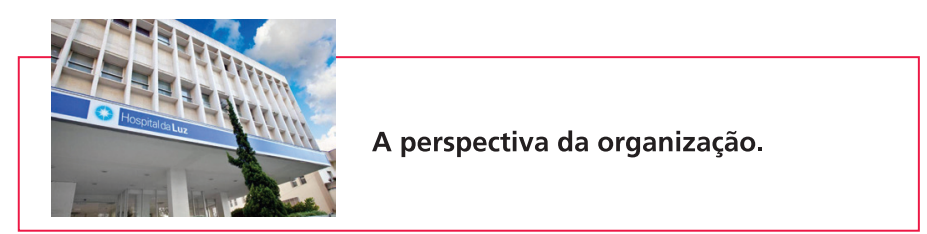

Fonte hospital: http://pt.wikipedia.org/wiki/Ficheiro:Hosp_da_Luz_-_S\%C3\%A3o_Paulo.JPG Autor: Rede Assistencial SP. 


\section{Envolvimento do paciente na segurança dos cuidados de saúde - perspetiva do paciente}

\section{Áreas e tarefas de envolvimento}

Quando se pensa no envolvimento do paciente nos cuidados de saúde e, especificamente, em matérias de segurança, consideram-se interrogações como: "O que se espera que o paciente faça?" ou "Qual o grau de fiabilidade/confiabilidade da contribuição do paciente?" e, evidentemente, "Quais os limites que devem ser considerados?" (Por exemplo, "O que ocorre quando o paciente expressa o desejo de não se envolver?" ou "O que se espera de um paciente que, emocionalmente perturbado, não temcondições para esse envolvimento?").

Relativamente ao "que se espera do paciente", vem sendo consensual que seu envolvimento não pode ser percebido como uma panaceia, nem ser regido por uma orientação em que são utilizados protocolos muito rígidos, e, como consequência, espera-se o mesmo de todos os pacientes. A constatação da diversidade de respostas dos pacientes às solicitações para o envolvimento tem despoletado/desencadeado investigações/pesquisas, com resultados frequentemente inconsistentes que apontam ações e níveis de participação muito diversos. A problemática estende-se à própria conceitualização de "envolvimento" e à diferenciação entre as representações de pacientes e de profissionais de saúde, à distinção entre envolvimento e participação, ou à modelização do envolvimento, considerando dimensões como a vontade do paciente, as características da doença e o efetivo grau de participação.

Em relação ao grau de participação, numa revisão de literatura, publicada em 2017, sobre a avaliação do envolvimento de pacientes e famílias na promoção da segurança no uso de medicamentos, Kim et al.(2017) definiram cinco níveis distintos de envolvimento:

- o nível mais baixo, em que os pacientes/famílias são apenas informados sobre os medicamentos;

- o segundo nível, com informação sobre o envolvimento com a equipa de saúde;

- o terceiro nível, com a capacitação do paciente/família sobre o tratamento;

- o quarto nível, em que pacientes e famílias partilham com a equipa os cuidados de saúde; e

- o nível mais elevado, em que pacientes e seus familiares são parte integrante da equipa de saúde. 
Apesar de ser consensual que a discussão e a investigação/pesquisa sobre o papel do paciente em questões de segurança deram apenas os primeiros passos, Vincent e Coultel, num artigo pioneiro, publicado em 2002 com o título Patient safety: what about the patient?, além de defenderem que os pacientes desempenham papel importante na promoção da sua segurança, indicavam já possíveis contribuições específicas do paciente em áreas como o estabelecimento do diagnóstico, a monitorização do tratamento e o relato/notificação de acidentes adversos (Momentol do Quadro 1). Mais recentemente, o reconhecimento de que o paciente pode ser um parceiro na discussão da qualidade dos serviços de saúde estendeu sua participação a contextos mais abrangentes (Momento 2 do Quadro 1), que vão para além de ações que respeitam, de forma mais restrita, sua segurança.

Quadro 1 - Papel do paciente na promoção da segurança

\begin{tabular}{|l|l|}
\hline Momento 1 & Momento 2 \\
\hline $\begin{array}{l}\text { Contribuição para o estabelecimento do } \\
\text { diagnóstico. }\end{array}$ & $\begin{array}{l}\text { Monitorização e gestão/gerenciamento de } \\
\text { tratamentos e procedimentos. }\end{array}$ \\
\hline Escolha da equipa de saúde mais adequada. & Redução de taxas de infeção hospitalar. \\
\hline $\begin{array}{l}\text { Participação na decisão de tratamento e na } \\
\text { gestão/gerenciamento do plano decuidados. }\end{array}$ & $\begin{array}{l}\text { Desenvolvimento de ações promotoras de } \\
\text { segurança e de qualidade dos serviços. }\end{array}$ \\
\hline $\begin{array}{l}\text { Verificação de que o tratamento é devidamente } \\
\text { administrado, monitorizado e seguido. }\end{array}$ & $\begin{array}{l}\text { Desenho e implementação de processos e } \\
\text { sistemas de cuidados centrados no paciente. }\end{array}$ \\
\hline $\begin{array}{l}\text { Identificação e relato/notificação de } \\
\text { complicações de tratamento e de eventos } \\
\text { adversos e incentivo de ações de alteração ou } \\
\text { remediação. }\end{array}$ & $\begin{array}{l}\text { Desenvolvimento e disseminação de programas } \\
\text { e materiais educativos. }\end{array}$ \\
\hline $\begin{array}{l}\text { Participação no desenho de projetos de } \\
\text { investigação/pesquisa. }\end{array}$ \\
\hline
\end{tabular}

Fonte: Coulter (2006); Coulter (2011); Koutantji et al. (2002); Vincent, Coulter (2002).

Institute for Patient and Family Centered Care (2013).

Ao considerarmos as contribuições do paciente indicadas no Quadro 1, é possível identificar quatro áreas principais de envolvimento:

* Tomadas de decisão em questões médicas de diagnóstico e tratamento.

滕 Monitorização dos procedimentos do diagnóstico e do tratamento.

噒 Identificação e relato/notificação de complicações e de eventos adversos.

滕 Participação em ações educativas e de formação.

* Participação em ações abrangentes de segurança do paciente no âmbito institucional (retornaremos a esse assunto mais adiante). 


\section{Envolvimento nas tomadas de decisão em questões médicas de diagnóstico e tratamento}

A saúde é, por excelência, uma área de tomadas de decisão. E se, no âmbito da saúde, considerarmos as situações de doença, identificaremos, com facilidade, vários processos de tomada de decisão:

* a decisão de procura de cuidados médicos;

a decisão do diagnóstico (que inclui todas as decisões de procedimentos de pesquisa/investigação e o estabelecimento final da patologia);

跕 a decisão de aceitação do diagnóstico;

路 a decisão do tratamento e de aceitação do tratamento, não menos importante (senão, a mais importante);

路 a decisão de implementação (isto é, adesão) ao tratamento.

Os processos de tomada de decisão apresentam sempre algum grau de complexidade e, evidentemente, a possibilidade de erro.

Iremos considerar, neste ponto, o envolvimento na prevenção (ou minoração) do erro médico no processo do diagnóstico, e o envolvimento na prevenção do erro do paciente relacionado com a inadequada adesão ao tratamento. Essas duas situações, o processo de diagnóstico e a adesão ao tratamento, são particularmente vulneráveis em questão de segurança do paciente.

Assim, por um lado, é hoje reconhecido que os erros do diagnóstico são frequentes (McDonald et al. 2013, Zwaan et al. 2010) e põem potencialmente em causa a segurança do paciente. Para além disso, constituem mais de $30 \%$ dos processos judiciais por má prática médica (Studdert et al. 2006). Por outro lado, apesar da adequação diagnóstica, a inadequada adesão ao tratamento põe potencialmente em risco a evolução positiva da doença e traz consequência para o bem-estar e a segurança do paciente. Interessa, então, saber de que forma a participação do paciente é capaz de contribuir para melhores diagnósticos e maior e mais responsável adesão às recomendações do tratamento.

O envolvimento do paciente nas tomadas de decisão acerca de sua saúde está consagrado em diretivas legislativas (por exemplo, a Diretiva 2011/24/EU Parlamento Europeu; a Política Nacional de Atenção Básica (2005), emanada pelo Ministério da Saúde, Brasília), e diz respeito à participação ativa do paciente na determinação do diagnóstico, nas decisões do tratamento (por exemplo, na escolha de planos terapêuticos), na escolha de equipas de saúde que mais se adequem a si e em quem ele confie a sua segurança. 
"Ouça o paciente, ele está a dizer-lhe o diagnóstico" (Osler 1937).

A frase, proferida por William Osler, considerado o pai da medicina moderna, tem tanta pertinência hoje como em 1937. A lição do professor Osler parece não ter ainda sido completamente aprendida, e os pacientes continuam a dizer que são pouco ouvidos, e suas preocupações pouco consideradas para o diagnóstico. Contudo, a contribuição do paciente, como "especialista sobre si", para o estabelecimento do diagnóstico, não só atempado/oportuno, mas também mais preciso, tem sido confirmada em investigações/pesquisas recentes (McDonald et al. 2013, Santos et al. 2010, Piker Institut Europe 2010).

Para a participação efetiva do paciente na determinação do diagnóstico, é essencial a valorização de todas as suas queixas, da sua história clínica, das suas crenças em relação a sintomas e do seu conhecimento em relação a si (Joyce-Moniz, Barros 2005). A participação do paciente ainda poderá ser maximizada pela sua motivação, pelo papel que ele próprio se atribui na sua relação com os profissionais de saúde e grau de literacia em relação a questões de saúde (Coulter 2011).

Quanto aos benefícios da participação nas decisões do tratamento, apesar do número reduzido de estudos que demonstram evidência científica, não é difícil entender que atitudes orientadas para a partilha com o paciente são mais facilitadoras do estabelecimento de comunicação entre o profissional de saúde e o paciente (e/ou família), e, que a comunicação é uma condição indispensável para que o paciente compreenda os procedimentos e os benefícios do tratamento (Santos et al. 2010).

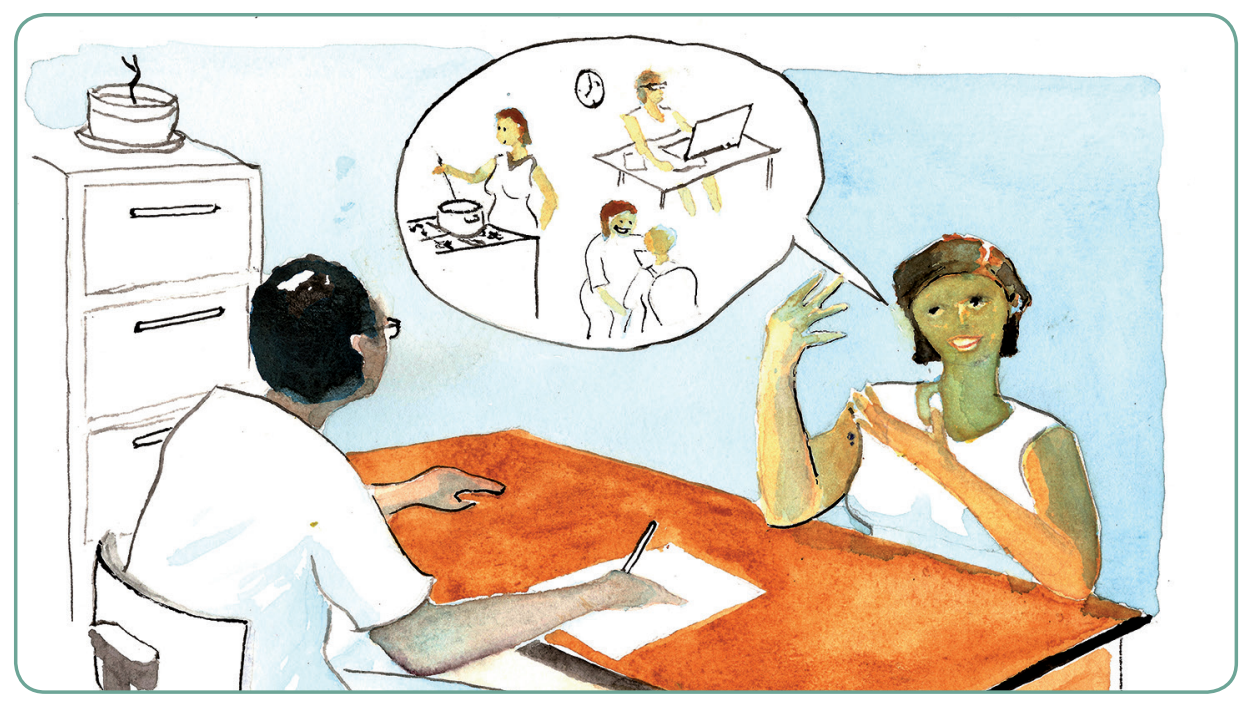

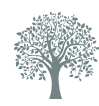

Sobre esse tema, sugerimos, como leitura complementar, o texto Shared Decision Making - The Pinnacle of Patient-Centered Care, de Michael J. Barry e Susan Edgman-Levitan, publicado em 2012 em The New England Journal of Medicine, disponível em: http://www. nejm.org/doi/full/10.1056/ NEJMp1 109283\#t=article 
Na realidade, a comunicação será essencial na: compreensão das preferências do paciente (mesmo em relação ao grau de envolvimento); capacitação quanto à sua doença e às recomendações do tratamento; adequação das decisões ao paciente e às suas competências. O paciente que conhece o tratamento, que percebe e discutiu suas implicações, seus possíveis efeitos secundários e sua efetiva ação na doença estará, com certeza, mais preparado não só para o seguir e não o abandonar devido, por exemplo, a falsas expetativas, mas também para identificar complicações, atempadamente/ oportunamente reportá-las ao médico e com ele discutir as alterações necessárias.

Para além disso, alguns estudos verificaram que a participação do paciente nas decisões de tratamento reduz a prescrição de medicamentos, diminuindo assim o potencial de dano do tratamento (Dentzer 2013), e aumenta a responsabilização do paciente pelo seu tratamento (Coulter et al. 2008). Ouvir o paciente e envolvê-lo nas tomadas de decisão são atitudes que vêm sendo também associadas a níveis mais elevados de adesão ao tratamento e à satisfação com os cuidados (Weingart et al. 2011).

Acresce ainda que, comparativamente a outros tipos de envolvimento na área da segurança, estudos referem essa forma de participação como da preferência de maior número de pacientes, porque é sentida como "menos intrusiva" do que outro tipo de ações, por exemplo, questionar os profissionais sobre a lavagem das mãos ou a esterilização de instrumentos (Waterman et al. 2006).

\section{Envolvimento na monitorização dos procedimentos do diagnóstico e do tratamento}

Nesta área, consideramos importante distinguir entre ações:

\section{Ações de envolvimento do paciente}

\author{
Em que o paciente intervém verificando de forma direta \\ as condições de segurança ligadas aos procedimentos a \\ que é sujeito, e
}

outras de automonitorização do tratamento e da evolução clínica.

\section{Quanto à participação do paciente na verificação e monitorização das condições de segurança}

O programa Partners in your care é um exemplo da promoção do envolvimento do paciente num problema antigo, que tem sido provado de difícil resolução: a lavagem das mãos (isto é, os profissionais lavarem as mãos antes e depois de qualquer procedimento que envolva contacto 
com risco de contaminação). Segundo a Joint Commission on Accreditation on Healthcare Organization (2005), apesar das diversas campanhas, os profissionais de saúde lavam as mãos apenas em 50\% das vezes consideradas adequadas. Com o referido programa, pretendeu-se envolver o paciente nesse cuidado. Os pacientes foram esclarecidos quanto aos objetivos, foi-lhes entregue a brochura Did You Wash Your Hands?. Os resultados da implementação do programa num Serviço de Cardiologia do Ingham Medical Center, no Michigan, foram considerados positivos, revelaram aumento do número de lavagens e diminuição dos índices de infeção hospitalar.

Exemplos semelhantes encontram-se em ações de incentivo do paciente e da família noutras áreas de cuidados, como cirurgias, em que é pedido ao paciente para, na sala de antecâmara da cirurgia, confirmar com o médico o campo cirúrgico (por exemplo, qual é a perna que será submetida à intervenção), o estabelecimento do tratamento, em que é pedida a ação direta do paciente na confirmação da adequação do tratamento (por exemplo, se foram tidos em consideração informações sobre dados de saúde como alergias), ou dos procedimentos do tratamento (por exemplo, confirmando o seu nome no protocolo de tratamento).

O envolvimento do paciente nessas ações tem levantado discussão e suscitado dúvidas que se prendem sobretudo com o acréscimo de responsabilidade do paciente em matérias que não domina (autores falam mesmo na passagem da responsabilidade do médico para o paciente) e com a falta de evidência científica em relação à efetiva eficácia dessas ações na segurança do paciente.

\section{Quanto à automonitorização}

Como já foi referido, os pacientes que são devidamente informados sobre o plano de tratamento e os possíveis efeitos secundários estarão em melhor situação para participar quer no seu autocuidado, quer na gestão do tratamento e na avaliação da evolução clínica. Os benefícios da automonitorização do tratamento têm sido estudados em áreas diversas, desde os tratamentos em patologias cardíacas/de foro cardíaco (Douketis 2001) até os cuidados primários. Como conclusão desses estudos, temos que o paciente pode ser um parceiro relevante na identificação de sinais de complicações do tratamento e, consequentemente, na necessidade e no reajuste dos planos de intervenção, bem como na prevenção de eventos adversos. Um dos estudos de referência nessa área é o realizado por Connock e colaboradores (2007) com o objetivo de analisar a efetividade e custo-benefício de autogestão/autogerencia-
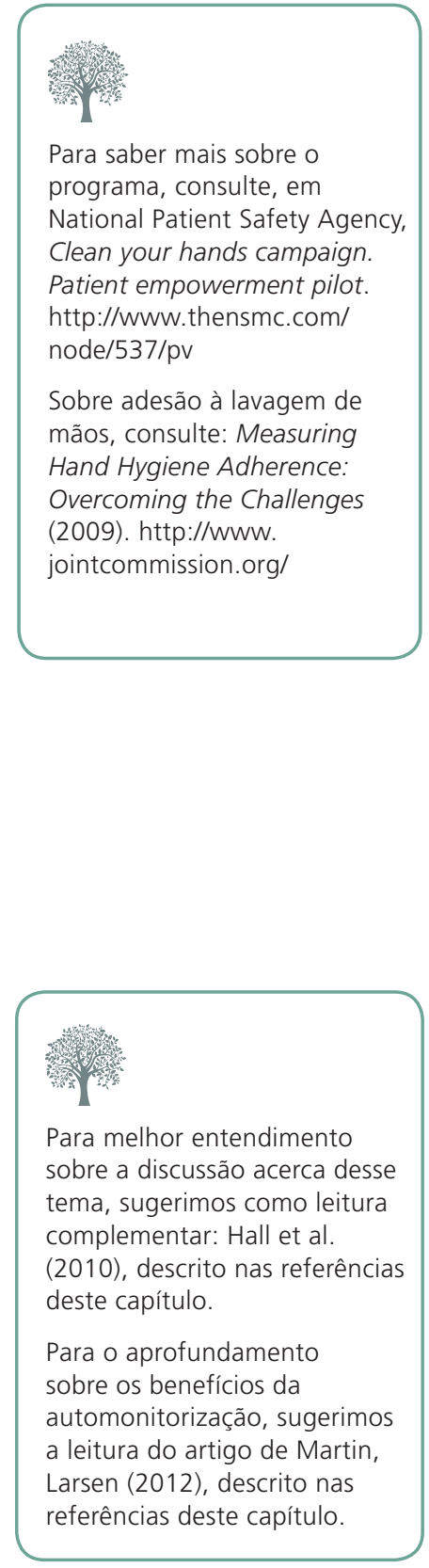


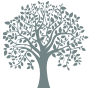

Sobre esse tema, sugerimos como leitura complementar o trabalho de A. Coulter (2011), também descrito nas referências.

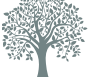

Para saber mais sobre esse tema, consulte Spencer J, Godolphin W, Karpenko N, Towle A The Health Care Foundation (2011), Inspiring Improvement. Report:Can patients be teachers?

Disponível em https://www. health.org.uk/sites/default/files/ CanPatientsBeTeachers.pdf mento no tratamento com anticoagulantes orais em comparação com a monotorização de base clínica (realizada por profissionais de saúde). Os autores concluíram que, entre os 16 (trails) estudados, a automonitorização do tratamento tinha melhores resultados que a monitorização clínica mais comum nesses casos, e os resultados foram tão bons como nas situações em que a monitorização clínica era avaliada como de qualidade e efetuada por especialistas.

\section{Envolvimento na identificação e relato de complicações e de eventos adversos}

A identificação e o relato de eventos adversos têm sido dois dos focos de maior atenção das ações para a segurança do paciente. Na realidade, se nem sempre os eventos adversos podem ser prevenidos, então eles devem ser cuidadosamente identificados e reportados de forma a reduzir o dano e aumentar o conhecimento de situações de risco. Esses procedimentos podem mesmo ajudar a implementação de processos que levem à sua diminuição. Em conformidade com essa constatação, têm vindo a ser implementados, em muitos países e organizações de saúde, sistemas de análise e relato/notificação de incidentes.

As contribuições dos pacientes para o relato/notificação de incidentes adversos é hoje, igualmente, objeto de atenção e investigação/pesquisa, e, de novo, resultados de estudos empíricos revelam alguma inconsistência. No entanto, a prática clínica e alguns programas, implementados quer em contexto hospitalar, quer em ambulatório (por exemplo, em relação a medicamentos), têm revelado benefícios.

A esse respeito, em 2008, Weissmane e colaboradores publicaram um estudo financiado pela Agency for Healthcare Research and Quality em que compararam as respostas de pacientes $(n=998$ pacientes cirúrgicos pós alta hospitalar) e profissionais de saúde a um questionário sobre eventos adversos ocorridos durante o internamento/internação. Os autores concluíram que os pacientes não só demonstravam ter consciência de eventos que não foram reportados, como, comparativamente, indicavam a ocorrência de um número maior desses eventos. Apesar de, como referido pelos autores, esses resultados não poderem ser considerados gold standard, e, apesar de questões como a possível confusão por parte dos pacientes entre eventos adversos e situações de diminuída qualidade de prestação, deverem ser consideradas, parece, neste estudo, claro, que os pacientes internados estão despertos para as questões de segurança e podem ser parceiros na identificação de situações de risco. 


\section{Envolvimento em ações de educação no âmbito da saúde}

"[...] for the junior student in medicine and surgery, it is a safe rule to have no teaching without a patient for a text, and the best teaching is that taught by the patient himself" (Osler 1903).

Tradução livre: para o estudante júnior em medicina e cirurgia, é uma regra segura não ter ensino sem um paciente, e o melhor ensino é aquele ensinado pelo próprio paciente.

A ideia de que o paciente pode ter um papel relevante na formação dos profissionais que lhe prestam cuidados de saúde não é recente. No entanto é pouco frequente ver pacientes ou familiares serem chamados a ter um papel ativo nessa formação. Existem, contudo, estudos que mostram evidência dos benefícios dessa participação, quer para os profissionais de saúde, quer para os próprios pacientes e suas famílias (Ashley et al. 2009, Towle et al. 2010).

Alguns países, como o Canadá (Farrell, Towle, Godolphin 2006) e o Reino Unido (UK) (Department of Health 2005), apresentaram estudos com esse tipo de participação e/ou têm já publicadas orientações para que o envolvimento dos pacientes faça parte dos Serviços Nacionais de Saúde e inclua a integração ativa dos pacientes nas atividades de treino e formação dos profissionais de saúde.

\section{Para refletir}

Como você percebe, em sua organização, o nível de envolvimento dos pacientes em questões como diagnósticos, tratamento e segurança do paciente?

Existe algum tipo de incentivo por parte dos profissionais de saúde para maior envolvimento dos pacientes e seus familiares?

Qual é seu grau de acordo com essa orientação?

\section{Determinantes e limites do envolvimento}

Após serem referidas as áreas de envolvimento, cabe, agora, mencionar a questão relativa aos determinantes e aos limites desse envolvimento. Partimos para essa discussão tendo como referência os resultados dos estudos nessa área, segundo os quais não só o grau de motivação para o envolvimento é muito diverso, como também os pacientes parecem mais disponíveis a se envolver em determinadas áreas e tarefas em detrimento de outras.

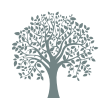

Para saber mais sobre esse tema, consulte Towle \& Godolphin, 2010 : www.chd. ubc.ca/ dhcc/node/67). 


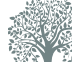

Para mais detalhes sobre factores determinantes para o engajamento, leia: Coulter (2011); Davis et al. (2007);

Martin, Larsen (2012).
Em relação aos determinantes para o envolvimento, são sobretudo referidos factores relacionados com:

a) o próprio paciente;

b) a doença e as tarefas; e

c) os profissionais de saúde.

\section{Quanto aos determinantes do próprio paciente}

O envolvimento tem provado estar associado a características demográficas, particularmente a idade, o género, os níveis de educação (em especial de literacia em saúde) e as redes de apoio. Assim, encontram-se níveis mais elevados de envolvimento em indivíduos mais jovens; nas mulheres; em pessoas com níveis mais elevados de literacia; e com melhores redes de apoio familiar (nesses casos, considerando também o envolvimento da família). Em relação a esses resultados, não é difícil entender que a idade e a literacia estão também a elas associadas. Na realidade, na grande maioria das sociedades de hoje, assiste-se ao aumento da literacia das camadas mais jovens e, consequentemente, a níveis mais elevados de sentimento de autoeficácia e de motivação para a participação nas mais variadas áreas de vida.

Ainda no que diz respeito ao paciente, tem sido atribuída progressiva relevância às suas crenças, em especial sobre a vulnerabilidade para a ocorrência de eventos adversos, a competência para o envolvimento e a atribuição de papel no processo de saúde e doença. Os resultados dos estudos apontam para níveis mais elevados de motivação para o envolvimento, associados a crenças de maior vulnerabilidade a incidentes e de atribuição de competência para sua prevenção, e atribuição de um papel mais ativo em relação à sua saúde, à doença e a seu tratamento. A esse respeito, é importante repetir que assistimos, nos nossos dias, ao aumento de vontade expressa dos pacientes em ser considerados parceiros nesses processos.

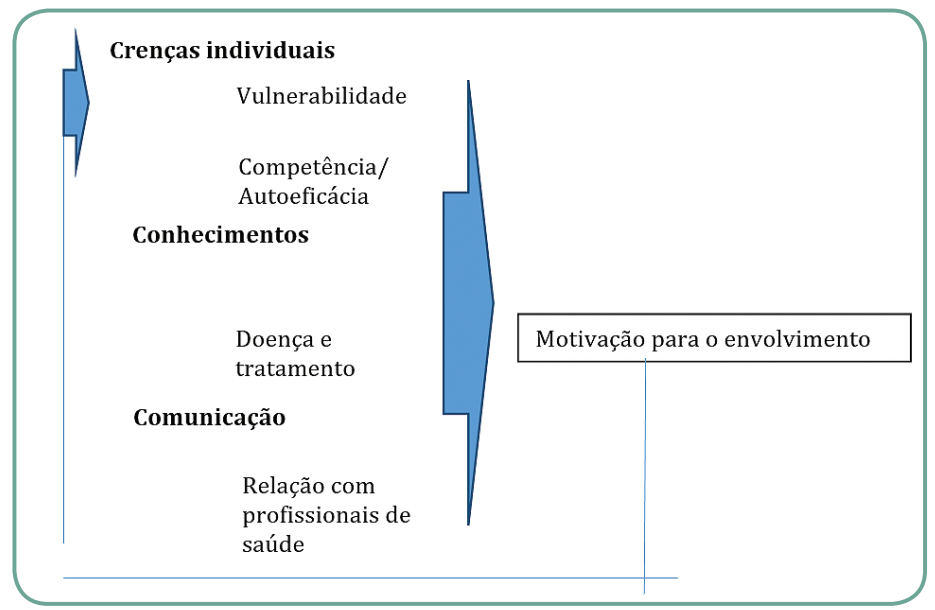




\section{Quanto aos factores relativos à doença e às tarefas}

Estudos preliminares associam níveis mais elevados de envolvimento em condições clínicas menos incapacitantes. Esses resultados são entendíveis se pensarmos que pacientes com condições clínicas mais severas ou incapacitantes estão, normalmente, mais debilitados, sentem-se menos conhecedores das questões associadas à gravidade do seu estado, estando, por isso, mais incapazes de tomar a responsabilidade na tomada de decisão. No entanto, em relação a esse aspeto, é de referir a existência de estudos, como o realizado por Stewart et al. (2000), no qual mulheres com cancro/câncer de ovário com pior prognóstico (isto é, maior possibilidade de metastização) mostraram estar mais envolvidas do que as que tinham melhor prognóstico.

Figura 1 - Determinantes do envolvimento do paciente

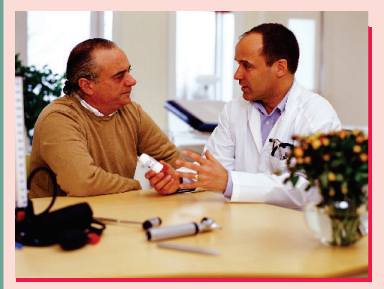

Tarefas associadas a maior envolvimento:

- que dizem respeito à monitorização;

- que não envolvem confronto com os profissionais de saúde; - que exigem menor conhecimento de temáticas médicas (por exemplo, manter um registo/registro diário de adesão ou a monitorização de sintomas).

Fonte: Wikipédia (2006).

\section{Quanto aos factores relacionados com os profissionais de saúde}

Parece claro que o envolvimento do paciente quer no que diz respeito à preparação, quer quanto ao nível de envolvimento, quer em relação às áreas ou tarefas de envolvimento e à efetiva importância atribuída a esse envolvimento é determinado pela influência e intervenção do profissional de saúde e pela coerência entre as crenças e vontades do paciente e as crenças e vontades do profissional.

A importância que atribuímos a esse factor leva ao seu aprofundamento nos pontos seguintes deste capítulo. 


\section{Envolvimento do paciente na segurança dos cuidados de saúde - perspetiva dos profissionais de saúde}

\section{Envolvimento do paciente e o modelo de centração no paciente}

"A era da medicina paternalista, onde o médico conhece o melhor para o paciente, e este se sente afortunado com isso, terminou" (Specter 2013).

É hoje aceito, pela maioria dos autores, que o modelo paternalista não promove o envolvimento e a segurança do paciente exige a inclusão desse último em todas as fases do processo terapêutico (planeamento/ planejamento, tomada de decisão, trabalho em equipa etc.) (Bronkart 2013). O modelo de centração no paciente é o modelo que sustenta o envolvimento do paciente pelo lado do profissional de saúde e pode ser definido como "os cuidados que respeitam e são responsivos às necessidades, desejos e preferências do paciente e asseguram que todas as decisões são guiadas pelos valores do paciente" (Institute of Medicine 2001, p. 3) .

Os profissionais de saúde apontam como principais benefícios do envolvimento do paciente a maior participação desse último, a automonitorização da saúde e a melhor compreensão da condição de saúde/doença, bem como dos tratamentos propostos (European Commission 2012).

Berwick (2009) destaca três asserções que sintetizam a centração no paciente, a saber:

1. As necessidades do paciente vêm primeiro.

2. "Nada acerca de mim sem mim" e

3. Todo o paciente é único. 
O primeiro ponto (1) enfatiza que o melhor interesse do paciente é o único que deverá ser considerado pelo profissional de saúde. Daqui decorre a necessidade de compreender, com minúcia, a experiência subjetiva do paciente e, quando adequado, da sua família. Efetivamente, o facto do profissional de saúde proceder com a melhor das intenções não garante a satisfação das necessidades do paciente e dos seus familiares (DiGioia et al. 2010).

No segundo ponto (2), o slogan, lançado pelo Ministério da Saúde do Reino Unido e utilizado mais recentemente (2001) pela Fundação Nacional de Segurança dos Pacientes (EUA), "Nada acerca de mim, sem mim" preconiza a necessidade de transparência e participação do paciente e exige que o profissional de saúde se comunique de forma eficaz (Bronkart 2013).

E, por último, o terceiro ponto (3) perspetiva o paciente como único e remete para a necessidade de o profissional dever considerar-se um "convidado" na vida do paciente, bem como para a aceitação da personalização dos cuidados prestados. Seguindo esses três pontos, fica claro que toda a equipa de saúde trabalhará empenhada em colmatar/atenuar as necessidades do paciente e dos seus familiares (DiGioia et al. 2007).

\section{Exigências do modelo de centração no paciente:}

- Partir da situação do paciente (explorar significações de doença e compreender a pessoa em sua totalidade).

- Legitimar a experiência de doença (por exemplo, reconhecer as preocupações, sentimento de perda do paciente).

- Aceitar o paciente como especialista (acreditar na capacidade do paciente para confrontar a situação de doença ou manter a sua saúde).

- Oferecer esperança realista (facultar esperança e suporte no contexto da incerteza ou de prognóstico reservado).

- Desenvolver uma parceria (essa parceria é negociada ao longo do tempo e assenta nas capacidades do paciente).

- Providenciar apoio para o paciente dentro no próprio sistema de saúde (guiar e apoiar o paciente no sistema de saúde).

Cabe, aqui, referir que os profissionais de saúde não podem responder às necessidades dos pacientes se estes não as expressam; para além disso, não conseguem diagnosticar com rigor ou prescrever com segurança se a informação relevante não consta do registo médico ou está incorreta. Nesse contexto, existem, atualmente, autores (por exem- 


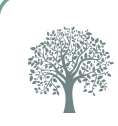

Para saber mais sobre o caso de Dave Bronkart, visite o endereço: http://www.ted. com/talks/dave_debronkart_ meet_e_patient_dave.html

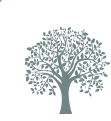

Para saber mais sobre o caso de Dave Bronkart, visite o endereço: http://www.ted. com/talks/dave_debronkart_ meet_e_patient_dave.html plo, Bronkart 2013; Coulter 2011), que poderemos apelidar de mais "radicais", defensores do livre acesso ao registo médico pelos pacientes e suas famílias, argu- mentando que se trata de uma forma especialmente eficaz de detetar erros e, como consequência, evitar incidentes. Os mesmos autores enfatizam que, considerando o constante progresso da medicina, é hoje humanamente impossível para qualquer profissional de saúde ser detentor de todo o conhecimento científico existente na sua área do saber. A título de exemplo, a partir de 2014, o número de artigos indexados, por ano, ao sistema de publicação da Medline ultrapassou o milhão. Dessa forma, quando um paciente inicia um processo de procura de informação, especialmente em situações de pior prognóstico ou mais raras (por exemplo, alguns tipos de cancro/ câncer), ele não deverá ser encarado com desconfiança, mas sim como possível coadjuvação ao próprio profissional.

São, aliás, cada vez mais comuns as situações em que o paciente confronta o clínico com possibilidades de tratamento encontradas por meio de pesquisas pessoais. Dave Bronkart é, atualmente, o exemplo mais divulgado dessas situações. Após o diagnóstico de cancro/câncer raro em estádio 4, Bronkart encontrou, fazendo suas pesquisas, um tratamento, desconhecido pelo seu médico, que lhe salvou a vida. Essa experiência levou o paciente a tornar pública sua condição e iniciar uma cruzada no sentido do maior envolvimento do paciente nos cuidados de saúde.

Figura 2 - Quando um paciente procura informação sobre sua condição de saúde (por exemplo, na internet), isso deve ser considerado pelo médico e discutido, pois demonstra o envolvimento do paciente com seu processo de cuidado

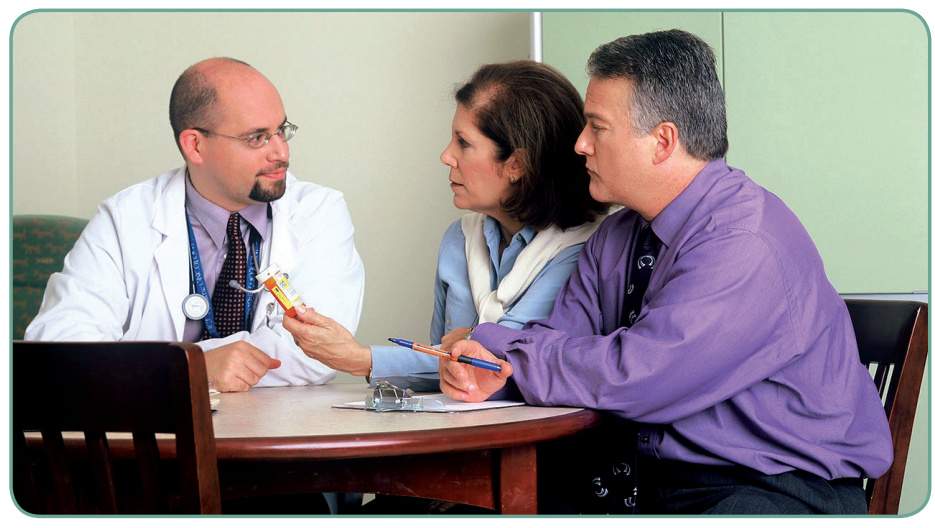

Fonte: Wikimedia Commons (2008).

Longe de considerar que tudo o que os pacientes encontram, nomeadamente na internet, aporta bons resultados terapêuticos, os autores parecem unânimes quanto à necessidade de valorizar a informação facultada no contexto da relação médico-paciente e encorajar o envol- 
vimento do paciente (Bronkart 2013; Coulter 2012). A atual Society for Participatory Medicine, traduz o esforço de vários pacientes e profissionais para promover esse envolvimento.

Centrado no princípio ético da autonomia (Neves 2006), o consentimento informado surge como um excelente exemplo da necessidade de envolvimento do paciente pelo lado do profissional de saúde. Afastando-se inequivocamente da perspetiva de Hipócrates, de quem ficou célebre a frase: "Fiz tudo ocultando ao paciente a maior parte das coisas [...]" (Hipócrates - 460-377 a.C. - Sobre a decência), o consentimento informado é hoje um conceito de tendência universal e pressupõe que “o paciente tem o direito a receber, e o médico o dever de prestar o esclarecimento sobre o diagnóstico, a terapêutica e o prognóstico da sua doença" (Ordem dos Médicos, n.1, art. 44, 2008).

O consentimento livre e informado requer que o profissional, após certificação da capacidade de discernimento do paciente, forneça informação de forma clara e honesta a respeito da natureza, duração, objetivos, riscos, efeitos e inconvenientes de um procedimento médico (por exemplo, exame de diagnóstico, tratamento) (Silva 1998). O profissional terá assim de, por meio de uma relação de pareceria (modelo de centração), confirmar a real compreensão do paciente e esclarecer suas eventuais questões, de modo a que esse último possa realizar uma escolha consciente e informada (Muniz, Fortes 1998).

\section{Para refletir}

Como profissional da área de saúde, como você vê a questão do envolvimento do paciente? Que benefícios você acredita que, na prática, esse tipo de postura pode trazer? E quais seriam os pontos negativos (caso existam)?

O que necessita de alterar/mudar para adquirir uma postura de centração no paciente?

Que dificuldades já experimentou ou prevê poder vir a experienciar na adoção dessa orientação?

Outro exemplo de centração no paciente diz respeito à comunicação de incidentes aos pacientes e famílias (disclosure). Ela pode ser definida como a "comunicação entre o profissional de saúde e o paciente ou familiar, na qual é reconhecida a ocorrência de um erro, discutido o acontecimento e estabelecida a ligação entre o erro e seu efeito, de forma que seja percetível para o paciente" (Lazare 2006).

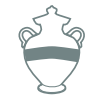

Importa notar que existem limites à aplicação do consentimento livre e informado que não cabem neste capítulo, nomeadamente os casos dos menores ou de adultos incapazes, e as situações de urgência (Oliveira, Pereira 2006).
Aqui, apresentamos uma visão geral do Disclosure, que será expandida e aprofundada no Capítulo 10 deste livro. 
A maioria dos autores considera essa informação como uma "boa prática", e, em vários questionários a profissionais de saúde, a porcentagem daqueles que têm intenção de comunicar um incidente é elevada, contrastando com o pequeno número daqueles que têm experiência real de o fazer (Sorensen et al. 2008; Gallagheret al. 2006 ).

Os pacientes que foram vítimas de um incidente e seus familiares esperam um pedido de desculpas, empatia e ajuda, bem como informação explícita e congruente de como o incidente ocorreu e do que será feito para que ele não volte a ocorrer no futuro (O'Donovan 2004). Para a grande maioria dos pacientes, as medidas que vão tomar após um incidente (decisão positiva ou negativa de litígio) estão diretamente relacionadas com a forma como a informação lhes foi transmitida nos dias imediatos à sua ocorrência (Berwick 2009; Boyle et al. 2006; Lazare 2006; Sorense et al. 2008).

\section{Aspectos a considerar pelo profissional de saúde na} comunicação de um incidente

A comunicação com o paciente deverá ser realizada por um profissional de saúde sênior (ainda que toda a equipa possa/deva ser envolvida no processo).

Providenciar um local que assegure privacidade e possa ser utilizado durante o tempo necessário.

Assegurar a possibilidade de o paciente estar acompanhado por familiares ou pessoas significativas.

Iniciar a comunicação com um pedido de desculpa, que expresse pesar pelo sucedido.

Fornecer uma explicação clara, evitando a utilização de terminologia técnica.

Mostrar disponibilidade para esclarecer todas as dúvidas do paciente e abertura para uma reunião futura (caso o paciente sinta necessidade)

Esclarecer o que será feito para melhorar a condição atual do paciente e minorar os efeitos provocados pelo incidente.

Indicar, de forma clara, que medidas serão tomadas pelos profissionais/ serviço para que um incidente dessa natureza não volte a ter lugar. 
O Consensus statement of the Harvard Hospitals: responding to adverse events, publicado em março de 2006 (Powell 2006), é um excelente guia para todo o processo de informação ao paciente relativo a um evento adverso, percorrendo, de forma prática e objetiva, as questões fundamentais de quais são os incidentes a serem revelados, por quem, quando e como. Sugere a necessidade de apoio para a vítima do incidente (cuidados de saúde gratuitos), mas também de uma estrutura dinâmica de apoio aos profissionais envolvidos (emotional first aid). Várias organizações de saúde, nas quais uma política de comunicação aberta é incentivada, verificaram, paradoxalmente, diminuição do número de reclamações e processos litigiosos (Berwick 2003; Berwick 2009; Lamb et al. 2003).

\section{Obstáculos/dificuldades dos profissionais de saúde no envolvimento do paciente}

A hipervalorização dos aspectos técnicos conduziu a que, durante muito tempo, a comunidade médica desvalorizasse a contribuição dos pacientes para seu processo terapêutico. Acreditava-se que a saúde/ doença englobava áreas muito específicas sobre as quais apenas profissionais altamente qualificados detinham conhecimento (Bronkart 2013). Não admira, portanto, que a literatura atual destaque algumas dificuldades que mergem quando os profissionais procuram utilizar um modelo mais centrado no paciente. Alguns manifestam certa apreensão perante a possibilidade de que, ao envolver o paciente, este possa, por um lado, discordar abertamente do profissional de saúde e, por outro lado, tente diagnosticar-se e tratar-se a si próprio (European Commission 2012) fazendo escolhas "erradas". Sem negar a possibilidade de que isso aconteça, Berwick (2009) salienta que essas situações constituem exceções, e casos extraordinários não devem servir de base para a construção de regras.

Outra dificuldade advém da sensação de que, ao trabalhar de acordo com o modelo de centração no paciente, o clínico negligencia seus próprios desejos e necessidades. Ora, como é sabido, esse modelo pressupõe que o profissional tome consciência das suas emoções e retome os princípios básicos de ajuda que caracterizam a relação profissional de saúde-paciente.

Por último, e com maior ênfase na literatura, surge a crença de que o envolvimento do paciente acarreta necessariamente mais custos. Contrapondo essa perspetiva, diversos estudos recentes (por exemplo, DiGioia et al. 2010; Greene, Hibbard 2011) têm vindo a demonstrar que a centração no paciente melhora os resultados de saúde sem acréscimo financeiro.

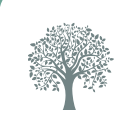

Para aprofundar esse tema, veja mais informações sobre o protocolo Spikes - protocolo de seis passos para comunicar más notícias (Baile et al. 2000). 


\section{Obstáculos dos profissionais de saúde para o envolvimento do paciente}

- Desejo de manter o controlo (dificuldade em passar do "fazer para" a "fazer com").

- Atitudes e crenças pessoais que dificultam mudança (por exemplo, considerar que a maioria dos pacientes são incapazes de tomar decisões na área da saúde).

- Tempo requerido para educação e resposta às questões do paciente.

- Tipo de doença do paciente.

- Especialidade do profissional de saúde (por exemplo, profissionais de cuidados primários tendem a envolver mais os pacientes, quando comparados com especialistas).

- Treino insuficiente (ou inexistente) para o envolvimento do paciente e medo da mudança.

Fonte: Bear \& Stockie (2014) e Longtin et al.(2010)

\section{Exemplo de comportamentos centrados no paciente que promovem envolvimento}

\begin{tabular}{|c|c|c|}
\hline $\begin{array}{l}\text { Comportamentos não } \\
\text { verbais (Epstein, Street } \\
\text { 2007) }\end{array}$ & $\begin{array}{l}\text { Comportamentos verbais } \\
\text { (Epstein, Street 2007; Stewart } \\
\text { et al. 2013) }\end{array}$ & $\begin{array}{l}\text { Verbalizações } \\
\text { (Brookart 2013) }\end{array}$ \\
\hline $\begin{array}{l}\text { - Manter contacto visual } \\
\text { - Acenos de cabeça } \\
\text { - Postura ligeiramente } \\
\text { inclinada } \\
\text { - Ausência de movimentos } \\
\text { distrativos (por exemplo, } \\
\text { agitação) }\end{array}$ & $\begin{array}{l}\text { - Escutar ativamente } \\
\text { - Encorajar a participação do } \\
\text { paciente utilizando perguntas } \\
\text { abertas } \\
\text { - Aceder às crenças, valores e } \\
\text { preferências do paciente } \\
\text { - Elicitar e legitimar as emoções } \\
\text { do paciente } \\
\text { - Indagar sobre família e } \\
\text { contexto social } \\
\text { - Sumarizar discurso do paciente } \\
\text { - Fornecer informação de forma } \\
\text { adequada de acordo com } \\
\text { as necessidades/desejos do } \\
\text { paciente } \\
\text { - Confirmar a compreensão do } \\
\text { paciente solicitando feedback } \\
\text { ou teachback } \\
\text { - Oferecer encorajamento e } \\
\text { suporte } \\
\text { - Evitar interrupções }\end{array}$ & $\begin{array}{l}\text { • "Estou aqui para trabalhar } \\
\text { em conjunto consigo em } \\
\text { prol da sua saúde. Somos } \\
\text { uma equipa." } \\
\text { "Estes são os assuntos que } \\
\text { eu gostaria de abordar } \\
\text { consigo hoje: Quais são as } \\
\text { suas preocupações?" } \\
\text { • "Existe um número } \\
\text { considerável de opções, } \\
\text { cada uma com prós e } \\
\text { contras. Vamos falar } \\
\text { daquela que prefere." } \\
\text { "Consegui abordar todas as } \\
\text { suas preocupações? Há mais } \\
\text { alguma coisa?" }\end{array}$ \\
\hline
\end{tabular}

Fonte:Epstein \& Street (2007) e Brookart (2013). 


\section{Envolvimento do paciente na segurança dos cuidados de saúde - perspetiva das organizações ou dos serviços}

\section{Cultura de segurança nas organizações: o envolvimento do paciente como prioridade}

Para que o envolvimento do paciente seja concretizado de forma consistente, torna-se imperativo que os serviços de saúde coloquem os pacientes no topo das suas prioridades (Athenahealth 2014; DiGioia et al. 2007). O mesmo é dizer que o envolvimento do paciente e da família, assim como sua integração na forma de parceiros efetivos da equipa de saúde, deverá constituir-se como um dos principais objetivos de qualquer serviço de saúde (European Commission 2012). Os pacientes e família precisam ser tratados com dignidade e respeito por todos os membros da organização e encorajados a reportar preocupações relacionadas com a segurança. Na verdade, a probabilidade de os pacientes aderirem aos tratamentos e, consequentemente, alcançarem melhores resultados é maior quando eles sentem suporte não apenas por parte dos clínicos, mas também de toda a organização de saúde que lhes presta cuidados (Joint Commission Resources 2006).

Líderes e membros da organização de saúde necessitam criar uma cultura de segurança que se traduz pela plena adoção do modelo de centração no paciente (Joint Commission Resources 2006), em oposição ao modelo tradicional. Nesse modelo, o foco da organização era colocado no estabelecimento de rotinas que funcionam para os profissionais de saúde, mas não promovem a qualidade e contribuem para a insatisfação dos pacientes e das suas famílias, e os pacientes, mais que ajudados, podem ser lesados (Kohn et al. 1999).

A perspetiva atual requer a reestruturação de muitos serviços, o que, de acordo com Tatterson (2002), só será possível por meio de uma verdadeira mudança cultural dentro das organizações de saúde. São assim essenciais lideranças concentradas em remover barreiras (DiGioia et al. 2007; Join Comission 2016), promover a mudança de atitudes por parte de todos os membros da organização (Joint Commission Resources 2016) e facilitar as práticas necessárias para alcançar os objetivos (DiGioia et al. 2007). Esse processo passa não apenas pela promoção da implementação de programas de envolvimento do paciente (por exemplo, higiene das mãos dos profissionais de saúde), mas também pela avaliação desses mesmos programas. O empenho da organização nesses programas permitirá que muitas barreiras (por exemplo, com o staff) sejam, desde logo, ultrapassadas.

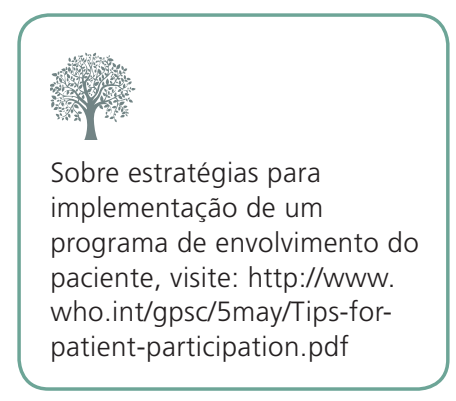


Essa mudança cultural exige tempo e esforço, pois depende do estabelecimento de relações baseadas na comunicação aberta e na confiança mútua entre líderes, administradores, restantes membros da organização e pacientes. Não admira, portanto, que essa alteração origine certo grau de desconforto no seio de algumas organizações. Contudo, esse parece ser um caminho sem retrocesso possível, pois a realidade atual demonstra, de forma clara, que, por um lado, quando a segurança é baseada em uma cultura da culpa gera animosidades e relações tensas entre os elementos da equipa. Por outro lado, a incapacidade para se comunicar de forma aberta e respeitosa com os pacientes contribui para a ocorrência de erros médicos, que podem provocar danos e até mesmo a morte do paciente.

\section{A criação de serviços que promovem envolvimento do paciente nas organizações}

“A ouvidoria em saúde é um instrumento da gestão/gerenciamento pública e do controlo social para o aperfeiçoamento da qualidade e da eficácia das ações e serviços prestados [...]". (Ministério da Saúde 2005 p. 13).

Figura 3 - Campanha de divulgação da Ouvidoria do SUS no Brasil

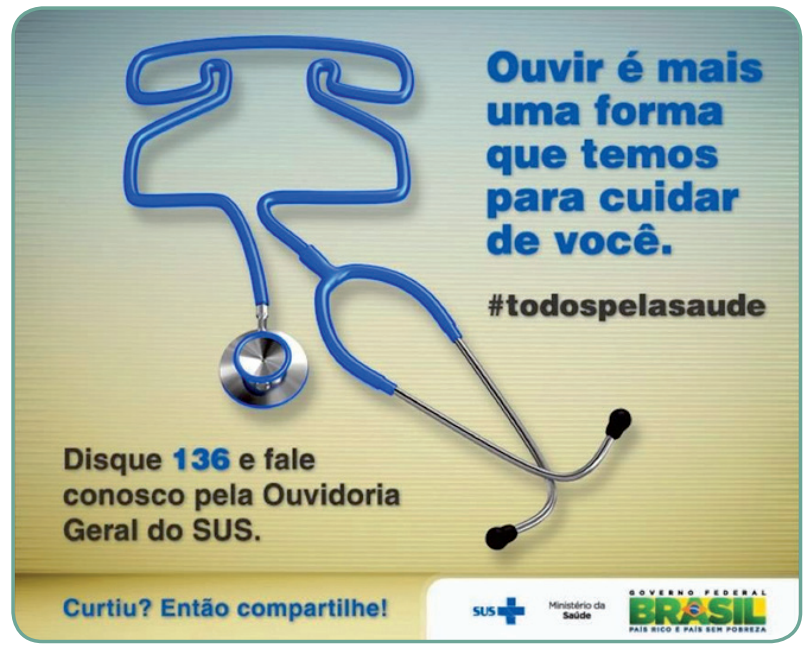

Fonte: Ministério da Saúde do Brasil.

Em algumas organizações que estabeleceram uma clara cultura de segurança, o envolvimento do paciente tem vindo a consubstanciar-se na criação de gabinetes de ouvidoria de apoio do utente/usuário e familiares. A Joint Commission Resources (2006) salienta que a criação desses gabinetes terá de ser suportada, em primeira instância, pelos líderes e apenas resultará se a organização de saúde possuir equipas multidisciplinares que trabalhem de forma verdadeiramente eficaz. 
Essa equipa deverá ser composta de pessoas que demonstrem respeito e sensibilidade para ouvir e assimilar as informações, sejam capazes de atuar valendo-se de consciência crítica e possuam os conhecimentos necessários para proceder ao melhor encaminhamento de cada caso apresentado pelo paciente (Ministério da Saúde 2005).

Esses gabinetes influenciam positivamente as atitudes dos membros da organização, na intenção de eles envolverem, de facto, o paciente e sua família como parceiros na prestação de cuidados de saúde. A experiência das instituições que construíram esses gabinetes tem vindo a demonstrar que o mais relevante resulta da criação de mecanismos que possibilitem aos pacientes e famílias trabalharem em colaboração com os profissionais de saúde e os administrativos para a contínua promoção dos cuidados prestados, assim como para a educação dos elementos da equipa. A título de exemplo, em 1998, na sequência dos efeitos provocados pelo facto de duas pacientes receberem quatro vezes sua dose de quimioterapia para tratamento de carcinoma mamário, o Instituto do Cancro/Câncer Dana-Fraber, em Boston, empenhou-se em promover ativamente a participação do paciente em todos os aspetos do funcionamento do hospital. Entre outras vertentes, os elementos que fazem parte do gabinete de ouvidoria dessa organização acompanham os médicos nas visitas médicas e são encorajados a perguntar ao paciente como tem sido a experiência do internamento/internação. Essa participação do paciente e da família como parceiros promoveu a qualidade dos cuidados, aumentou a autoestima dos pacientes e incrementou a segurança do paciente ao tornar possível não apenas a identificação atempada/oportuna de potenciais problemas, mas também o desenvolvimento de soluções mais eficazes (isto é, que atendam às necessidades dos pacientes) para os problemas encontrados.

\section{Para refletir}

Qual a postura da sua organização em relação aos canais de comunicação com os pacientes? Existe uma ouvidoria ou gabinete do utente/usuário ou serviço ou departamento semelhante? Como você os avalia?

\section{Estratégias para a promoção do envolvimento do paciente}

Depois de abordar as questões principais do envolvimento do paciente em matérias de segurança, cabe, agora, sistematizar algumas estratégias de promoção do envolvimento (Quadro 2), não apenas para o paciente, 
mas também para os profissionais de saúde e as próprias organizações de saúde. Várias dessas estratégias requerem mudanças de atitudes e até treino de competências.

\section{Quadro 2 - Estratégias e promoção do envolvimento do paciente}

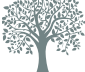

Sobre aprendizagem do paciente, ver mais em: http://cdn-www. informedmedicaldecisions.org

Sobre aprendizagem do profissional, ver mais em:

- Family practice management website: www.aafp.org/fpm

- Promoting patient-centered care in chronic disease (Grilo et al. 2017).

\begin{tabular}{|l}
\hline Paciente \\
\hline Desenvolver o sentido positi envolvimento ${ }^{1}$ \\
do Promoção da literacia² \\
Treino das competências \\
comunicacionais²
\end{tabular}

Aprender a: clarificar suas queixas e sintomas; expressar emoções; apresentar dúvidas; deixar claro suas preferências e desejo de envolvimento; identificar e questionar informação ambígua; estruturar informação recebida e estratégias para recordar; expressar desagrado.

\begin{tabular}{|l|} 
Profissionais de saúde \\
$\begin{array}{l}\text { Desenvolver o sentido positivo } \\
\text { do envolvimento }{ }^{1}\end{array}$ \\
Motivar e dotar de \\
competências para a utilização \\
do modelo de centração no
\end{tabular}
paciente

(por exemplo, ser capaz de perceber necessidades e preferência do paciente enquadrando-as nas suas circunstâncias de vida)

Promoção de atitudes facilitadoras do envolvimento do paciente 1

Aprender a: avaliar o grau de motivação e competência para o envolvimento e motivar a partir desse grau com estratégias adequadas (por exemplo, usar níveis diferentes de informação ou de pedidos de monitorização)

Treino das competências comunicacionais $^{1}$

Aprender a: expressar empatia; colocar questões abertas; clarificar informação recebida; pedir feedback fornecer informação de forma clara

Utilizar o consentimento livre e informado de forma apropriada

Comunicação adequada De de cidentes aos pacientes, dede incidentes de incidentes aos pacientes
Organizações de saúde

Fomentar uma cultura que priorize e suporte o envolvimento e segurança do paciente por meio de:

- Formação das lideranças para o envolvimento do paciente

- Formação e treino para a comunicação e coordenação entre os diferentes profissionais envolvidos no cuidado do paciente

- Formação para a comunicação e gestão/ gerenciamento pessoal e institucional nas situações de erro/evento sentinela

- Desenvolvimento de plataformas adequadas de comunicação com o paciente (por exemplo, portais informativos ou educacionais; plataformas interativas online)

- Criação de gabinetes do utente/usuário/ouvidoria, envolvendo os pacientes como parceiros integrais em todos os aspetos da organização

${ }^{1}$ Entwistle, Watt (2006).

2 Joint Commission Resource (2006). 


\section{Considerações finais}

O envolvimento do paciente e da família na sua segurança não pode ser mandatário, mas deverá ser promovido e desenvolvido (Pernet et al. 2016). Para tal, é necessário atender não apenas às oportunidades para a criação de gabinetes do utente/usuário/ouvidoria, envolvendo os pacientes como parceiros integrais em todos os aspetos da organização nesse envolvimento, mas igualmente dos seus limites e obstáculos. Portanto, parece existir, ainda, um longo caminho a percorrer. Com efeito, o cidadão comum mantém a perceção de que os profissionais de saúde não respondem às questões e preocupações dos pacientes (Entwistle et al. 2005) e, em muitas situações, a afirmação de Slack e colaboradores (1970), "os pacientes são o recurso mais desaproveitado na saúde", continua a ser verdadeira.

Atenda-se neste contexto a um estudo realizado no Departamento de Oncologia, no Hospital Universitário de Karolinska (Kullberg et al. 2015), que colocou em evidência os riscos para a segurança do paciente decorrentes dos défices claros no fornecimento e trocas de informação entre pacientes com cancro/câncer e profissionais de saúde. Refira-se que o envolvimento efetivo do paciente implica sempre que este tenha oportunidade para avaliar e discutir os cuidados que recebe, com a certeza de que os profissionais que prestam esses cuidados utilizarão essa informação de forma construtiva, orientada para a melhoria da sua qualidade.

Por último, importa ressaltar que nas próximas décadas, as escolas de saúde serão chamadas a alertar os profissionais de saúde para a importância da comunicação eficaz com os pacientes (Grilo et al. 2017, Popa-Velea, Purãrea 2014). A comunicação centrada no pacienteé efetivamente a principal ferramentapara a promoçãodo envolvimento do paciente e consequentemente da sua segurança e prevenção de incidentes (Gong et al. 2006). Na maioria das escolas, esse desafio acarreta alterações substanciais na sua oferta formativa, uma vez que os resultados de estudos realizados com estudantes e profissionais apontam, de forma inequívoca, para a necessidade da promoção do treino de competências comunicacionais no ensino pré (Escher et al. 2017; Grilo et al. 2017; Grilo 2010) e pós-graduado (Grilo et al. 2017; Grilo 2010). Assim, é necessário que o ensino das competências comunicacionais no ensino pré-graduado se prolongue até a entrada na vida profissional. Deverá tratar-se de um processo contínuo, com início nos primeiros anos da formação dos futuros profissionais, e vá acompanhando os contactos desses com os pacientes em contexto de supervisão (Grilo 
2010; Joint Commission Resources 2006). Já no decurso da vida profissional, importa considerar que os profissionais necessitam de tempo e esforço para corrigir suas falhas (Fallowfield et al. 1998), justificando-se a inclusão de programas de treino que partam das competências comunicacionais de cada profissional, de forma a responder mais adequadamente às suas necessidades específicas (Grilo et al. 2017; Rollnick, Kinnersley, Butler 2002).

\section{Referências}

Adams RJ, Smith BJ, Ruffin RE. Patient preferences for autonomy in decision making in asthma management. Thorax. 2001 Feb;56(2):126-32.

Agência Nacional de Vigilância Sanitária. Brasília, DF: Anvisa; 2012 [citado 2019 jan 30]. Disponível em: www.anvisa.gov.br.

Agency of Healthcare Research and Quality. Five steps to safer healthcare: patient fact sheet. Rockville (MD): AHRQ; 2004

Ashley P, Rhodes N, Sari-Kouzel H, Mukherjee A, Dornan T. 'They all got to learn': Medical students' learning from patients in ambulatory (outpatient and general practice) consultations. Med Teac 2009;31:e24-e31.

Athenahealth. 5 elements of a Successful patient Engafement Strategy. Disponivel em http://www. pharmengage.com/wp-content/uploads/2015/06/5-Elements-of-a-Successful-Patient-EngagementStrategy.pdf , 2014

Baile W. et al. Spikes: a six-step protocol for delivering bad news. Oncologist. 2000 Aug;5(4):30211.

Balint M, Ball DH, Hare ML. Training medical students in patient-centered medicine. J Compr Psychiatry. 1969; 10(4):249-58.

Bear RA, Stockie S. Patient engagement and patient-centred care in the management of advanced chronic kidney disease and chronic kidney failure. Can J Kidney Health Dis. 2014;1:24. doi: 10.1186/s40697-014-0024-7.

Berwick D. Errors today and errors tomorrow. N Engl J Med. 2003;348(25); 2570-2.

Berwick, D. What "patient-centered" should mean: confessions of an extremist. Health Aff. 2009;28(4):w555-5.

Boyle D, O'Connell D, Platt FW, Albert RK. Disclosing errors and adverse events in the intensive care unit. Crit Care Med. 2006;34:1532-7.

Bronkart D. "Let patients help": a patient engagement handbook. California: Create Space Independent Publishing Platform; 2013.

Carroll SL, Embuldeniya G, Abelson J, McGillion M, Berkesse A, Healey JS. Questioning patient engagement: research scientists' perceptions of the challenges of patient engagement in a cardiovascular research network. Patient Preference and Adherence, 2017:11 Pages 1573-1583 .

Center for Advancing Health. A new definition of patient engagement: hat is engagement and why is it important? Washington, D: CAH; 2010. 
Connock M, Stevens C, Fry-Smith A, Jowett S, Fitzmaurice D, Moore D, Song F. Clinical effectiveness and cost-effectiveness of different models of managing long-term oral anticoagulation therapy: a systematic review and economic modelling. Health Technol Assess. 2007;11(38):iii-iv,ix-66.

Conselho Federal de Medicina. (2009) Código de médica ética. Brasília, DF: CFM; 2009.

Coulter A. Engaging patients in healthcare. New York: Open University Press; 2011.

Coulter A. Engaging patients in their healthcare. Oxford: Picker Institute Europe; 2006.

Coulter A, Parsons S, Askham J. Where are the patients in in decision-making about their own care? Geneva: World Health Organization; 2008.

Davis RE, Jacklin R, Sevdalis N, Vincent CA. Patient involvement in patient safety: what factors influence patient participation and engagement? Health Expect. 2007 Sep;10(3):259-67.

Dentzer S. RX for the 'blockbuster drug' of patient engagement. Health Aff. 2013;32(2):202.

Department of Health (UK). Creating a patient-led NHS. London: Department of Health; 2005.

DiGioia A, Greenhounse P, Levison, T. Patient and Family-centered collaborative care. Clin Orthop Relat Res. 2007; 463:13-9.

DiGioia A, Lorenz H, Greenhouse P, Bertoty D, Rocks S. A patient-centered model to improve metrics without cost increase. J Nurs Adm. 2010 Dec;40(12):540-6.

Douketis JD. Patient self-monitoring of oral anticoagulant therapy: potential benefits and implications for clinical practice. Am J Cardiovasc Drugs. 2001;1(4):245-51.

Dykes PC, Rozenblum R, Dalal A, Massaro A, Chang F, et al,. Prospective evaluation of a multifaceted intervention to improve outcomes in intensive care: the promoting respect and ongoing safety through patient engagement communication and technology study. Crit Care Med. 2017;45(8):e806-e813.

Entwistle VA, Mello MM, Brennan TA. Advising patients about patient safety: current initiatives risk shifting responsibility. Jt Comm J Qual Patient Saf. 2005 Sep;31(9):483-94.

Entwistle VA, Watt I. Patient involvement in treatment decision-making: the case for a broader conceptual framework. Patient Educ Couns. 2006;63(3):268-78.

Epstein RM, Street RL, Jr. Patient-centered communication in cancer care: promoting healing and reducing suffering. Bethesda, (MD): National Cancer Institute; 2007. (NIH Publication No. 07-6225).

Escher C, Creutzfeldt J, Meurling L, Hedman L, Kjellin A, Felländer-Tsai L. Medical students' situational motivation to participate in simulation based team training is predicted by attitudes to patient safety. BMC Medical Education. 2017;17:37. doi:10.1186/s12909-017-0876-5.

European Commission. Eurobarometer qualitative study: patient involvement. Brussels: DirectorateGeneral for Health and Consumers; 2012.

Fallowfield L, Lipkin M, Hall A. Teaching senior oncologists communication skills: results from phase I of a comprehensive longitudinal program in the United Kingdom. J Clin Oncol. 1998; 16(5):1961-8.

Farrell C, Towle A, Godolphin W. Where's the patient voice in health professional education? Vancouver: University of British Columbia; 2006.

Finkelstein J, Knight A, Marinopoulos S, et al. Enabling patient-centered care through health information technology. Rockville (MD): AHRQ; 2012 Jun. (AHRQ Publication, n. 12-E005-EF).

Frampton S, Patrick AC. Putting patients first: best practices in patient-centered care, 2nd edition. San Francisco: Jossey-Bass Publishers; 2008. 
Gallagher TH, Garbutt JM, Waterman AD, et al. Choosing your words carefully: how physicians would disclose harmful medical errors to patients. Arch Intern Med. 2006;166:1585-93.

Gong Y, Zhu M, Li J, Turley J, Zhang J. Clinical communication ontology for medical errors. AMIA Annu Symp Proc. 2006:930.

Greene, J, Hibbard, J. Why does patient activation matter? An examination of the relationships between patient activation and health-related outcomes. J Gen Inern Med. 2011;27(5):520-6.

Grilo AM. Processos comunicacionais em estudantes de fisioterapia e fisioterapeutas: categorização e proposta de um treino individual de competências [tese]. Lisboa: Faculdade de Psicologia, Universidade de Lisboa; 2010.

Grilo AM, Santos M, Gomes A, Rita J. Promoting patient-centered care in chronic disease. In: Sayligil, O, editor. Patient centered medicine. Croatia: IntechOpen; 2017. p. 51-70. doi: $10.5772 / 63030$.

Hall J, Peat M, Birks Y, Golder U, et al. Effectiveness of interventions designed to promote patient involvement to enhance safety: a systematic review. Qual Saf Health Care. 2010 Oct;19(5):e10. doi:10.1136/qshc.2009.032748.

Harvard Hospitals. When things go wrong: responding to adverse events: a consensus Statement. [Local desconhecido]: Harvard Hospitals; 2006.

Hibbard J, Green J. What the evidence shows about patient activation: better health outcomes and care experiences; fewer data on costs. Health Aff. 2013; 32:2207-14. doi:10.1377/ hlthaff.2012.1061

Hudon C, Fortin M, Haggerty J, Loignon C, Lambert M, Poitras M. Patient-centered care in chronic disease management: a thematic analysis of the literature in family medicine. Patient Educ Couns. 2012; 88:170-6.

Institute of Medicine. Crossing the quality chasm: a new health system of the 21st century. Washington, DC: National Academies Press, 2001.

Institute for Patient- and Family-Centered Care. Partnering with patient and families to enhance safety and quality: a mini toolkit. Bethesda, MD: IPFCC; 2013 [citado 2019 jan 30]. Disponível em: http://www.ipfcc.org/tools/Patient-Safety-Toolkit-04.

Joint Commission. Busting the myths about engaging patients and families in patient safety. Oakbrook Terrace (IL): JC; 2016.

Joint Commission. Patient as partners: how to involve patients and families in their own care. Oakbrook Terrace (IL): Joint Commission on Accreditation of Healthcare Organizations; 2006.

Joint Commission. Speak up initiatives. Oakbrook Terrace (IL): JC; 2004.

Joint Commission on Accreditation of Healthcare Organization. Joint Commission Resources Mission: patients as partners. Oakbrook Terrace (IL): JC; 2006 [citado 2014 set 5]. Disponível em: http://www.jcrinc.com.

Joint Commission on Accreditation of Healthcare Organization. Speak up: help prevent errors in your care. Oakbrook Terrace (IL): JC; 2005 [citado 2014 set 5]. Disponível em: http://www.jcahao. org/accredited+organizations/speak+up/speak+up+index.htm.

Joint Commission Resources. Case study: Ingham Regional Medical Center involves patients in the infection control process. Jt Comm Perspect Patient Saf. 2005 Apr; 5:9-10.

Joyce-Moniz L, Barros L. Psicologia da doença para cuidados de saúde: desenvolvimento e intervenção. Lisboa: Edições Asa; 2005. 
Kohn LT, Corrigan JM, Donaldson MS, editors. To err is human: building a safer health system. Washington, DC: National Academy Press, Institute of Medicine; 1999.

Koutantji M, Davis R, Vincent C, Coulter. The patient's role in patient safety: engaging patients, their representatives, and health professionals. Clin Risk. 2005; 1199-204.

Kim JM, Suarez-Cuervo C, Berger Z, Gayleard J, Rosenberg C, Nagy N et al. Evaluation of patient and family engagement strategies to improve medication safety. Patient. 2017 Aug 9;11(2)193206. doi: 10.1007/s40271-017-0270-8

Kullberg A, Sharp L, Johansson H, Bergenmar M. Information exchange in oncological inpatient care. Patient satisfaction, participation, and safety. Eur J Oncol Nurs. 2015;19(2):142-7.

Lamb RM, Studdert DM, Bohmer RMJ, Berwick D, Brennan TA. Hospital disclosure practices: results of a national survey. Health Aff. 2003; 22(2):73-83.

Lazare A. Apology in medical practice: an emerging clinical skill. JAMA. 2006;296:1401-04.

Lindblad S, Ernestam S, Van Citters AD, Lind C, Morgan TC, Nelson EC. Creating a culture of health: evolving healthcare systems and patient engagement. QJM: an international journal of medicine. 2017;110 (3):125-9.

Martin H, Larsen J. Patient involvement in patient safety: a literature review about European primary care. Copenhagem: Danish Institute for Health Services Research; 2012.

McDonald, KM, Bryce, CL, Graber, ML. The patient is in: patient involvement strategies for diagnostic error mitigation. BMJ Qual Saf. 2013;22: ii33-9.

Ministério da Saúde (Brasil). Política Nacional de Atenção Básica. Brasília, DF: MS; 2007.

Ministério da Saúde (Brasil). Secretaria de Gestão Participativa. Oficinas de Ouvidoria. Brasília, DF: Departamento de Ouvidoria-Geral do SUS; 2005.

Muñoz R, Fortes P. O princípio da autonomia e o consentimento livre e esclarecido. In: Conselho Federal de Medicina (BR). Iniciação à bioética. Brasília, DF: CFM; 1998. p. 53-70.

National Health Services (NHS). Plan for investment: plan for reform. London: Secretary of State for Health by Command of Her Majesty UK; 2000.

Neves N. Ética para futuros médicos: é possível ensinar? Brasília, DF: Conselho Federal de Medicina; 2006.

O’Donovan C. Apologies in clinical medicine. In: Macdonald E. Difficult conversations in medicine. Oxford: Oxford University Press; 2004.

Oliveira G. Pereira, A. Consentimento informado. Coimbra: Centro de Direito Biomédico; 2006.

Ordem dos Médicos (Portugal). Código deontológico. Lisboa: OM; 2008.

Osler W. A way of life. New York: Harper \& Row; 1937.

Pernet A, Mollo V, Bibault JE, Giraud P. Evaluation of patients' engagement in radiation therapy safety. Cancer Radiother. 2016 Dec;20(8):765-7.

Piker Institute Europe, Department of Health. Invest in engagement. Oxford: Picker Institute Europe; 2010 .

Popa-Velea O, Purcãrea V. Issues of therapeutic communication relevant for improving quality of care. J Med Life. 2014;7(Spec. n.4), 39-45.

Rollnick S, Kinnersley P, Butler C. Context-bound communication skills training: development of a new method. Med Educ. 2002;36:377-83. 
Santos M, Grilo A, Andrade G, Guimarães T. Comunicação em saúde e segurança do paciente: problemas e desafios. Rev Port Saúde Pública. 2010;10:47-57.

Secretary of State for Health England. The national health plan: a plan for investment, a plan for reform. London: The Stationery Office; 2002.

Silva F. Da ética filosófica à ética em saúde. In: Conselho Federal de Medicina (BR). Iniciação à bioética. Brasília, DF: CFM; 1998. p. 19-38.

Simmons LA, Wolever RQ, Bechard EM, Snyderman R. Patient engagement's a risk factor in personalized health care: a systematic review of the literature on chronic disease. Genome Med. 2014 [citado 2019 jan 30]; 6(2):16. http://www.genomemedicine.com/content/6/2/16.

Slack WV, Van Cura LJ, Greist JH. Computers and doctors: use and consequences. Comput Biomed Res. 1970 Oct 5;3(5):521-7.

Sorensen R, ledema R, Piper $D$, et al. Health care professionals views of implementing a policy of open disclosure of errors. J Health Serv Res Policy. 2008;13:227-32.

Specter M. The operator. New Yorker, 2013 Feb 4.

Spencer J, Godolphin W, Karpenko N,Towle A. Report: Can patients be teachers? Involving patients and service users in healthcare professionals' education. St. Johns (NL)The Health Care Foundation, Inspiring Improvement; 2011.

Stewart DE, Wong F, Cheung AM, Dancey J, Meana M, Cameron JI, et al. Information needs and decisional preferences among women with ovarian cancer. Gynecol Oncol. 2000; 77:357-61.

Street RL, Makoul G, Arora NK, Epstein RM. How does communication heal? Pathways linking clinician-patient communication to health outcomes. Patient Educ Couns. 2009; 74:295-301.

Studdert DM, Mello MM, Gawande AA, et al. Claims, errors, and compensation payments in medical malpractice litigation. N Engl J Med. 2006; 354(19):2024-33.

Tatterson, R. The expert patient: a new approach to chronic disease management for the twentyfirst centuary. Clin Med. 2002; 2(3): 227-9.

Thormton KC, Schwarz JJ, Gross AK, Anderson WG, et al. Preventing harm in the ICU-building a culture of safety and engaging patients and families. Crit Care Med. 2017:1531-7.

TNS Qual+; European Commission. Eurobarometer qualitative study: patient involvement: aggregate report 2012. Brussel: TNS Qual+; 2012.

Towle A, Bainbridge L, Godolphin W, Katz A, Kline C, Lown B, et al. Active patient involvement in the education of health professionals. Med Educ. 2010;44:64-74.

UK. Department of Health. Equality and excellence: liberating de NHS. London: The Stationery Office, 2010 Jul.

Vincent CA, Coulter A. Patient safety: what about the patient? Qual Safe Health Care. 2002;11(1):76-80.

Waterman AD, Gallagher TH, Garbutt J, Waterman BM, Fraser V, Burroughs TE. Hospitalized patients' attitudes about and participation in error prevention. J Gen Intern Med. 2006;21:367-70.

Weissman JS, Schneider EC, Weingart SN, Epstein AM, David-Kasdan J, et al. Comparing patientreported hospital adverse events with medical record review: do patients know something that hospitals do not? Ann Intern Med. 2008 Jul 15; 149(2):100-8.

Weingart SN, Zhu J, Chiappetta L, et al. Hospitalized patients' participation and its impact on quality of care and patient safety. Int J Qual Health Care. 2011;23:269-277L. 
Wikimedia Commons. File: Doctor and couple talking (1).jpg. 2008 [citado 2014 Out 21]. Disponível em: http://commons.wikimedia.org/wiki/File:Doctor_and_couple_talking_(1).jpg

Wikipédia. Relación médico paciente. 2006 [citado 2014 Out 21]. Disponível em: http:// en.wikipedia. org/wiki/Medicalization\#mediaviewer/File:Relaci\%C3\%B3n_M\%C3\%A9dico_ Paciente.png

World Health Organization. Adherence to long-term therapies: evidence for action. Geneva: WHO; 2008 [citado 2013 Jan 26]. Disponível em: ww.who.int/chronic_conditions/adherencereport/en.

World Health Organization. Declaration of Ata Alma. Geneva: WHO; 1978.

World Health Organization. Patient engagement: technical series on safer primary care. Geneva: WHO; 2016.

World Health Organization. Patient Safety Program: patient for patient safety. Geneva: WHO; 2006.

Zwaan L, Bruijne M, Wagner C, Thijs A, Smits A, et al. Patient record: review of the incidence consequences and causes of diagnostic adverse events. Arch Int Med. 2010;170(12):28. 


\section{Investigação/pesquisa em segurança do paciente}

Bárbara do Nascimento Caldas, Paulo Sousa e Walter Mendes

Neste capítulo, você aprenderá um pouco sobre investigação/pesquisa em segurança do paciente. Inicialmente, destacamos a importância da investigação/pesquisa na área, bem como apresentamos algumas características gerais. A seguir, abordamos certos princípios metodológicos das investigações/pesquisas de forma geral e, especificamente, os tipos de estudos mais utilizados na área de segurança do paciente. O ciclo da investigação/pesquisa em segurança do paciente da Organização Mundial da Saúde (OMS) é apresentado como um possível guia. Por se tratar de uma área com muitos desafios no contexto da saúde, em que os recursos são sempre limitados, prioridades para esse tipo de investigação/ pesquisa objetivam orientar novos estudos. Por fim, as questões éticas são brevemente tratadas.

Este texto pretende ser um contributo/colaborador essencial para ajudar a compreender um pouco a importância que a investigação/pesquisa em segurança do paciente tem nos dias de hoje por todo o mundo, bem como servir de referência e apoio à elaboração do Trabalho de Conclusão do Curso (TCC) a desenvolver no âmbito deste curso.

\section{Introdução}

A segurança do paciente, como componente-chave da qualidade do cuidado de saúde, assumiu grande relevância nos últimos anos, tanto para os pacientes e seus familiares, que desejam ter confiança e segurança, como para os profissionais de saúde, cuja "missão" principal é prestar cuidados de elevada efetividade, eficiência e baseados na melhor evidência disponível. Paralelamente, temos assistido ao aumento da 
Como já vimos no livro Segurança do paciente: conhecendo os riscos nas organizações de saúde, no Capítulo 13, "Segurança do paciente na atenção primária à saúde" , a investigação/pesquisa em segurança do paciente na atenção primária está engatinhando impulsionada por diversas iniciativas internacionais, com destaque para o projeto Safer Primary Care da OMS.

Sobre a magnitude dos eventos adversos, reveja, no livro Segurança do paciente: conhecendo os riscos nas organizações de saúde, o Capítulo 5, "Magnitude do problema e os factores contribuintes do erro e dos eventos adversos" investigação/pesquisa na área da segurança do paciente, bem como a necessidade de desenvolver e avaliar o impacte de soluções inovadoras que possam acrescentar valor em termos clínicos, económicos e sociais.

A investigação/pesquisa em segurança do paciente é fundamental para:

Produzir/aumentar conhecimento.

Disseminar informação.

Apoiar as tomadas de decisão.

Promover práticas baseadas na evidência.

Monitorizar e avaliar o impacte de medidas que visam aumentar a segurança dos pacientes e melhorar a qualidade dos cuidados prestados.

A maioria das investigações/pesquisas tem sido desenvolvida no ambiente hospitalar, em função da: maior complexidade organizacional; realização de procedimentos de maior risco; maior gravidade dos casos; e diversidade e especificidade de procedimentos realizados.

Na área dos cuidados continuados, a investigação/pesquisa é ainda muito residual. A exceção fica a cargo dos países escandinavos, que sempre dedicaram particular atenção à área. Porém, a divulgação dos resultados obtidos é comprometida, pois a maioria dos estudos não é publicada em periódicos de língua inglesa (Sousa et al. 2010).

\section{Considerações metodológicas}

O início da investigação/pesquisa na área da segurança do paciente foi marcado pelos estudos epidemiológicos sobre a magnitude e os padrões dos eventos adversos. Embora existam estudos anteriores a respeito da ocorrência de eventos adversos em hospitais, o Harvard Medical Practice Study é considerado pioneiro por seu escopo, desenho e instrumentos de coleta/recolha de dados (Brennan et al. 1991). Esse estudo e aquele realizado por Thomas EJ e colaboradores (1999), que avaliou o custo dos eventos adversos em pacientes internados nos estados de Utah e Colorado, constituíram a principal base para as estimativas apresentadas no relatório To Err is Human, que chamou a atenção para a gravidade do problema da segurança do paciente (Kohn et al. 2000). 
Após o estudo de Harvard, estudos de abrangência nacional ou regional foram desenvolvidos com o objetivo de demonstrar a magnitude dos eventos adversos em diversos países como Austrália (Wilson et al. 1995), Inglaterra (Vincent et al. 2001), Canadá (Baker et al. 2004), Brasil (Mendes et al. 2009), Espanha (Aranaz-Andrés et al. 2008) e Portugal (Sousa et al. 2014).

Os estudos a respeito da relevância dos eventos adversos foram logo seguidos de estudos a fim de avaliar a efetividade de intervenções específicas para os problemas de segurança do paciente. Para tanto, um dos destaques foi o documento Making health care safer: a critical analysis of patient safety practices (Shojania et al. 2001), publicado pela Agency for Healthcare Research and Quality (AHRQ), dos Estados Unidos. O objetivo desse documento foi identificar e revisar criticamente as evidências existentes sobre práticas de segurança do paciente (PSP), definidas como processo ou estrutura, cuja aplicação fosse capaz de reduzir a probabilidade da ocorrência de eventos adversos.

Uma década após a publicação desse documento, a AHRQ comissionou um novo estudo sobre PSP, estimulada pela necessidade de atualização do tema e pelo reconhecimento de que a magnitude do problema da segurança do paciente persistia, apesar dos sistemáticos esforços e investimentos aplicados para modificação desse quadro (Shekelle et al. 2013). Em 2013, foi publicado o documento Making health care safer II: an updated critical analysis of the evidence for patient safety practices (Shekelle et al. 2013), cujo objetivo foi revisar PSP relevantes, privilegiando evidências sobre efetividade, considerações a respeito de implementação e aspectos ligados à disseminação da prática em outros cenários.

O reconhecimento da importância do contexto nas práticas de segurança do paciente foi parte do amadurecimento da pesquisa na área ao longo da última década. Esse foi o objeto do relatório da AHRQ, Assessing the evidence for context-sensitive effectiveness and safety of patient safety practices: developing criteria, publicado pela mesma equipe de pesquisa do Making health care safer II. A necessidade de desenvolver critérios para avaliar a evidência da efetividade sensível ao contexto e a segurança das PSP surgiram da constatação de que os critérios metodológicos para avaliar qualidade na pesquisa clínica e nos estudos avaliativos pareciam insuficientes para os estudos de efetividade de mudanças organizacionais e comportamentais necessárias à implementação de práticas de segurança (Shekelle et al. 2010). 
Epistemologia: episteme conhecimento, ciência; logos estudo, discurso.

"A teoria do conhecimento pertence a um ramo da filosofia chamado epistemologia. Como a ciência trata essencialmente de produzir conhecimento sobre o mundo que possa ser considerado válido, é importante dar atenção à epistemologia. Diferentes tradições epistemológicas implicam diferentes formas de 'conhecer' o mundo, e considerações bem diferentes quanto ao status desse conhecimento" (Green, Thorogood 2004, p. 10, tradução dos autores).
Se pretendemos avançar no conhecimento sobre como fazer mudanças a fim de melhorar a qualidade do cuidado de saúde, a compreensão do como e do porquê intervenções funcionam - não apenas se elas funcionam - é crucial. Em uma seara complexa tal como o cuidado de saúde, estudos epidemiológicos são uma forma empobrecida para gerar aprendizado (Berwick 2008). Abordagens metodológicas que permitam analisar o desenrolar de PSP devem ser agregadas aos estudos sobre efetividade com a intenção de aumentar a probabilidade de replicação bem-sucedida de intervenções, com resultados positivos para a segurança do paciente.

Exemplo de estudo que conseguiu atingir tal objetivo foi o realizado por Dixon-Woods e colaboradores (2011), com teorização a posteriori sobre os mecanismos envolvidos no sucesso do Michigan Keystone Project (Pronovost et al. 2006).

O Michigan Project foi divulgado como obtendo seus resultados impressionantes por conta da adoção de uma simples lista de verificação para a conferência da execução de medidas baseadas em evidência, durante a inserção e manutenção de cateter venoso central. Porém, a verdadeira história do projeto se refere a como o apoio para a coordenação do trabalho em torno do controle de infecção foi mobilizado, assegurando, dessa forma, que as medidas fossem efetivamente adotadas (Bosk et al. 2009).

O sucesso do projeto permitiu ilustrar que intervenções para melhoria da segurança englobam um componente técnico (estrutural/funcional) e um componente adaptativo (sociocultural), e, sem atenção ao componente adaptativo (isto é, compreender e ter estratégias para mitigar barreiras técnicas, culturais e políticas para implementação), o componente técnico das intervenções tem grande chance de ser abandonado (Bosk et al. 2009).

O estudo sobre a implementação e a prática de intervenções para segurança se beneficia do reconhecimento de que "compreensão adicional sobre as condições para melhoria podem surgir do estudo das mudanças para melhoria menos como intervenções discretas e limitadas e mais como ações evolutivas por parte de atores/intervenientes conscientes que interpretam e respondem ao entorno" (Øvretveit 2011, p. i19).

Porém, é importante salientar que, para isso, faz-se necessário partir de outras perspectivas epistemológicas. Os estudos epidemiológicos com a finalidade de identificar a magnitude dos eventos adversos e os estudos clínicos que intencionam avaliar a efetividade de intervenções para 
melhoria da segurança são informados, em sua maioria, pelo pensamento positivista (assim como as ciências naturais e as ciências sociais quantitativas). A filosofia positivista assume que existe uma realidade objetiva "lá fora", que independe de a compreendermos ou não. Essa filosofia tem algumas implicações metodológicas, como:

䠌 ênfase no empirismo ou no estudo apenas de fenômenos observáveis;

único método, a ideia de que, quando maduras, todas as ciências compartilharão os mesmos métodos de pesquisa; e

踏 investigação/pesquisa livre de valores, isto é, a ciência é percebida como algo à parte da sociedade e como algo objetivo, racional e neutro (Green, Thorogood 2004).

Para melhor compreender o desenvolvimento de uma intervenção, incluindo a resposta dos sujeitos a esta, precisamos recorrer a formas alternativas de pensar a realidade e aos modos como construímos o conhecimento científico. Nas ciências sociais, a pesquisa, normalmente, parte de outras tradições epistemológicas, que se afastam de um ou mais dogmas do positivismo, e fazem parte das chamadas "comunidades interpretativas" (Denzin, Lincoln 2000). Esse termo foi proposto por Denzin e Lincoln (2000) para representar a ampla gama de paradigmas e teorias (por exemplo, construtivista, feminista, queer theory) que informam estudos com o propósito comum de analisar os significados atribuídos pelos sujeitos aos fatos, relações, experiências e práticas relacionadas à intervenção que se estuda e que nela também interagem.

Além do compromisso com o naturalismo (isto é, estudar as coisas na forma como elas ocorrem normalmente) e o foco na compreensão dos significados, as diversas perspectivas epistemológicas, na investigação/pesquisa qualitativa, compartilham, também, como orientação geral para metodologia, a flexibilidade na estratégia de pesquisa (Green, Thorogood 2004). Estudos etnográficos, teoria fundamentada (grounded theory), fenomenologia e avaliação qualitativa são estratégias possíveis, que podem fazer uso de um ou mais métodos de coleta/ recolha de dados, incluindo entrevistas em profundidade, entrevistas em grupo, métodos de observação e uso de fontes documentais.

Estudos qualitativos são desenvolvidos há algumas décadas na área da Saúde. A premissa central da investigação/pesquisa qualitativa de dar voz a grupos - muitas das vezes, minoritários - da sociedade (Brandão et al. 2018) encontra-se refletida no escopo dos trabalhos publicados que abordam desde experiências e percepções de pacientes com relação 
ao seu cuidado, no contato com os serviços/departamentos de saúde, até percepções de determinados grupos profissionais.

Na área da segurança do paciente, estudos qualitativos podem contribuir particularmente na análise de fatores do contexto que influenciam a prática na ponta do cuidado, oferecendo lições para otimizar a implementação de intervenções para a segurança. Como exemplo, podemos citar o estudo de Aveling e colaboradores (2013), que comparou experiências quanto à lista de verificação de segurança cirúrgica em países desenvolvidos e em desenvolvimento, e o estudo de Dixon-Woods e colaboradores (2013), que buscou explicar os resultados apresentados por UTIs da Inglaterra, na tentativa de reprodução do Michigan Project.

A necessidade de integração das abordagens quantitativa e qualitativa tem sido reconhecida por diversos autores. Tal questão é tratada, no campo da avaliação, pelas avaliações por métodos mistos, que possuem como característica definidora a união de metodologias e/ou métodos e técnicas quantitativas e qualitativas em um dado projeto de avaliação (Deslandes 2015). As avaliações por métodos mistos começaram a ganhar destaque no fim dos anos 1980, apresentando grande expansão desde então.

O principal argumento para o uso de métodos mistos é o de que a combinação das abordagens quantitativas e qualitativas pode fornecer melhor compreensão dos problemas de pesquisa do que cada uma das metodologias separadamente. Tal argumento é coerente. Entretanto, conforme já apresentado, métodos quantitativos e qualitativos podem estar relacionados a perspectivas epistemológicas distintas, e, dessa forma, faz-se necessária uma postura crítica quanto ao grau com que tais métodos podem ser integrados (Deslandes 2015).

Os estudos com uso de métodos mistos também são encontrados no campo da qualidade do cuidado e segurança do paciente. Uma síntese narrativa foi a opção adotada por Dixon-Woods e colaboradores (2014) para integrar os resultados de sete subestudos sobre cultura e comportamento no sistema de saúde inglês, com abordagens analíticas distintas (por exemplo, análise de conteúdo, grounded theory, estatística descritiva, análise de variância). Além da síntese narrativa, o metaestudo, a síntese realista e o inquérito de casos são exemplos de possíveis métodos para sintetizar evidências qualitativas e quantitativas (Dixon-Woods et al. 2005). 


\section{Estudos epidemiológicos}

Os estudos epidemiológicos correspondem à maior parte das pesquisas/investigações na área da segurança do paciente. Dessa forma, uma breve apresentação dos principais conceitos torna-se necessária para auxiliar tanto uma leitura crítica de artigos como no planejamento/ planeamento e condução da pesquisa.

O passo inicial na aproximação de uma pesquisa é caracterizar o desenho do estudo. O primeiro enfoque diz respeito ao papel desempenhado pelo investigador/pesquisador. Ele pode optar por realizar uma série de medições nos objetos de estudo ou, então, aplicar uma intervenção e examinar seus efeitos. No primeiro caso, teremos um estudo observacional, e, no segundo, um estudo de intervenção.

De acordo com a opção temporal, os estudos observacionais podem ser classificados em transversais, retrospetivos e prospetivos.

Um estudo transversal é aquele em que as observações são feitas em uma única ocasião, ou seja, ele mensura a distribuição de alguma característica em uma dada população, em um dado momento. Um exemplo de estudo transversal é medir a ocorrência dos eventos adversos em um hospital em um dia.

Os estudos retrospetivos baseiam-se em informações recolhidas/coletadas durante períodos passados, isto é, estuda os eventos ocorridos em uma população durante determinado período passado, como avaliar as mortes ocorridas no ano anterior.

Estudos prospetivos começam no presente e acompanham a ocorrência de um evento numa população por um período específico, por exemplo, monitorar infeções associadas ao cuidado hospitalar, com vigilância ativa durante um ano (Hulley et al. 2013).

Os estudos observacionais podem ser classificados ainda como descritivos ou analíticos.

Os estudos descritivos visam caracterizar o fenômeno de interesse. Normalmente, são realizados nas fases iniciais de investigação/pesquisa de um determinado tópico, sendo seguidos ou acompanhados de estudos analíticos com o propósito de avaliar associações que permitam inferências sobre relações de causa e efeito (Hulley et al. 2013). Medir a ocorrência de eventos adversos em uma unidade de terapia intensiva é
Aqui, adotamos o termo estudo observacional como classificação de um estudo epidemiológico.

Cuidado para não confundir com a observação, que se trata de um método de recolha/coleta de dados. 
um exemplo de estudo descritivo. Estudo que busca determinar a associação entre a relação enfermeiro-cama/leito e a taxa de mortalidade é um exemplo de estudo analítico.

Os estudos de intervenção têm por objetivo avaliar a efetividade de uma dada intervenção, que pode ser tanto uma nova forma de realizar um procedimento, como um novo esquema terapêutico ou novo treinamento. Esses estudos são fundamentalmente classificados como não controlados ou controlados (Brown et al. 2008). O termo controlo diz respeito a um grupo de sujeitos, pacientes ou profissionais que não será submetido à intervenção e com o qual o grupo de intervenção terá seus resultados comparados.

Estudos que se baseiam na avaliação de resultados antes e depois são não controlados. Embora, em muitos casos, seja o único método viável de avaliação, é considerado um método relativamente fraco para distinguir causa e efeito (Brown et al. 2008). Seu uso na área de segurança do paciente é bastante frequente, como os estudos que demonstraram a redução de infeção da corrente sanguínea após a implantação de um pacote de intervenções (bundle) para inserção de cateter venoso central (Pronovost et al. 2006); a redução de mortalidade e da morbilidade/ morbidade operatórias após a implementação da lista de verificação de segurança cirúrgica (Haynes et al. 2009); a redução da ocorrência de erros durante cirurgias após a realização de um treinamento do tipo Crew Resource Management (CRM).

Dentre os estudos controlados, os ensaios clínicos controlados randomizados são considerados o padrão-ouro da investigação/pesquisa clínica. A escolha aleatória dos controlos reduz as chances de interferências nos resultados obtidos decorrentes de vícios de seleção (viés de seleção). Um exemplo é utilizar um estudo controlado a fim de avaliar o impacte da alocação de enfermeiras em exclusividade para a administração de medicamentos na taxa de erros de administração.

Importa ressaltar que não há um tipo de estudo melhor que o outro. O planeamento/planejamento da investigação/pesquisa deve buscar um desenho de estudo mais adequado para responder à pergunta de investigação/pesquisa. Cada tipo de estudo tem potencialidades e limitações que devem ser explicitadas e discutidas para melhorar a qualidade da investigação/pesquisa e balizar a interpretação dos resultados obtidos. 
Figura 1 - Desenhos de estudo e métodos de investigação/pesquisa na área da segurança do paciente

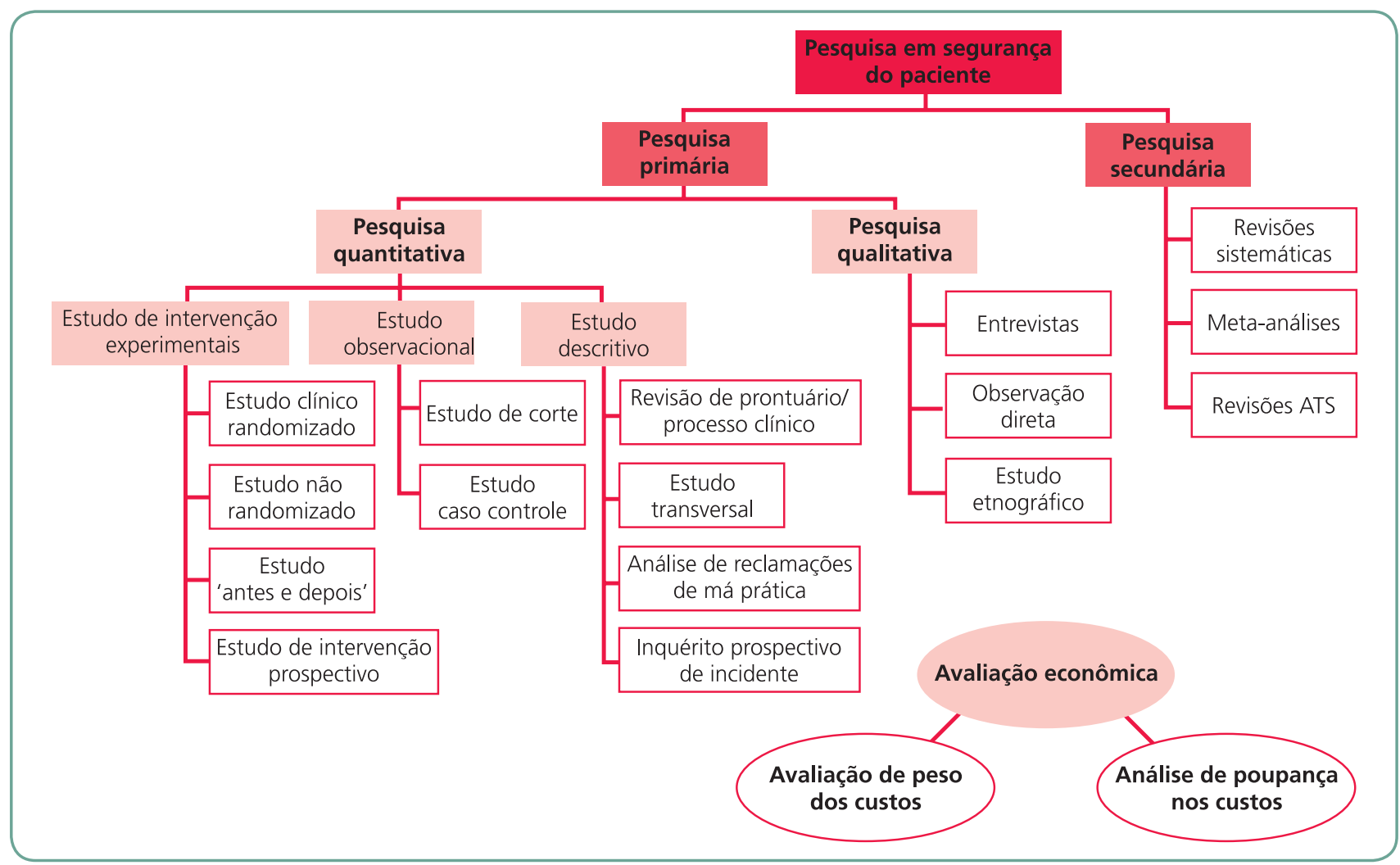

Fonte: Adaptado de Andermann e colaboradores (2013, p. 556).

O esquema proposto por Andermann e colaboradores (2013) ilustra como desenhos de estudo e métodos de investigação/pesquisa distintos podem ser adotados na investigação/pesquisa em segurança do paciente. Trata-se de um esquema abrangente que inclui também as investigações/ pesquisas/investigações secundárias - aquelas realizadas com base em investigações/pesquisas primárias, como as revisões sistemáticas, com ou sem meta-análise, e as revisões para Avaliação Tecnológica em Saúde (ATS). Repare que, com relação aos estudos observacionais, os autores optaram por apresentar os estudos descritivos separadamente dos analíticos.

Agora que você já compreendeu alguns elementos relacionados com os desenhos de estudo e os métodos de investigação/pesquisa na área da segurança do paciente, observaremos especificamente os métodos e as fontes de dados utilizados para medir erros e eventos adversos.

Para consolidar seus
conhecimentos, assista à Sessão
2 do Curso Introdutório de
Investigação em Segurança do
Paciente/Doente - Princípios da
investigação em segurança do
paciente/doente: visão geral,
apresentada pela Profa. Mônica
Martins, da Escola Nacional de
Saúde Pública/Fiocruz, disponível
em: http://www.slideshare.
net/Proqualis/princpios-da-
investigao-em-segurana-do-
pacientedoente-viso-geral


Erro aleatório é um resultado errado decorrente do acaso, fontes de variação que têm a mesma probabilidade de distorcer as medidas de um estudo em qualquer direção.

Erro sistemático é um resultado errado decorrente de viés, fontes de variação que distorcem os achados de um estudo em determinada direção (Hulley et al. 2013).

Sobre a distinção entre falhas latentes e erros ativos, reveja, no livro Segurança do paciente: conhecendo os riscos nas organizações de saúde, o Capítulo 4, "O erro e as violações no cuidado de saúde".

\section{Métodos e fontes de dados utilizados para medir erros e eventos adversos}

A mensuração de erros e eventos adversos é realizada por profissionais de saúde envolvidos com atividades de melhoria da qualidade no cotidiano dos serviços/departamentos de saúde e também por investigadores/pesquisadores da área de segurança do paciente. Portanto, é fundamental a compreensão dos pontos positivos e das limitações dos diversos métodos de mensuração, para que o método escolhido seja apropriado aos objetivos a alcançar.

A mensuração descreve os fenômenos de forma que possam ser estatisticamente analisados, deve ser precisa e acurada. A precisão (ou fiabilidade/confiabilidade) de uma variável é o grau com que ela é reprodutível, com aproximadamente o mesmo valor a cada vez que for medida. A precisão é função do erro aleatório; quanto maior o erro aleatório, menor a precisão da medida. A acurácia (ou validade) de uma variável é o grau com o qual ela representa de facto o que pretende representar. A acurácia é função do erro sistemático; quanto maior o erro sistemático, menor a acurácia (Hulley et al. 2013).

Diversos têm sido os métodos e as fontes de dados utilizados para medir os erros e eventos adversos relacionados ao cuidado de saúde. Em 2003, Thomas e Petersen publicaram um artigo com o resumo desses métodos e fontes. Na Figura 2, está representada a utilidade relativa de cada método e fonte de dados. Essa figura já foi apresentada no Capítulo 5 do livro Segurança do paciente: conhecendo os riscos nas organizações de saúde; no entanto, aqui, ela será trabalhada sob outro ponto de análise.

Figura 2 - Utilidade relativa dos métodos para medir falhas latentes, falhas ativas e eventos adversos

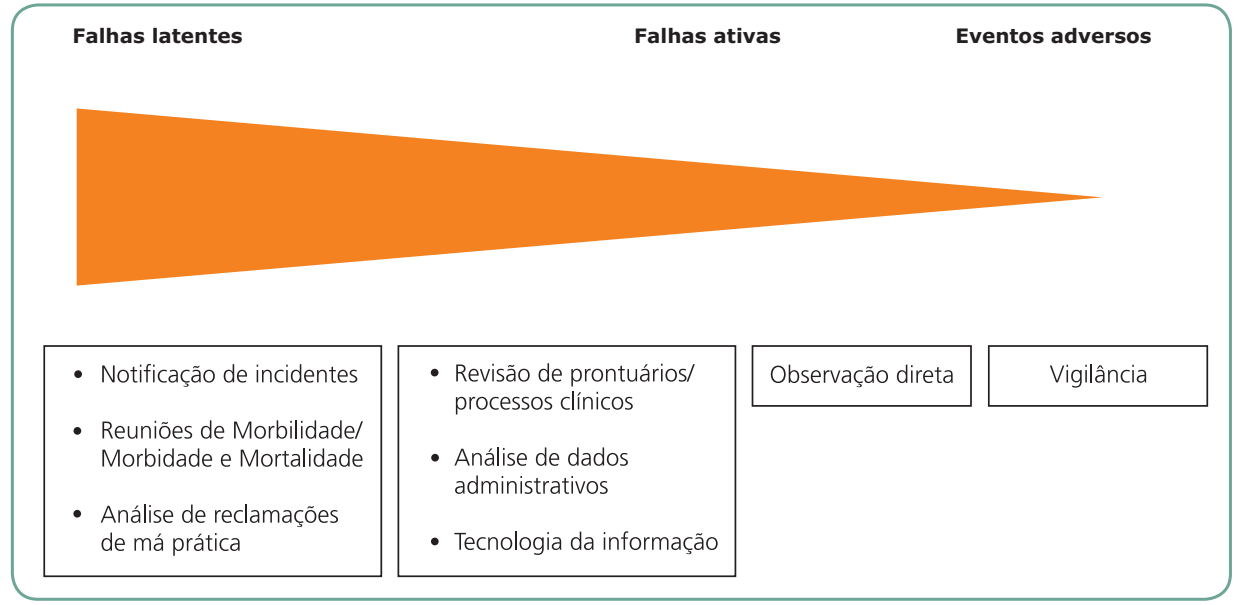

Fonte: Thomas, Petersen (2003, p. 64) 


\section{Reuniões de Morbilidade/Morbidade e Mortalidade e necropsias}

As Reuniões de Morbilidade/Morbidade e Mortalidade (RMM), com ou sem apresentação de resultados da necropsia, têm por objetivo aprender com os erros e eventos adversos ocorridos, contribuindo para a formação dos residentes e a melhoria da qualidade do cuidado, possuindo papel central na formação do cirurgião. Essas reuniões são também conhecidas como sessões clínicas ou anatomoclínicas. A necropsia, quando acom- panhada da revisão do processo clínico/prontuário do paciente e discussão com a equipa responsável pelo cuidado do paciente durante a RMM, é uma fonte de informação importante para apontar falhas que levaram a diagnóstico equivocado (misdiagnosis).

A RMM é uma fonte melhor para avaliar as falhas latentes do que as falhas ativas. Podemos destacar como vantagens das RMM o levantamento de condições ou falhas latentes, a familiaridade dos profissionais de saúde com essa prática e a exigência de sua existência por algumas organizações acreditadoras. Como desvantagens, ressaltam-se o viés retrospetivo, o viés de relato/notificação, o foco no erro diagnóstico, sua utilização infrequente e não aleatória.

\section{Para refletir}

Em sua organização, ocorrem Reuniões de Morbilidade/Morbidade e Mortalidade? Com ou sem necropsias?

Em caso afirmativo, saberia dizer se essa metodologia tem trazido bons resultados? De que maneira?

\section{Análise de reclamações de má prática}

Os arquivos de reclamações de má prática, com os registos médicos e depoimentos, constituem grande conjunto de dados que investigadores/pesquisadores e profissionais de saúde podem utilizar para analisar qualitativamente os erros no cuidado de saúde. A análise desses arquivos é um método melhor para avaliar as falhas latentes do que as falhas ativas.

A principal vantagem dessa fonte de dados é que fornece múltiplas perspetivas: pacientes, prestadores e advogados. Porém, os dados disponíveis não são padronizados, o que dificulta comparações. A análise de reclamações de má prática também está sujeita aos vieses retrospetivo e de relato/notificação.
Viés retrospetivo (hindsight bias) é definido como "a crença de que um evento é mais previsível depois que ele se torna conhecido do que ele era antes" (Roese, Vohs 2012, p. 411). Envolve segunda opinião/laudo, que é o uso de factos atualmente disponíveis para fazer o julgamento de uma pessoa que teve acesso a uma série mais limitada de informações no momento em que a decisão-chave foi tomada.

Viés de relato é definido como a revelação ou supressão seletiva de informação sobre uma história passada. 


\section{Sistemas de notificação/relato de incidentes}

Incidentes testemunhados ou cometidos por profissionais de saúde podem ser notificados/relatados por meio de um sistema de recolha/ coleta de dados. Sistemas de notificação/relato, incluindo os inquéritos e entrevistas estruturadas, são uma forma de envolver os profissionais na investigação/pesquisa e em projetos de melhoria da qualidade.

A análise de relatos/notificações de incidente pode fornecer detalhes sobre condições latentes que contribuíram para a falha ativa e o evento adverso; porém, esses sistemas não podem ser utilizados para medir a ocorrência de erros e eventos adversos (EA). Diversos factores podem ocasionar a subnotificação/sub-relato por parte dos profissionais, entre eles a carga de trabalho, o medo de ser judicialmente processado e a preocupação com sua reputação. Os sistemas de notificação/relato de incidentes também são passíveis de viés retrospetivo e viés de relato/ notificação. Mesmo assim, sua adoção deve ser considerada, pois, além da possibilidade de deteção de falhas latentes, é capaz de fornecer múltiplas perspetivas ao longo do tempo e há possibilidade de ser incorporado às atividades de rotina.

\section{Análise de dados administrativos}

As bases de dados administrativos podem parecer uma fonte de dados atrativa para a mensuração de eventos adversos, pois utilizam informação prontamente disponível, tornando-se assim uma fonte económica. Entretanto, é possível que esses dados estejam incompletos e/ou sujeitos a vieses decorrentes das políticas de pagamento. Como a lógica da geração de dados é a administrativa, os dados encontram-se separados do contexto clínico.

\section{Revisão de processo clínico/prontuário do paciente}

Sobre esse assunto retome, no livro Segurança do paciente: conhecendo os riscos nas organizações de saúde, o Capítulo 5, "Magnitude do problema e os factores contribuintes do erro e dos eventos adversos".
A revisão de processos clínicos/prontuários dos pacientes tem sido a base dos principais estudos de erros e eventos adversos. A utilização de dados prontamente disponíveis e a frequência com que a revisão de processos clínicos/prontuários dos pacientes é adotada de forma rotineira constituem suas vantagens. Porém, mesmo com o aprendizado decorrente do uso desse método, ele apresenta muitas limitações. A primeira refere-se ao baixo ou moderado grau de fiabilidade/confiabilidade do julgamento acerca do evento adverso. A documentação incompleta nos processos clínicos/prontuários dos pacientes também é outra fragilidade. Por demandar intenso trabalho de médicos e enfermeiros investigadores/pesquisdores para análise, é considerado um método caro. Por fim, como faz um julgamento presente de um evento passado, está sujeito ao viés retrospetivo. 


\section{Revisão de processo clínico/prontuário eletrónico}

A revisão de processo clínico/prontuário eletrónico pode aprimorar a deteção de erros e EA por meio do monitoramento em tempo real e pela integração de várias fontes de dados (por exemplo, laboratório, farmácia, faturamento). É considerado um método económico, após o investimento inicial para implantação do processo clínico/prontuário eletrónico que inclui grande custo financeiro. Ao se trabalhar com a revisão de processo clínico/prontuário eletrónico, deve-se ter em mente a suscetibilidade a erros de programação e/ou na entrada dos dados. Não é um bom método para detetar falhas latentes.

\section{Observação direta do cuidado}

A observação direta ou a gravação do cuidado ao paciente pode ser um bom método para medir falhas ativas. Esse método tem sido utilizado em salas de cirurgia, unidades de cuidado intensivo, enfermarias cirúrgicas e para avaliar erros na administração de medicamentos; é potencialmente preciso e válido, fornece dados de outra maneira indisponíveis e tem a capacidade de detetar mais falhas ativas que outros métodos.

A observação direta é limitada por questões práticas e metodológicas, como a confidencialidade, já que os profissionais podem temer que tais informações sejam utilizadas contra eles, além da necessidade de treinamento intensivo dos observadores.

As observações são realizadas no cuidado prestado ao paciente, não sendo possível, muitas vezes, capturar as contribuições do sistema de cuidado, não se tornando, assim, um bom método para detetar condições ou falhas latentes. A observação pode gerar sobrecarga de informação, dificultando sua análise. Por fim, o efeito Hawthorne, que é a mudança de comportamento dos indivíduos pelo facto de estarem sendo observados, também é uma limitação.

\section{Vigilância clínica}

A vigilância ativa e prospetiva, típica dos estudos epidemiológicos, é ideal para avaliar a efetividade de intervenções específicas com o propósito de redução de eventos adversos explicitamente definidos. Tem sido utilizada, há anos, pelos profissionais que investigam as infeções associadas ao cuidado de saúde. Porém, assim como o método de observação direta, não capta bem falhas latentes. Em algumas situações, o método exige medidas diagnósticas para acompanhar a ocorrência de eventos adversos, como a realização de eletrocardiograma e dosagem de enzimas cardíacas em todos os pacientes para medir o enfarte/infarto do miocárdio pós-operatório, o que pode torná-lo um método de alto custo financeiro.
Sobre vigilância, veja, novamente, no livro Segurança do paciente: conhecendo os riscos nas organizações de saúde, o Capítulo 7, "Infeções associadas aos cuidados de saúde". 


\section{Ciclo da investigação/pesquisa}

Medir a ocorrência de erros e eventos adversos é um importante componente da investigação/pesquisa em segurança do paciente. Segundo o ciclo de investigação/pesquisa proposto pela OMS (Figura 3), esse é o primeiro passo. Depois de conhecer a magnitude de um problema, é fundamental compreendermos suas causas para então testar e identificar possíveis soluções. Se a avaliação do impacte das soluções testadas for positiva, ou seja, se elas contribuírem para a redução da ocorrência de danos, chegamos ao último componente, que consiste na incorporação da evidência científica ao cuidado de saúde, de forma a torná-lo mais seguro.

Figura 3 - Utilidade relativa dos métodos para medir falhas latentes, falhas ativas e eventos adversos

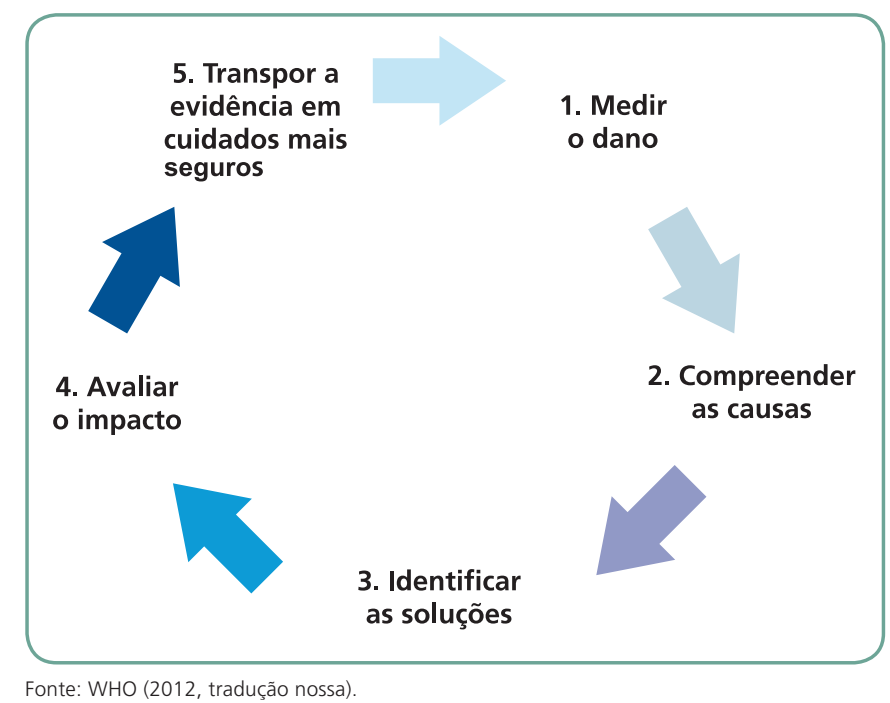

A seguir, são apresentados os principais métodos adotados em cada componente do ciclo, segundo documento da OMS para orientar a formação de investigadores/pesquisadores em segurança do paciente (WHO 2012). Ao final deste tópico, será possível perceber que cada projeto de investigação/pesquisa em segurança do paciente tem seu objetivo geral relacionado a um dos componentes do ciclo de investigação/pesquisa. 


\section{Medir o dano}

Medir o que vai errado no cuidado de saúde inclui contar quantos pacientes sofrem dano ou morrem a cada ano e de quais tipos de eventos adversos, tais como erros de medicação, infeções associadas ao cuidado de saúde, cirurgias em sítio errado, entre outros. Estudos para estimar a incidência de eventos adversos em uma UTI ou a prevalência de infeções de sítio cirúrgico são exemplos de investigações/pesquisas relacionadas com o primeiro componente do ciclo.

As fontes de dados que podem ser usadas para medir o dano incluem:

腆 sistemas de notificação/relato;

滕 dados administrativos;

滕 reclamações administrativas;

滕 reclamações de má prática;

橉 reuniões de morbilidade/morbidade e mortalidade, com ou sem necropsias;

繗 auditorias/revisões ou investigações/pesquisas nacionais e regionais; e

滕 processo clínico/prontuário do paciente.

\section{Métodos para} coleta de dados

As entrevistas com profissionais

A observação direta.

O monitoramento clínico.

Para unidades menores e/ou com poucos recursos, em que tanto os registos médicos como a organização da documentação são limitados, alguns métodos são mais indicados. Os seguintes métodos foram avaliados como viáveis e bem-aceitos em tais ambientes: revisão retrospetiva de processos clínicos/prontuários dos pacientes; revisão do processo clínico/prontuário dos pacientes internados - estabelece a prevalência pontual do EA, exige menos recursos financeiros e de tempo que o método anterior -; entrevista com profissionais sobre os pacientes internados; observação direta associada à entrevista; e técnica de grupo nominal baseada em consenso (WHO 2010).
Como mencioando anteriormente sistemas de notificação/relato não devem ser utilizados para medir a ocorrência de erros e EA, por exemplo, calcular taxas de incidência. Porém, eles se constituem em importante fonte para análise geral da ocorrência de EA.

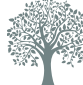

Para consolidar seus conhecimentos, assista à Sessão 3 do Curso Introdutório de Investigação em Segurança do Paciente/Doente - Medir o dano, disponível em: http:// www.slideshare.net/Proqualis/ medir-o-dano 


\section{Compreender as causas}

Sobre a complexidade do cuidado de saúde e a multicausalidade dos erros e eventos adversos relembre, no livro Segurança do paciente: conhecendo os riscos nas organizações de saúde, o modelo do queijo suíço que você conheceu no Capítulo 4, "O erro e as violações no cuidado de saúde", e também reveja o Capítulo 5, "Magnitude do problema e os factores contribuintes do erro e dos eventos adversos".

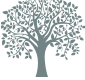

Para consolidar seus conhecimentos, assista à Sessão 4 do Curso Introdutório de Investigação em Segurança do Paciente/ Doente - Compreender as causas, disponível em: http:// www.slideshare.net/Proqualis/ compreender-as-causas

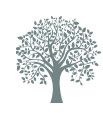

Para consolidar seus conhecimentos, assista à Sessão 5 do Curso Introdutório de Investigação em Segurança do Paciente/Doente Identificar e implementar soluções, disponível em: http:// www.slideshare.net/Proqualis/ sessao5-pt
Por conta da natureza complexa do cuidado de saúde, não há uma única razão pela qual as coisas dão errado. A investigação/pesquisa, dessa forma, é necessária para identificar as principais causas subjacentes de um evento adverso.

As fontes de dados que podem ser utilizadas para compreender as causas são as mesmas para medir o dano: sistemas de notificação/relato; dados administrativos; reclamações administrativas; reclamações de má prática; reuniões de morbilidade/morbidade e mortalidade, com ou sem necropsias; auditorias/revisões ou investigações/pesquisas nacionais ou regionais; e processo clínico/prontuário do paciente.

Os métodos para recolha/coleta de dados com o objetivo de compreender as causas são: análise de causa raiz; inquéritos com profissionais; análise de reclamações de má prática; análise dos incidentes encontrados em sistemas de notificação/relato; observação direta.

\section{Identificar as soluções}

Para melhorar a segurança do paciente, precisamos realizar investigações/pesquisas a fim de determinar que soluções são efetivas em transformar o cuidado de saúde mais seguro e reduzir o dano ao paciente, comparado com o padrão de cuidado presente.

Os métodos para identificar soluções que ainda não foram avaliadas são: estudos de intervenção do tipo "antes e depois"; ensaios clínicos controlados randomizados duplo cego; e randomização por conglomerados. Para as soluções já conhecidas, o que devemos fazer é melhorar a fiabilidade/confiabilidade de práticas efetivas.

As intervenções a testar ou aprimorar podem se dar nos pacientes (por exemplo, tratamento diferente), nos profissionais de saúde (por exemplo, treinamento para melhorar a comunicação da equipa), no ambiente de trabalho (como adaptações nos quartos para prevenção de queda dos pacientes) ou no sistema (alterações em um sistema de prescrição eletrónica).

\section{Avaliar o impacte}

Mesmo quando soluções dão certo em ambientes controlados de investigação/pesquisa, é importante avaliar sua efetividade na realidade dos serviços/departamentos de saúde em termos de: impacte; aceitabilidade; e capacidade de oferta (affordability). 
Para avaliar o impacte de uma intervenção, podemos medir:

\section{A frequência do dano, para saber se houve redução;}

a prevalência do cuidado apropriado, esperando que

esta tenha aumentado;

mudanças na prática decorrentes do aprendizado;
Aqui, também as intervenções e a avaliação do seu impacte podem ser direcionadas aos pacientes, profissionais de saúde, ambiente de trabalho ou ao sistema.

É possível avaliar os resultados sob diferentes perspetivas: clínica, do paciente ou da sociedade. A perspetiva do paciente inclui perceção do estado de saúde, qualidade de vida e satisfação. A perspetiva da sociedade inclui a utilização dos serviços/departamentos e o custo a ele associado.

\section{Transpor a evidência em cuidados mais seguros}

O passo final do ciclo de investigação/pesquisa é compreender como os achados (resultados) da investigação/pesquisa podem ser transpostos para a prática. Isso é especialmente importante em países em desenvolvimento e nas economias de transição, em que os recursos são escassos e a infraestrutura de investigação/pesquisa é com frequência limitada.

Entre as estratégias para transpor a evidência em cuidados mais seguros estão:

\section{Resumir a evidência;}

滕 Identificar barreiras locais à implementação;

滕 Compreender o contexto;

Medir o desempenho;

滕 Garantir que todos os pacientes recebam a intervenção.

Existe crescente preocupação para que as pesquisas/investigações se aproximem da melhoria das práticas seguras criadas nos serviços/ departamentos de saúde (Øvretveit 2015; Portela et al. 2015).

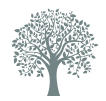

Para consolidar seus conhecimentos, assista à Sessão 6 do Curso Introdutório de Investigação em Segurança do Paciente/Doente - Avaliar o impacte após implementação, disponível em: http://www. slideshare.net/Proqualis/avaliaro-impacto

Assista também à Sessão 7 do Curso Introdutório de Investigação em Segurança do Paciente/Doente - Traduzir a evidência em cuidados de saúde mais seguros, disponível em: http://www.slideshare. net/Proqualis/transpor-aevidncia-em-cuidados-maisseguros-15672393

Para consolidar e sintetizar o que foi referido ao longo das sete sessões do curso, assista à Sessão 8 do Curso Introdutório de Investigação em Segurança do Paciente/Doente Aprofundar o conhecimento em segurança do paciente/ doente, disponível em: http:// www.slideshare.net/Proqualis/ princpios-da-investigao-emsegurana-do-paciente 


\section{Prioridades para investigação/pesquisa em segurança do paciente}

Como demonstrado até agora, ainda há muitos desafios para a área de segurança do paciente, e novas investigações/pesquisas são a chave para melhorar o conhecimento sobre a segurança dos cuidados de saúde prestados.

Ao considerarmos os recursos restritos destinados ao financiamento das investigações/pesquisas na área, como saber quais questões devem ser abordadas primeiro? Com essa preocupação em mente, em 2006, a Aliança Mundial para Segurança do Paciente da OMS organizou um grupo de trabalho com especialistas a fim de identificar uma série de prioridades globais para a investigação/pesquisa em segurança do paciente. O grupo contava com 19 profissionais, entre eles clínicos, investigadores/pesquisadores e formuladores de políticas, originários de países em desenvolvimento, economias de transição e países desenvolvidos. As diversas áreas de investigação/pesquisa também estavam representadas, incluindo investigadores/pesquisadores das áreas epidemiológica, qualitativa e de factores humanos (WHO 2008).

A partir da revisão das evidências científicas, foram identificados 50 tópicos relacionados com a segurança do paciente. O grupo ranqueou os tópicos considerando: a frequência do problema; a magnitude do dano e sua distribuição na população; o impacte na eficiência do sistema; a viabilidade, disponibilidade e sustentabilidade das soluções; a urgência ou apoio político necessário para atacar o problema; e o grau de desenvolvimento dos países (Bates et al. 2009).

O Quadro 1 apresenta as dez áreas prioritárias para investigação/pesquisa em segurança do paciente. A avaliação de custo-efetividade de estratégias para redução do risco foi de alta prioridade para todas as nações, sendo o único tópico semelhante entre os países em desenvolvimento e os países desenvolvidos. As economias de transição compartilharam prioridades com os países em desenvolvimento (quatro tópicos) e com os países desenvolvidos (cinco tópicos).

Quadro 1 - Áreas prioritárias para investigação/pesquisa em segurança do paciente nos países em desenvolvimento, economias de transição e países desenvolvidos

\begin{tabular}{|l|l|l|l|}
\hline & Países em desenvolvimento & Economias de transição & Países desenvolvidos \\
\hline 1 & $\begin{array}{l}\text { Identificação, design e teste de soluções } \\
\text { eficazes e acessíveis localmente }\end{array}$ & $\begin{array}{l}\text { Identificação, design e teste de soluções } \\
\text { eficazes e acessíveis localmente }\end{array}$ & Falhas de comunicação e de coordenação \\
\hline
\end{tabular}


Quadro 1 - Áreas prioritárias para investigação/pesquisa em segurança do paciente nos países em desenvolvimento, economias de transição e países desenvolvidos (cont.)

\begin{tabular}{|c|c|c|c|}
\hline & Países em desenvolvimento & Economias de transição & Países desenvolvidos \\
\hline 2 & $\begin{array}{l}\text { Custo-efetividade das estratégias de } \\
\text { redução de risco }\end{array}$ & $\begin{array}{l}\text { Custo-efetividade das estratégias de } \\
\text { redução de risco }\end{array}$ & Falhas latentes da organização \\
\hline 3 & $\begin{array}{l}\text { Medicamentos contrafeitos ou de baixa } \\
\text { "qualidade" }\end{array}$ & $\begin{array}{l}\text { Falta de conhecimento adequado e sua } \\
\text { transferência }\end{array}$ & $\begin{array}{l}\text { Cultura de segurança do doente pouco } \\
\text { enraizada }\end{array}$ \\
\hline 5 & Cuidados de saúde materno infantil & Falhas de comunicação e de coordenação & $\begin{array}{l}\text { Indicadores de segurança do doente } \\
\text { inadequados (ou ausentes) }\end{array}$ \\
\hline 6 & Infeção associada aos cuidados de saúde & $\begin{array}{l}\text { Cultura de segurança do doente pouco } \\
\text { enraizada }\end{array}$ & $\begin{array}{l}\text { Falta de consideração dos factores } \\
\text { humanos no projeto e desenvolvimento } \\
\text { da prestação de cuidados }\end{array}$ \\
\hline 8 & $\begin{array}{l}\text { Falta de conhecimento adequado e sua } \\
\text { transferência }\end{array}$ & $\begin{array}{l}\text { Dimensão e natureza dos eventos } \\
\text { adversos }\end{array}$ & $\begin{array}{l}\text { Envolvimento do doente na formulação } \\
\text { da agenda de investigação em segurança } \\
\text { do doente }\end{array}$ \\
\hline 9 & Segurança inerente a injeções & Falhas latentes da organização & $\begin{array}{l}\text { Falta de consideração dos factores } \\
\text { humanos na utilização de dispositivos } \\
\text { médicos }\end{array}$ \\
\hline 10 & Transfusões de sangue seguras & $\begin{array}{l}\text { Indicadores de segurança do doente } \\
\text { inadequados (ou ausentes) }\end{array}$ & $\begin{array}{l}\text { Eventos adversos medicamentosos e erros } \\
\text { de medicação }\end{array}$ \\
\hline
\end{tabular}

Fonte: Sousa et al. (2010, p. 93).

\section{Para refletir}

Considere o grau de desenvolvimento do seu país e indique em que áreas se estão apostando mais em investigação/pesquisa. Você conhece algum grupo de investigação/pesquisa que esteja desenvolvendo projetos em uma das dez áreas prioritárias definidas pela OMS?

O grupo de trabalho educação e treinamento em investigação/pesquisa em segurança do paciente da OMS publicou, em 2010, um conjunto de competências necessárias para investigações/pesquisas na área. As competências encontram-se distribuídas em três grandes grupos: ciência da segurança do paciente, metodologias de investigação/pesquisa epidemiológica e nos serviços de saúde, e princípios da transferência de conhecimento (Andermann et al. 2011). Se você tiver interesse em saber mais, leia o artigo Core competencies for patient safety research: a corner stone for global capacity strengthening, disponível em: http://qualitysafety. bmj.com/content/20/1/96.full.pdf 


\section{Questões éticas relacionadas à investigação/pesquisa em segurança do paciente}

A investigação/pesquisa envolvendo seres humanos deve ser conduzida de forma a respeitar a dignidade, a segurança e os direitos dos participantes da investigação/pesquisa. Preocupada com as questões éticas relacionadas à investigação/pesquisa em segurança do paciente, a OMS comissionou, em 2010, um grupo de especialistas para trabalhar sobre essa questão.

Figura 4 - O Apotecário, de Pietro Longhi (1752), exposta na Galleria dell'Academia, em Veneza

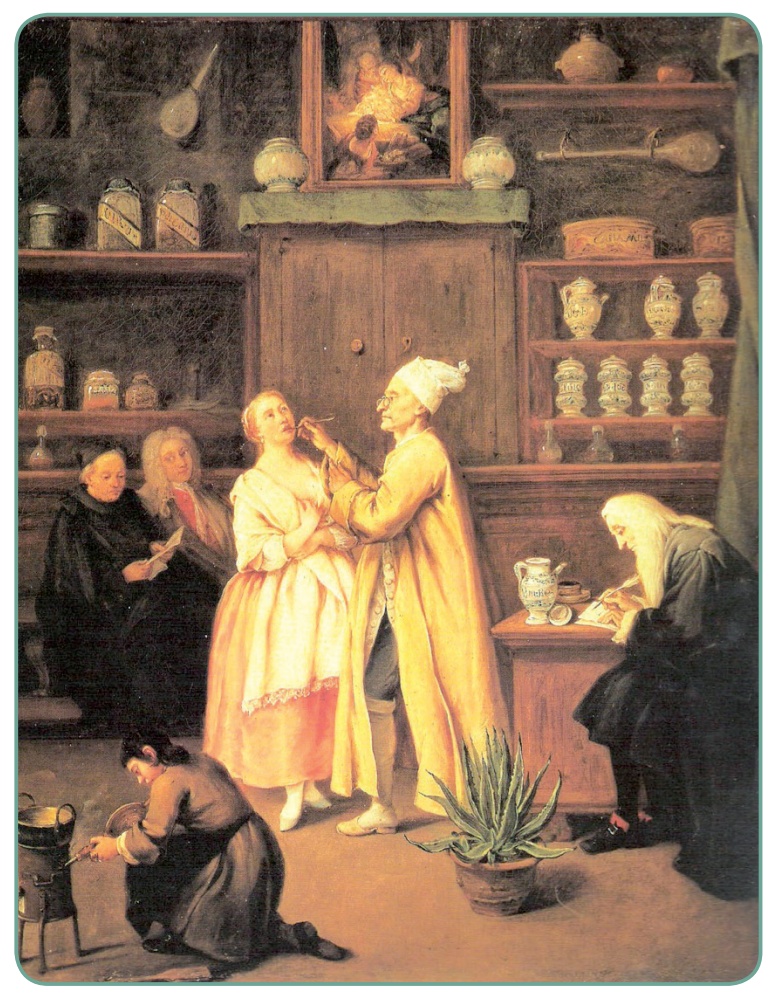

Os princípios éticos identificados pelo grupo de especialistas e endossados pela OMS são as Diretrizes Éticas Internacionais para Pesquisas Biomédicas Envolvendo Seres Humanos (2002) e as Diretrizes Éticas Internacionais para Pesquisa Epidemiológica (2009), ambas do Councilon International Organizations of Medical Sciences (CIOMS) e a Declaração de Helsinki (2008) da Associação Médica Mundial.
Fonte: UFF (2014)

Nota: A experimentação em seres humanos é uma prática antiga e necessária ao avanço da ciência. No entanto, abusos cometidos levaram à criação dos mecanismos de controlo que hoje conhecemos.

O produto desse trabalho foi a publicação, em 2013, do documento Ethical issues in Patient Safety Research: interpreting existing guidance, que representa uma interpretação e aplicação dos princípios éticos existentes, internacionalmente aceitos, às questões específicas que surgem no contexto das atividades de segurança do paciente. Apresenta 13 orientações éticas com a adoção complementar de casos de estudo para 
exemplificá-las. O documento foi elaborado para consulta por profissionais de segurança do paciente, investigadores/pesquisadores, organizações de saúde, comitês de ética em investigação/pesquisa, autoridades de saúde e demais interessados em garantir a conduta ética das atividades de investigação/pesquisa em segurança do paciente.

As orientações éticas contemplam, entre outros, que (WHO 2013): os projetos devem ser submetidos à apreciação de comitê de ética em investigação/pesquisa; no geral, os investigadores/pesquisadores devem buscar o consentimento informado de pacientes e profissionais que estejam participando da investigação/pesquisa; a equipa envolvida nas atividades ou investigações/pesquisas de segurança do paciente deve se preocupar com a preservação da privacidade e da confidencialidade dos envolvidos; e a equipa de investigação/pesquisa tem o dever de relatar os resultados do estudo para os hospitais e unidades após o término do projeto.

\section{Considerações finais}

A investigação/pesquisa em geral e a realizada na área da segurança do paciente, em particular, devem obedecer a um conjunto de pressupostos metodológicos, como sejam:

滕 a explicitação do paradigma adotado;

跘 a definição clara de objetivos;

镂 o tipo de estudo;

䗉 a identificação da população ou amostra;

a definição das variáveis;

滕 a seleção dos instrumentos de recolha/coleta e análise dos dados;

綞 a definição da estratégia metodológica a seguir;

a apresentação e discussão dos resultados encontrados e a síntese das principais conclusões a retirar da investigação/pesquisa.

Tais pressupostos condicionam o sucesso de desenvolvimento da investigação/pesquisa, permitem caracterizar seu rigor e consistência (interna e externa) e determinam a robustez e a validade dos resultados obtidos.

Acautelados os pressupostos enunciados, destacamos que o grande desafio da investigação/pesquisa em segurança do paciente será criar conhecimento e, por meio de sua transferência, possibilitar o desenvolvimento de soluções inovadoras que contribuam para diminuir o risco inerente à prestação de cuidados de saúde e, dessa forma, melhorar a qualidade e a segurança dos pacientes.

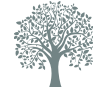

Conheça mais sobre o documento Ethical issues in Patient Safety Research: interpreting existing guidance (WHO 2013) visitando o endereço: http://apps.who.int/ iris/bitstream/10665/85371/1/ 9789241505475_eng.pdf. 


\section{Referências}

Andermann A, et al. Core competencies for patient safety research: a cornerstone for global capacity strengthening. BMJ Qual Saf. 2011;20:96-101.

Andermann A, Wu AW, Lashoher A, Norton P, Arora NK, Bates DW, et al. Case studies of patient safety research classics to build research capacity in low- and middle-income countries. Jt Comm J Qual Patient Saf. 2013;39(12):553-60.

Aranaz-Andrés JM, et al. Incidence of adverse events related to health care in Spain: results of the Spanish National Study of Adverse Events. J Epidemiol Community Health. 2008 Dec;62(12):102229.

Aveling EL, Mcculloch P, Dixon-Woods M. A qualitative study comparing experiences of the surgical safety checklist in hospitals in high-income and low-income countries. BMJ Open 2013 Aug. 15;3(8):e003039.

Baker GR, et al. The Canadian adverse events study: the incidence of adverse events among hospital patients in Canada. CMAJ. 2004 May 25;170(11):1678-86.

Bates DW, Larizgoitia I, Prasopa-Plaizier N, Jha AK. Global priorities for patient safety research. BMJ. 2009;338:b1775.

Berwick DM. The science of improvement. JAMA. 2008 Mar 12;299(10):1182-4.

Bosk CL, et al. Reality check for checklists. Lancet. 2009 Aug 8;374(9688):444-5.

Brandão C, Ribeiro J, Costa AP. Investigação qualitativa: em que ponto estamos? Ciên Saúde Colet. 2018 Jan;23(1):4.

Brennan, T. A. et al. Incidence of adverse events and negligence in hospitalized patients. Results of the Harvard Medical Practice Study I. N Engl J Med. 1991 Feb 7;324(6):370-6.

Brown C, Hofer T, Johal A, Thomson R, Nicholl J, Franklin BD, et al. An epistemology of patient safety research: a framework for study design and interpretation, part 2: study design. Qual Saf Health Care. 2008;17:163-9.

Denzin NK, Lincoln YS, editors. Handbook of qualitative research. 2nd ed. Thousand Oaks: Sage Publications; 2000.

Deslandes SF. Revisitando as metodologias qualitativas nas pesquisas de avaliação: vertentes, contribuições e desafios. In: Baptista TWF, Azevedo CS, Machado CV, editors Políticas, planejamento e gestão em saúde: abordagens e métodos de pesquisa. Rio de Janeiro: Ed. Fiocruz; 2015. p. 193-217.

Dixon-Woods $\mathrm{M}$, et al. Culture and behaviour in the English National Health Service: overview of lessons from a large multimethod study. BMJ Qual Saf. 2014 Feb;23(2):106-15.

Dixon-Woods $M$, et al. Explaining Matching Michigan: an ethnographic study of a patient safety program. Implement Sci. 2013 Jun 20;8:70.

Dixon-Woods M, et al. Explaining Michigan: developing an ex post theory of a quality improvement program. Milbank Q. 2011 Jun;89(2):167-205.

Dixon-Woods $M$, et al. Synthesising qualitative and quantitative evidence: a review of possible methods. J Health Serv Res Policy. 2005 Jan;10(1):45-53.

Green J, Thorogood N. Qualitative methods for health research. London: SAGE Publications; 2004.

Haynes $A B$, et al. A surgical safety checklist to reduce morbidity and mortality in a global population. New Engl J Med. 2009 Jan 29;360(5):491-9.

Hulley SB, Newman TB, Cummings SR. Getting started: the Anatomy and Physiology of clinical research. In: Hulley SB, et al. Designing clinical research: an epidemiologic approach. 4th. ed. Philadelphia: LWW; 2013. 
Kohn LT, Corrigan J, Donaldson MS, editors. To err is human: building a safer health system. Washington, D.C: National Academy Press, 2000.

Mendes W, et al. The assessment of adverse events in hospitals in Brazil. Int J Qual Health Care. 2009 Aug.;21(4):279-84.

Øvretveit J. Melhoria de qualidade que agrega valor: o cuidado de saúde. Rio de Janeiro: Proqualis; ICICT; 2015.

Øvretveit J. Understanding the conditions for improvement: research to discover which context influences affect improvement success. BMJ Qual Saf. 2011 Apr;20(Suppl 1):i18-23.

Portela MC, Pronovost P, Woodcock T, Carter P, Dixon-Woods M. How to study improvement interventions: a brief overview of possible study types. BMJ Qual Saf, 2015;0:1-12.

Pronovost $\mathrm{P}$, et al. An intervention to decrease catheter-related bloodstream infections in the ICU. New Eng J Med. 2006 Dec 28;355(26):2725-32.

Roese NJ, Vohs KD. Hindsight bias. Perspect Psychol Sci. 2012;7(5):411-26.

Shekelle PG, et al. Assessing the evidence for context-sensitive effectiveness and safety of patient safety practices: developing criteria. Rockville (MD): Agency for Healthcare Research and Quality; 2010 Dec.

Shekelle PG, et al. Making health care safer II: an updated critical analysis of the evidence for patient safety practices. Evid Rep Technol Assess. 2013 Mar;(211):1-945.

Shojania KG, et al. Making health care safer: a critical analysis of patient safety practices. Evid Rep Technol Assess (Summ). 2001;(43):i-x, 1-668.

Sousa $\mathrm{P}$, et al. Estimating the incidence of adverse events in Portuguese hospitals: a contribution to improving quality and patient safety. BMC Health Serv Res. 2014 Jul 18;14:311.

Sousa P, Uva AS, Serranheira F. Investigação e inovação em segurança do doente. Rev. Port. Saúde Pública. 2010;Vol.Tem.(10):89-95.

Thomas EJ, et al. Costs of medical injuries in Utah and Colorado. Inquiry. 1999:36 (3);255-64.

Universidade Federal Fluminense. Disciplina de semiologia. Niteroi: UFF; 2014.

Vincent C, Neale G, Woloshynowych M. Adverse events in British hospitals: preliminary retrospective record review. BMJ. 2001 Mar. 3;322(7285):517-9.

Wilson RM, et al. The quality in Australian health care study. Med J Aust. 1995 Nov 6;163(9):45871.

World Health Organization. Ethical issues in patient safety research: interpreting existing guidance. Geneva: WHO; 2013 [citado 2013 Set 14]. Disponível em: http://apps.who.int/iris/ bitstream/10665/85371/1/9789241505475_eng.pdf.

World Health Organization. Patient Safety. Assessing and tackling patient harm: a methodological guide for data-poor hospitals. Geneva: WHO; 2010 [citado 2013 Out 17]. Disponível em: http:// www.who.int/patientsafety/research/methodological_guide/PSP_MethGuid.pdf.

World Health Organization. Patient safety research: a guide for developing training programmes. Geneva: WHO; 2012 [citado 2013 Ago 19]. Disponível em: http://apps.who.int/iris/ bitstream/10665/75359/1/9789241503440_eng.pdf.

World Health Organization. The Research Priority Setting Working Group. Global priorities for research in patient safety. 1st. ed. Geneva: WHO; 2008 Dec [citado 2013 Ago 19]. Disponível em: http://www.who.int/patientsafety/research/priorities/global_priorities_patient_safety_research.pdf. 


\section{Disclosure: a "arte" de saber comunicar ao paciente um incidente relacionado com os cuidados de saúde}

Maria João Lage e Paulo Sousa

Este capítulo explora o que é a comunicação (disclosure) de um incidente relacionado com os cuidados de saúde e qual a expectativa do paciente a respeito do comportamento dos profissionais e das instituições após a ocorrência de um incidente.

Serão, também, analisados os principais riscos e benefícios de comunicar abertamente uma ocorrência, abordando a perspetiva de cada uma das partes envolvidas (paciente, profissional, organização). Por ser o disclosure um processo complexo e sensível, é necessário conhecer as estratégias mais corretas de o fazer, e incluir essa aprendizagem na formação/treino dos profissionais de saúde.

\section{O que é o disclosure - comunicação de um incidente relacionado com os cuidados de saúde?}

O Australian Open Disclosure Act (Lei Australiana para a Comunicação Aberta) define a comunicação aberta como "fornecer uma estratégia consistente de comunicação com os pacientes após a ocorrência de um incidente/evento adverso. Esta definição inclui a expressão de pesar pelo sucedido e a informação sistemática sobre a investigação do evento, a sua prevenção e a respetiva melhoria do sistema" (Sorensen et al. 2008).

De uma forma mais pragmática, disclosure é a revelação/comunicação de um incidente/evento adverso, decorrente da prestação de cuidados 
de saúde, incluindo as causas que estiveram na sua ocorrência, bem como as melhorias instituídas para evitar acontecimentos semelhantes no futuro.

Curiosamente, ao reunir, num único documento, as definições dos termos usados na segurança do paciente (taxonomia para a segurança do paciente), a OMS não incluiu a definição de "disclosure" como comunicação ao paciente. A definição "mais próxima" é a de comunicação de um incidente crítico, na intenção, porém, de relatar no sistema de notificação, e não de comunicar ao paciente. Essa definição inclui as ocorrências que poderiam ter conduzido ou, na realidade, conduziram a um resultado indesejável. Ainda de acordo com essa definição, tal comunicação deve ser feita pelo pessoal diretamente implicado no processo em causa, na altura em que o evento foi identificado - ou seja, os profissionais envolvidos nessa situação devem proceder ao registo da ocorrência. Nessa definição redutora, fica de fora toda a dimensão de abertura e transparência característica das organizações com cultura de segurança justa e que valorizam a aprendizagem com o erro e base em acontecimentos indesejados (OMS 2011).

Com maior foco na perspetiva do paciente e no conteúdo da comunicação, Fein e colaboradores (2007) definem a comunicação de erros como a "comunicação entre um profissional de saúde e um paciente ou familiar que reconhece a ocorrência de um erro, discute o que aconteceu e descreve a ligação entre o erro e o resultado, de uma forma que faça sentido para o paciente".

Apontando o caminho para cuidados de saúde mais centrados no paciente, esses autores reforçam que “a comunicação de erros é um processo essencial para garantir que os pacientes recebem a informação necessária para tomar decisões informadas sobre os cuidados que lhes são prestados, contribuindo dessa forma para entender melhor a sua doença, o tratamento e os resultados".

Ao relatar os comentários de profissionais de saúde ao processo de comunicação dos erros, Sorensen e colaboradores (2008) sugeriram que “a comunicação aberta dos erros é a formalização de um processo de comunicação entre o clínico e o paciente, e que tal deveria ser comum a toda a comunicação, relacionada ou não com um incidente/evento adverso".

A maior parte dos autores concordam que a comunicação aberta e transparente de incidentes é uma boa prática, independentemente do facto de resultarem ou não numa redução do número de ações de 
litígio (Berwick 2009). A intenção de comunicar erros, incidentes e eventos adversos é comum a muitos profissionais, mas o número dos que referem ter tido essa experiência é, surpreendentemente, diminuto (Boyle et al. 2006; Gallagher et al. 2006; Mazor et al. 2004). São vários os factores que estão na origem e acentuam essa diferença encontrada entre teoria e prática. Vamos analisá-los ao longo do capítulo.

Após a ocorrência de um incidente relacionado com os cuidados de saúde do qual resultou uma lesão para o paciente (evento adverso), qual a reação habitual e qual a expectativa do paciente?

Após a ocorrência de um incidente relacionado com os cuidados de saúde do qual resultou uma lesão para o paciente (evento adverso), qual a reação habitual e qual a expectativa do paciente?

Os inquéritos de base populacional, as discussões em grupos focais e as entrevistas com vítimas de incidentes/eventos adversos revelam que, após a ocorrência de um incidente, os pacientes esperam uma comunicação explícita a esse respeito. Ou seja, esperam que seja partilhado com eles a informação sobre aquilo que sucedeu, como será prevenido no futuro e um pedido de desculpas (Gallagher et al. 2006; Gallagher 2009; Lazare 2006; Mazor et al. 2004). Com base em inquéritos realizados a grupos de pacientes, usando cenários de incidentes/eventos adversos, os indivíduos inquiridos respondem de forma diferente, conforme o comportamento evidenciado pelos profissionais de saúde, em relação ao incidente descrito. Esse facto reforça a importância do conteúdo e do momento em que se dá o primeiro encontro entre profissionais de saúde e os pacientes/famílias depois da ocorrência de um incidente/ evento adverso (Gallagher 2009; Mazor et al. 2004; Schwappach, Koeck 2004). Algo que deve ficar bem claro para todos os pacientes e familiares é que um mau resultado em saúde (por exemplo, uma complicação cirúrgica, uma reação adversa a um medicamento, uma infeção associada à intubação, ou um efeito secundário de um tratamento) não é, necessariamente, uma consequência de erros ou falhas por parte do(s) profissional(ais) de saúde (Boyle et al. 2006).

Na visão do paciente, a organização deve estar envolvida na gestão/ gerenciamento de uma ocorrência indesejada ou incidente/evento adverso, procurando conhecer sua perspetiva e da sua família, oferecendo apoio e compensação financeira, se for necessário (Boyle et al. 2006; Gallagher 2009; House of Commons Health Committee 2008). 


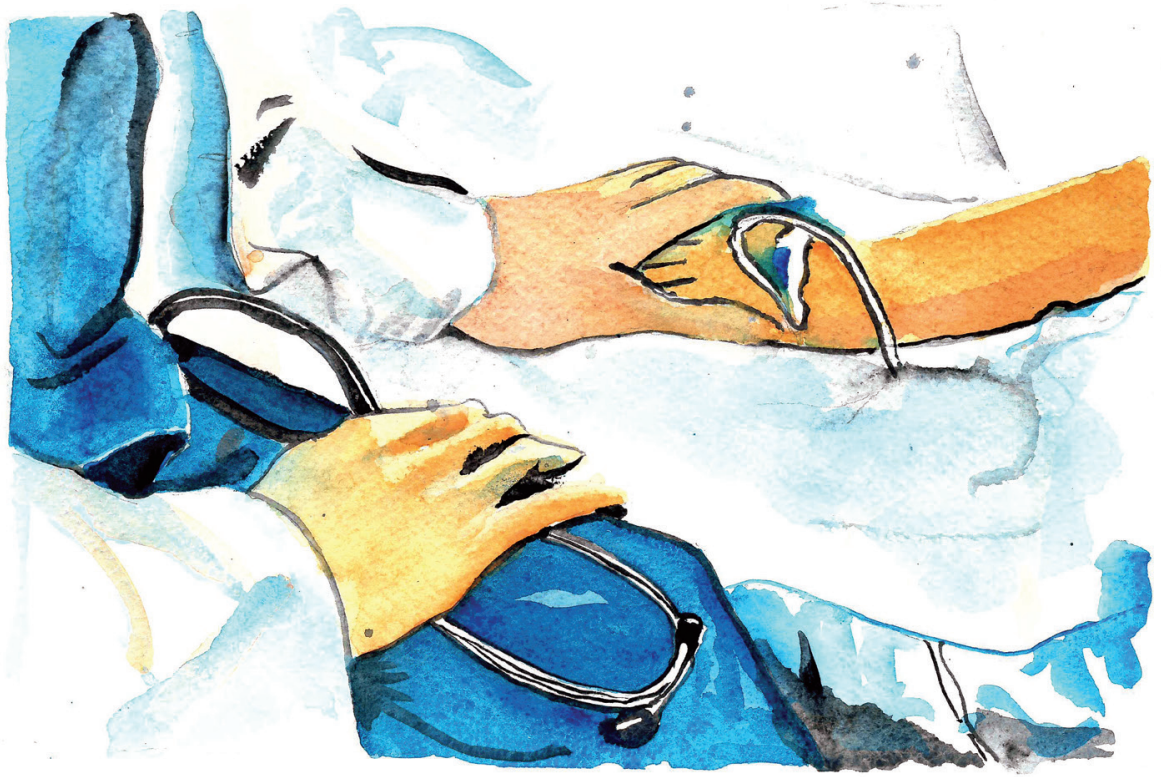

\section{Riscos, barreiras e benefícios para a comunicação de incidente/evento adverso}

A decisão de fazer a comunicação de uma ocorrência indesejada/evento adverso depende da forma como são geridos os medos, os receios, os riscos e as vantagens dessa comunicação, tanto para os profissionais como para os pacientes e as organizações de saúde. Vejamos quais os factores que podem ter impacto nessa decisão.

No Quadro 1, apresenta-se um resumo de alguns dos riscos, barreiras e benefícios para a comunicação de incidentes, de acordo com a perspetiva do paciente. As vantagens de uma comunicação aberta, para o paciente, são muito superiores aos riscos: o paciente não tem, habitualmente, muito a perder, a não ser o grau de confiança no sistema e nos profissionais de saúde. Existem, no entanto, algumas barreiras que traduzem, muitas vezes, a relação médico-paciente pobre e a fraca valorização da participação e envolvimento do paciente nas questões da segurança do cuidado.

Durante a estadia hospitalar, uma boa prática de comunicação regular com os pacientes acerca do diagnóstico, dos planos de tratamento, dos resultados esperados e das complicações possíveis pode levar a uma relação de maior abertura e confiança, na qual a comunicação aberta de um incidente/evento adverso seja facilitada. De acordo com relatos/notificações de pacientes, que foram vítimas de incidentes/eventos 
adversos, esta não é a situação mais frequente (Delbanco, Bell 2007; Goldberg et al. 2002; House of Commons Health Committee 2008).

Se a forma como o incidente/evento adverso é comunicado tem ou não efeito na decisão, por parte do paciente, de iniciar uma ação litigiosa, é uma questão que ainda se debate na literatura actual.

Várias pesquisas/investigações realizadas analisaram a alteração do padrão de litígio antes e depois da implementação de uma política de comunicação aberta perante um incidente/evento adverso. Alguns desses estudos constataram que um dos factores que mais influencia a decisão, por parte do paciente, de entrar em litígio é a gravidade do dano infligido pelo incidente/evento adverso.

Quadro 1 - Factores que influenciam a comunicação do incidente/evento adverso na perspectiva do paciente

\begin{tabular}{|c|c|}
\hline $\begin{array}{l}\text { Razões que os pacientes podem alegar para não ser } \\
\text { envolvidos na comunicação de um incidente/evento adverso }\end{array}$ & $\begin{array}{l}\text { Benefícios referidos pelos pacientes após a comunicação de um } \\
\text { incidente/evento adverso }\end{array}$ \\
\hline $\begin{array}{l}\text { - Medo de represálias por parte dos profissionais e da } \\
\text { instituição (Delbanco, Bell 2007) }\end{array}$ & - Ajuda para conseguir tratamento adicional (Boyle et al. 2006) \\
\hline $\begin{array}{l}\text { - Sentimento de culpa por parte dos familiares (falta de } \\
\text { vigilância) (Delbanco, Bell 2007) }\end{array}$ & $\begin{array}{l}\text { - Possibilidade de compensação financeira pelo dano causado (Boyle et al. } \\
\text { 2006) }\end{array}$ \\
\hline - Medo de ser abandonado pelos profissionais de saúde & $\begin{array}{l}\text { - Redução da ansiedade face a uma situação inexplicada (Boyle et al. } \\
\text { 2006) }\end{array}$ \\
\hline $\begin{array}{l}\text { - Canais de comunicação difíceis entre pacientes e } \\
\text { profissionais de saúde }\end{array}$ & $\begin{array}{l}\text { - Recuperação da confiança e da relação com os profissionais de saúde } \\
\text { (Boyle et al. 2006; Schawappach, Koeck 2004) }\end{array}$ \\
\hline $\begin{array}{l}\text { - Dano ou erro podem não ser percetíveis para o paciente } \\
\text { (Gallagher et al. 2006) }\end{array}$ & $\begin{array}{l}\text { - Menor probabilidade de entrar em litígio com os profissionais de saúde } \\
\text { (Schwappach, Koeck 2004) }\end{array}$ \\
\hline $\begin{array}{l}\text { - Explicações dos erros pouco claras ou atrasadas (Fein et al. } \\
\text { 2007) }\end{array}$ & $\begin{array}{l}\text { - Perceção de passar a ser mais respeitado pelos profissionais de saúde } \\
\text { (Gallagher 2009) }\end{array}$ \\
\hline $\begin{array}{l}\text { - Perda de confiança nos profissionais e nas organizações de } \\
\text { saúde (Schwappach, Koeck 2004) }\end{array}$ & $\begin{array}{l}\text { - Possibilidade de contribuir para a análise do incidente/evento adverso } \\
\text { (Gallagher 2009) }\end{array}$ \\
\hline $\begin{array}{l}\text { - Culpa atribuída ao sistema com perda da responsabilidade } \\
\text { individual (Schwappach, Koeck 2004) }\end{array}$ & $\begin{array}{l}\text { - Maior envolvimento do paciente e da sua perspetiva sobre os cuidados } \\
\text { de saúde (Berwick 2009) }\end{array}$ \\
\hline $\begin{array}{l}\text { - Medo de ofender os profissionais de saúde ao referir falhas } \\
\text { nos cuidados (Gallagher 2009) }\end{array}$ & - Melhor aceitação dos cuidados de saúde (Berwick 2009) \\
\hline - Baixos níveis de iliteracia em saúde & $\begin{array}{l}\text { - Possibilidade de contribuir para prevenir ocorrências semelhantes que } \\
\text { possam atingir outros pacientes }\end{array}$ \\
\hline
\end{tabular}

Fonte: Elaborado pelos autores. 


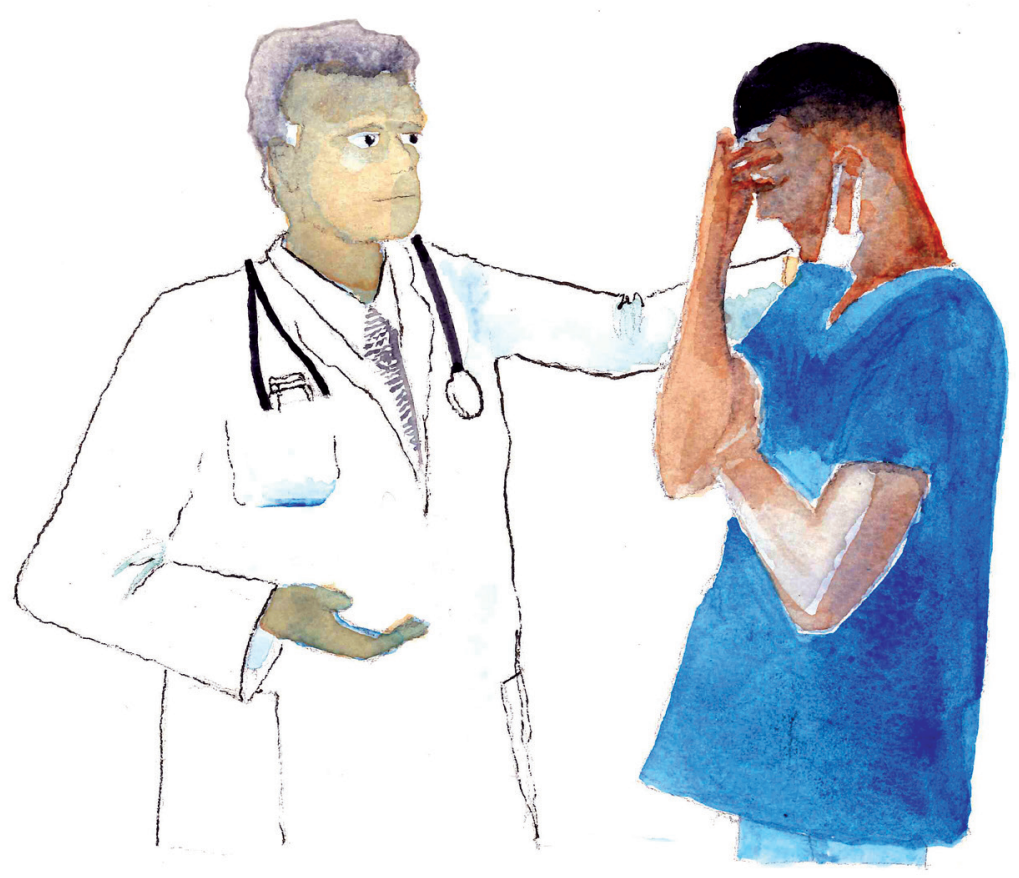

Uma elevada porcentagem de profissionais de saúde são favoráveis à comunicação de incidentes/eventos adversos, considerando que é a atitude certa a tomar. No entanto, são poucos os que relatam/notificam terem feito tal experiência. Quando o fazem, descrevem uma sensação de alívio, o reforço da relação médico-paciente, maior sensibilidade para detetar as limitações do sistema de saúde e, ainda, por consequência, maior empenho e vontade para contribuir com sua melhoria. $\mathrm{O}$ maior risco, que pode impedir a comunicação aberta de um incidente/ evento adverso, parece ser a falta de apoio institucional e dos seus pares, associado ao medo, por vezes justificado, de que a comunicação forneça base documental que possa dar origem a um processo de litígio (Quadro 2).

O processo de comunicação pode ser uma barreira em si se existirem dúvidas sobre o que dizer e quando se verifica falta de treino na comunicação de más notícias aos pacientes. 
Quadro 2 - Factores que influenciam o profissional de saúde na decisão de comunicar abertamente incidentes/eventos adversos aos pacientes e às famílias

\begin{tabular}{|c|c|}
\hline $\begin{array}{l}\text { Riscos e barreiras, relacionados com a comunicação de } \\
\text { incidentes/eventos adversos, para os profissionais de saúde }\end{array}$ & $\begin{array}{l}\text { Benefícios, relatados pelos profissionais, após a comunicação aberta } \\
\text { de um incidente/evento adverso aos pacientes e famílias }\end{array}$ \\
\hline - Medo de um processo judicial (Gallagher et al. 2006) & - Sensação de alívio e de partilha (Gallagher et al. 2006) \\
\hline $\begin{array}{l}\text { - Sentimento de vergonha/falta de coragem (Gallagher et al. } \\
\text { 2006) }\end{array}$ & - Menor probabilidade de litígio (Gallagher et al. 2006) \\
\hline - Incerteza no conteúdo da comunicação (Gallagher et al. 2006) & $\begin{array}{l}\text { - Feedback dos pacientes sobre os cuidados e como introduzir } \\
\text { melhorias (Gallagher 2009) }\end{array}$ \\
\hline - Receio de alarmar o paciente e os familiares (Gallagher 2009) & $\begin{array}{l}\text { - Cumprimento das boas práticas (Boyle et al. 2006; House of } \\
\text { Commons Health Committee 2008; Sorensen et al. 2008) }\end{array}$ \\
\hline $\begin{array}{l}\text { - Isolamento/falta de apoio dos pares e por parte da instituição } \\
\text { de saúde (Gallagher 2009; Sorensen et al. 2008) }\end{array}$ & • Transparência (Berwick 2009) \\
\hline - Medo de revelar dados em excesso (Gallagher 2009) & - Conhecimento acrescido sobre o sistema (Boyle et al. 2006) \\
\hline - Medo da reação do paciente (Gallagher 2009) & $\begin{array}{l}\text { - Prevenção de dano para outros pacientes e em outras situações } \\
\text { (Boyle et al. 2006) }\end{array}$ \\
\hline - Perda de estatuto ou de licença profissional & - Comunicação centrada no paciente (Sorensen et al. 2008) \\
\hline $\begin{array}{l}\text { - Pressão das seguradoras ou de outras entidades pagadoras/ } \\
\text { financiadoras (Gallagher et al. 2006) }\end{array}$ & - Politicas para mitigação/resolução de falhas (Goldberg et al. 2002) \\
\hline $\begin{array}{l}\text { - Complexidade do processo de comunicação e de investigação } \\
\text { (Sorensen et al. 2008) }\end{array}$ & $\begin{array}{l}\text { - Abertura para maior participação no processo de análise do } \\
\text { incidente/evento adverso e nas medidas de correção das falhas } \\
\text { detetadas. }\end{array}$ \\
\hline - Falta de apoio da liderança (Sorensen et al. 2008) & \\
\hline
\end{tabular}

Fonte: Elaborado pelos autores. 


\section{A discussão sobre a comunicação aberta de incidentes/eventos adversos com os pacientes centra-se, com muita frequência, no seu efeito apa- rentemente dissuasor para os processos de litígio entre os pacientes e as organizações de saúde. No Quadro 3, apresentam-se alguns dos prin- cipais factores que podem influenciar a comunicação de um incidente/ evento adverso ao paciente e família, na perspetiva das organizações de saúde.}

Quadro 3 - Factores que influenciam a comunicação de um incidente/evento adverso ao paciente e família na perspetiva das organizações de saúde

\begin{tabular}{|c|c|}
\hline $\begin{array}{l}\text { Riscos e barreiras que influenciam as organizações de } \\
\text { saúde no processo de comunicação de incidentes/eventos } \\
\text { adversos ao paciente }\end{array}$ & $\begin{array}{l}\text { Benefícios para as organizações relacionados com a comunicação aberta } \\
\text { de incidentes/eventos adversos aos pacientes }\end{array}$ \\
\hline $\begin{array}{l}\text { - Perda de confiança do paciente e da sociedade na } \\
\text { "infalibilidade" das organizações de saúde (Schwappach, } \\
\text { Koeck 2004) }\end{array}$ & $\begin{array}{l}\text { - Possível redução do litígio (Gallagher et al. 2006; Schwappach, Koeck } \\
\text { 2004) }\end{array}$ \\
\hline $\begin{array}{l}\text { - Redução da expectativa irrealista de perfeição dos cuidados } \\
\text { de saúde por parte dos pacientes (Gallagher et al. 2006) }\end{array}$ & $\begin{array}{l}\text { - Reputação de uma cultura de transparência perante a sociedade e } \\
\text { dentro do sistema de saúde }\end{array}$ \\
\hline $\begin{array}{l}\text { - Efeito dissuasor exercido pela gestão/gerenciamento de } \\
\text { risco e pelas seguradoras (Gallagher et al. 2006) }\end{array}$ & $\begin{array}{l}\text { - Política não punitiva pode compensar alguns resultados imprevisíveis } \\
\text { (Gallagher 2009) }\end{array}$ \\
\hline $\begin{array}{l}\text { - Negação dos direitos dos pacientes por diluição da } \\
\text { responsabilidade no sistema (Schwappach, Koeck 2004) }\end{array}$ & $\begin{array}{l}\text { Desenvolvimento de instrumentos para a melhoria da qualidade dos } \\
\text { cuidados (Gallagher 2009) }\end{array}$ \\
\hline - Impacto negativo da imagem da organização nos "media" & $\begin{array}{l}\text { - Envolvimento dos pacientes na análise de barreiras e melhoria dos } \\
\text { processos (Gallagher 2009) }\end{array}$ \\
\hline $\begin{array}{l}\text { - Falta de formação/treino em comunicação (Gallagher } \\
\text { 2009) }\end{array}$ & $\begin{array}{l}\text { - Prevenção de ocorrência semelhante no futuro - aprendizagem com o } \\
\text { erro (House of Commons Health Committee 2008) }\end{array}$ \\
\hline $\begin{array}{l}\text { - Fraca perceção das falhas dentro da própria organização } \\
\text { (Gallagher 2009) }\end{array}$ & $\begin{array}{l}\text { - Criação de uma política local não punitiva e centrada no paciente } \\
\text { (House of Commons Health Committee 2008) }\end{array}$ \\
\hline $\begin{array}{l}\text { - Imperativo para anonimização impedindo/dificultando a } \\
\text { análise das causas (Sorensen et al. 2008) }\end{array}$ & $\begin{array}{l}\text { - Contributo/apoio positivo para maior personalização dos cuidados } \\
\text { (Berwick 2009) }\end{array}$ \\
\hline $\begin{array}{l}\text { - Processo de relato/notificação e investigação/pesquisa de } \\
\text { incidentes/eventos adversos lento e confuso (Sorensen et } \\
\text { al. 2008) }\end{array}$ & $\begin{array}{l}\text { - Reforço da ligação das políticas organizacionais à prática clínica } \\
\text { (Sorensen et al. 2008) }\end{array}$ \\
\hline $\begin{array}{l}\text { - Falta de guião/roteiro para o processo de comunicação } \\
\text { (Mazor et al. 2004) }\end{array}$ & \\
\hline
\end{tabular}

Fonte: Elaborado pelos autores. 
Estudos de âmbito nacional, realizados em vários países por todo o mundo, demonstraram que a ocorrência de incidentes/eventos adversos em hospitais e nos cuidados de saúde primários/atenção primária têm uma magnitude expressiva e um impacto clínico, económico e social bastante significativo. Por essa razão, apostar em políticas, estratégias e ações que promovam uma comunicação de incidentes/eventos adversos mais aberta e efetiva pode influenciar a reação dos pacientes, reforçando uma atitude mais de parceiros ao invés de simples vítimas (Gallagher et al. 2006; Schwappach, Koeck 2004).

O argumento principal a favor de uma comunicação aberta de incidentes/eventos adversos deveria ser, no entanto, a evidência de que uma cultura de segurança robusta e a prestação de cuidados centrados no paciente agregam mais valor ao cuidado de saúde (Berwick 2009).

Sorensen e colaboradores (2008) relatam que, nas instituições com estruturas de qualidade frágeis, pode haver uma desconexão entre aqueles que comunicam os incidentes/eventos adversos, os que estão envolvidos localmente com eles e os que têm a informação e o conhecimento necessários para implementar medidas de melhoria. Isso pode constituir uma barreira, na medida em que o profissional de saúde que deseja, de facto, fazer a comunicação do incidente/evento adverso ao paciente ou família pode deparar-se com um processo complexo de relato/notificação e de investigação de incidentes.

\section{Estudo de caso}

O caso relatado a seguir é real e nos ajuda a refletir sobre algumas das questões abordadas até o momento neste capítulo. Leia, com atenção, e avalie os acontecimentos usando como linha mestra as questões propostas ao final.

Linda Kenney, de 37 anos, deu entrada num hospital, em Boston, em 1999, para uma cirurgia no calcanhar direito. O anestesista Rick Van Pelt fez a injeção para o bloqueio do membro inferior direito, como já tinha feito centenas de vezes, com monitorização completa da paciente.

Um minuto depois da injeção, Linda teve uma convulsão e entrou em paragem/parada cardíaca. Rick percebeu que parte do anestésico tinha entrado em circulação. Chamou ajuda e começaram as manobras de reanimação que não tiveram sucesso. Levaram-na, então, para a sala de cirurgia cardiotorácica, onde foi realizada uma toracotomia, e iniciou-se circulação extracorporal até o coração reiniciar. 
Depois da cirurgia, Linda foi levada para a unidade de cuidados intensivos e disseram-Ihe que tinha feito uma reação alérgica ao anestésico. Rick achou que tinha sido responsável por essa complicação e quis falar com a paciente e a família. No entanto, na unidade de cuidados intensivos, disseram-Ihe que ela estava acordada, neurologicamente bem, mas não era boa ideia falar com ela. Linda foi para casa ao fim de 10 dias, e o anestesista não conseguiu falar com ela. Rick, então, decidiu que tinha que comunicar a ela o ocorrido e escreveu-lhe uma carta a pedir desculpa e a dizer que estaria disponível para falar, deixando seu contacto. Como estava muito revoltada quando recebeu a carta, ela não respondeu. Seis meses após o evento, conversando com seu ortopedista, ficou sabendo que era um milagre estar viva.

Apesar de tudo, Linda decidiu não processar o hospital e começou a pensar em falar com o anestesista, imaginando o que ele deveria estar a passar, e foi, enfim, procurá-lo. Nessa conversa, foi a primeira vez que Linda percebeu o que tinha acontecido. Perguntou-Ihe como se sentia e disse que percebia o que tinha acontecido e não o culpava. Para Rick foi como se um peso lhe saísse de cima, e a vida pudesse recomeçar de novo.

Quando Rick voltou a Boston, encontraram-se frente a frente e perceberam como a falta de apoio a ambos foi ruim para o desenrolar do incidente/evento adverso. Decidiram, então, fazer juntos algo que pudesse melhorar a comunicação médico-paciente e o apoio emocional necessário na ocorrência de um incidente/evento adverso. Foi assim que criaram a Medical Induced Trauma Support Services (MITSS), que apoia os pacientes e os profissionais envolvidos em incidentes/eventos adversos.

Fonte: Adaptado de Berwick et al. (2018).

\section{Para refletir}

Após ler o caso relatado, como você avaliaria a postura inicial do anestesista? E a reação da paciente? O que todos os envolvidos no evento poderiam ter feito de diferente? Considera importante que as instituições de saúde tenham um roteiro/protocolo de como reagir diante dos pacientes e profissionais de saúde, após a ocorrência de um incidente/evento adverso? Existe algo semelhante em sua organização? E quais as vantagens, para todos os envolvidos, de uma estratégia de comunicação diferente da que foi realizada? 


\section{A tarefa de comunicar um incidente/ evento adverso relacionado com os cuidados de saúde}

A seguir, abordaremos, de forma bastante objetiva algumas sugestões de como proceder a comunicação de um incidente/evento adverso.

O que dizer quando se comunica a ocorrência de um incidente/evento adverso?

O conteúdo de uma comunicação pode incluir, no mínimo, a expressão de humildade e pedido de desculpa pelo sucedido. Numa situação na qual a evidência de uma falha evitável, nos cuidados de saúde ao paciente, é inequívoca, poderá ser mais completo, incluindo também a admissão de responsabilidade e a explicação do sucedido, bem como um plano de apoio e a dimensão do compromisso institucional com o percurso do paciente após o incidente/evento adverso (Gallagher 2009).

Que tipo de incidentes/eventos adversos comunicar?

O conjunto de incidentes/eventos adversos passíveis de ser comunicados inclui aqueles que causaram dano ao paciente e aqueles em que uma ação incorrecta foi realizada por oposição à que seria considerada correcta pelos pares (Boyle et al. 2006; House of Commons Health Committee 2008).

\section{Como poderá decorrer o processo de comunicação?}

O grupo de Consensus Statement of The Harvard Hospitals elaborou, em março de 2006, o documento intitulado Responding to Adverse Events, que, nos dias de hoje, ainda constitui um guia muito interessante para o processo de disclosure. Esse documento sugere várias formas para lidar com as questões da comunicação em situações complexas e delicadas; a necessidade de apoiar os pacientes e as famílias, bem como algumas sugestões para programas de formação, treino e apoio para os profissionais de saúde.

Boyle e colaboradores (2006) sugeriram um guia prático para fazer a comunicação de incidentes/eventos adverso nos cuidados de saúde, 
reforçando a importância de uma preparação prévia que inclua a análise do incidente/evento adverso, a discussão de um plano de ação e a clarificação de quem, em que local e como vai ser feita a comunicação. Nesse documento, são sugeridas várias regras simples para conduzir o processo de comunicação aberta, referindo, por exemplo, a presença do clínico sénior envolvido no incidente/evento adverso, de um representante do Conselho de Administração (alta liderança da instituição de saúde em causa) e de alguma pessoa relevante para o apoio emocional ao paciente (por exemplo, psicólogo ou assistente social).

Existem vários estudos em que foi analisada a reação de profissionais de saúde face a alguns cenários hipotéticos de incidentes/eventos adversos. Nesses estudos, foram registadas diferenças relevantes no conteúdo da comunicação proposta pelos vários profissionais para um mesmo incidente/evento adverso. No Quadro 4, apresenta-se um exemplo em que é possível ver cinco tipos de comunicação possíveis: i) Comunicação parcial; ii) Comunicação enganadora; iii) Comunicação adiada; iv) Comunição total; v) Comunicação praticamente nula (Fein et al. 2007). Quando os profissionais dizem ter comunicado um incidente/evento adverso, esse processo pode assumir inúmeras formas. De acordo com o documento atrás referido (Harvard Hospitals 2006), a primeira comunicação do incidente/evento adverso deve acontecer nas 24 h seguintes à sua ocorrência.

Quadro 4 - Cenário de incidente/evento adverso e diversas formas de o comunicar

\begin{tabular}{|l|l|}
\hline \multicolumn{2}{|l}{$\begin{array}{l}\text { Cenário proposto } \\
\text { Paciente diabético, com } 62 \text { anos, com insuficiência renal crónica dá entrada no hospital com hemorragia gastrointestinal aguda. É } \\
\text { prescrita pausa alimentar, mas não é parada sua medicação antidiabética. O doente tem um episódio de hipoglicémia seguido de uma } \\
\text { convulsão, que origina uma queda, da qual resulta uma fratura do colo do fémur. }\end{array}$} \\
\hline Comunicações possíveis & Conteúdo da comunicação \\
\hline Comunicação completa & $\begin{array}{l}\text { "Por erro da minha parte, recebeu sua medicação quando não o deveria ter } \\
\text { feito. Peço desculpa por isso. Foi a causa da sua baixa de açúcar no sangue que } \\
\text { originou a convulsão, que levou à sua queda da cama/leito e à fratura do fémur." }\end{array}$ \\
\hline Comunicação parcial / Não fazer conexões & $\begin{array}{l}\text { "Teve uma convulsão e caiu da cama/leito. Parece que sua dose de insulina } \\
\text { baixou o nível de açúcar no sangue, e não se estava a alimentar." }\end{array}$ \\
\hline Comunicação enganadora & $\begin{array}{l}\text { "Teve uma convulsão. Pensamos que teve a ver com o facto de ter o açúcar baixo } \\
\text { e ser diabético." }\end{array}$ \\
\hline Comunicação adiada & $\begin{array}{l}\text { "Não temos ainda a certeza do que é que causou sua convulsão. Podem ter } \\
\text { sido várias coisas. Teremos que analisar." (sem intenção de voltar a falar com o } \\
\text { paciente) }\end{array}$ \\
\hline Não comunicar & $\begin{array}{l}\text { "Tenho pena que tenha fraturado a anca. Vamos levá-lo ao bloco operatório para } \\
\text { corrigir a fratura." }\end{array}$ \\
\hline
\end{tabular}


Em 2010, o Institute for Healthcare Improvement publicou um manual muito interessante e elucidativo com indicações práticas, com exemplos, referências e instrumentos de auditoria para a implementação de práticas mais robustas de comunicação de incidentes/eventos adversos. Esse documento destaca a importância fundamental em centrar a resposta organizacional de forma eficaz, integrada e atempada/oportuna. Nos dois anos seguintes, foram ampliadas as indicações do manual, dando origem ao documento, intitulado Respectful Management of Serious Clinical Adverse Events (2011), que reúne, num único documento, muitas das indicações até então dispersas na literatura, incluindo listas de palavras a utilizar, sugestões para o contacto com os meios de comunicação social (media/mídia) e propostas para o apoio às equipas envolvidas, com o lema "nunca se preocupe sozinho" (Conway et al. 2011).

Mais recentemente, em 2015, o Lucian Leape Institute publicou o relatório Shining a Light: Safer Health Care Through Transparency (National Patient Safety Foundation 2015), no qual aborda o tema da transparência na área da segurança do paciente, não se referindo apenas à comunicação entre profissionais de saúde e pacientes, mas também entre profissionais (partilha de conhecimento e informação clínica), entre organizações (colaborações interinstituições) e entre os profissionais e o público em geral - os cidadãos (partilha de dados e informação sobre a segurança do paciente).

Nesse relatório, é reforçada a necessidade de os profissionais de saúde informarem, de forma clara, objetiva e tão pormenorizada quanto possível, os pacientes sobre algum dano resultante do tratamento. É, igualmente, destacada a importância do pedido de desculpas e da elaboração conjunta de um plano de resolução/mitigação das falhas e análise das causas que levaram a essa ocorrência, incluindo estratégias de apoio ao paciente e famílias e sua inclusão na análise dos factos e no plano de ação de melhorias a implementar.

\section{Questões em aberto}

Veremos, a seguir, algumas sugestões de como reagir e se comunicar com os pacientes após um incidente/evento adverso

\section{Elementos-chave a incluir na comuniação efetiva após um incidente/evento adverso}

Não existe "receita única" de como fazer um disclosure efetivo; no entanto, há um conjunto consistente de elementos-chave que devem ser incluídos aquando da comunicação após um incidente/evento 
adverso. De acordo com Wu e colaboradores (2013), são quatro os elementos-chave:

1. Explicação do ocorrido;

2. Reconhecimento da responsabilidade de forma apropriada;

3. Pedido de desculpas;

4. Compromisso de aprendizagem com o erro, ou seja, que se vai atuar na intenção de evitar que episódios semelhantes voltem a ocorrer.

Em relação à explicação e partilha do sucedido com o paciente e familiares, tipicamente, elas devem incluir o como e o porquê de o incidente/ evento adverso ter ocorrido. Essa explicação deve-se cingir aos factos conhecidos e evitar especulação e cenários sem fundamento. Ao ser envolvido e esclarecido sobre o que aconteceu, o paciente tende a ser mais compreensivo e menos litigioso. O mesmo acontece quando é assumido, por parte do(s) profissinal(ais) e da própria organização de saúde, o reconhecimento apropriado de responsabilidade.

Os pacientes tendem a responder de forma muito positiva a um pedido de desculpas sincero. No momento da comunicação, a causalidade e preventabilidade do incidente/evento adverso podem não estar ainda identificadas. Na visão do paciente, depois de uma experiência traumática nos cuidados de saúde, pode ser difícil perceber que um mau resultado não traduza necessariamente a ocorrência de um erro ou falha. Pode ainda não ter sido esclarecida a gravidade do erro ou do dano, o que torna um pedido de desculpas prematuro.

Num questionário aplicado a 4.193 profissionais de saúde, com 2.637 respostas $(62,9 \%)$, só $33 \%$ dos participantes pediriam desculpa de forma explícita. No entanto, de acordo com vários autores, um pedido de desculpas sincero e sentido é o que os pacientes mais esperam (Gallagher et al. 2006, 2009; Mazor et al. 2004).

Em 2009, foi publicada pelo National Health System (NHS), do Reino Unido, uma recomendação na qual as organizações de saúde foram incentivadas a pedir desculpa aos pacientes sempre que se verificasse uma situação de um paciente lesado na sequência da prestação de cuidados de saúde. Nos Estados Unidos da América (EUA), os pedidos de desculpa têm sido tradicionalmente considerados como "admissão de culpa, passível de ação judicial". Esse facto tem constituido uma das principais barreiras à comunicação de incidentes/eventos adversos. Alguns estados implementaram uma lei denominada I’m sorry, aplicável a incidentes/ eventos adversos em contexto médico, protegendo, assim, os médicos que optam por comunicar e pedir desculpa (Gallagher 2009). 
Vitrano (2007) argumenta que pedir desculpa ao paciente lesado, na sequência da prestação de cuidados de saúde, é sempre a atitude correta, e as instituições deveriam apoiar ativamente os profissionais nessa prática. Langer e colaboradores (2016) relata a opinião dos pacientes, expressa em grupos focais, de que a frase "peço desculpa" é sempre bem recebida, sobretudo se for associada a uma atitude de escuta do paciente e de colaboração sincera no processo de análise de um incidente/evento adverso.

\section{Para refletir}

Pensando como um profissional de saúde que esteve envolvido em um caso que resultou em incidente/evento adverso (EA), o que você pensa sobre a questão do pedido de desculpas? Há situações em que o profissional de saúde envolvido em um EA não deve se desculpar? Como paciente, vítima de um EA, o que você esperaria?

No que diz respeito ao quarto e último elemento-chave, Compromisso para prevenir recorrências semelhantes, ele é o ponto fulcral/central, a essência de que se deve aprender com os erros e com os incidentes/ eventos adversos e introduzir todas as melhorias para evitar que tais acontecimentos voltem a ocorrer. Ou seja, os pacientes e as famílias valorizam muito o que a organização fez ou fará (mudou/melhorou) para evitar que situações semelhantes ocorram no futuro com outros pacientes. Nesse ponto, o que foi experienciado pelo paciente e pelo profissional de saúde/equipa é muito importante para que se identifique o que correu mal, e se introduzam melhorias - que a organização/ profissionais/sistema aprendam, façam mudanças que resultem em melhorias e em cuidados de saúde mais seguros.

\section{Compensação: como, quando e quanto?}

A este propósito, Vitrano (2007) afirma que a expressão de um pedido de desculpas é apenas o primeiro passo, num processo que deveria levar a uma oferta de compensação monetária, para o paciente e sua família depois de uma situação de dano associado aos cuidados de saúde. No mínimo, deveria incluir a oferta de apoio psicológico e a cobertura das despesas relacionadas com o tratamento das complicações associadas ao dano.

Habitualmente, o paciente daria início a um processo litigioso com queixa de má prática e esperaria pelo desenvolvimento do processo de averiguação. Neste momento, algumas instituições nos EUA estão 
a permitir a comunicação precoce de um incidente/evento adverso e a respetiva compensação financeira, comprometendo-se o paciente a não iniciar um processo litigioso. O paciente e a família são convidados para uma conversa, com o profissional de saúde, acerca do incidente/evento adverso, é-lhes oferecido um pedido de desculpas e, quando justificado, uma compensação financeira pelo dano ocorrido durante a prestação dos cuidados de saúde. Isto é apenas permitido para casos sem dano grave ou indício de negligência grosseira, e é assumido pelos intervenientes/atores que não será iniciado um processo judicial (Gallagher 2009; National Patient Safety Foundation 2015; Vitrano 2007).

No Reino Unido, foi estabelecido, em 2003, pelo NHS um redress scheme ou esquema de compensação para incentivar os médicos a realizar uma comunicação aberta dos incidentes/eventos adversos e a compensação dos pacientes lesados e que não tenham iniciado ação judicial. O projeto de lei foi aprovado no parlamento em novembro de 2006, mas sua implementação (planeada/planejada para 2008) foi sendo sucessivamente adiada (House of Commons Health Committee 2008).

Na Austrália, o National Open Disclosure Act foi aprovado pelo Ministério da Saúde em 2003, e vários estados desenvolveram políticas e projetos tendo em vista sua implementação. A avaliação de uma iniciativa piloto revelou falta de recursos e um compromisso ambíguo por parte das administrações (alta liderança) em relação à compensação financeira a atribuir aos pacientes lesados (Iedema et al. 2008).

\section{É necessário reforçar a formação/treino dos profissionais de saúde para comunicar de forma adequada e efetiva com os pacientes?}

Várias avaliações de iniciativas de comunicação nos EUA, no RU e na Austrália reconheceram que existem lacunas nas competências de comunicação, sentidas pelos pacientes e admitidas pelos profissionais de saúde. É muito importante a preparação da comunicação, incluindo um plano antecipado para o apoio ao paciente e ao profissional/equipa envolvidos num incidente/evento adverso, para que não se associem mais danos (por exemplo, psicológicos) aos já desencadeados pelo incidente/evento adverso.

Também no relatório Responding to Adverse Events (Harvard Hospitals 2006) se podem encontrar muitas sugestões para melhorar as competências dos profissionais e das equipas de saúde na área da comunicação de incidentes/eventos adversos. A avaliação do padrão de comunicação de incidentes/eventos adversos na Austrália propõe listas de indicações 
práticas para os profissionais e pacientes envolvidos no processo (Iedema et al. 2008). Boyle e colaboradores (2006) desenvolveram recomendações para os períodos antes e durante a comunicação na gestão/gerenciamento dos incidentes/eventos adversos em cuidados intensivos.

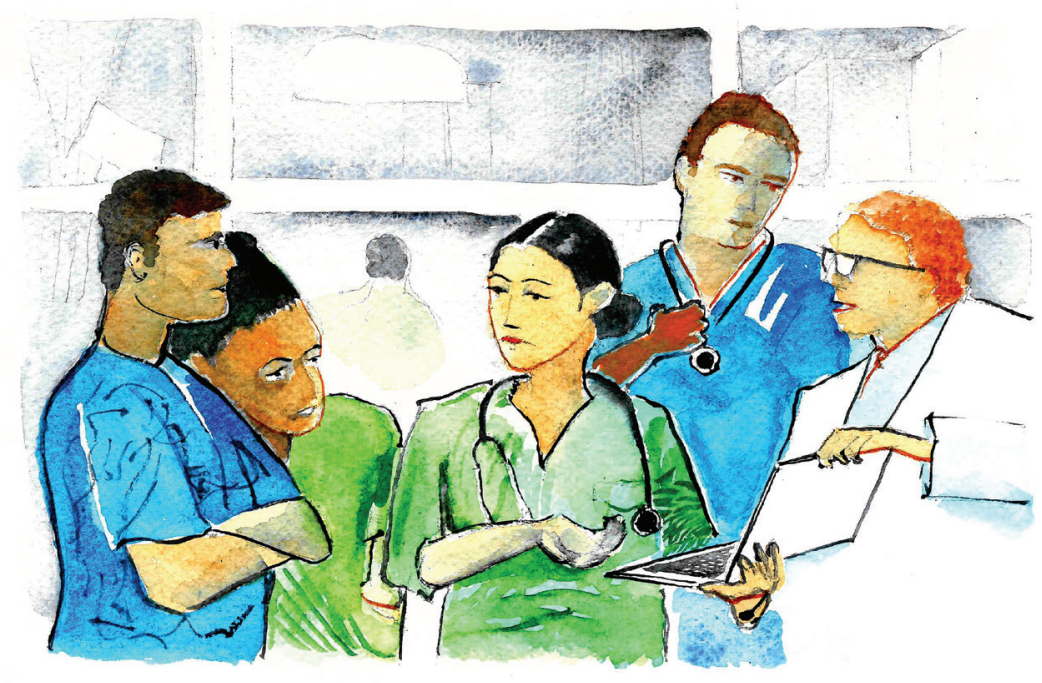

Ainda de acordo com esse relatório de Harvard Hospitals (2006), é muito importante que tais programas de formação/treino para os profissionais de saúde providenciem orientações para, de forma atempada/ oportuna e efetiva, comunicar e partilhar o sucedido com o paciente. Assim, para o melhor enquadramento da comunicação efetiva, é fundamental ter conhecimentos sobre: quem deve fazer a comunicação (por exemplo, o médico que atendeu o paciente ou, na sua ausência, um elemento sénior da equipa); o que aconteceu (relatar/notificar apenas factos e informações que se conheçam e manter o paciente informado à medida que se forem conhecendo mais factos); quando comunicar (o mais precoce possivel, desde que o paciente/família tenham condições, mesmo que não se conheçam todos os pormenores - o disclosure é um processo de comunicação contínuo, não se esgota num só momento); onde fazer o disclosure (num espaço tranquilo, reservado e confortável para o paciente e família); como (deve-se manter a dignidade do paciente, a conversa deve fluir de forma tranquila e empática, e deve dar-se espaço ao paciente e à família para falar sobre sua experiência, dúvidas, incertezas etc.).

Em 2016, Langer e colaboradores relataram/notificaram a experiência de fazer a formação das competências de comunicação dos profissionais de saúde em sessões conjuntas com pacientes recrutados das associações de pacientes da instituição. Na avaliação prévia, os pacientes antecipa- 
ram dificuldades com a terminologia médica e uma postura defensiva dos clínicos. Os profissionais de saúde anteciparam receios de expo suas fragilidades. No final, os pacientes apreciaram a abertura dos profissionais de saúde no reconhecimento das suas fragilidades e o conhecimento da forma como o erro afeta os profissionais. Do lado dos profissionais de saúde, foi valorizado o feedback direto dos pacientes e as sugestões práticas de como melhorar e tornar mais eficaz a comunicação.

No Quadro 5, são apresentadas algumas sugestões de como comunicar, ao paciente, a ocorrência de um incidente/evento adverso. As sugestões são apresentadas destacando-se as prioridades a ter em consideração; os aspetos que se devem ter em conta na fase prévia a iniciar a comunicação aberta e no momento da comunicação aberta e, depois, no período de seguimento.

Quadro 5 - Guia prático para a comunicação de incidentes/eventos adversos

\begin{tabular}{|l|l|}
\hline Prioridades & - Assegurar a atenção da equipa médica às necessidades do paciente \\
& - Assegurar que se avisam e se envolvam as pessoas certas, incluindo \\
& O médico assistente e a estrutura operacional local de segurança do \\
& paciente \\
- Contactar alguém com experiência para planear/planejar a & comunicação ao paciente \\
- Recolher informação sobre o incidente/evento adverso falando com \\
todos os profissionais envolvidos e avaliando os dispositivos ou \\
medicação utilizados \\
\hline comtes de iniciar a \\
$\begin{array}{ll}\text { - Determinar se o incidente/evento adverso necessita de ser comunicado } \\
\text { ao paciente e/ou família (mudança de plano terapêutico, registo no } \\
\text { diário, lesão evidente) } \\
\text { - Recordar que esta comunicação é para o paciente e o(s) } \\
\text { profissional(ais) será(ão) apoiado(s) separadamente } \\
\text { - Determinar quem estará presente na comunicação } \\
\text { - Avaliar a necessidade de apoio familiar para o paciente ou de apoio } \\
\text { para a família } \\
\text { - Decidir quem inicia a conversa e qual o conteúdo a comunicar } \\
\text { - Determinar o momento e o local ideal } \\
\text { - Decidir e transmitir, de forma clara, quem vai ser o profissional de } \\
\text { contacto e ligação à família } \\
\text { - Discutir com a equipa qual o possível impacto, tendo em consideração } \\
\text { o nível cultural/social/estado de consciência/do paciente e família }\end{array}$ \\
\hline
\end{tabular}


Quadro 5 - Guia prático para a comunicação de incidentes/eventos adversos (cont.)

\begin{tabular}{|c|c|}
\hline $\begin{array}{l}\text { Durante a } \\
\text { comunicação }\end{array}$ & $\begin{array}{l}\text { - Manter um contacto cordial, simpático, humano e sincero } \\
\text { - } \text { o paciente } \\
\text { - Regra de ouro: O que gostaria que Ihe dissessem se o caso } \\
\text { acontecesse consigo? } \\
\text { - Transmitir sua empatia pelo sofrimento do paciente e da família } \\
\text { - Explicar a sequência da reunião } \\
\text { - Usar o modelo de comunicação ask-tell-ask (dar espaço para a } \\
\text { colocação de questões por parte do paciente e/ou família) } \\
\text { - Explicar com clareza os factos tal como são conhecidos no momento } \\
\text { - Pedir desculpa se e quando for apropriado } \\
\text { - Explicar o que já foi feito pelo paciente e o plano de cuidados futuros } \\
\text { - Avaliar se é necessário que o paciente mude de médico assistente } \\
\text { - Assegurar que o incidente/evento adverso vai ser investigado e os } \\
\text { dados transmitidos ao paciente } \\
\text { - Abordar a questão da compensação financeira se tiver autoridade para } \\
\text { isso } \\
\text { - Oferecer serviços de apoio - religioso, social, psicológico } \\
\text { - Lembrar-se que a comunicação de incidentes/eventos adversos pode } \\
\text { não ser bem-recebida (tem riscos) }\end{array}$ \\
\hline $\begin{array}{l}\text { Follow-up - } \\
\text { seguimento }\end{array}$ & $\begin{array}{l}\text { - Fazer a avaliação da conversa com a equipa } \\
\text { - Avaliar as necessidades emocionais e psicológicas dos profissionais } \\
\text { envolvidos e a necessidade de acompanhamento } \\
\text { - Registar a comunicação ao paciente no diário clínico } \\
\text { - Não registe no diário o apoio dado aos profissionais envolvidos }\end{array}$ \\
\hline
\end{tabular}

Fonte: Harvard Hospitals (2006).

Sendo o processo de comunicação de um incidente/evento adverso algo complexo e peculiar, convém ter presente, de forma sistematizada e concisa, algumas das razões que fundamentam sua realização (Quadro 6), bem como as principais barreiras que se podem colocar (Quadro 7).

Quadro 6 - Razões para realizar o disclosure após a ocorrência de incidentes/eventos adversos

Os pacientes têm o direito a ser informados.

O disclosure é essencial para reforçar a confiança do paciente nos profissionais e nas organizações de saúde. Isso é, ainda, mais fundamental nas situações em que o paciente vai necessitar de mais cuidados para sua recuperação.

Uma boa comunicação fortalece a relação médico-paciente/profissional de saúde-paciente. 
Quadro 6 - Razões para realizar o disclosure após a ocorrência de incidentes/eventos adversos (cont.)

\begin{tabular}{l} 
Se o paciente descobrir, após a ocorrência do incidente/evento adverso, que este não foi \\
comunicado, a relação médico-paciente/profissional de saúde-paciente ficará fragilizada e \\
comprometida. \\
\hline O disclosure aumenta as possibilidades de perdão/desculpa. \\
\hline Boas práticas em disclosure tornam o relato/notificação de erros e a aprendizagem mais efetivos. \\
\hline O disclosure pode diminuir a probabilidade de processos litigiosos.
\end{tabular}

Fonte: Elaborado pelos autores.

Quadro 7 - Barreiras ao disclosure

Preocupações inerentes com possíveis processos litigiosos.

Medo de destruir a relação com o paciente, e este perca a confiança nos profissionais e nas organizações de saúde (em vez de parceiro, se torne um "adversário").

Medo, da parte do profissinal de saúde, de prejudicar sua reputação ou progressão na carreira.

Falta de apoio institucional (os profissionais de saúde terem receio que sua organização de saúde não os apoie numa situação de incidente/evento adverso ou EA).

Falta de formação/treino em comunicação de ocorrência de incidentes/eventos adversos.

O impacto emocional nos médicos/profissionais e equipas de saúde após a ocorrência de um incidente/evento adverso.

Fonte: Elaborado pelos autores.

\section{Considerações finais}

Após décadas a desenvolver esforços para tornar os cuidados de saúde mais efetivos e seguros num ambiente hospitalar, com cada vez mais predomínio técnico, no qual os pacientes e os próprios profissionais são, muitas vezes, anónimos, surge a tarefa inesperada, dolorosa e não desejada de comunicar ao paciente a ocorrência de um incidente/evento adverso relacionado com os cuidados de saúde, no qual foi vítima.

Mesmo que alguns pacientes tenham expectativas irrealistas sobre a perfeição dos resultados de saúde, ou dificuldade em compreender o conceito de lapso, erro ou negligência, as grandes barreiras que se opõem à comunicação aberta de incidentes/eventos adversos estão habitualmente relacionadas com vias de comunicação pouco desenvolvidas entre pacientes e profissionais de saúde.

Podemos verificar, nos questionários aos profissionais de saúde, que estes, na sua maioria, desejam comunicar um incidente/evento adverso, 
considerando essa uma boa prática. As fragilidades ao nível da formação pré e pós-graduada na área da Comunicação, associadas à falta de uma cultura de apoio institucional e dos pares, fazem com que ainda seja difícil realizar, de forma adequada, o disclosure, após a ocorrência de um incidente/evento adverso.

\section{Referências}

Berwick D, et al. The patient and the anesthesiologist. Boston: Institute of Healthcare Improvement; 2018 [citado 2019 Jan 31]. Disponível em: http://www.ihi.org/education/IHIOpenSchool/resources/ Pages/Activities/PatientandAnesthesiologistPartThree.aspx.

Berwick D. What "patient-centered" should mean: confessions of an extremist. Health Aff. 2009; 28(4):w555-5.

Boyle D, O'Connell D, Platt FW, Albert RK. Disclosing errors and adverse events in the intensive care unit. Crit Care Med. 2006;34:1532-37.

Conway J, Federico F, Stewart K, Campbell M. Respectful management of serious clinical adverse events. 2nd ed. Cambridge (MA): Institute for Healthcare Improvement; 2011. IHI Innovation Series white paper. Disponível em: www.IHI.org.

Delbanco T, Bell SK. Guilty, afraid, and alone: struggling with medical error. N Engl J Med. 2007;357(17):1682-83.

Fein SP, Hilborne LH, Spiritus EM, Seymann GB, et. al. The many faces of error disclosure: a common set of elements and a definition. J Gen Intern Med.2007;22,755-61.

Gallagher TH. A 62-year-old woman with skin cancer who experienced wrong-site surgery. JAMA. 2009;302(6);669-77.

Gallagher TH, Garbutt JM, Waterman AD, Flum DR, Larson EB, Waterman BM et al. Choosing your words carefully. How physicians would disclose harmful medical errors to patients. Arch Intern Med. 2006;166:1585-93.

Goldberg RM, Kuhn G, Andrew LB, Thomas HA. Coping with medical mistakes and errors in judgment. Ann Emerg Med. 2002;39(3):287-92.

Harvard Hospitals. When things go wrong: responding to adverse events: a consensus statement. [Local desconhecido]: Harvard Hospitals; 2006.

House of Commons Health Committee. Patient safety: sixth report of session 2008-9. London: The Stationery Office; 2008.

ledema R, Mallock N, Sorensen R, Manias E, Tuckett A, Williams A, et al. The national open disclosure pilot: evaluation of a policy implementation initiative. Med J Aust. 2008;188(7):397-400.

Langer T, Martinez W, Browning DM, Varrin P, Sarnoff Lee B, Bell SK. Patients and families as teachers: a mixed methods assessment of a collaborative learning model for medical error disclosure and prevention. BMJ Qual Saf. 2016;25:615-25.

Lazare A. Apology in medical practice: an emerging clinical skill. JAMA. 2006;296(11):1401-04.

Mazor KM, Simon SR, Gurwitz JH. Communicating with patients about medical errors: a review of the literature. Arch Intern Med. 2004;164(15):1690-7. 
National Patient Safety Foundation, Lucian Leape Institute. Shining a light: safer health care through transparency. Boston (MA): National Patient Safety Foundation; 2015.

Organização Mundial de Saúde [OMS]. Estrutura conceptual da classificação internacional sobre segurança do paciente: relatório técnico final. Tradução realizada pela Divisão de Segurança do Doente, Departamento da Qualidade na Saúde. Lisboa: Direção Geral de Saúde; 2011.

Schwappach DLB, Koeck CM. What makes an error unacceptable? A factorial survey on the disclosure of medical errors. Int J Qual Health Care. 2004;16(4):317-26.

Sorensen R, ledema R, Piper D, Manias E, Williams A, Tuckett A. Health care professionals views of implementing a policy of open disclosure of errors. J Health Serv Res Policy. 2008;13:227-32.

Vitrano C. Book review: after harm. Medical error and the ethics of forgiveness. Theor Med Bioeth. 2007:28:83-6.

Wu AW, Boyle DJ, Wallace G, Mazor KM. Disclosure of adverse events in the United States and Canada: an update, and a proposed framework for improvement. J Public Health Res. 2013;2(32):186-92. 


\section{O ensino de segurança do paciente}

Vera Neves Marra e Walter Mendes

A Aliança Mundial para a Segurança do Paciente, lançada em 2004 pela Organização Mundial da Saúde (OMS), identificou 13 áreas de ação para reduzir os danos e as consequências sociais de cuidados inseguros (WHO 2005). No cenário pedagógico, destaca-se a área 11 , que orienta a inclusão do tema "Segurança do Paciente" na educação de todos os profissionais das carreiras da Saúde, incluindo a graduação, pós-graduação, formação de técnicos e educação permanente. Neste capítulo, vamos abordar a importância estratégica do ensino para a melhoria das condições de segurança dos pacientes.

\section{Por que ensinar segurança do paciente aos alunos de graduação e técnicos da área da Saúde?}

Ao considerar que erros são cometidos involuntariamente, e os seres humanos são falíveis, é necessário que os estudantes da área da Saúde entendam como lidar com erros, porque, possivelmente, os cometerão ao longo de suas vidas profissionais. Devem compreender o "erro zero" como impossível, e tudo deve ser feito para que os erros não provoquem dano no paciente.

No entanto, é preciso destacar que, culturalmente, os erros têm sido definidos como resultado de incompetência, imperícia, negligência e/ou imprudência de um ou mais profissionais de saúde, o que gera grande desconforto e sentimento de culpa nos envolvidos. 
Cabe aos educadores esclarecer que, diferente de violações, os erros em saúde são, muitas vezes, de natureza sistêmica e, quando individuais, não intencionais e não devem ser abordados por um viés punitivo. Ao contrário, precisam ser usados como objeto de análise para evitar sua recorrência. Os estudantes devem aprender, ainda, que os fatores contribuintes dos erros são múltiplos e, entre esses, destacam-se os latentes, nem sempre perceptíveis no momento em que o erro ocorreu. Devem compreender que eventos adversos ocorrem devido à progressiva complexidade do cuidado nos sistemas de saúde; logo, não dependem exclusivamente da competência individual dos profissionais.

Os profissionais de saúde que trabalham atualmente nos estabelecimentos de saúde aprenderam, durante seus cursos de graduação, que o erro no cuidado é algo que nunca deveria acontecer, e somente os maus profissionais erram. Além disso, os atuais profissionais não foram preparados para trabalhar em equipe. Trata-se de um enorme desafio implantar uma cultura de segurança, pois depende da mudança comportamental e emocional dos membros da equipe de saúde, que se habituaram a ter outra cultura ao longo do tempo e, principalmente, no período da graduação. Trabalhar com a possibilidade de errar e em equipe deveria ser algo automático, apoiado nas atitudes dos outros membros da corporação.

É necessário, portanto, que os estudantes de medicina, odontologia, enfermagem, fisioterapia, nutrição, farmácia, fonoaudiologia, biologia, biomedicina, bioquímica, psicologia, além de técnicos em saúde (de radiologia, de laboratórios, de enfermagem, entre outros) iniciem suas carreiras exercendo o "novo normal do cuidado de saúde". Essa cultura exige a aquisição de competências específicas para enfrentar os riscos, reduzir os erros e lidar com suas consequências. Trata-se de desenvolver o conhecimento, as habilidades, as atitudes e os comportamentos que refletem o cuidado seguro e centrado no paciente, com respeito às suas crenças e ao seu contexto psicossocial, partilhando com ele as informações, as opções e os riscos do seu tratamento. A título de exemplo, vamos citar apenas algumas dessas competências de segurança (Frank 2008):

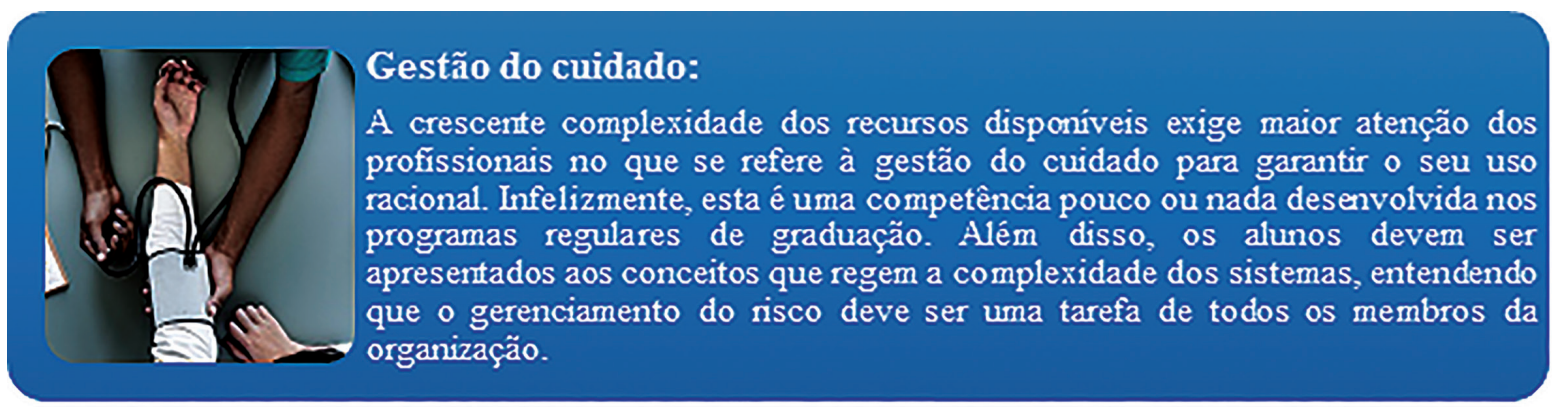




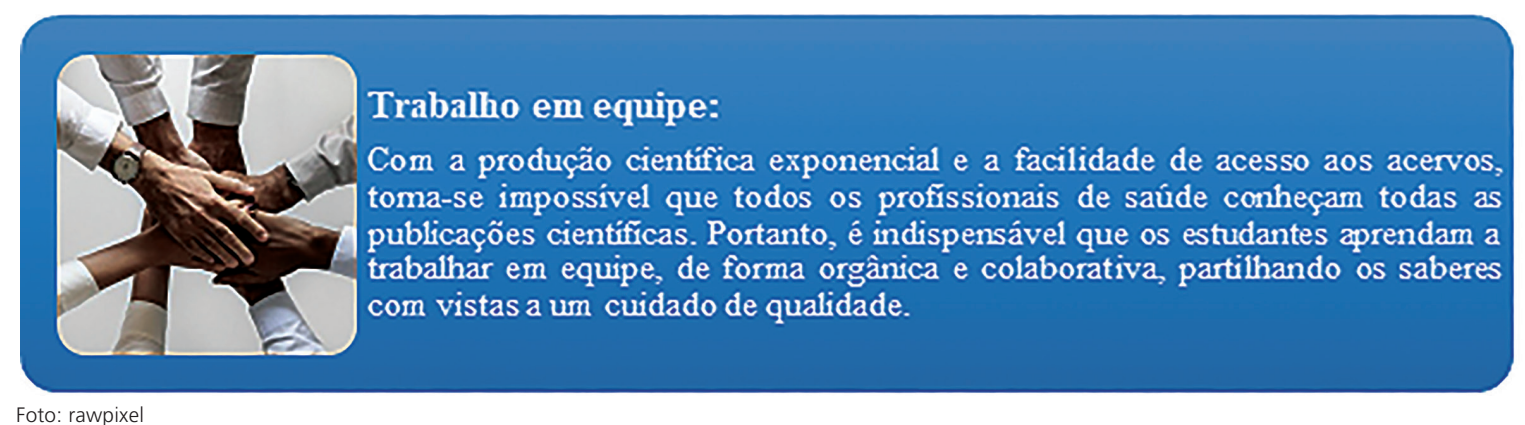

Foto: rawpixe

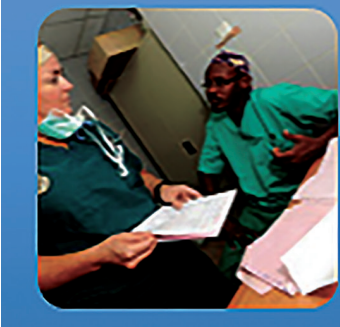

\section{Comunicação efetiva:}

A comunicação entre profissionais de saúde é um dos pilares do cuidado seguro e corresponde a um grande desafio para organizaçöes complexas, que contam com diferentes niveis hierárquicos de responsabilidade. Ainda que o aluno não tenha um perfil extrovertido, é possivel que desenvolva essa competencia. Trata-se de fazer com que os futuros profissionais sejam pessoas com quem os colegas de trabalho possam contar e que também sejam capazes de criar fortes vinculos com pacientes e familiares por meio da habilidade de comunicação interpessoal. Importante lembrar que a comunicação precária é certamente uma das principais causas de processos legais contra os profissionais de saúde.

Foto: Leslie Pratt

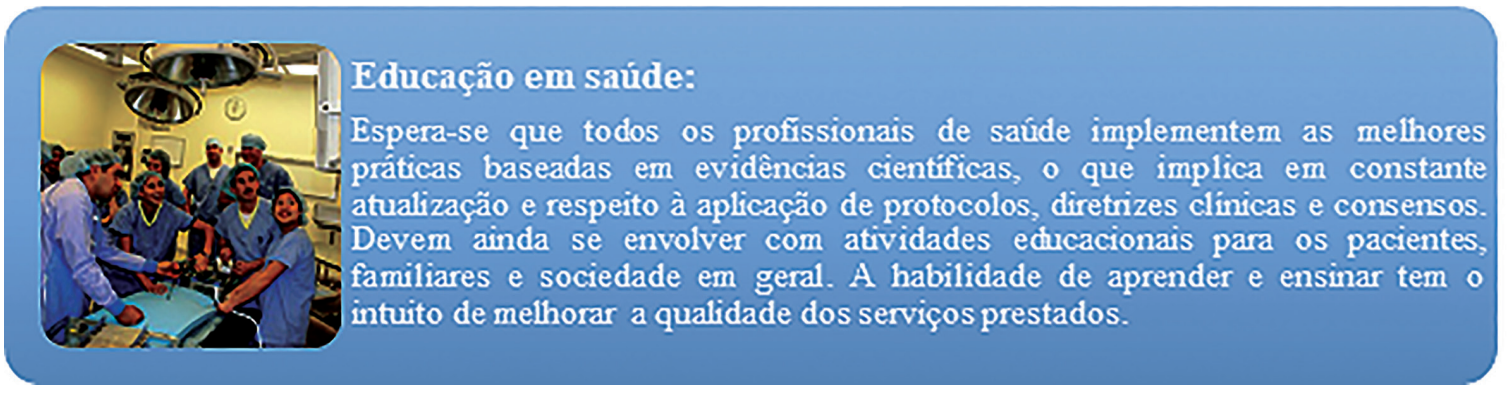

Foto: Douglas H. Stutz

\section{Quando e onde ensinar segurança do paciente na graduação?}

É senso comum que quanto mais experiência um profissional de saúde acumular, mais qualificado ele será em sua prática clínica. Essa premissa nos convida a refletir sobre o fato de que, na área do cuidado aos pacientes, a aprendizagem implica, necessariamente, riscos, pois o objeto de estudo dos alunos e dos profissionais novatos é outro ser humano que se encontra enfermo. Essa constatação é a prova inequívoca da importância da inclusão do tema nos cursos de todas as carreiras da saúde.

No entanto, o que se observa é uma enorme resistência das universidades na incorporação desse tema em seus currículos. Segundo Walton (2007), a abordagem de um tema que se originou fora dos meios acadêmicos e o desconhecimento de educadores sobre o assunto podem 


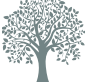

O Guia Curricular de Segurança do Paciente da OMS objetiva auxiliar instituições acadêmicas da área da Saúde no ensino desse tema. Sua edição multiprofissional está acessível nos seguintes endereços:

https://proqualis.net/ guideline/ guia-curricularde-seguran\%C3\%A7ado-paciente-daorganiza \%C3\%A7\% C3\% A3o-mundial-dasa \%C3\%BAde-edi\%C3\% A7\% $\mathrm{C} 3 \% \mathrm{~A} 3 \mathrm{O}$

http://apps.who.int/iris/ bitstream/handle/10665/ 44641/9788555268502 -por. pdf; jsessionid=1458287CE89 5BBE69738D20CBC B7B781 ? sequence $=32$ explicar tal resistência. Por isso, a OMS lançou o Guia Curricular de Segurança do Paciente: Edição Multiprofissional (WHO 2011), que fornece as bases para a inclusão do tema nos currículos de graduação de todas as profissões da saúde. Abrangente, a obra visa não apenas preparar os alunos para a prática segura nos diferentes contextos de trabalho, mas também objetiva incrementar as pesquisas/investigações a respeito da educação em segurança do paciente no meio universitário. Trata-se de uma base flexível para o desenvolvimento de currículos, programas de treinamento internos e pesquisas/investigações científicas sobre o tema. A obra baseou-se em dois grandes trabalhos, considerados fundamentais. O primeiro é o Marco Australiano sobre Educação em Segurança do Paciente, Australian Patient Safety Education Framework (APSEF), lançado em julho de 2005 pelo Conselho Australiano Para Segurança e Qualidade em Cuidados à Saúde (Walton 2006). O outro é Estudo Canadense sobre as Competências em Segurança do Paciente (The Safety Competencies, First Edition), lançado pelo Instituto Canadense de Segurança do Paciente, Canadian Patient Safety Institute (CPSI), em 2008 (Frank 2008).

O APSEF foi um trabalho pioneiro em todo o mundo, resultado de ampla revisão bibliográfica, consultas e contribuições de todas as áreas da Saúde, incluindo inúmeras organizações internacionais. Essa extensa obra identificou as competências que todos os trabalhadores da saúde devem ter para oferecer um atendimento seguro ao paciente, além de descrever o desempenho esperado por nível de responsabilidade de cada profissional das organizações de saúde, conforme demonstrado na Figura 1. Sua maior contribuição foi oferecer uma descrição detalhada dos tópicos relativos à segurança do paciente, que devem compor os programas de educação de escolas e organizações de saúde. O guia da OMS aproveitou 16 dos 22 tópicos propostos pelo APSEF.

Figura 1 - Estrutura do Marco Australiano de Segurança do Paciente

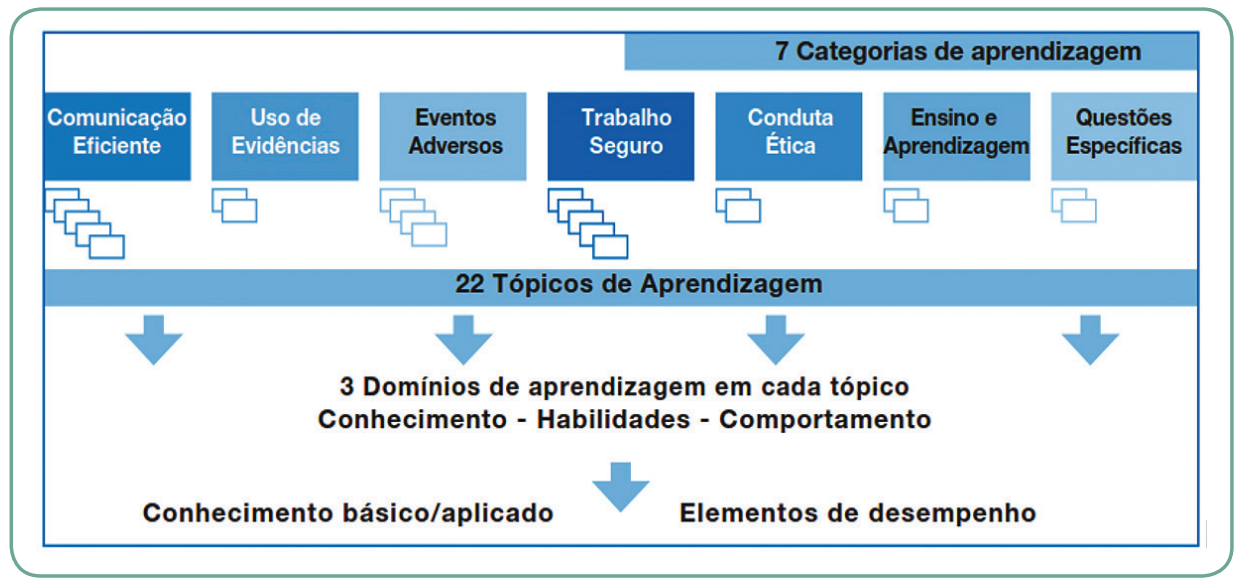

Fonte: Organização Mundial da Saúde (2016). 
Já o trabalho do CPSI, posterior ao australiano, incumbiu-se de compilar as competências de segurança do paciente (conhecimento, habilidade, atitudes e comportamento) em seis domínios básicos (Figura 2). Para cada domínio, determinou o perfil almejado para os profissionais de saúde, sobretudo no que diz respeito às competências voltadas ao cuidado seguro.

Iniciado em 2006 e concluído em 2008, o estudo do CPSI iniciou por meio de uma pesquisa/investigação nas escolas canadenses/canedianas de todas as carreiras da saúde, com o objetivo de identificar os conceitos de segurança do paciente que estavam incorporados a seus programas de graduação. Numa segunda fase, as competências de segurança foram propostas em reuniões interprofissionais e por um painel de peritos em educação das diferentes áreas da Saúde. Sua maior contribuição se deu pela descrição detalhada do desempenho esperado quanto às habilidades, atitudes e comportamento.

Figura 2 - Competências de segurança necessárias a todas as profissões da área da Saúde

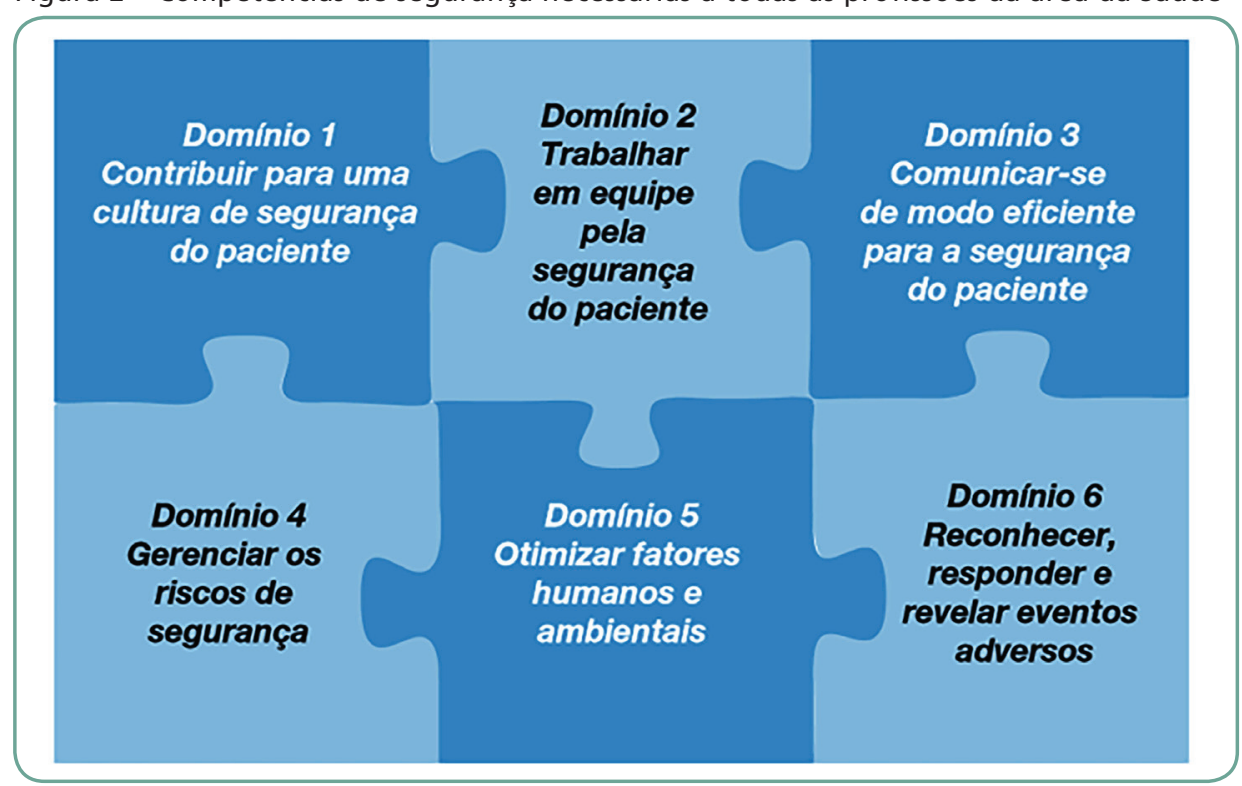

Fonte: Organização Mundial da Saúde (2016).

Esses trabalhos não deixam dúvida quanto à época ideal para se iniciar o ensino de segurança do paciente. Recomendam que a aprendizagem deva ser introduzida desde os primeiros anos dos cursos de graduação, de todas as carreiras da saúde e, também, na formação de técnicos dessa área. Da mesma forma, Wachter (2013), no Capítulo 17 do livro Compreendendo a Segurança do Paciente, argumenta ser imprescindível que os futuros profissionais aprendam segurança do paciente durante a fase de graduação, antes de ingressarem em seus estágios práticos nos hospitais, e sofram a interferência de cenários pedagógicos não seguros, que 
A avaliação dos programas curriculares também deve ser considerada, mas, por se tratar de um tema bastante específico, optamos por não abordar neste capítulo. funcionariam como um "currículo oculto", e afetam a aprendizagem dos estudantes e profissionais iniciantes.

Os cenários apropriados ao ensino da matéria são os ambientes assistenciais, e não a sala de aula, como veremos a seguir. É importante assinalar que os cenários assistenciais referidos podem ser reais, com pacientes reais ou em ambientes controlados, como os laboratórios de habilidades.

Além da graduação, o ensino de segurança do paciente deve se manter por meio dos programas de pós-graduações e por toda a trajetória dos profissionais, valendo-se de capacitações e atualizações permanentes (WHO 2011).

Como ensinar segurança do paciente nas graduações e em cursos técnicos das áreas da Saúde?

A maneira de ensinar segurança do paciente aos alunos de graduação e técnicos das diferentes áreas da Saúde deve considerar:

蝶 a disposição do tema segurança do paciente no currículo;

瞵 o conteúdo programático de segurança do paciente;

as estratégias pedagógicas adequadas para o ensino de segurança do paciente;

蝶 a avaliação de desempenho dos alunos.

\section{Disposição do tema no currículo}

A disposição do tema segurança do paciente nos planos curriculares é classificada como interdisciplinar, termo usado por Pombo (2006) para designar "[...] as disciplinas constituídas na confluência de várias disciplinas de diferentes áreas de conhecimento", em que a segurança do paciente serve de integração entre todas as disciplinas. Trata-se, portanto, de um exemplo perfeito de interdisciplinaridade, no qual várias ciências apresentam forte relacionamento com outras, por compartilharem conceitos, teorias e métodos. Contudo, para além da polêmica quanto ao uso dos termos multi, pluri, trans e interdisciplinaridade, passaremos a conceituar a matéria segurança do paciente não como uma interdisciplina, e sim uma disciplina integradora, ou seja, que transcende à especialização, não sendo antagônica à estruturação dos currículos em disciplinas (Pombo 2005). No entanto, quanto maior a 
integração da matéria ao currículo, maior sua dispersão e a dificuldade de coordenar seu ensino. Diante dessas questões, uma proposta conciliadora é a estruturação de um módulo temático longitudinal, composto de dois eixos paralelos, que contemplam a integração entre as diferentes disciplinas e sua identidade temática (Marra 2015), dispostos da seguinte forma:

滕 Eixo integrador: eixo pedagógico que se destina a fornecer um fio condutor aos diferentes módulos ou disciplinas, com intuito de desenvolver as competências de segurança comuns a todas as disciplinas, tais como comunicação, identificação correta dos pacientes, prevenção de infecções, segurança com o uso de medicação e trabalho em equipe. Esse eixo perpassa por todos os períodos das graduações da área da saúde e se baseia na introdução de temas de segurança do paciente pelas diferentes disciplinas.

Eixo específico: eixo pedagógico que se destina a fornecer uma identidade própria à matéria, como preconizado pela OMS (WHO 2011 ), e corresponde à estruturação e ao aprofundamento de temas específicos sobre segurança do paciente, tais como instrumentos de gestão do risco, cultura justa, indicadores de segurança, entre outros.

É claro que nem sempre essa disposição é possível de ser implantada imediatamente, já que implica um processo lento e muito custoso, que é uma reforma curricular. No entanto, a introdução do eixo integrador pode ser feita de imediato sob qualquer estrutura curricular.

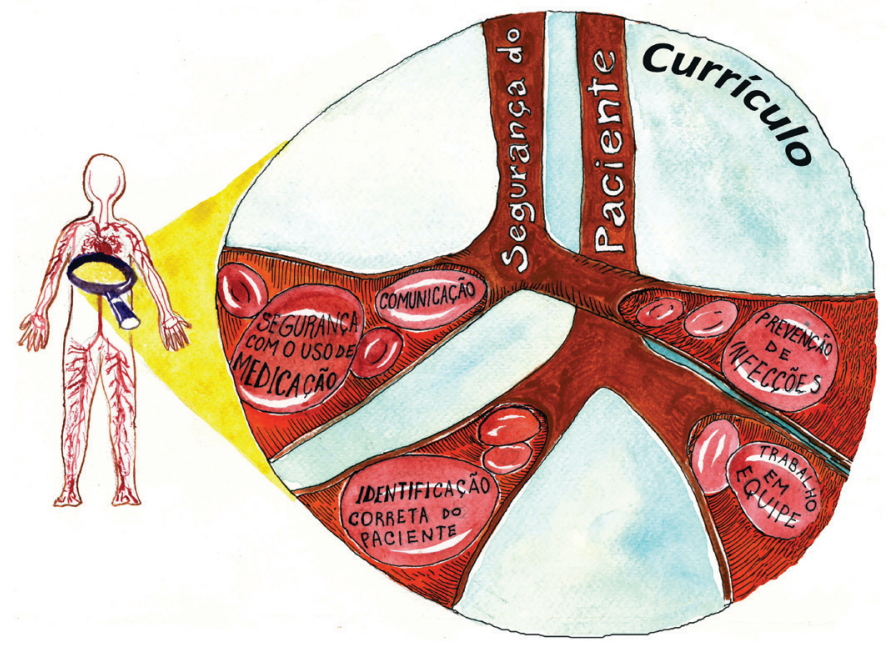

Podemos imaginar o sistema circulatório humano como uma metáfora do Eixo Integrador discutido no texto. Os vasos do sistema distribuem, ao longo do corpo humano, os nutrientes necessários às células de órgãos e tecidos, assim como a temática "Segurança do Paciente" (vasos) integra as diversas disciplinas da área de saúde (componentes sanguíneos) que perpassam por diversos módulos/ disciplinas do currículo (corpo humano). 


\section{Conteúdo programático}

O conteúdo programático de segurança do paciente se baseia no Guia Curricular da OMS, que selecionou 11 tópicos que devem compor os currículos das faculdades de todas as carreiras da saúde. Dez desses 11 tópicos foram retirados do Marco Australiano (Walton 2006). O tópico 9 (Prevenção e controle de infecções) foi inserido pela OMS, já que a infecção hospitalar corresponde a um número significativo de eventos adversos em todo o mundo e representa uma ameaça global em função do desenvolvimento da resistência bacteriana. Os tópicos de segurança do paciente do Guia da OMS encontram-se listados no Quadro 1.

Quadro 1 - Tópicos de segurança do paciente para inserção nos currículos das graduações da área da saúde*

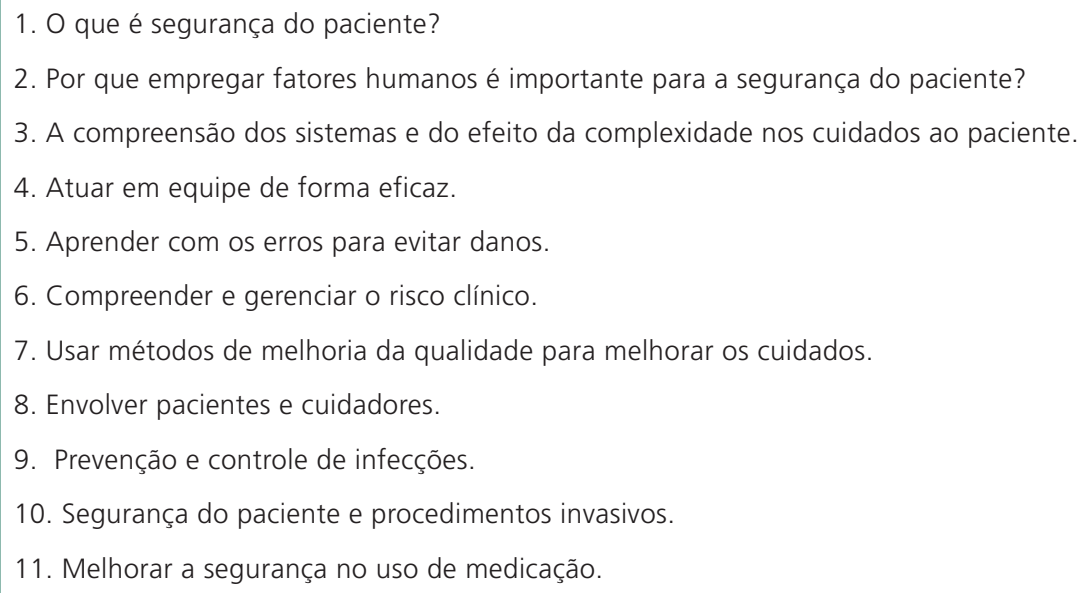

O eixo específico abordaria, além desses, outros tópicos, relacionados ao ensino e desenvolvimento acadêmico do assunto, como:

藉 Cultura de segurança;

苇 Indicadores de segurança;

橉Cultura justa;

路 Legislação e políticas locais para a revelação de erros em saúde;

落 Cuidado centrado no paciente.

A inclusão desses tópicos se justifica por representarem as principais linhas de investigação a serem desenvolvidas pelas entidades acadêmicas e de pesquisa/investigação em nosso meio. O tópico "Cuidado 
centrado no paciente" é uma "invasão" de outra dimensão da qualidade - cuidado centrado no paciente. As dimensões da qualidade, tal qual idealizadas por Donabedian (1990) e atualizadas pelo Institute of Medicine (2001), são uma forma didática de apresentar a complexidade da qualidade do cuidado, mas que, na prática, como dimensões interdependentes se misturam, conforme frequentemente acontece entre a segurança do paciente e o cuidado centrado no paciente.

O eixo integrador, responsável principalmente pelo desenvolvimento de habilidades gerais de segurança do paciente, teria como conteúdo programático os seguintes tópicos:

1. Identificação correta dos pacientes

2. Comunicação eficaz com pacientes, familiares e cuidadores

3. Comunicação eficaz com a equipe de saúde

4. Trabalhar em equipe de forma efetiva e colaborativa

5. Evitar erros relacionados ao diagnóstico

6. Envolver paciente e cuidadores na segurança do paciente

\section{Estratégias pedagógicas para o ensino de segurança do paciente}

Uma vez determinados os objetivos pedagógicos, que correspondem à aquisição/mudança de visão e de comportamentos voltada à garantia da segurança do paciente, passamos a selecionar as estratégias pedagógicas adequadas.

É preciso destacar que a grande maioria das universidades ainda não dispõe de professores capacitados em segurança do paciente, por ser um assunto relativamente novo. Portanto, é recomendável que as escolas de todas as carreiras da saúde se estruturem a fim de suprir essa lacuna. A escola pode organizar uma oficina multidisciplinar de segurança do paciente, composta de docentes das diferentes áreas, tendo o Guia Curricular da OMS como grande aliado. Outra estratégia é identificar as intercessões dos temas já existentes nos respectivos currículos com os temas de qualidade e segurança em saúde por intermédio de grupos focais de educadores e profissionais de saúde. De qualquer forma, será necessário que o corpo docente da escola se debruce intensamente sobre a matéria para que ela seja incorporada ao seu currículo. 
Antes de falar sobre as estratégias pedagógicas adequadas para o ensino de segurança do paciente, será necessário fazer um breve comentário acerca das metodologias pedagógicas adotadas pelas escolas de graduação da área da Saúde, em todo o mundo.

Existem, fundamentalmente, duas metodologias pedagógicas aplicadas pelas universidades de ensino em saúde. A chamada "metodologia tradicional de ensino", que é hegemônica em todo o mundo e se baseia na transmissão passiva do conhecimento, e a figura central é o professor. Trata-se de metodologia que usa como principal recurso pedagógico a aula expositiva, e como cenário pedagógico dominante a sala de aula. O conteúdo programático é fragmentado em disciplinas autônomas, conferindo enorme abismo entre os primeiros anos, exclusivamente teóricos, e os últimos, nos quais o aluno entra em contato com cenários reais de cuidado e começa a ter as chamadas "aulas práticas".

Como alternativa à metodologia tradicional, destacam-se as "metodologias de aprendizagem ativa", que podem ser resumidas pela seguinte frase, cunhada por Davis (1993): "Não fale aos alunos quando você pode demonstrar, e não demonstre quando eles podem fazer sozinhos." De acordo com essa metodologia, a função do professor não é mais de transmissor do conhecimento, mas sim de realizar um trabalho de mediação, de facilitador da aprendizagem, no qual o protagonista do método é o próprio aluno. É uma metodologia que se alicerça na aprendizagem significativa (que corresponde ao saber adquirido à medida que o indivíduo atribui um novo significado ao que já conhecia ou vivenciou), e recorre a atividades pedagógicas que buscam a construção do conhecimento e a aquisição de habilidades, atitudes e comportamentos essenciais ao futuro profissional (Moreira 1982).

Importante mencionar que as Diretrizes Curriculares Nacionais para a graduação em medicina preconizam a adoção de metodologias de aprendizagem ativa desde 2001 (Câmara Nacional de Educação 2001) e, mais recentemente, em 2014 (Câmara Nacional de Educação 2014). Algumas universidades brasileiras mesclam certas atividades de aprendizagem ativa à metodologia tradicional de ensino, como a inclusão de aprendizagem baseada em problemas (problem-based learning-PBL) e o estudo de caso. O Quadro 2 mostra as principais diferenças entre essas duas metodologias de ensino. 
Quadro 2 - Comparação entre a metodologia tradicional de ensino e a metodologia de aprendizagem ativa

\begin{tabular}{|l|l|l|}
\hline Itens & Metodologia tradicional & Aprendizagem ativa \\
\hline Currículo & $\begin{array}{l}\text { Compartimentado em } \\
\text { matérias isoladas e autônomas } \\
\text { Ciclo básico "não dialoga" } \\
\text { com o ciclo profissional }\end{array}$ & $\begin{array}{l}\text { Integrado e preferencialmente } \\
\text { interdisciplinar } \\
\text { Ciclos básico e profissional } \\
\text { integrados, introdução precoce } \\
\text { da prática }\end{array}$ \\
\hline Cenários pedagógicos & $\begin{array}{l}\text { Ciclo básico - sala de aula } \\
\text { Ciclo profissional - hospital }\end{array}$ & $\begin{array}{l}\text { Ciclo básico e profissional - } \\
\text { comunidade, laboratórios de } \\
\text { habilidades, ambulatórios, } \\
\text { hospital, sala de aula etc. }\end{array}$ \\
\hline Atividades pedagógicas & Básico - palestras expositivas & $\begin{array}{l}\text { Palestras expositivas, atividades } \\
\text { de pequenos grupos, PBL, estudo } \\
\text { de casos, problematização, TBL* } \\
\text { simulação, prática, portfólios, } \\
\text { projetos etc. }\end{array}$ \\
\hline Profissional - prática, PBL & Provas dissertativas, múltipla \\
escolha, oral e prática & $\begin{array}{l}\text { Processual e múltipla - provas } \\
\text { escritas, orais, observacionais } \\
\text { (OSCE**, Mini-Cex***), portfólio, } \\
\text { incidente crítico etc. }\end{array}$ \\
\hline Avaliação do curso & Indireta & \begin{tabular}{l} 
Direta (corpo discente e docente) \\
\hline
\end{tabular} \\
\hline
\end{tabular}

Fonte: Elaboração dos autores, baseados em Faust e Paulson (1998), Robertson et al. (2011), Troncon et al. (1996) e Marra (2015).

Legenda:

*TBL - Team-based learning ou aprendizagem baseada em equipes.

**OSCE - Objective structered clinical examination ou exame clínico objetivo e estruturado.

***Mini-Cex - Mini-clinical evaluation exercise ou miniexercício clínico avaliativo.

As atividades pedagógicas recomendadas para o ensino de segurança do paciente são aquelas em que o aluno se utiliza de vários sentidos que desencadeiam emoção, e não apenas a audição e a visão usadas para assistir a uma aula expositiva. Em outras palavras, com relação ao ensino de segurança do paciente, é inteiramente diferente participar de uma simulação ou dramatização a respeito de erro médico - momento em que os alunos experimentam fortes emoções - do que ouvir de forma passiva uma aula sobre o assunto.

Algumas premissas devem ser respeitadas no ensino-aprendizagem das competências de segurança. Além da percepção, imaginação e criatividade, fundamentais para o desenvolvimento cognitivo, destaca-se a contextualização, que significa, essencialmente, o ato de envolver os alunos com exemplos com os quais possam se identificar. Assim, usar casos reais e relacionados ao entorno de onde vivem é mais relevante do que "importar" casos de outras regiões. No entanto, entre todos os requisitos, destaca-se a necessidade de aplicação prática dos conheci- 
mentos, que é uma das principais estratégias pedagógicas utilizadas para fazer com que os aprendizes fiquem mais atentos aos preceitos de um cuidado seguro. O Quadro 3 resume, de forma esquemática, os princípios pedagógicos ideais para o ensino de segurança do paciente, e eles devem ser considerados para a inclusão dessa matéria nas graduações e no ensino técnico da área da saúde (WHO 2011).

Quadro 3 - Princípios pedagógicos essenciais para o ensino de segurança do paciente nas graduações das carreiras da saúde

\begin{tabular}{|c|c|c|}
\hline Princípios & Por quê? & Como \\
\hline Contextualize & $\begin{array}{l}\text { Os temas significativos são } \\
\text { mais relevantes para os } \\
\text { alunos. }\end{array}$ & $\begin{array}{l}\text { - Use exemplos realistas para o } \\
\text { seu entorno } \\
\text { - Identifique e estimule a aplicação } \\
\text { prática } \\
\text { - Use exemplos que sejam ou que, } \\
\text { em breve, serão de interesse dos } \\
\text { alunos } \\
\text { - Crie ambientes de ensino } \\
\text { desafiadores e estimulantes }\end{array}$ \\
\hline $\begin{array}{l}\text { Exerça o papel } \\
\text { de mediador da } \\
\text { aprendizagem }\end{array}$ & $\begin{array}{l}\text { Facilitar ou conduzir o } \\
\text { processo de aprendizagem } \\
\text { torna o estudante } \\
\text { protagonista e autônomo } \\
\text { da construção de seu } \\
\text { conhecimento }\end{array}$ & $\begin{array}{l}\text { - Sendo provedor de informações } \\
\text { - Servindo de modelo a ser } \\
\text { seguido } \\
\text { - Mediando conhecimento } \\
\text { - Avaliando a aprendizagem } \\
\text { - Planejando/planeando as } \\
\text { atividades pedagógicas } \\
\text { - Produzindo recursos }\end{array}$ \\
\hline $\begin{array}{l}\text { Considere a inclusão } \\
\text { do paciente na } \\
\text { aprendizagem de } \\
\text { segurança }\end{array}$ & $\begin{array}{l}\text { O paciente é uma das } \\
\text { melhores fontes de } \\
\text { ensinamento sobre sua } \\
\text { enfermidade. }\end{array}$ & $\begin{array}{l}\text { - Aplique o tema em vários } \\
\text { contextos pedagógicos (sala } \\
\text { de aula, à beira do leito/cama, } \\
\text { nas bancadas de laboratório, } \\
\text { cadeiras de procedimentos etc.). } \\
\text { - Esteja atento às oportunidades } \\
\text { de incluir os temas de segurança } \\
\text { na prática }\end{array}$ \\
\hline
\end{tabular}

Fonte: Baseado em WHO (2011).

O Guia Curricular da OMS (WHO 2011) oferece uma série de exemplos que podem ser adaptados e aplicados imediatamente seja qual for a estrutura de currículo das universidades de qualquer parte do mundo. O estudo de caso, as atividades em pequenos grupos, a simulação e a dramatização ocupam lugar de destaque entre as estratégias recomendadas. As principais atividades pedagógicas que consideram os princípios anteriormente discriminados, bem como seus desafios e benefícios, encontram-se descritas no Quadro 4. 
Quadro 4 - Principais atividades pedagógicas, indicadas para o ensino de segurança do paciente nas graduações e ensino técnico das carreiras da saúde

\begin{tabular}{|c|c|c|c|}
\hline Atividade & Observações & Benefícios & Desafios \\
\hline $\begin{array}{l}\text { Palestras, aulas } \\
\text { expositivas interativas, } \\
\text { presenciais ou podcasts }\end{array}$ & $\begin{array}{l}\text { Para melhor apreensão do } \\
\text { conteúdo, é recomendável } \\
\text { que tenham duração de, } \\
\text { no máximo, } 45 \text { minutos } \\
\text { e haja debate entre os } \\
\text { alunos. Preferencialmente, } \\
\text { deve-se trazer um "perito } \\
\text { externo", ou seja, um } \\
\text { engenheiro ou piloto de } \\
\text { avião para palestrar, já que } \\
\text { motivam a participação do } \\
\text { aluno. }\end{array}$ & $\begin{array}{l}\text { - Apresentação para um grupo } \\
\text { grande de alunos; } \\
\text { - Introdução de conceitos } \\
\text { teóricos difíceis de serem } \\
\text { abordados; } \\
\text { - Apresentar informações } \\
\text { atualizadas e de difícil acesso. }\end{array}$ & $\begin{array}{l}\text { - Manter a atenção dos alunos; } \\
\text { - Dependência de habilidades de } \\
\text { apresentação; } \\
\text { - O conteúdo de segurança } \\
\text { do paciente pode ser } \\
\text { desestimulante. }\end{array}$ \\
\hline $\begin{array}{l}\text { Aprendizagem em } \\
\text { pequenos grupos }\end{array}$ & $\begin{array}{l}\text { São atividades que } \\
\text { desenvolvem habilidades } \\
\text { intelectuais superiores } \\
\text { e estratégias cognitivas } \\
\text { de alta complexidade, } \\
\text { bem como promovem } \\
\text { a integração dos alunos } \\
\text { no que diz respeito à } \\
\text { solidariedade, cortesia, } \\
\text { cooperação, trabalho } \\
\text { colaborativo, entre outras. } \\
\text { Como exemplo, citamos o } \\
\text { PBL, TBL, problematização, } \\
\text { entre outras. }\end{array}$ & $\begin{array}{l}\text { - Compartilhar as próprias } \\
\text { histórias; } \\
\text { - Aprender com seus pares } \\
\text { e desenvolver perspectivas } \\
\text { múltiplas; } \\
\text { - Aprender a trabalhar em } \\
\text { equipe e a desenvolver } \\
\text { habilidades de comunicação. }\end{array}$ & $\begin{array}{l}\text { - Aplicar diferentes dinâmicas de } \\
\text { grupo - perícia do mediador; } \\
\text { - Implicações de recursos, em } \\
\text { termos do tempo do mediador. }\end{array}$ \\
\hline $\begin{array}{l}\text { Aprendizagem baseada } \\
\text { na prática e estudo de } \\
\text { caso }\end{array}$ & $\begin{array}{l}\text { Ensino que ocorre no } \\
\text { contexto da experiência } \\
\text { clínica à beira do leito/ } \\
\text { cama, na bancada de um } \\
\text { laboratório, na cadeira } \\
\text { odontológica, em sessões } \\
\text { clínicas ou estudo de caso. } \\
\text { Corresponde a uma das } \\
\text { formas mais eficazes de } \\
\text { aprendizagem. }\end{array}$ & $\begin{array}{l}\text { - Método contextualizado e } \\
\text { real, desafiador, logo, muito } \\
\text { relevante; } \\
\text { - Ideal para a aquisição de } \\
\text { habilidades de comunicação, } \\
\text { tomada de decisão e trato } \\
\text { interpessoal; } \\
\text { - Vinculação de conceitos } \\
\text { abstratos à vida real. }\end{array}$ & $\begin{array}{l}\text { - Pressão do trabalho; } \\
\text { - Dificuldade em incorporar } \\
\text { tópicos à aprendizagem na } \\
\text { prática; } \\
\text { - Elaboração de um currículo } \\
\text { dinâmico para contemplar a } \\
\text { diversidade dos casos. }\end{array}$ \\
\hline Simulação & $\begin{array}{l}\text { Deve-se usar a } \\
\text { aprendizagem baseada em } \\
\text { simulação realizada em } \\
\text { laboratórios de habilidade, } \\
\text { com o intuito de preparar } \\
\text { os alunos para o ambiente } \\
\text { real de cuidado, quando, } \\
\text { então, poderão aprender } \\
\text { na prática. }\end{array}$ & $\begin{array}{l}\text { - Não há riscos para os } \\
\text { pacientes; } \\
\text { - Podem ser apresentadas } \\
\text { situações incomuns, porém } \\
\text { críticas; } \\
\text { - Ideal para o treinamento } \\
\text { de trabalho em equipe, } \\
\text { liderança e comunicação. }\end{array}$ & $\begin{array}{l}\text { - Algumas modalidades podem ser } \\
\text { muito dispendiosas; } \\
\text {-É necessário conhecimento } \\
\text { especializado para conduzir a } \\
\text { atividade. }\end{array}$ \\
\hline
\end{tabular}


Quadro 4 - Principais atividades pedagógicas, indicadas para o ensino de segurança do paciente nas graduações e ensino técnico das carreiras da saúde (cont.)

\begin{tabular}{|c|c|c|c|}
\hline Atividade & Observações & Benefícios & Desafios \\
\hline $\begin{array}{l}\text { Encenação ou } \\
\text { dramatização }\end{array}$ & $\begin{array}{l}\text { Atividade em que os } \\
\text { alunos improvisam } \\
\text { diálogos e ações em um } \\
\text { cenário pré-determinado, } \\
\text { interpretando papéis e } \\
\text { diálogos de uma situação } \\
\text { de estudo de caso. } \\
\text { Podem ser usados atores/ } \\
\text { intervenientes, pacientes } \\
\text { ou os próprios alunos para } \\
\text { a encenação. }\end{array}$ & $\begin{array}{l}\text { - Custo baixo; } \\
\text {-É interativo e empírico } \\
\text { - introduz e sensibiliza } \\
\text { os alunos para papéis } \\
\text { que pacientes, famílias, } \\
\text { profissionais de saúde e } \\
\text { administradores exercem; } \\
\text { - Ideal para explorar fatores de } \\
\text { trabalho interprofissionais e } \\
\text { a comunicação na prevenção } \\
\text { de erros. }\end{array}$ & $\begin{array}{l}\text { - Escrever os roteiros; } \\
\text { - Desenvolver situações que } \\
\text { provoquem escolhas, decisões, } \\
\text { conflitos; } \\
\text { - Alguns alunos serão apenas } \\
\text { espectadores passivos; } \\
\text { - A encenação pode perder o } \\
\text { rumo. }\end{array}$ \\
\hline $\begin{array}{l}\text { Atividades com criação } \\
\text { de um produto }\end{array}$ & $\begin{array}{l}\text { Trata-se de atividades } \\
\text { como a Aprendizagem } \\
\text { Baseada em Projetos, } \\
\text { PDSA*, confecção de } \\
\text { portfólio, entre outras. São } \\
\text { atividades que permitem } \\
\text { que o aluno aplique o que } \\
\text { está aprendendo enquanto } \\
\text { cria um produto. }\end{array}$ & $\begin{array}{l}\text { - Aprendizagem de } \\
\text { resolução de problemas, } \\
\text { gerenciamento/gestão de } \\
\text { mudanças e proatividade. }\end{array}$ & $\begin{array}{l}\text { - Manter a motivação; } \\
\text { - Cumprir horários. }\end{array}$ \\
\hline
\end{tabular}

Fonte: Baseado em WHO (2011).

Legenda:

*PDSA (do inglês Plan/Do/Study/Act) é um método de gestão utilizado para controlar e melhorar processos e produtos.

\section{Avaliação de desempenho dos alunos}

Diferente da metodologia tradicional de ensino, no contexto da aprendizagem ativa, o desempenho dos alunos é avaliado antes, durante e ao final do processo de aprendizagem. Essa conformação estratégica objetiva avaliar o nível de desempenho antes de iniciar a aprendizagem (avaliação diagnóstica), ao longo do processo de aprendizagem (avaliação processual ou formativa) e ao final do processo pedagógico (avaliação somativa). Proporcionando aos educadores e alunos várias oportunidades de redefinir as estratégias pedagógicas, essa tática também reduz a enorme carga emocional que uma única prova de avaliação exerce nos estudantes. Particularmente no que tange à aprendizagem de segurança do paciente, as avaliações formativas são úteis para que os alunos percebam seu próprio desenvolvimento gradual quanto ao manejo dos erros e comprometimento às normas de garantia de qualidade do cuidado. 
As finalidades gerais dessas avaliações são:

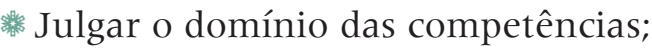

* Diagnosticar as dificuldades dos alunos;

* Proporcionar aos alunos comentários críticos;

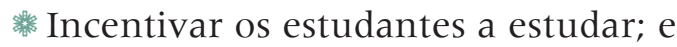

哺 Adequar a estratégia pedagógica.

Segundo Miller (1990), são quatro os níveis de desempenho a serem avaliados: No nível básico, avalia-se se o aluno (1) sabe e (2) se sabe fazer (teoricamente). Nesses níveis, as melhores formas de avaliação são as provas escritas (dissertativas e as provas de múltipla escolha). No nível imediatamente acima, o aluno deverá demonstrar (3) como se faz. Nesse caso, os métodos observacionais ou os métodos em contextos simulados são os mais adequados, e, finalmente, para avaliar se o aluno (4) efetivamente faz (executa), o método de observação direta em ambientes reais são os recomendados. A Figura 3 mostra o chamado Triângulo de Miller, que expõe esquematicamente essas fases.

Figura 3 - Triângulo de Miller das fases de aprendizagem a serem avaliadas

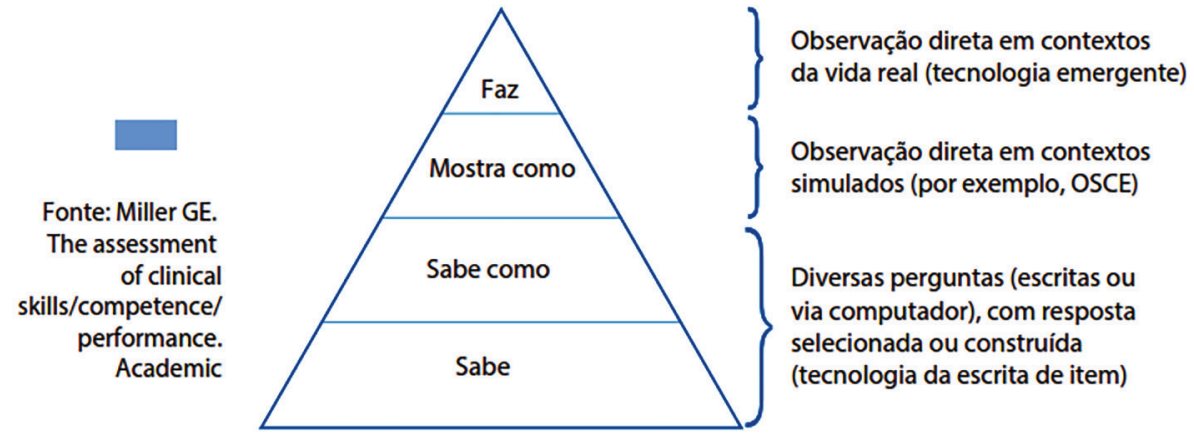

Fonte: Organização Mundial da Saúde (2016).

Com essas quatro fases, é possível avaliar o conhecimento, a habilidade e a atitude do aluno sobre determinado assunto. É pouco provável que apenas um único método de avaliação seja suficiente para abarcar as competências de segurança; por isso, habitualmente, são utilizadas múltiplas formas de avaliação ao longo do período.

Os métodos escritos tendem a avaliar apenas o conhecimento. Existem inúmeras variantes dos instrumentos escritos, como as provas escritas de perguntas simples, múltiplas escolhas, questões dissertativas modi- 
ficadas, dissertação, portfólio, entre outras. O único método escrito que também é capaz de avaliar as habilidades dos alunos é a aplicação de questões dissertativas modificadas ou Modified Essay Questions-MEQ (Newble Cannon 2001). Esse tipo de prova corresponde a uma sequência de questões feitas a propósito de casos clínicos, comumente encontrados na prática clínica, e são projetados para avaliar não apenas o conhecimento do aluno, mas, sobretudo, suas habilidades de raciocínio clínico e tomada de decisão.

No entanto, os métodos práticos são sempre observacionais, versáteis e adequados a fim de avaliar as habilidades e atitudes. Podem ser desenvolvidos em cenários artificiais e também na prática do cuidado. São eles: o exame clínico objetivo estruturado (Objective Structured Clinical Examination-OSCE), o miniexercício clínico avaliativo (Mini Clinical Evaluation Exercise-Mini-Cex), os debates de casos clínicos e as observações de múltiplas fontes. Oferecem como grande vantagem a possibilidade de o tutor e até outros profissionais poderem avaliar o aluno ao longo de todo o período pedagógico ou em datas pré-programadas, com mais de um avaliador, o que é bastante recomendável, como no caso das estações de avaliação.

\section{O ensino de segurança do paciente na pós-graduação}

Mesmo quando o tema segurança do paciente já tiver sido implantado nos currículos dos cursos de graduação, deverá ser também inserido nos programas de pós-graduação dos profissionais de saúde.

A regulamentação de cursos de pós-graduação é diferente em cada país. Portugal segue a política da União Europeia, a partir do Processo de Bolonha. Já a classificação brasileira adota o termo stricto sensu, "senso estrito", para designar os cursos que formam mestres e doutores em determinada área de conhecimento, e o termo lato sensu, "lato senso", que corresponde a vários formatos de cursos de pós-graduação (especialização, Master in Business Administration-MBA e as residências/internatos).

O alvo principal dos cursos do Processo de Bolonha e do "senso estrito" no Brasil deveria ser o profissional que se dedica às atividades acadêmi-

No Brasil, se faz uma distinção entre educação continuada e permanente, atribuindo à continuada uma educação apenas técnica. Neste capítulo, não será feita essa distinção. cas, quer no campo da pesquisa/investigação, quer no campo do ensino. Profissionais de saúde que atuam diretamente no cuidado se beneficiariam mais de programas de educação continuada (permanente) subordinados aos seus locais de trabalho. Contudo, aqueles que participam de comitês de qualidade ou núcleos de segurança do paciente deveriam 
buscar cursos que pudessem capacitá-los melhor para lidar com políticas de qualidade em saúde.

No Brasil, quanto às pós-graduações, o ensino de segurança do paciente é obrigatório apenas nas residências/internatos multiprofissionais, conforme a Resolução n. 5, de 7 de novembro de 2014, da Comissão Nacional de Residência Multiprofissional da Secretaria de Educação Superior, em seu artigo $2^{\circ}$, parágrafo que trata das estratégias educacionais práticas e teórico-práticas (Comissão Nacional de Residência Multiprofissional em Saúde 2015).

Os cursos de segurança devem contextualizar a segurança do paciente no campo de conhecimento maior da qualidade em saúde e, sob o ponto de vista pedagógico, observar o contexto em que vive o aluno. Foi com essas diretrizes e com base nas metodologias de aprendizagem ativa que a Escola Nacional de Saúde Pública Sergio Arouca da Fundação Oswaldo Cruz (ENSP/Fiocruz) e a Escola Nacional de Saúde Pública da Universidade Nova de Lisboa (ENSP/UNL) se uniram para criar o Curso Internacional de Qualidade em Saúde e Segurança do Paciente (Figura 4), oferecido na modalidade à distância.

Figura 4 - Logotipos e as fachadas dos edifícios das Escolas Nacionais de Saúde Pública da Fundação Oswaldo Cruz e da Universidade Nova de Lisboa

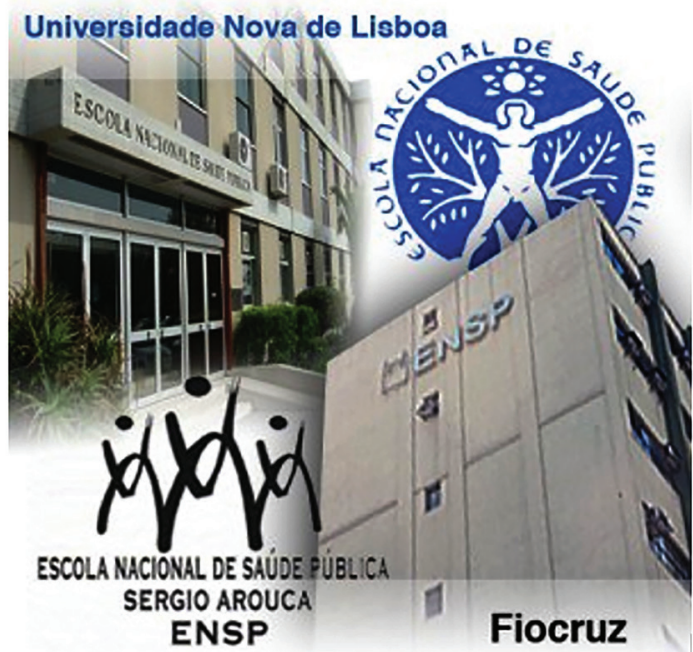

Fonte: Proqualis.

Este livro é um dos elementos de apoio didático do Curso Internacional de Qualidade em Saúde e Segurança do Paciente, que obedece a lógica das metodologias de aprendizagem ativa. Para cada grupo de 20 alunos, que são profissionais de saúde já graduados, um tutor faz a mediação 


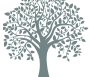

Na página da Opas/OMS, disponível em http:// www.paho.org/bra/index. php?option=com_content\&vi ew=article\&id=1585: desenvol vimento-integral-de-recursoshumanos\&ltemid=875, é possível fazer uma busca com termos indicadores de segurança do paciente e encontrar diversos materiais para estudo. pedagógica do processo de ensino-aprendizagem se comunicando por meio de fóruns, chats e contatos, utilizando todo tipo de recurso tecnológico de mídia social. O curso segue um roteiro que intercala filmes, videoaulas, muitas atividades e leituras de textos extraídos, principalmente, deste livro. Logo, propicia associações constantes entre teoria e prática profissional.

No Brasil, cujo número de alunos é grande, o curso também gera "produtos" para as organizações de saúde. Como o processo de seleção é institucional, cada organização de saúde indica um grupo de profissionais chamado de "aluno equipe", que realiza as atividades em conjunto, facilitando futuros trabalhos em equipe. O trabalho de conclusão de curso das equipes é sempre um produto para a organização, por exemplo, um plano local de segurança do paciente, um plano para implantação de um protocolo de segurança, projetos de intervenção voltados para estratégias de implantação real dos núcleos de segurança do paciente nos hospitais em que os alunos atuam, entre outros.

\section{Educação permanente de segurança do paciente}

"Para que uma organização de saúde seja acreditada, precisa demonstrar que implementou um plano de educação continuada para todos os profissionais" (Joint Commission International 2017).

O plano de educação continuada precisa obedecer alguns requisitos, como: (1) ser abrangente, alcançando todos os profissionais, (2) estejam previstos a disponibilização de tempo, o local e os equipamentos para capacitação, (3) seja periódico, (4) capacite obrigatoriamente em técnicas de ressuscitação e (5) as políticas e programas de qualidade e segurança do paciente e outras façam parte do escopo.

O ideal seria que a organização de saúde atuasse na formação e atualização dos profissionais por meio de uma gestão de pessoas baseada em competências. Nesse tipo de gestão, existe um monitoramento do desempenho técnico e comportamental de cada profissional, de forma a nortear um programa mais individualizado de capacitação. O monitoramento dos indicadores de qualidade em geral e aqueles especificamente de segurança seriam excelentes índices para orientar prioridades na educação continuada, segundo recomendação da Organização Pan-Americana de Saúde. 
É preferível que o máximo de capacitações sejam realizadas em serviço. Vários métodos podem ser utilizados nesse processo de formação, desde aulas dialogadas, vídeos, filmes, textos, situações vivenciadas, casos fictícios, situações problemas, entre outros. A simulação realística, no caso da segurança do paciente, é um recurso precioso. Ela pode ser de alta ou baixa fidelidade; realizada em manequins simples ou em manequins computadorizados, em que é possível programar reações a determinadas intervenções clínicas (Brandão et al. 2014). O uso de atores/intervenientes é outro recurso muito importante a fim de, por exemplo, capacitar a equipe para a abertura de informação (disclosure ou open disclosure) após a ocorrência de um incidente.

Outra estratégia é o uso da chamada educação interprofissional, definida como um método no qual "duas ou mais profissões aprendem com, de e sobre cada uma delas para melhorar o trabalho colaborativo e a qualidade do cuidado" (Reeves 2016). Algumas evidências de melhoria no trabalho de equipe, com repercussão na segurança do paciente, já foram descritas, incluindo o envolvimento da OMS nesse assunto (WHO 2010).

\section{Considerações finais}

Como já, diversas vezes, demonstrado neste livro, a dimensão segurança do paciente está subordinada à qualidade dos cuidados em saúde. Os processos de educação aqui descritos devem possibilitar deixar isso muito claro - não é possível afirmar que um cuidado apenas seguro seja um cuidado de qualidade!

Não adianta ter um cuidado seguro se ele for desatualizado, ou desconsiderar as preferências do paciente, ou desvalorizar as vulnerabilidades de alguns grupos, ou ser perdulário, ou não oportuno.

Por fim, ressaltamos que a cultura de segurança do paciente ocupa um local de destaque para os sistemas de saúde de todo o mundo, mas seu alcance encontra, nos processos educacionais, o principal caminho para sua construção, consolidação e crescimento.
Neste livro, no Capítulo 4, "Cultura de segurança em organizações de saúde", e no Capítulo 10, "Disclosure: a "arte" de saber comunicar ao paciente um incidente relacionado com os cuidados de saúde", discute-se intensamente a importância da notificação/relato de incidentes e o disclosure como partes integrantes de uma cultura justa.

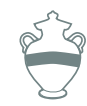

A comunicação entre membros da equipe de saúde foi abordada em outros capítulos deste livro, em especial no Capítulo 7, "Comunicação entre os profissionais de saúde e a segurança do paciente". 


\section{Referências}

Brandão CFS, Collares CF, Marin HF. A simulação realística como ferramenta educacional para estudantes de medicina. Sci Med. 2014;24(2):187-92.

Comissão Nacional de Residência Multiprofissional em Saúde (BR). Resolução CNRMS n. 5 de 7 de novembro de 2014. Diário Oficial da União. 2015 abr 10.

Conselho Nacional de Educação (BR), Câmara de Educação Superior. Resolução CNE/CES n. 3, de 20 de junho de 2014

Conselho Nacional de Educação (BR), Câmara de Educação Superior. Resolução CNE/CES n. 04/2001. Diretrizes Curriculares Nacionais do Curso de Graduação em Medicina. Diário Oficial da União. 2001 nov 9;seção 1:38.

Davis BG. Tools for teaching. San Francisco: Jossey-Bass Publishers; 1993.

Donabedian A. The seven pillars of quality. Arch. Pathol. Lab. Med. 1990;114 (11):1115-18.

Faust J, Paulson D. Active learning in the college classroom. J Excell Coll Teach. 1998;9(2):3-24.

Frank JR, Brien S, editors. The safety competencies: enhancing patient safety across the health professions. Ottawa (ON): Canadian Patient Safety Institute; 2008.

Institute of Medicine, Committee on Quality of Health Care in America. Crossing the quality chasm: a new health system for the 21st Century. Washington, DC: National Academy Press; 2001.

Joint Commission International. Accreditation standards for hospitals. 6th ed. 2017.

Marra VN. Metodologias de aprendizagem ativa na graduação médica: uma proposta de ensinoaprendizagem de segurança do paciente [tese]. Rio de Janeiro: PUC-Rio; 2015 [citado 2019 Jan 20]. Disponível em: https://www.maxwell.vrac.puc-rio.br/26419/26419.PDF.

Miller GE. The assessment of clinical skills/competence/performance. Acad Med. 1990;65(Suppl.): S63-S67.

Moreira MA, Masini EAFS. Aprendizagem significativa: a teoria de David Ausubel. São Paulo: Editora Moraes; 1982 [citado 2017 abr 4]. Disponível em:http://lief.if.ufrgs.br/pub/cref/pe_Goulart/ Material_de_Apoio/Referencial\%20Teo.

Newble D, Cannon R. A handbook for medical teachers, 4th ed. Dordrecht: Kluwer Academic Publishers; 2001.

Organização Mundial da Saúde. Guia curricular de segurança do paciente: edição multiprofissional. Rio de Janeiro: Autografia; 2016.

Pombo O. Interdisciplinaridade e integração dos saberes. Liinc Rev. 2005 Mar;1(1):3-15.

Pombo O. Práticas interdisciplinares. Sociol. 2006 Jan/Jun;15:208-49.

Reeves S. Porque precisamos da educação interprofissional para um cuidado efetivo e seguro. Interface. 2016;20(56):185-96.

Robertson MK, Umble KE, Cervero RM. Impact studies in continuing education for health professions: update. J Contin Educ Health Prof. 2003;23(3):146-56. 
Santos WS. Organização curricular baseada em competência na educação médica. Rev Bras Educ Méd.2011;35(1): 86-92.

Troncon LE. Avaliação do estudante de medicina. Med. 1996 out/dez;29:429-39.

Wachter RM. Compreendendo a segurança do paciente. 2. ed. Porto Alegre: AMGH; 2013.

Walton MM. Teaching patient safety to clinicians and medical students. Clin Teach. 2007;4:1-8.

Walton MM et al. Developing a national patient safety education framework for Australia. Qual Saf Health Care. 2006;15:437-42.

World Health Organization. Framework for action on interprofessional education \& collaborative practice. Geneva: WHO; 2010.

World Health Organization. World Alliance for Patient Safety: forward programme. Geneva: WHO; 2005.

World Health Organization. WHO patient safety curriculum guide: multiprofessional edition. Geneva: WHO; 2011. 
Formato: 205 x 260mm

Tipografia: Meridien LT Std e Frutiger Lt Std

Papel do Miolo: Papermax 90g/m2

Papel e Acabamento Capa: Papel Cartão supremo 250g/m2

Ctp Digital: Gráfica

Impressão e acabamento: Gráfica

Rio de Janeiro, maio de 2019. 